\title{
MADE TO MEASURE
}

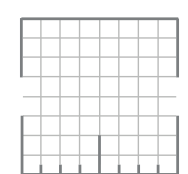

REVEALING AND MEASURING A DYNAMIC COASTAL ENVIRONMENT 


\section{$+2^{2}$}

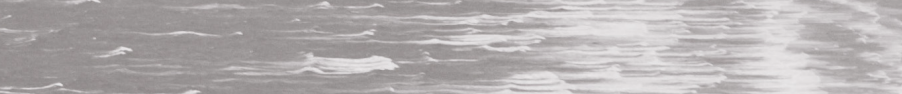

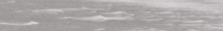

$-\frac{1}{3}=$

$\frac{2 y}{2}$

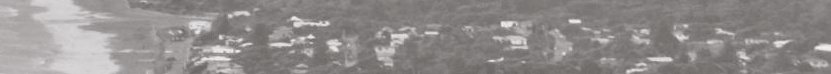

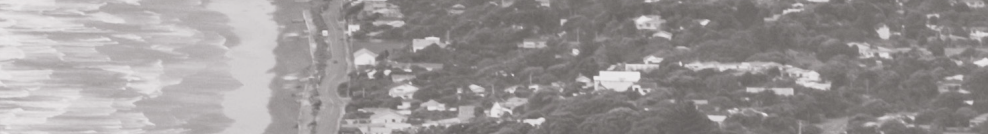

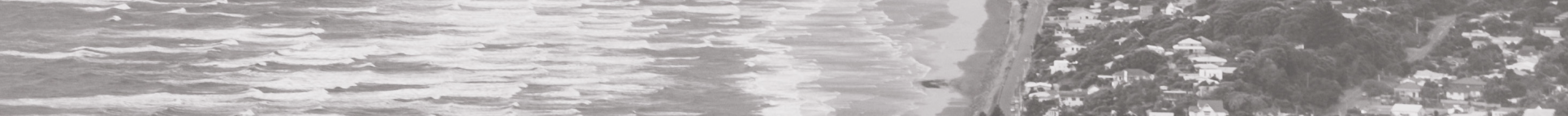

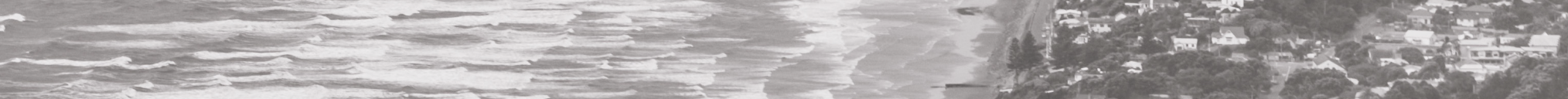

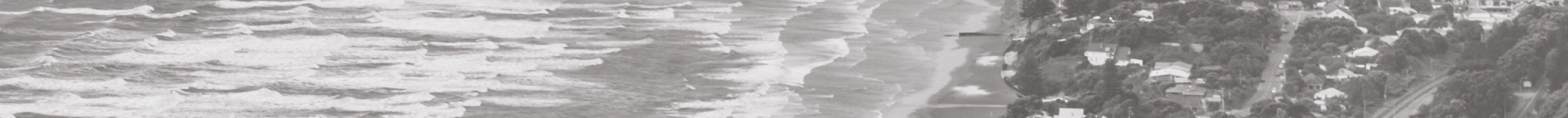

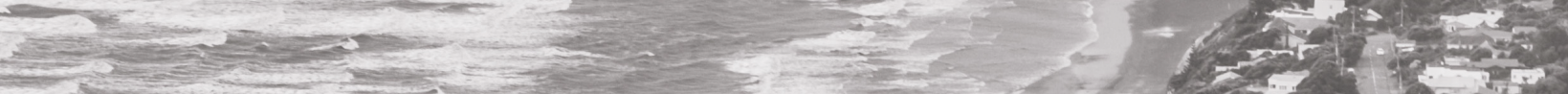

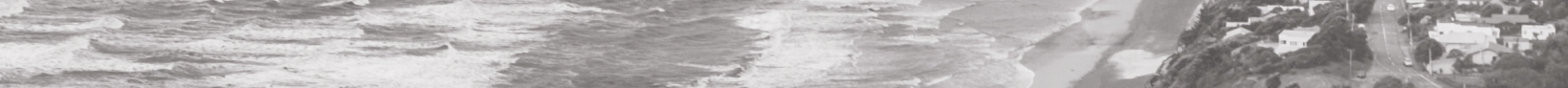

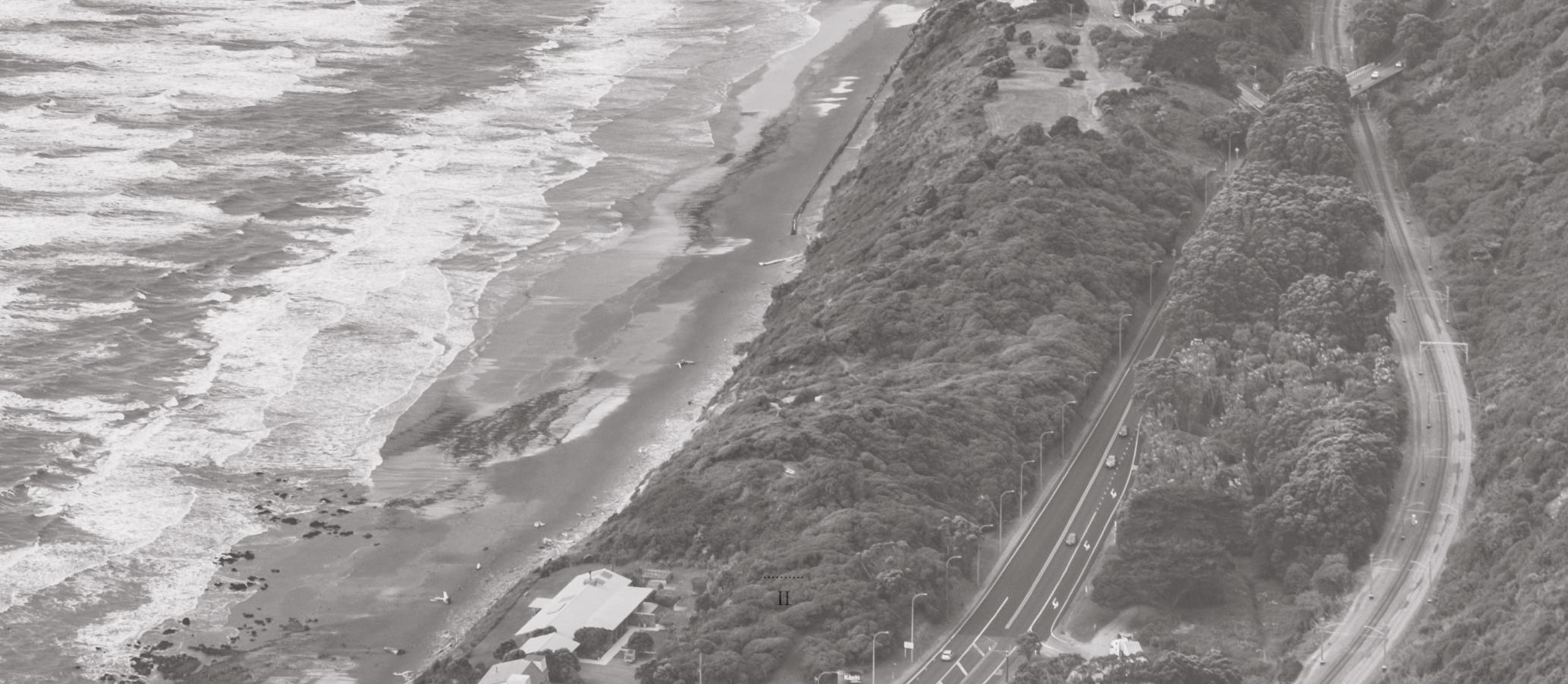




\title{
MADE TO MEASURE
}

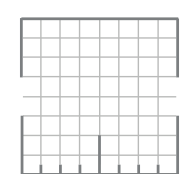

OBSERVING AND MEASURING A DYNAMIC COASTAL ENVIRONMENT

\section{Callum James Leslie}

\author{
A 120 point thesis submitted in partial fulfilment of the \\ requirements for the Master of Architecture [Professional] \\ Victoria University of Wellington, \\ School of Architecture
}

2018 


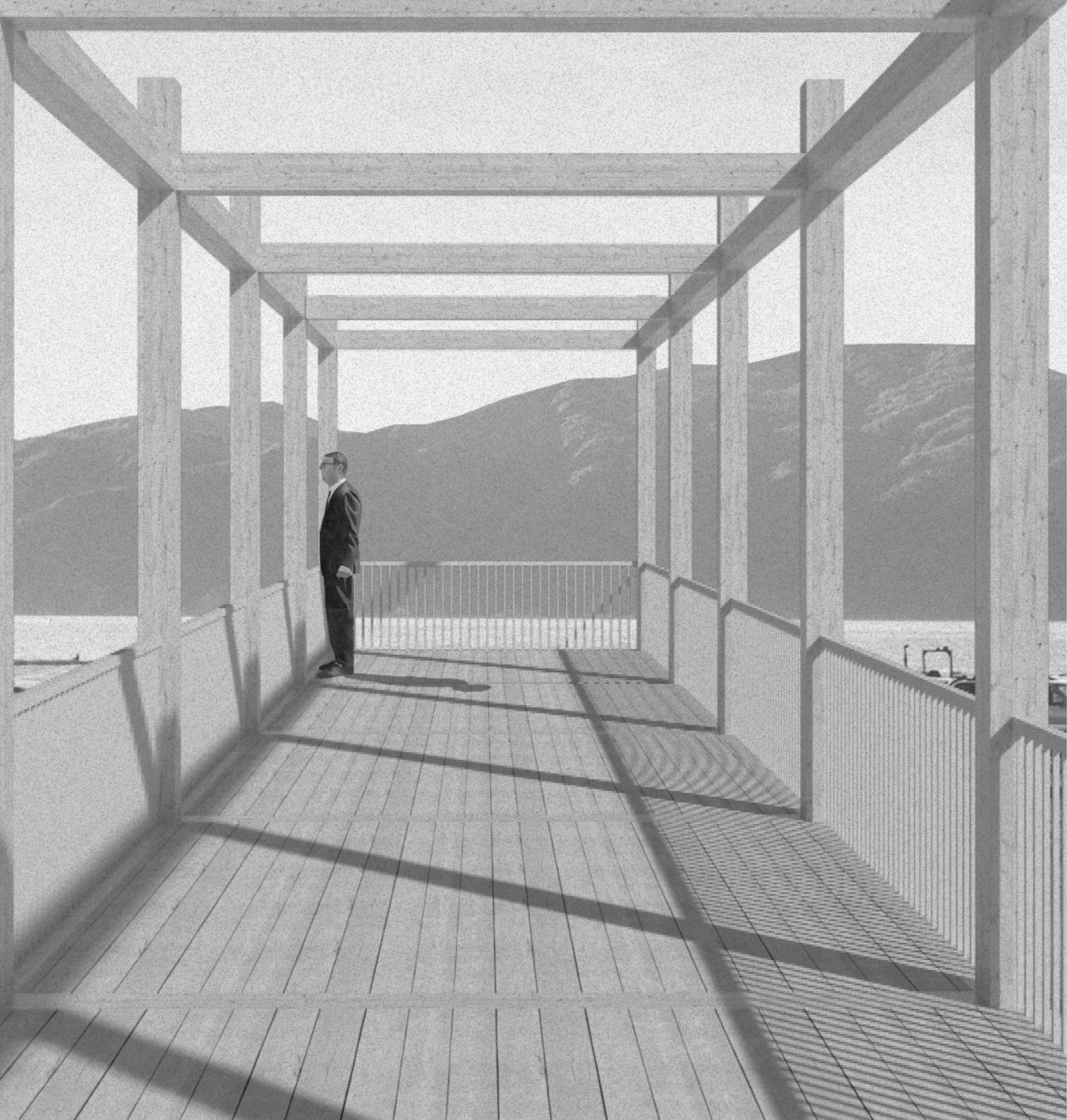




\section{ACKNOWLEDGEMENTS}

To my parents: For the meals, phone calls and love. Thank you for your never-ending support.

To my stream: Jason, Will, Elise, Ryan and Joe, and the rest of the cohort. Your friendship this year and throughout our studies has been unforgettable.

To my supervisor Sam Kebbell: Your guidance, advice, opinions and thoughts have been invaluable. This year has been more challenging and rewarding than ever expected, and your passion for this discipline is second to none.

To my friends outside university: I look forward to seeing what you've been up to whilst I did this degree.

Lastly, to Yi-Lin: Thanks for listening to 'architecture talk', laughing, and believing in me. I couldn't have done it without you. 

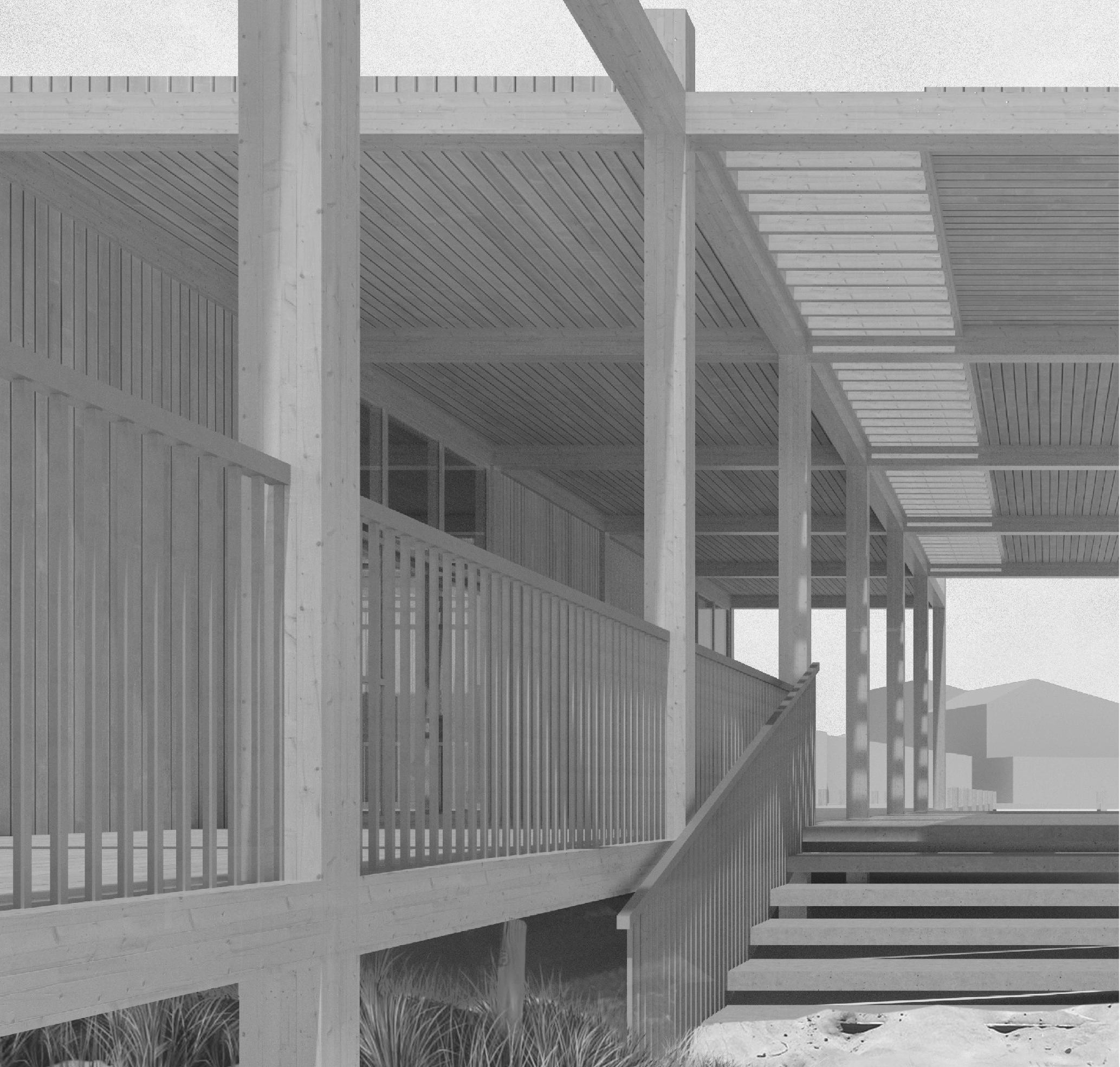
WW way $-4 y=$ -

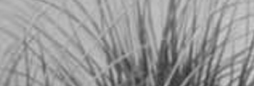
(a) 1.:
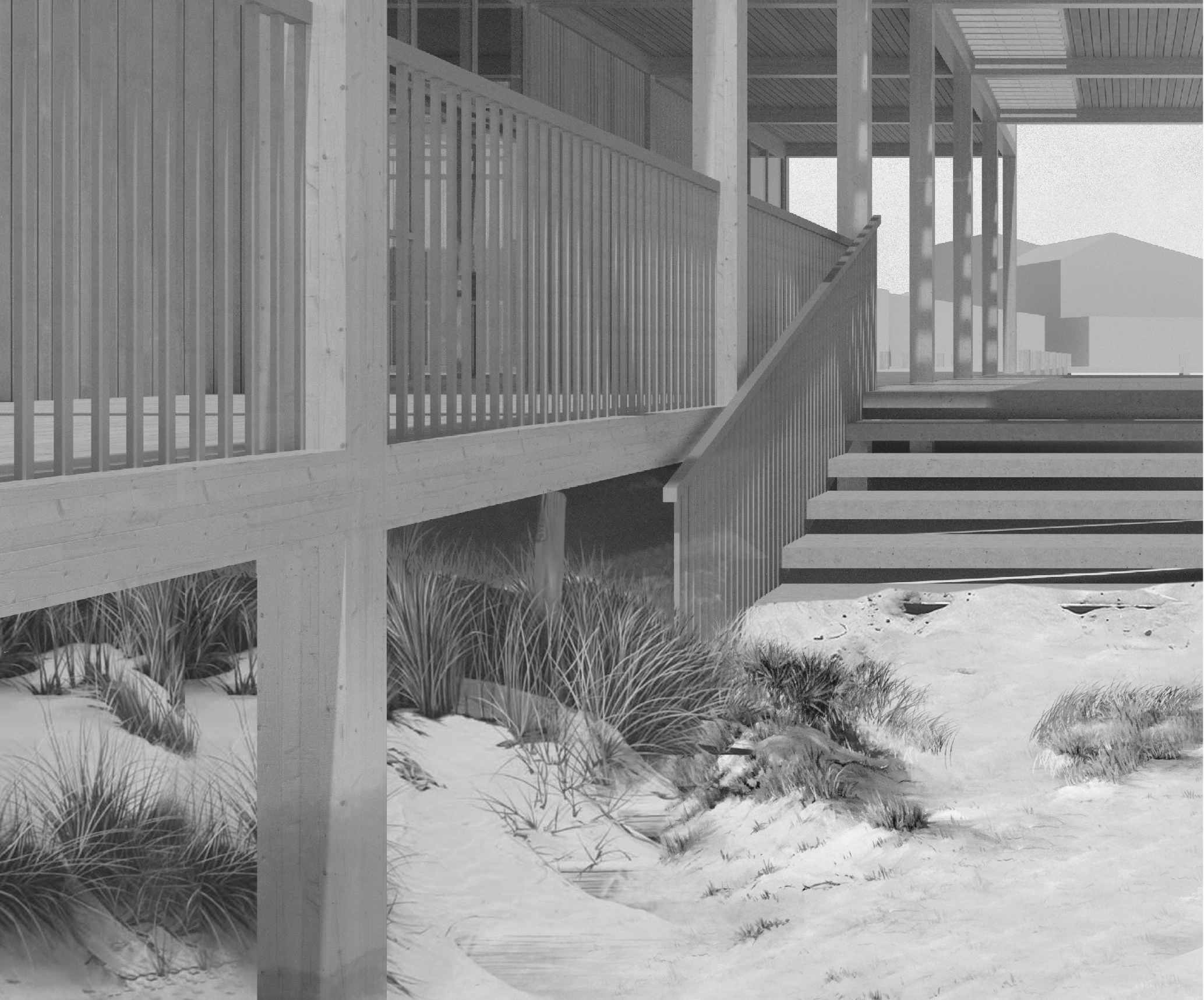


\begin{abstract}
MacLean Park located on the Kapiti Coast has one of the most dynamic natural environments in the country. As tides rise, dunes shrink and grow and rivermouths shift over time, it can be difficult to perceive these environmental changes due to promptly forgotten benchmarks.

Within this thesis, I argue that architecture could provide both a benchmark and datum by which we can begin to understand and register these environmental changes, highlighting a need for architecture's role to act as a mediator between our natural and urban environment.

The project explores a series of methods and strategies to make this dynamic and shifting environmental condition visible. A rigid and reductive geometry forms a potential answer. This informs a series of experiments which look to uncover how we can visually measure and observe our built and natural environment. A design-led research methodology leads to initial investigations on form and reduction within a chaotic landscape, followed by approaches

to register site specific data and historic landmarks. The final design investigations centre on a holistic coexistence of built form amongst the dunescape, lifting the modular structure on piloti above the delicate ecosystem below to allow the landscape, dunes and flora to flow freely in a temporal manner and interact with the building. The resulting design method shifts from a reductive approach to taking measure through ordering systems and composition to a more integrated approach between landscape and architecture. Here, measurement and observation become both an instrumental and poetic narrative as the building becomes a reflection of its surrounds.

The resulting tension between a rational and poetic approach to designing sees the Kapiti Island Biosecurity Visitor's Centre become a measurement device on a coastal threshold. Through this architectural response, we can begin to observe, measure, read and understand the ecological qualities of the immediate site and its association with the township beyond.
\end{abstract} time and dune movements against it 


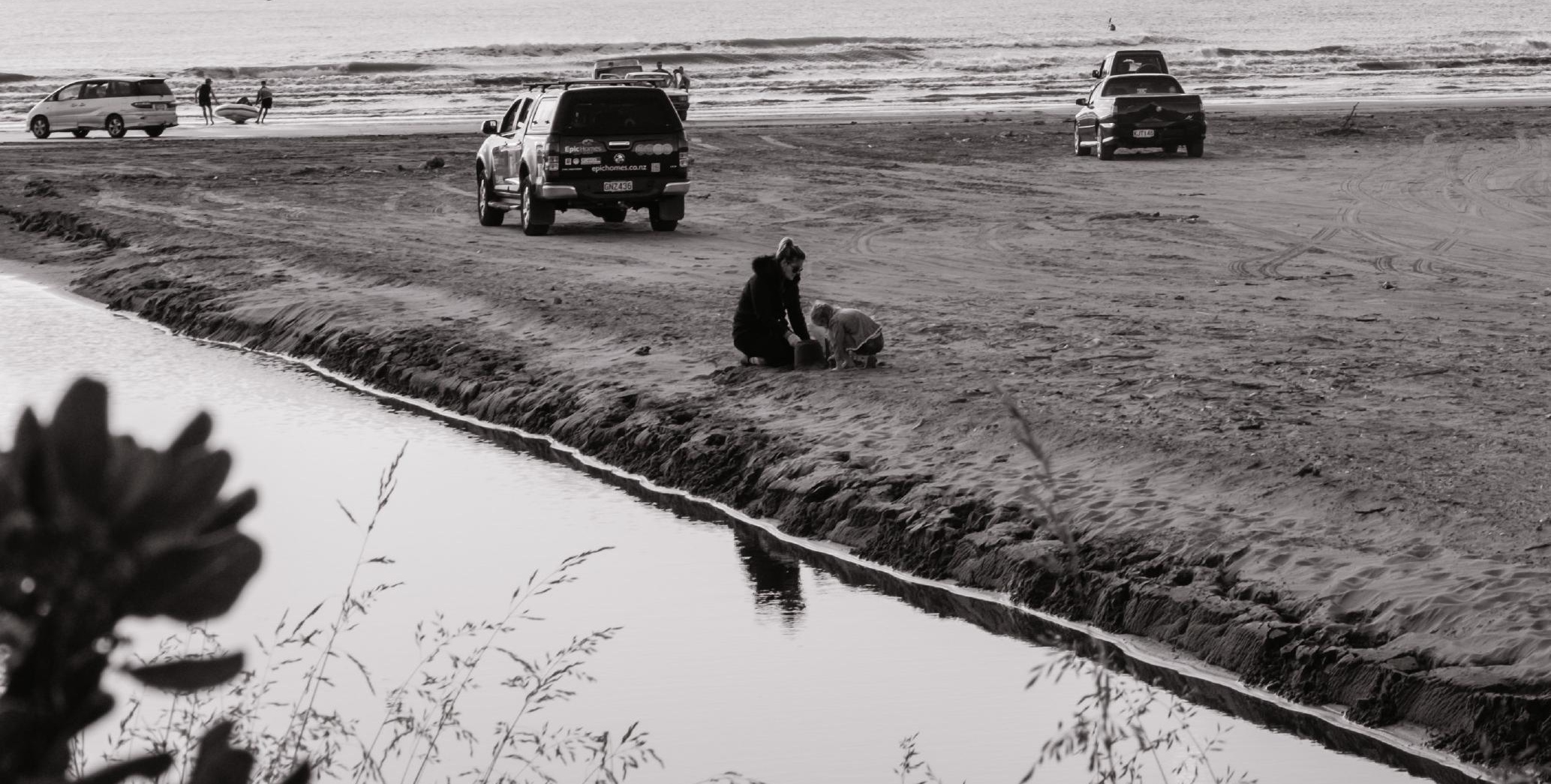




\section{CONTENTS}

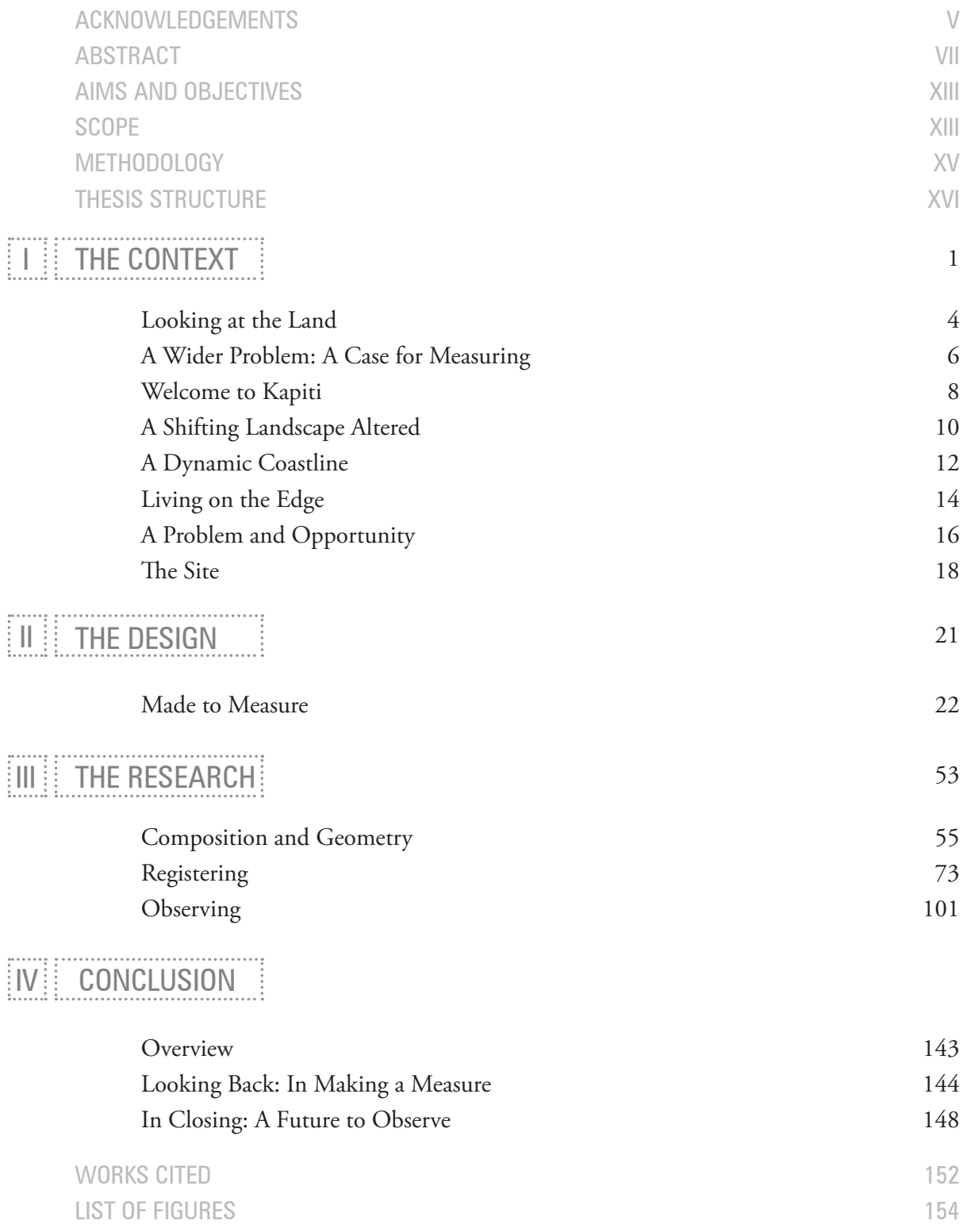

Figure 4: Author's own image looking towards Kapiti Island from MacLean Park, Tikotu Stream in the foreground 
Figure 5: Author's own image looking towards Kapiti Island from MacLean Park, Tikotu Stream in the foreground 

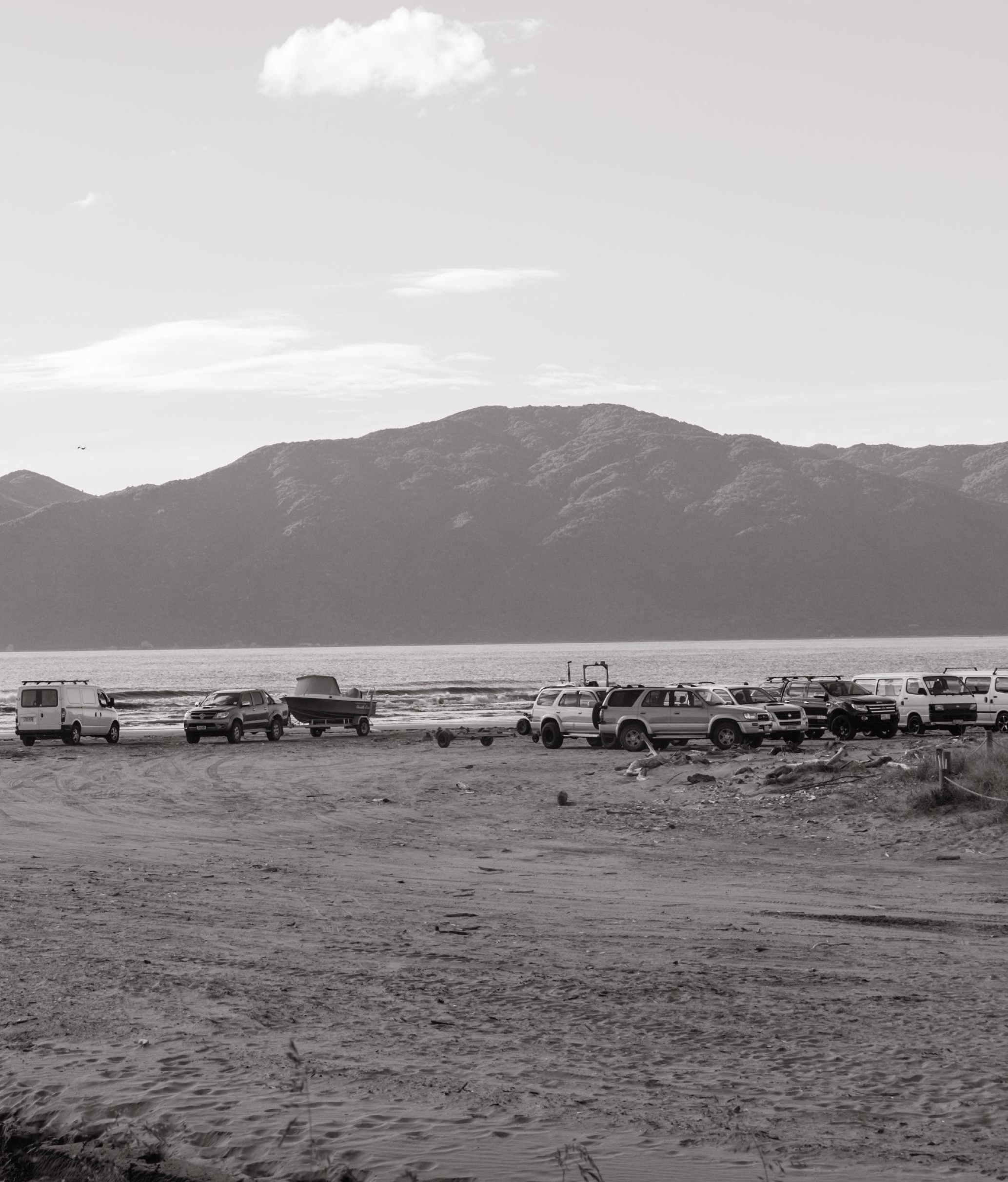


\section{AIMS AND OBJECTIVES}

This thesis is driven by an ever-changing coastal landscape and is a response to this issue. Prompted by recent reports into the risks of living close to the eroding shorelines of Kapiti Coast, this thesis highlights a wider issue of when suburban sprawl meets the shore in our regional coastal towns. As tides rise, dunes shrink and grow and rivermouths shift over time, it can be difficult to perceive these environmental changes due to promptly forgotten benchmarks on a delicate and dynamic coastal site. This forms an issue which architecture could help alleviate by enabling an observation and understanding of these changes.

The key objectives of the research therefore are:

1. To investigate an architectural language, material palette and system that can enable the public to observe and measure the changing environment, and enhance the public's ability form a closer understanding of the landscape

2. To imagine how architecture may engage with this dynamic site, enhancing the qualities of the visitor's experience of both the landscape and the public Gateway Centre.

This research therefore presents The Design as a potential architectural strategy to measuring and revealing the dynamic, shifting quality of the coastal environment, reflecting on a relationship between a rational and poetic approach to how we represent these changes in our environment over time.

\section{SCOPE}

The project scope was initially wider than The Design, with early experiments focussing on the chaotic nature of the park and wider urban and landscape context as a provocateur. The experiments then narrowed to focus predominantly on the Visitor Centre and immediate landscape as the design enquiry. Outcomes from The Design then formed the basis for examining the wider implications of lessons learnt from the design on the surrounding park to a masterplanning level.

The brief for a Kapiti Island Visitor's Gateway Centre based on community needs formed the initial prompt into the design process. The process itself, including form studies, site studies, and the resulting reflection upon these, helped to further develop and inform the research questions.

Whilst this thesis delves into the potential premise for architectural typologies for other dynamic coastal sites, it does not aim to solve, or alleviate climate change issues. It serves only to acknowledge and reveal these to a further degree. Likewise, it does not set out to make accurate scientific insights through measuring environmental changes, rather focussing on the potential of a closer observation of the landscape to enable the public to gather an understanding of its movements. 

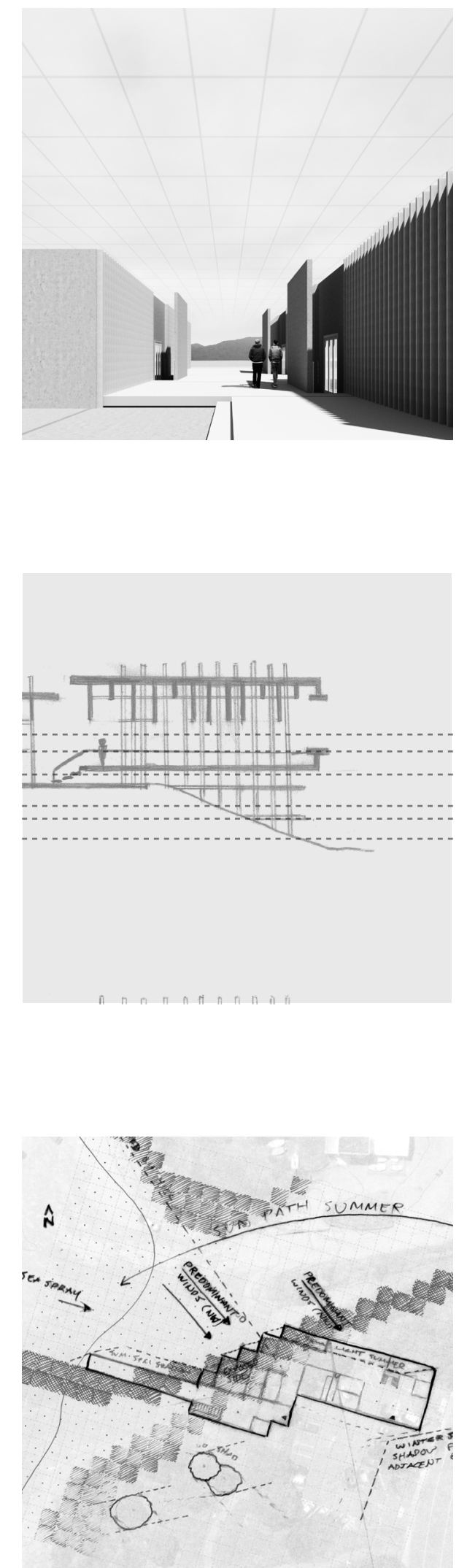


\section{METHODOLOGY}

This research takes a design-led approach. It sits within a wider collaborative body of student work investigating architecture's role within the Kapiti Coast Region. It was this initial theme that prompted explorations into the MacLean Park site in question, with the thesis objectives and problem based upon these findings.

Framed by the opportunities and challenges of a coastal site, the experiments and final design act as the vehicle to discuss the differing approaches to enabling observation and measurement of a dynamic coastal environment, many of which could not have been envisaged at the beginning of the thesis. Literature review and case studies are treated as part of the overarching design process, and were critically reflected on whilst designing to help envision new ways for architecture to enable observation of the site. These reflections became more nuanced and specific towards the final stages of the thesis.

The nature of design-led research in this case was non-linear and speculative. Plans, sections, elevations, physical models and perpective images were all tools to provide insight in differing ways, leading to wider implications of differing approaches. This prompted reflective discussions on a personal and disciplinary level as to the validity and effect of these approaches on the design.

Figure 7: Key design methods at each stage of the design process from top to bottom: Geometry and Composition, Registering and Observing 


\section{DESIGN CHRONOLOGY}

Although the benefits of an oscillatory design process allowed for iterative discovery through alternative methods, a lack of a clear initial direction and focussed definition of 'measurement' proved to be a challenge of where to begin. However, case studies and the discovery of relevant theoretical context provoked shifts in method and positioning. In hindsight, these challenges, confusing moments and repeated self-questioning were the main instigators for provoking the final discussions and settling on a personal position on how best to observe changes in the landscape.

\section{THESIS STRUCTURE}

Due to the design led nature of the research, the thesis document is structured as follows:

\section{A SHIFTING CONTEXT}

The thesis begins with a contextual background and motivation for the research from a country wide perspective. Starting with how we currently 'observe' our environment, it then narrows into a contextual analysis of the Kapiti Coast, selecting a site based on its dynamic and changeable landscape. After uncovering a local need for taking a closer measure of the changing coastline, the chapter ends with a speculation on the importance of architecture for understanding and observing the coastal environment.

\section{THE DESIGN: MADE TO MEASURE}

This chapter presents the design as a response to the aims, objectives and scope outlined in the introduction.

\section{THE EXPERIMENTS:}

This chapter acts a catalogue of the design process, highlighted by the three predominant shifts in thinking: Composition and Geometry, Registering and Observing. The experiments oscillate between rational and quantitative measurements and observation, towards the poetic and metaphorical and in between. Case studies and relevant literature sit alongside the experiments in this chapter, highlighting the design led nature of these explorations.

\section{THE DISCUSSION:}

Identifying tensions from earlier experiments, a concluding discussion occurs between the benefits and drawbacks between rational and poetic approaches to measurement and observation of landscape within architecture - and the importance for architectural discourse to find a balance between these approaches beyond the scope of the thesis. 
1.0 | A SHIFTING CONTEXT

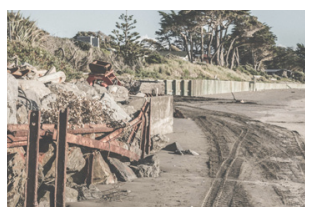

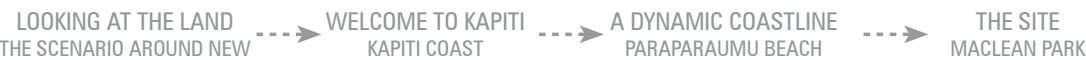
ZEALAND

2.0 | THE DESIGN: MADE TO MEASURE

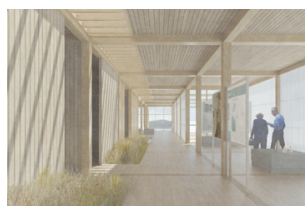

THE DESIGN

THE RESULT FROM THE RESEARCH

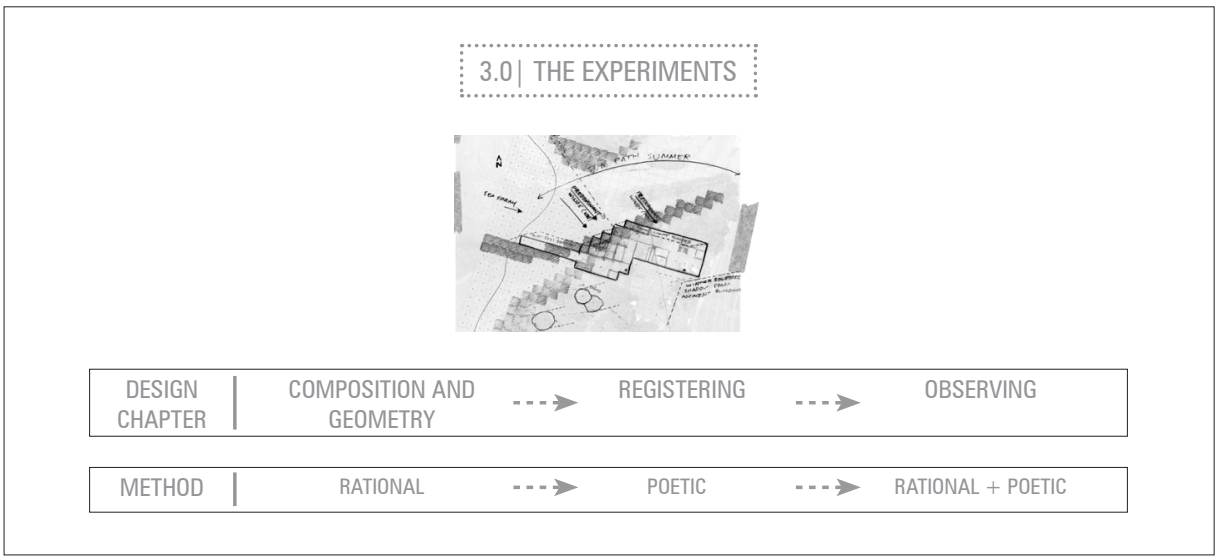

4.0| THE DISCUSSION

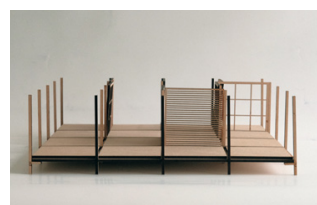

LOOKING BACK $\cdots$ LOOKING FORWARD 
\begin{tabular}{|l|}
\hline THE CONTEXT \\
\hline
\end{tabular}

THE DESIGN
$\vdots$
$\vdots$
THE RESEARCH 
I

\section{THE CONTEXT}

A SHIFTING LANDSCAPE 

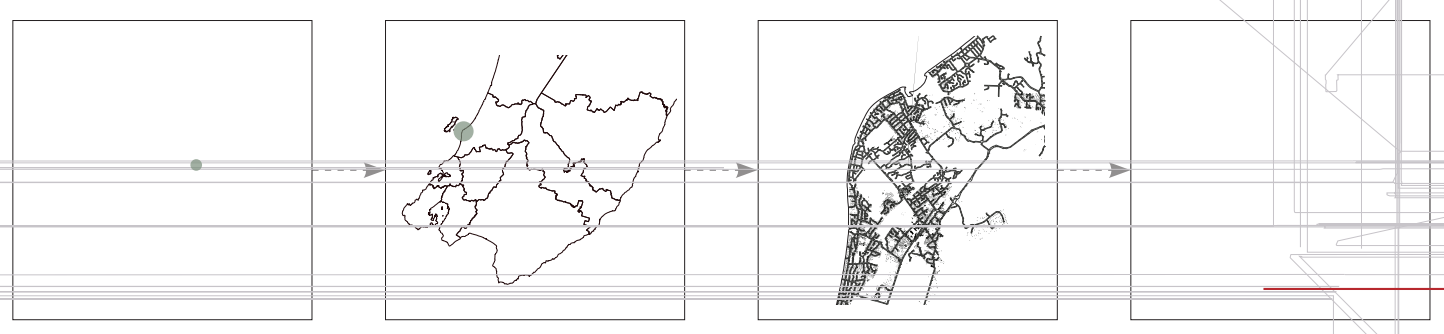


\subsection{1}

\section{AN ISSUE OF CONTEXT}

This section of the exegesis details the contextual background and motivations of the research from a New Zealand wide perspective, narrowing its focus through the chapter to the specific MacLean Park site in which the design is located. Whilst the predominant focus of the research is a site specific response on the Kapiti Coast, the contextual reasoning to measure and observe our environment extends beyond Kapiti Coast to many of New Zealand's hinterland areas.

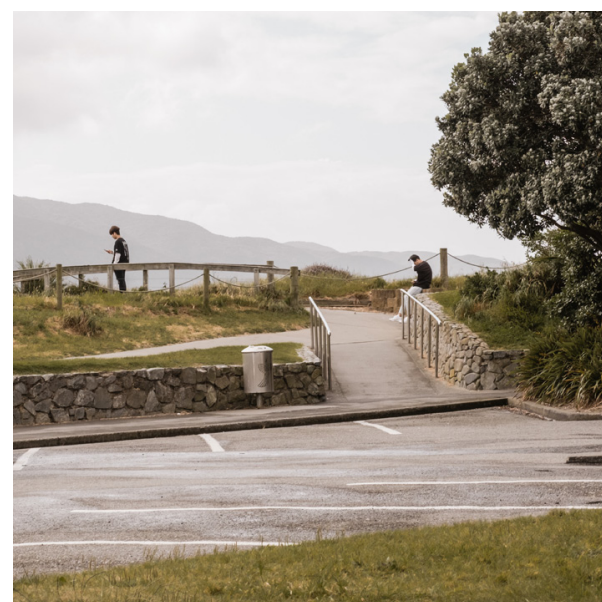

Figure 9: A foredune within the site of The Design partially flattened by development of the park over time

Figure 10: A diagram of the chapter structure 


\subsection{2}

\section{LOOKING AT THE LAND}

Much of New Zealand's identity is defined by its landscape, yet perceptions of this landscape come from many sources. From early settlers painting the landscape to ecological movements of today and the economic benefits of tourism, it's hard to deny the importance of the environment to the country.

The forces of our environment have long defined how we observe the landscape too. Early Maori often observed and described it in symbols and metaphor. The name of the country, Aotearoa, 'The Land of the Long White Cloud' alludes to this. Hills, rivers and other natural features of the environment reveal the stories of ancestors of past.

When European settlers arrived, the premise of observing the landscape for its aesthetic quality was introduced. Romantic notions of a wild natural country were shown in art and colonial advertising. Europeans also observed the landscape in an alternate manner, bringing the rigour of science with them. Early surveyors created maps, writers noted their views and scientists recorded the natural features of the land (Phillips).

Historically, New Zealander's have been obsessed with the measure of the landscape too. As Geoff Park points out, "the colonial surveyor's grid reshaped New Zealand's best land", instilling "an obsession with land boundaries in New Zealand society. . . central to our way of life" (Park 26). However, the obsession with boundaries, lead to the demise of much of the natural features of the landscape. Forests, swamps and wetlands were ruthlessly and rapidly cleared to make way for agriculture and housing.

Over time, the way in which people observed the landscape and measured the land has proved critical to the development, for better and worse, of New Zealand's built and natural environment today. 


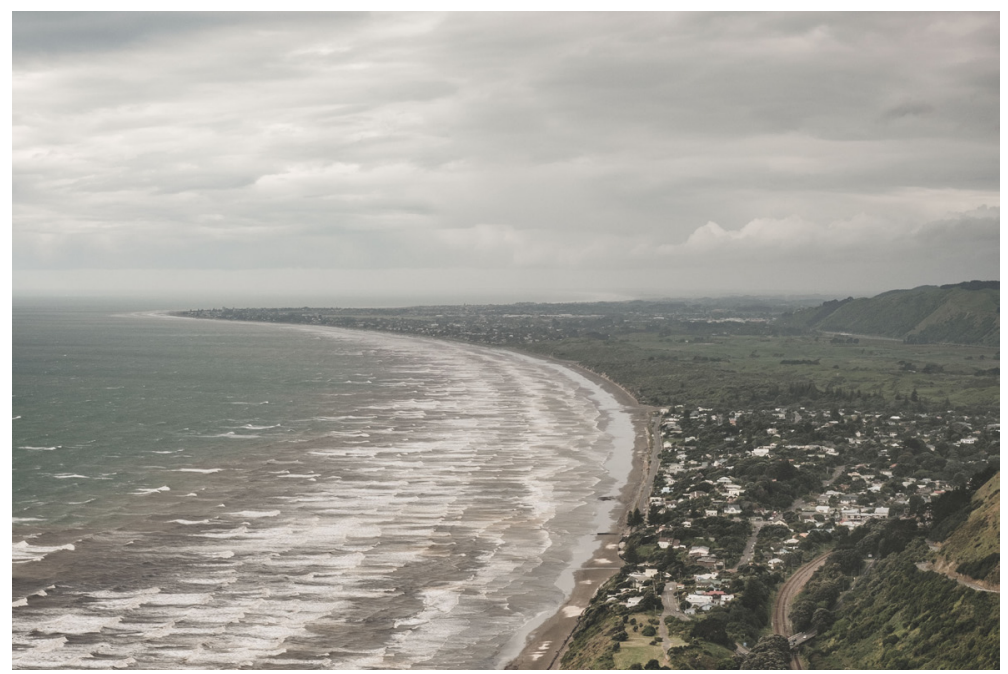

$\wedge$

Figure 12: Author's own photograph, Hill Road, 2017 


\section{A WIDER PROBLEM: A CASE FOR MEASURING}

The dynamic forces of the landscape define the country too. With New Zealand being shaped as a narrow long band, $65 \%$ of the population is within 5 kilometres of the coast (Statistics New Zealand), where natural forces of coastal and tidal changes are shown most clearly, thus affecting most of the population at least indirectly.

With so much of the country irrefutably linked to the changes in the environment, it is fundamental that New Zealanders retain a close observation of how their environment changes around them. A 2016 report by the Parliamentary Commissioner identified that "we need to understand and measure the state of our environment" and build a further knowledge of the pressures our environment Is under, and the effects they have (Wright 5).

Figure 13: A series of sites across New Zealand highlighting a wider dynamic environmental condition of coastal erosion 

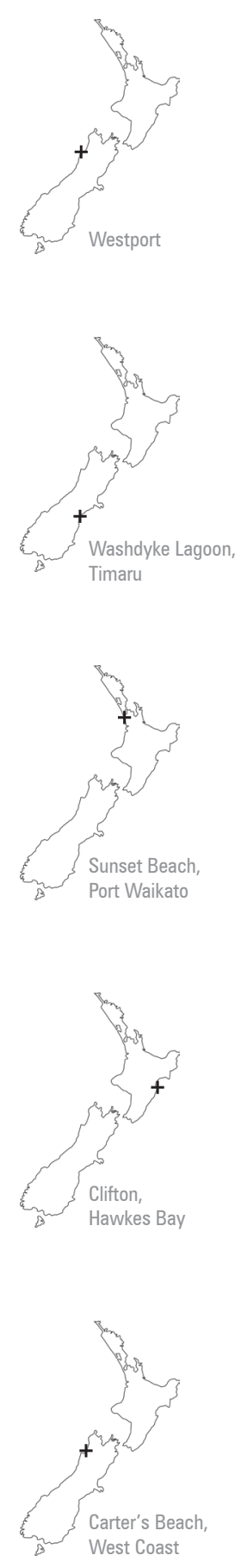


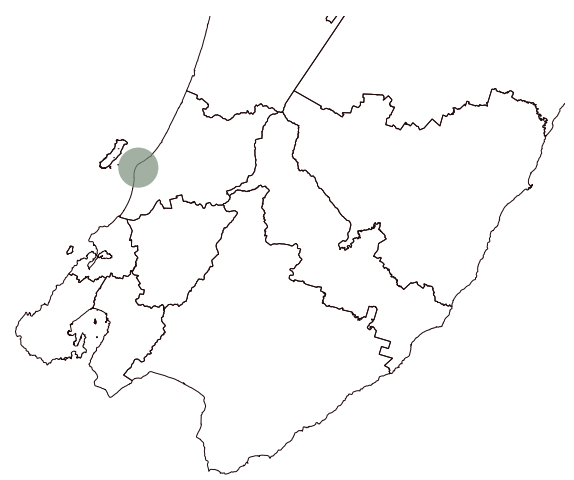

1.04

\section{WELCOME TO KAPITI}

The area chosen to explore for this thesis is Kapiti Coast. Stretching for 30 kilometres from Paekakariki to Otaki, it looks out to Kapiti Island.

Kapiti Island, for which the area is named, is located 5 kilometres off-shore from where visitors currently depart from at Paraparaumu Beach. It acts as a protected sanctuary home to native birds, flora and fauna. The area was once home to vibrant coastal forests and wetlands (Maclean).

Figure 14: The foreshore of Paraparaumu Beach and the site in the background. White line shows boat route to Kapiti Island, in the foreground 


\section{A SHIFTING LANDSCAPE ALTERED}

During the early settling of the land in the 19th century however, most of the Kapiti Coast's forests and wetlands were cleared for sheep and dairy farming. In their place, rapid development of the area occurred, with the Paraparaumu population growing to 26,838 residents by 2013 (Maclean). Over time, suburban sprawl ballooned, with a mix of low density housing and industrial warehouses extending in patches towards Raumati in the South and Waikanae in the north, creating a discontinuous urban grain expanding towards the coastline.

Figure 15: Looking towards Paraparaumu from the Hill Road lookout highlights Queen Elizabeth Park and dunes between discontinuous suburban sprawl in the distance 


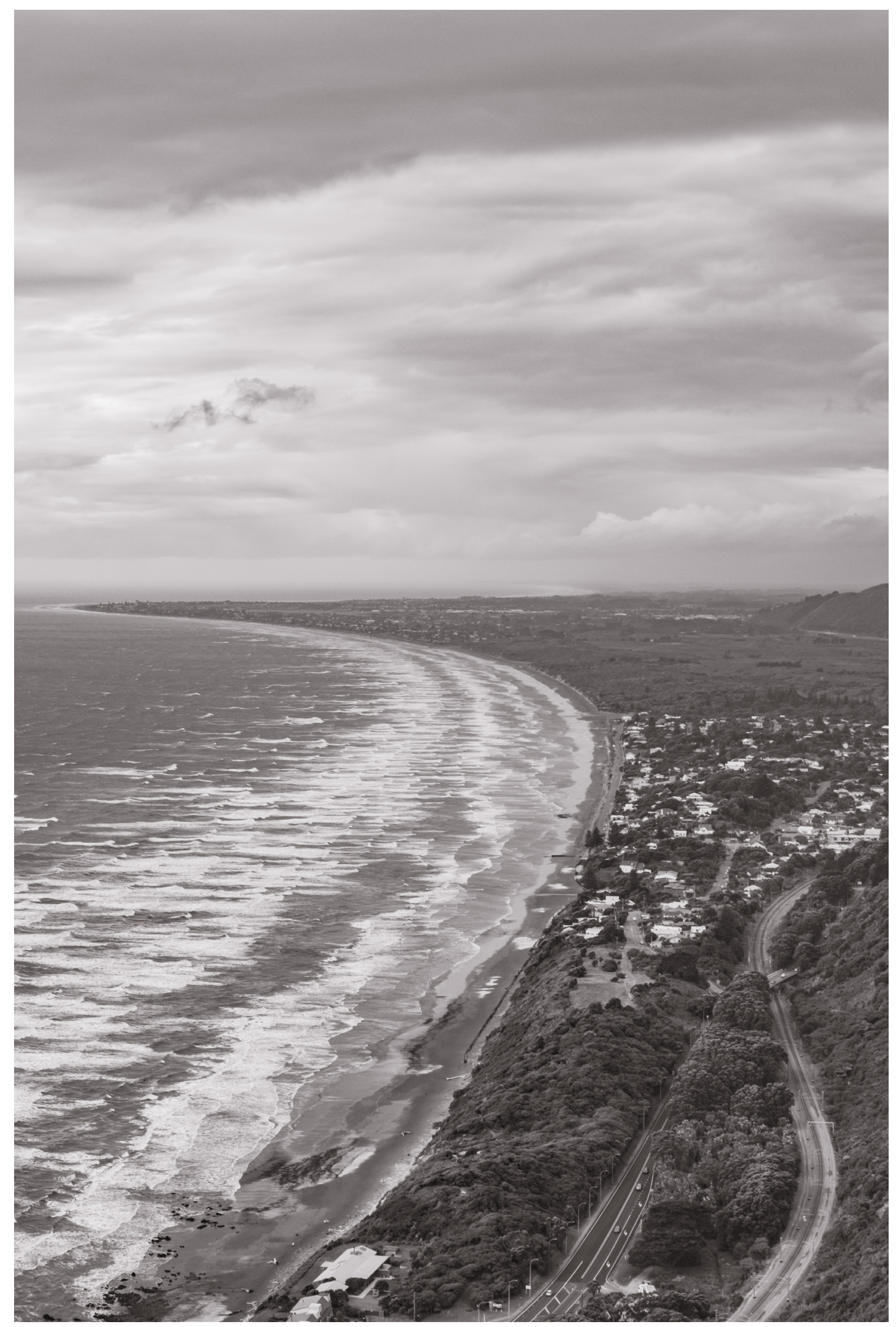




\section{A DYNAMIC COASTLINE}

Due to this expansion, the population experiences natural risks similarly to other coastal areas in New Zealand such as eroding shorelines, sea level rise, flooding, dune migration, ("Natural Hazard Maps.") tsunami and liquefaction ("Kapiti Coast Combined Earthquake Risk"). With the Waikanae Estuary to the North and Raumati to the south, Paraparaumu Beach itself is an incredibly fluid and dynamic area. The geology of the coastline is made up of "alluvial debris and windblown silt, overlaid by sand dunes" (Maclean). In selecting a site, Paraparaumu Beach provides a naturally shifting landscape, and as such, is an idea location to explore the architectural implications of observing and taking a measure of this landscape in flux.

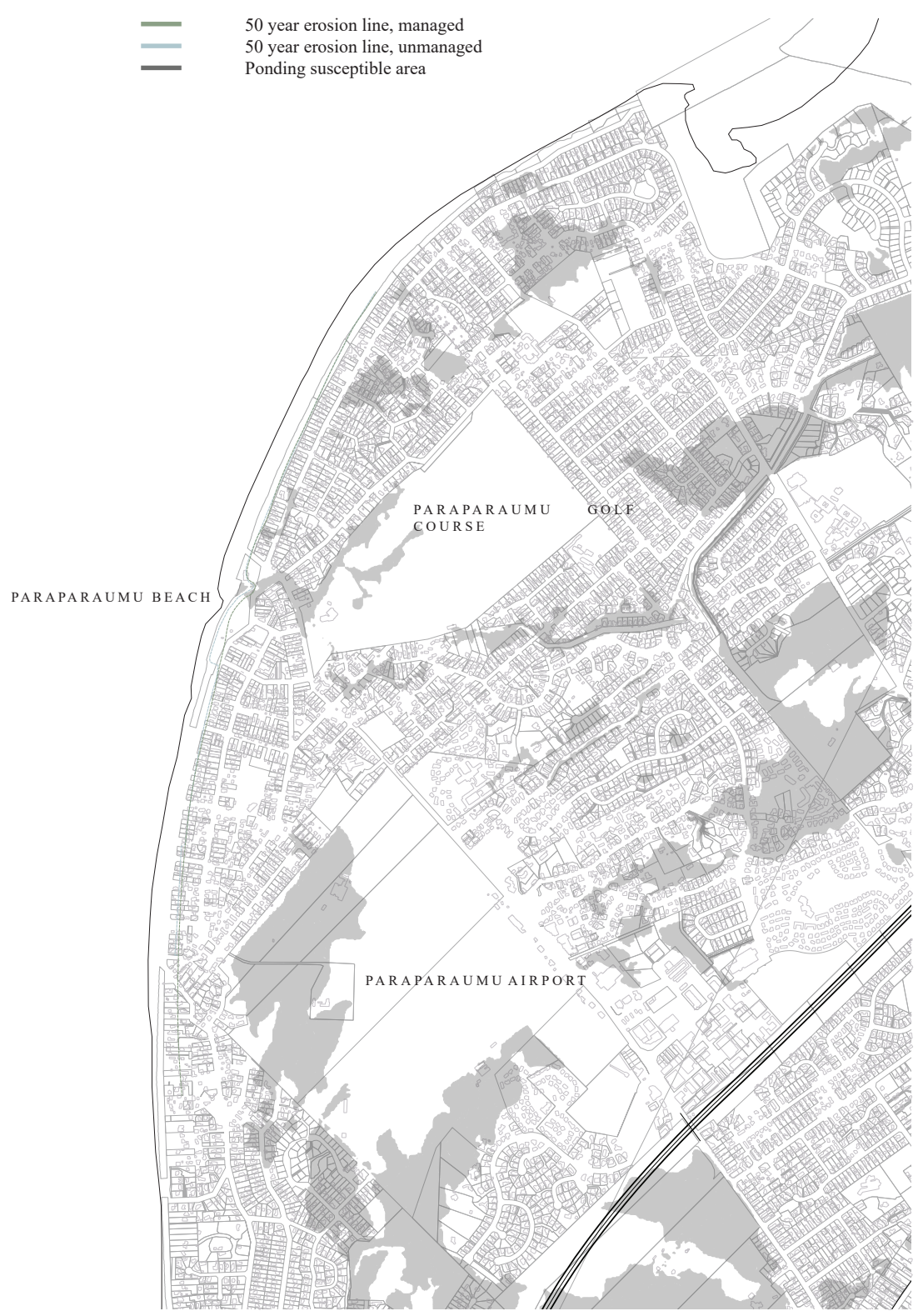

$\wedge$

Figure 16: An Urban plan highlights both discontinuous urban sprawl towards the coastline, as well as ponding and environmental risks impacting Paraparaumu on a wider scale

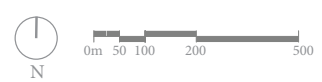




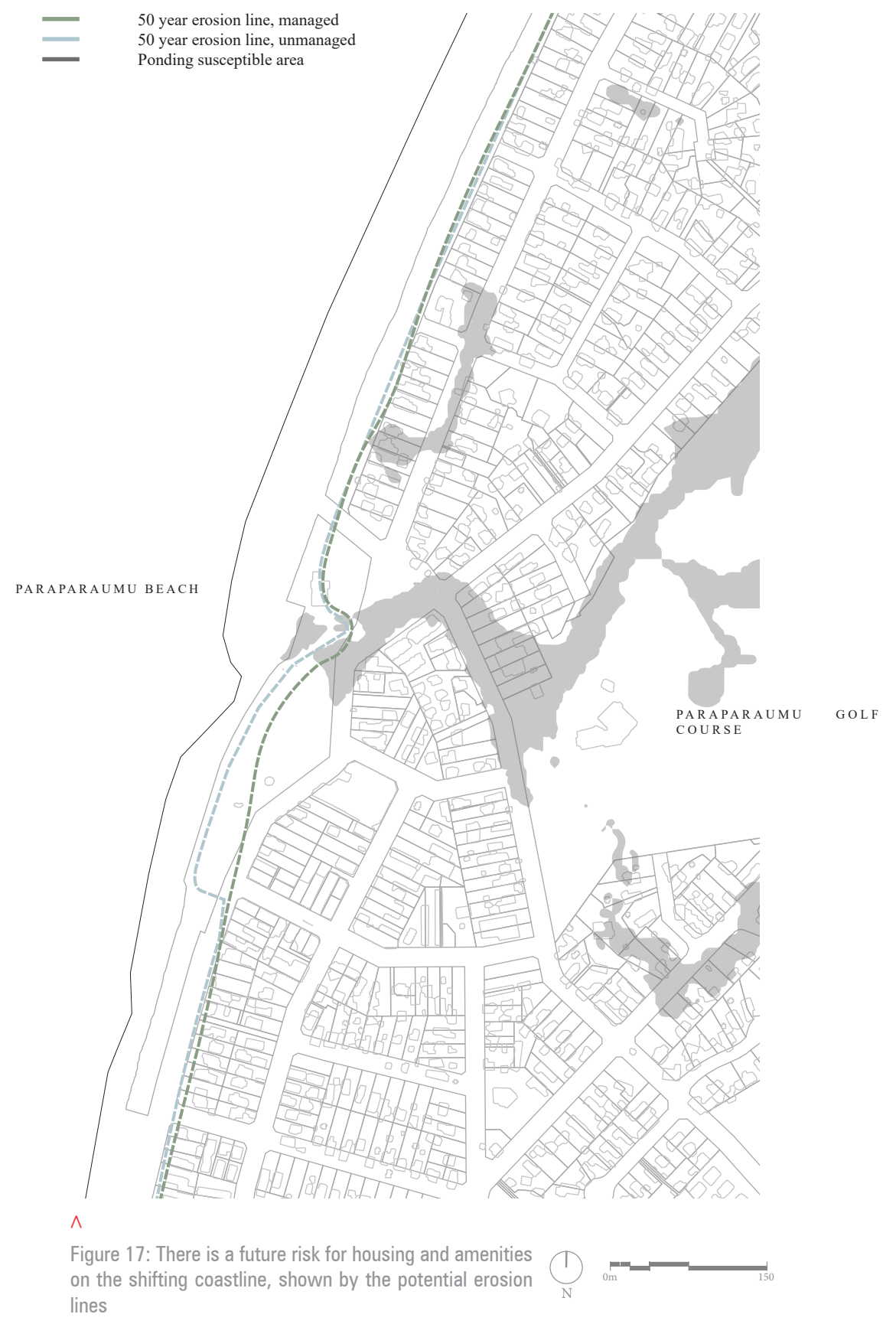




\section{LIVING ON THE EDGE}

There is a localised context underlining the importance of taking measure of this changing coastal environment. In 2012, the Kapiti Coast District Council commissioned an assessment to understand the extent of coastal erosion on local homes close to the coastal edge. The report highlighted many homes that were at risk of eventual destruction, particularly on the southern end of the beachfront (adapted in fig. 16-17). Despite disputes as to the report methodology, alternative reports still highlight coastal areas are at risk (Kapiti Coast District Council, FAQs Withdrawal of Provisions).

Even if indicated erosion projections legally shift, the signs of physical change are visible all along the coast. Eroded sections of dunes and the shoreline are clearly visible towards the south, and a combination of homemade and council-built seawalls litter the beach in various states of condition attempting to hold back the sea.

One may argue that from a standpoint of resilience, that it would be best to slowly move the built environment off the coastal edge. From a council view, the "managed retreat over time of buildings and infrastructure" may be one of the only ways to retain a natural shore (Kapiti Coast District Council, Proposed Kāpiti Coast District Plan: Coastal Environment 47), however this idea has met resistance from locals.

If no significant action can be taken now, how do we proceed at the coast, acknowledging the natural forces at play? 

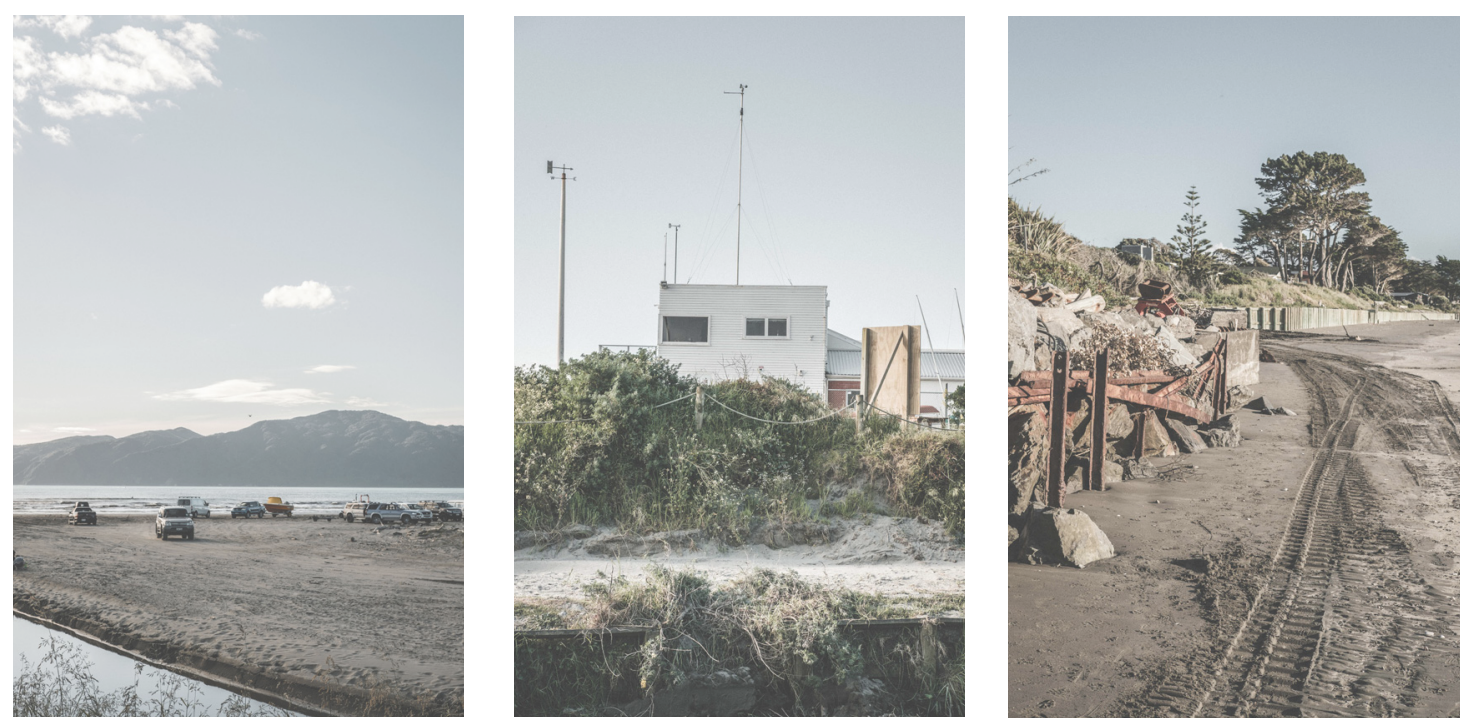

$\wedge$

Figure 18: Author's own photographs adjacent to site of evidence of the site's movements.

Left: Kapiti Island from Tikotu Stream mouth

Middle: Partially flattened dunes meeting the boat club on MacLean Park

Right: Residential Sea Wall: Fill, Blockwork and Timber attempts along the coast 
A PROBLEM AND OPPORTUNITY: A GATEWAY TO THE ISLAND

The opportunities and benefits of highlighting and taking a measure of this coastal edge plays a part in improving public education about the changing landscape and encouraging a deeper understanding of these coastal processes that impact the local population so often.

An opportunity to create a formal Visitor's Centre and Biosecurity Checkpoint on Paraparaumu Beach has been floated by the Kapiti Coast District Council (KCDC) for several years. The KCDC identifies the current Kapiti Island departure point as a basic solution, where visitors unload their gear in the Boat Club's carpark to check for vermin and pests before departing. This lacklustre experience has been identified as being in dire need of change. However, with major parties including the nearby
Boat Club members, residents, The Department of Conservation and the KCDC having differing scopes and ideal solutions to the problem, progress on a new departure point is slow.

With the nearby Boating Club under lease until 2023, feasibility studies have highlighted MacLean Park as a preferred location for a Gateway Visitor's Centre. The MacLean Park Development Plan highlights that as part of a wider park renovation, this building should provide a boost to local tourism and a destination attraction for visitors to Kapiti Island, as well as educating visitors on the local environment. However, with climate change issues in future, the design must tread carefully on this delicate beachfront. 

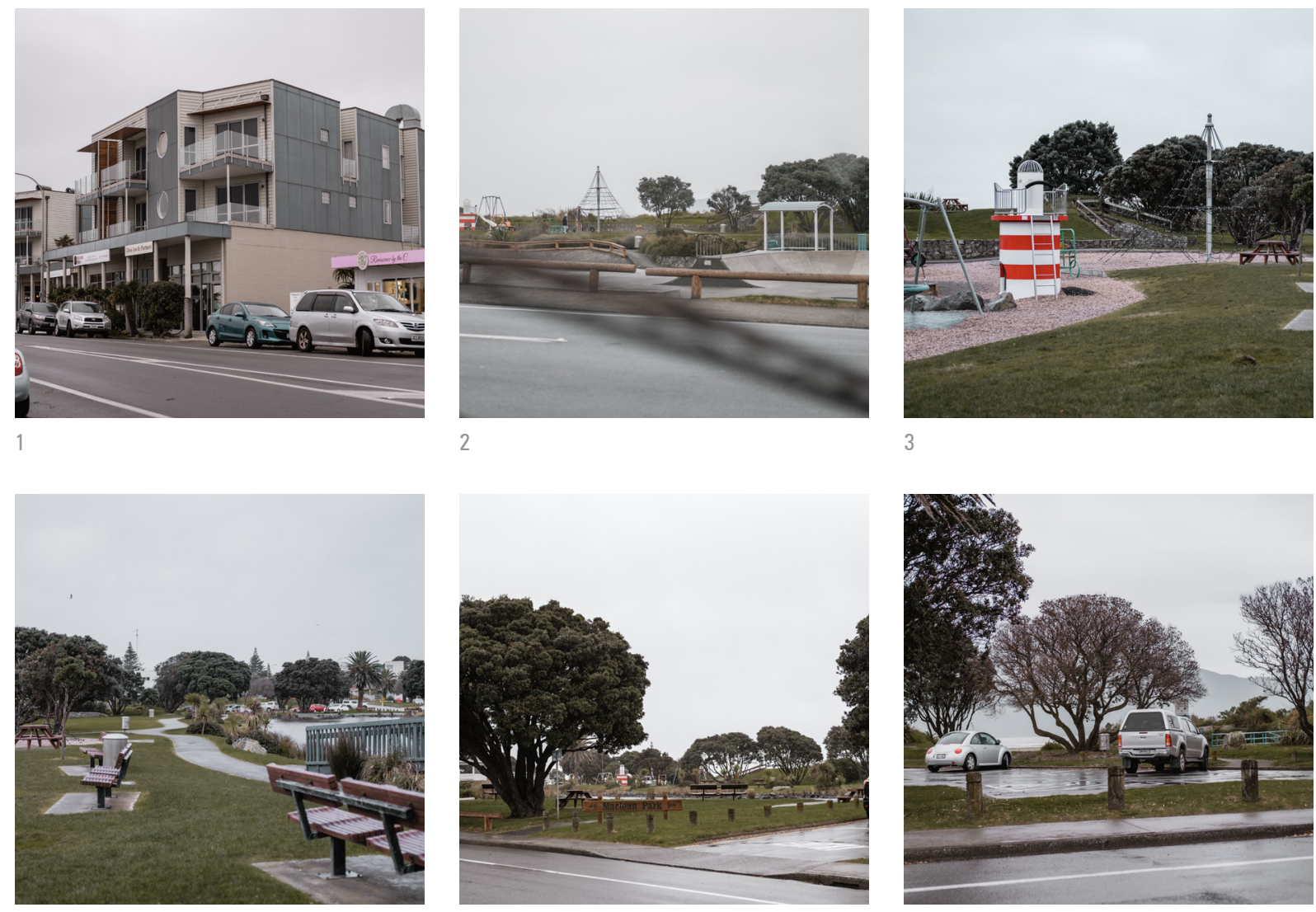

3

4

5
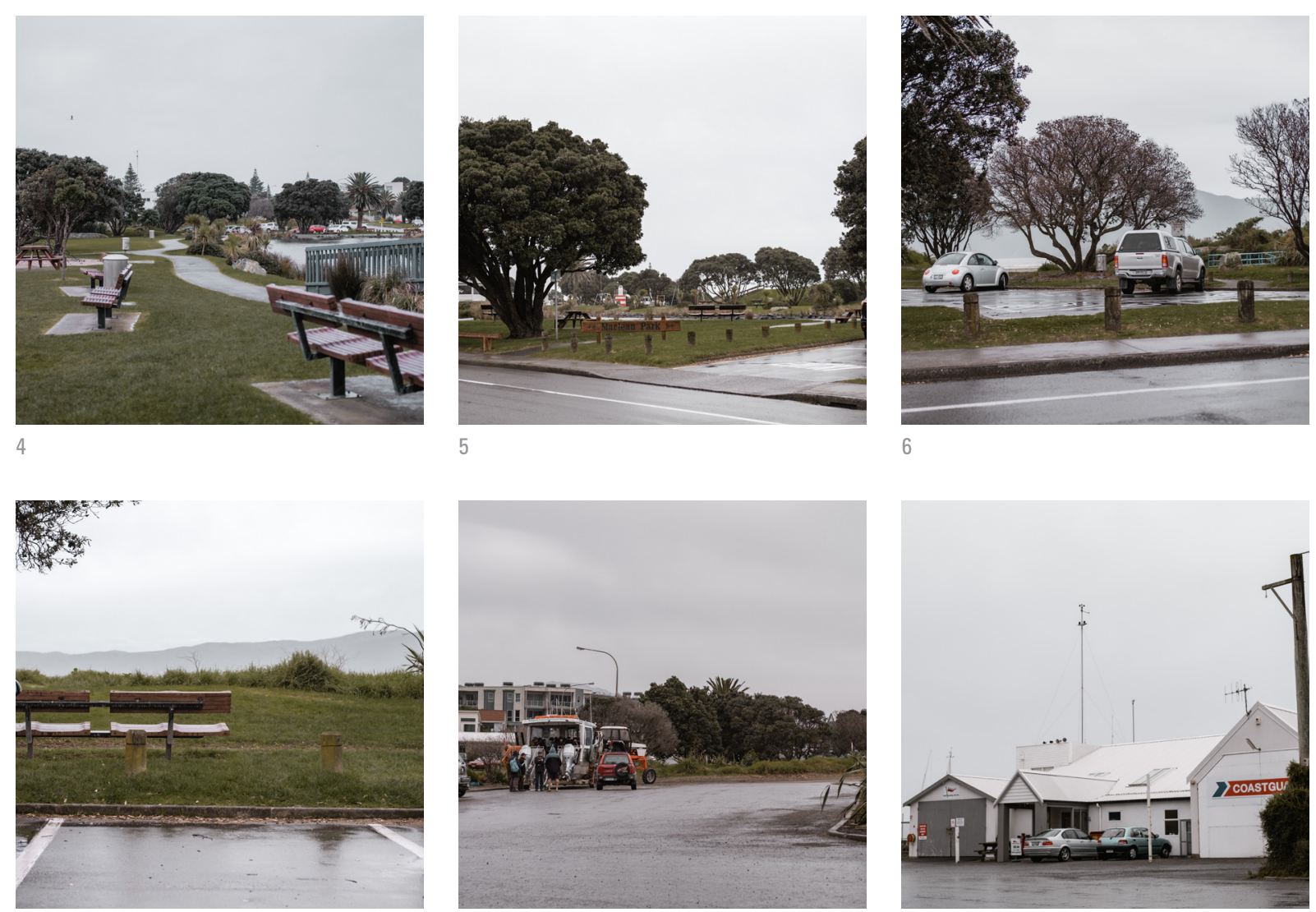

8

9 
THE SITE

The northern side of Maclean Park adjacent to Paraparaumu Beach is the selected location for the design. The site presents a unique opportunity for the Visitor's Centre to act as a gateway to the island, close enough to the township and highway to allow for easy transport links, and near to the boat launch site for to ensure minimisation of biosecurity risk in-between checking and visitor departure.

The park is also a community hub, with much of the local population using it for events, play and relaxation throughout the years despite its chaotic planning and somewhat tired state.

This grassy park located on the foreshore faces a multitude of environmental risks common to the Kapiti Coast. Flooding, coastal erosion, tsunami, high water table, a delicate dune system and a constantly shifting stream mouth all contribute to both a risk in the siting of the design, and an opportunity to engage with and observe the dynamic fluidity of a coastal environment.

$>$

Figure 20: The selected site of The Design

\author{
A. Paraparaumu Beach \\ B. Existing small lookout \\ C. Carparks \\ D. Boat Club (Existing Bio-Security Checking Area) \\ E. Pond \\ F. Children's Playround \\ G. Tikotu Stream
}

Maclean Park Site Plan

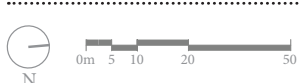




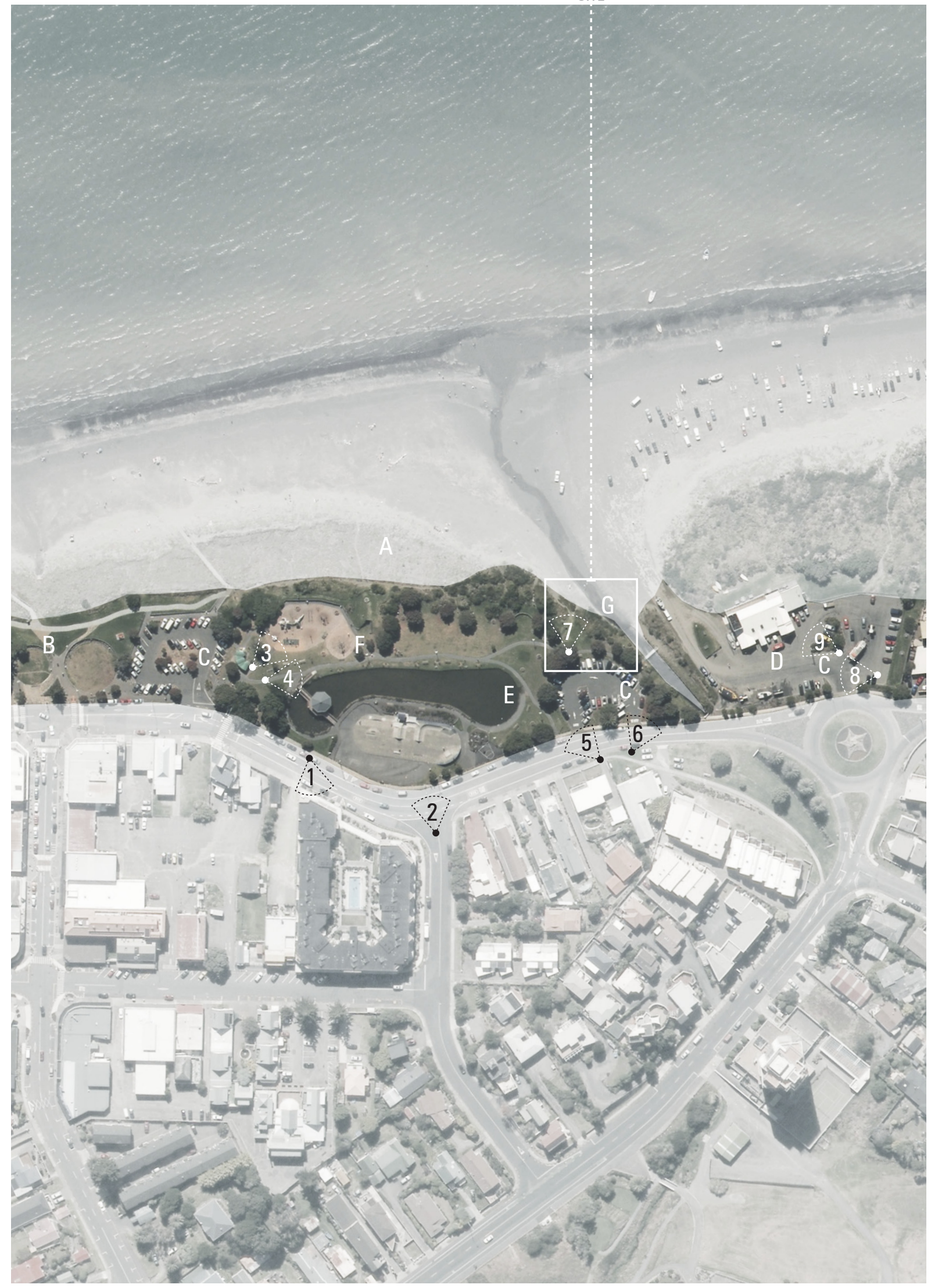




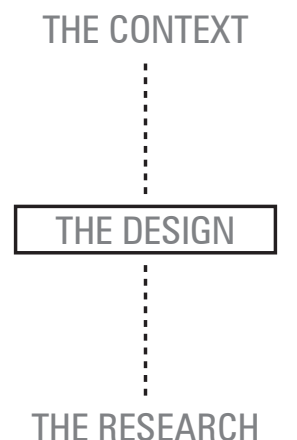

THE RESEARCH 


\section{THE DESIGN \\ MADE TO MEASURE}

A Dynamic Site 
MADE TO MEASURE

\begin{abstract}
Made to Measure is a proposition for a Gateway Visitor's Centre and masterplan of MacLean Park. The project is prompted by the pragmatic need for a Visitor's Centre to improve tourism on the coast, and the need to take a closer observation of a dynamic coastal environment.

Intended to facilitate engagement with the public and a greater understanding and feel of landscape movements, the design draws from an architectural language of other structures that dwell sensitively on delicate sites. A light, lifted and modular timber framed grid is proposed. This 3.6 metre gridded framework acts as a static measuring device in a shifting landscape, allowing natural site processes to occur around the structure, which acts a point of reference and measure.

Taking both rational measures of the landscape through the $3600 \mathrm{~mm}$ grid and showing more poetic gestures of revealing it through wear and patina over time, the architectural response forms a lens through which the public to look and relook at how the coastal environment and building continually change.
\end{abstract}



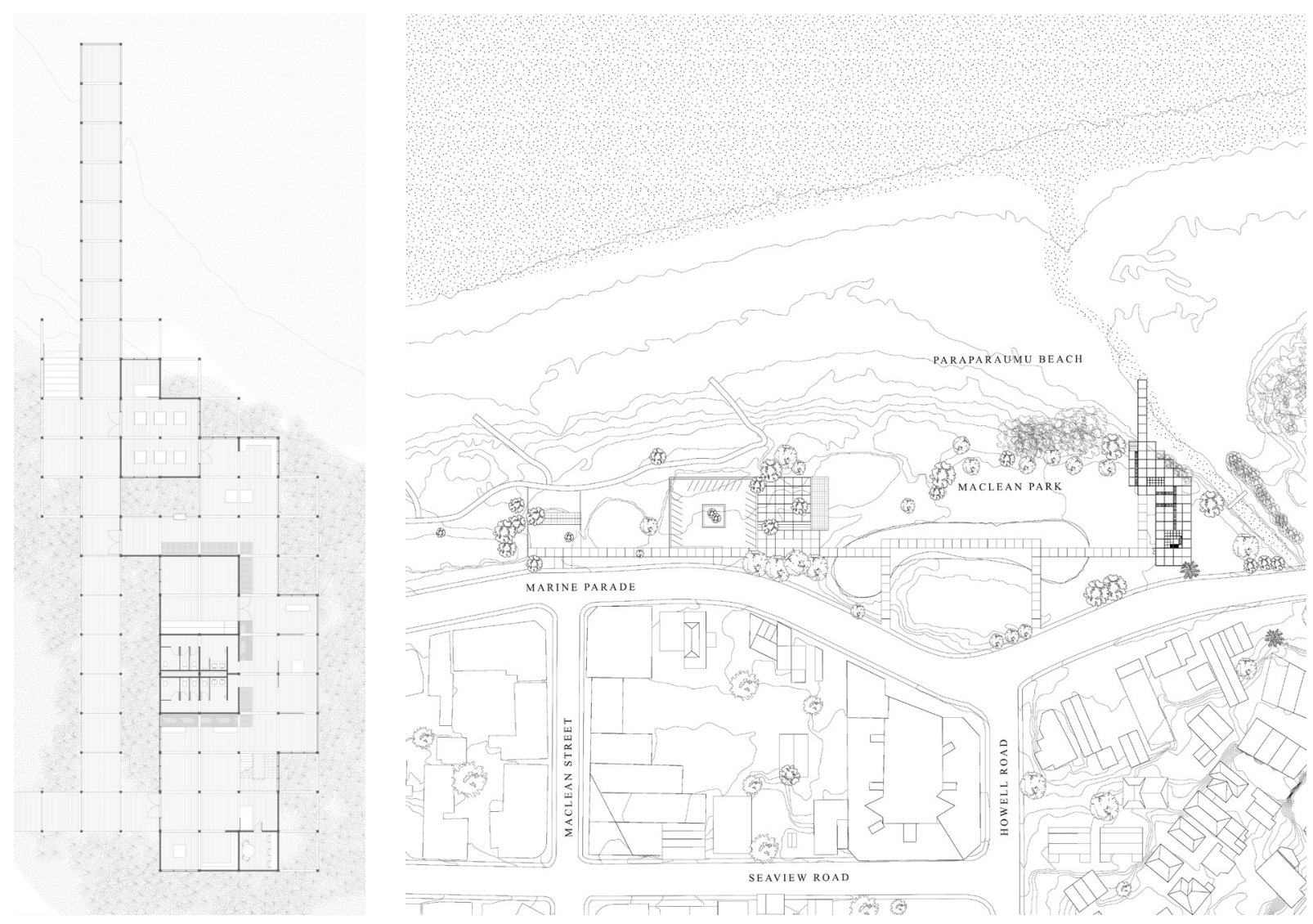

$O_{\mathrm{N}}$ 


\section{AN EXISTING URBAN CONDITION}

The current site is a scattered ad-hoc arrangement of hard structures, concrete carparks, paths and grass. There is visibility of the island through gaps in the foredunes. The site has opportunities to observe the edges through a visitor centre based on the threshold of the beachfront and develop a more cohesive dialogue with the surrounding natural landscape.

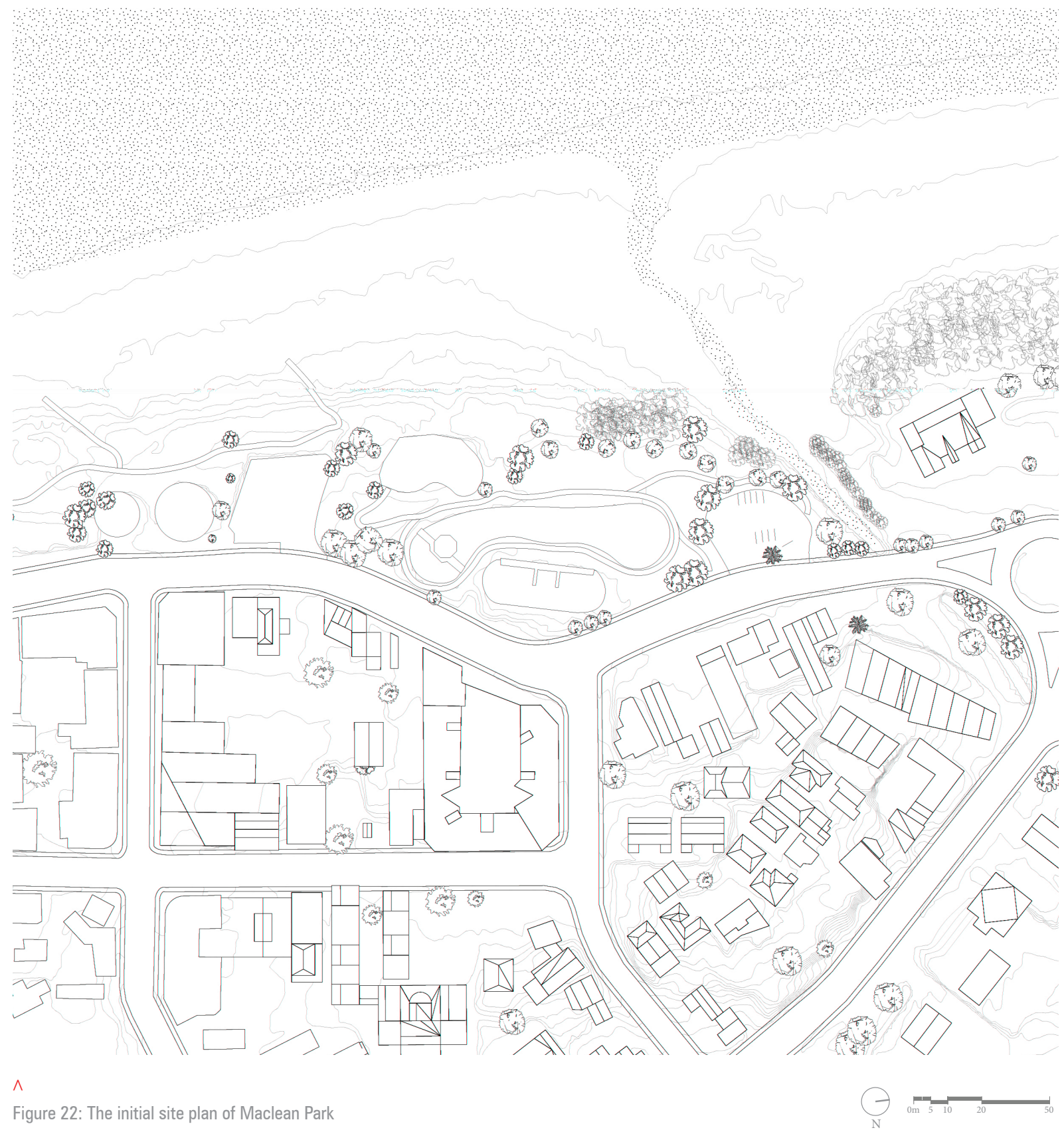




\section{A MEASURED RESPONSE}

A new building sits on the edge of the site, only encroaching onto the beachfront to allow public connectivity and an extended jetty for the boats to Kapiti Island to dock to. Atop the site, the gridded timber walkways provide a promenade to the building and public access to the beach. These are lifted to allow uninhibited growth of long grasses below. The design takes a multidisciplinary approach: Native planting extends under the building, encouraging a more natural and resilient movement of the foredunes in changing conditions under the light framework. The existing planting extends further into the park, with the existing concrete pond replaced by a wetland which encourages natural ecosystem processes, previously common, to once again occur on the site.

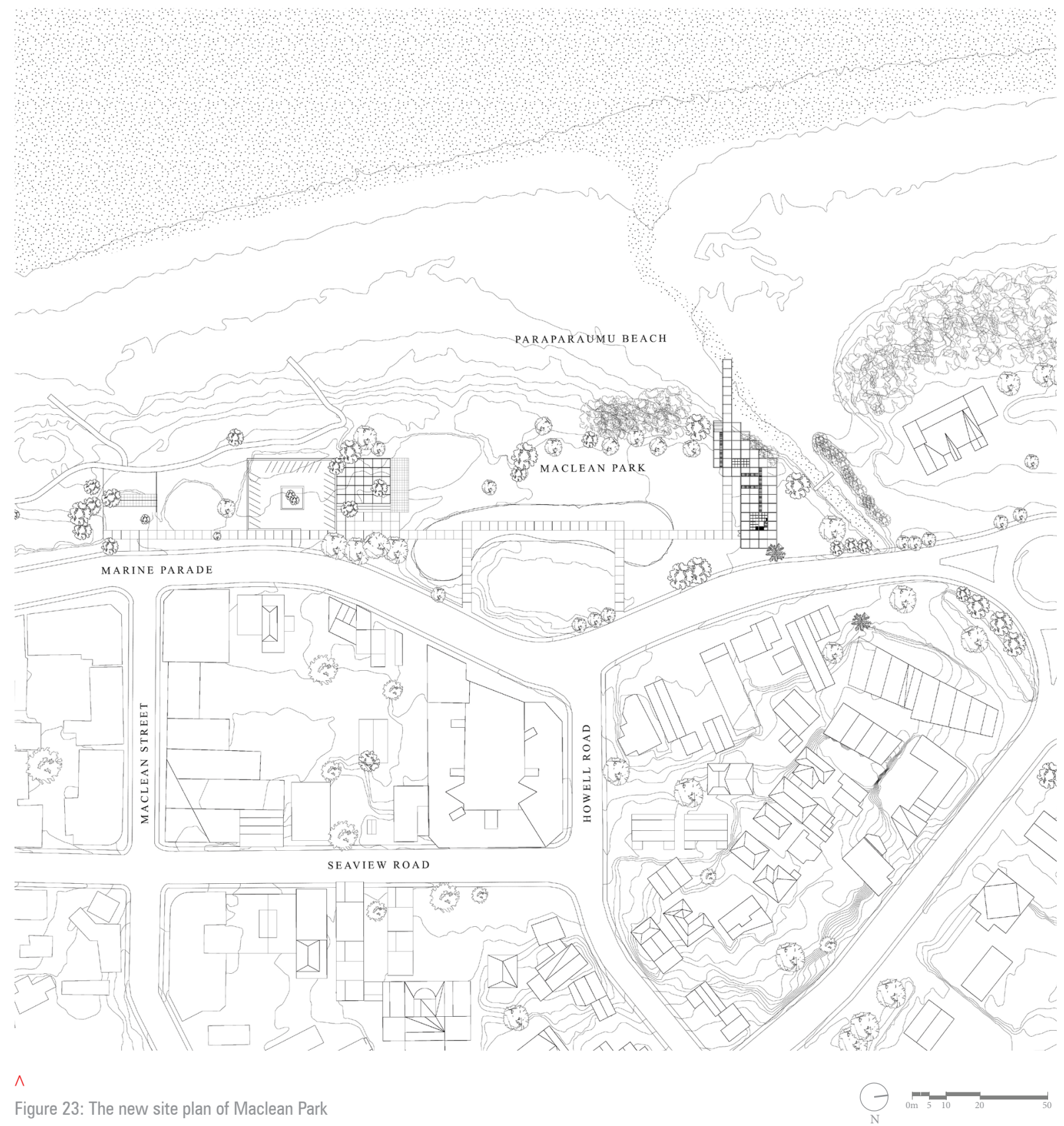




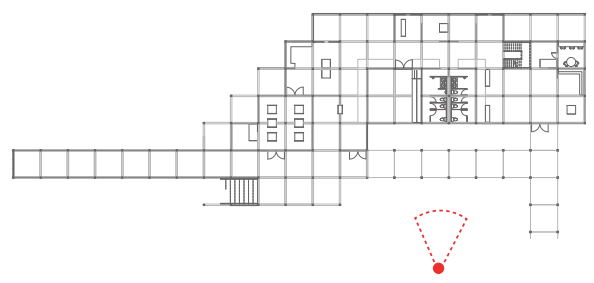

Lookout tower allows the public to visually observe the +surrounding coastline

Steel band detail wrapping tower will age and patina in differing ways dependant on orientation, highlighting wear on sides closer to the sea and exposed to sea spray

Openings are cut into locations on the tower to

purposefully frame specific locations in the surrounding area allowing visual observation, in this case, Queen Elizabeth Park

Public pier accessible from park, allowing the public access to the beachfront

Native dune restoration planting encourages dune and flora growth and unencumbered movement. Structure is lifted on piloti to further encourage freedom of landscape movement as a process.

Figure 24: A perspective looking towards the north from MacLean Park 

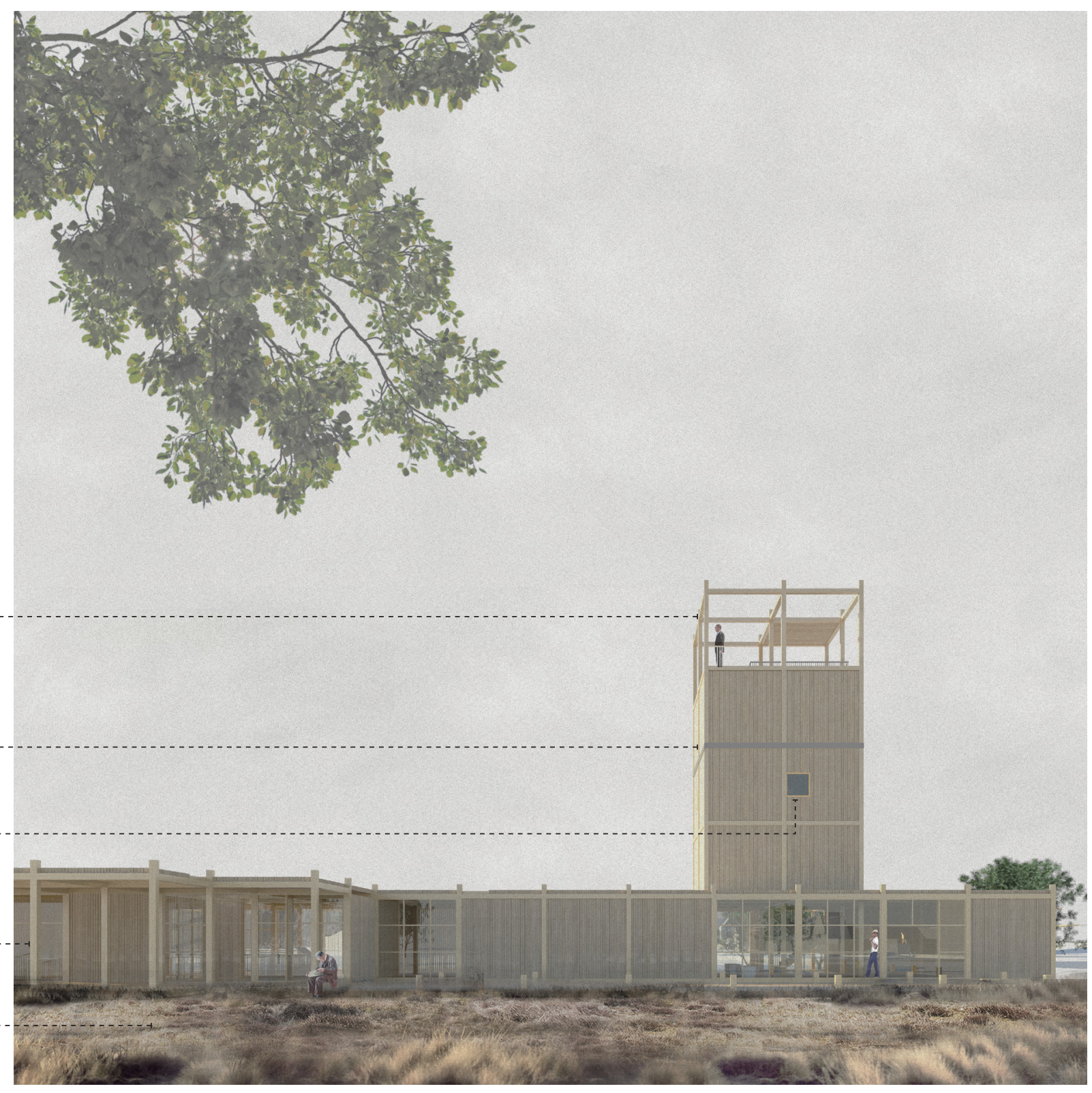


\section{ON A DYNAMIC EDGE}

On the MacLean Park site of the building, a raised timber walkway splits into two. Visitors enter through the Northern Entrance to the main lobby and gift shop. From here, they can climb the observation tower to observe the coastline or wait for their tour guide. The exhibition space features environmental history and is a semi-enclosed space. Rationalised by the local site's environment, the use of an open weathering-steel rainscreen on the northern wall of the space exposes visitors to the heat of summer, predominant north-east breezes and the yearlong changing conditions.

The building is layered in plan to allow both exposure to the environment, and protection from the elements in areas where visitors sit for longer periods of time in the central core of the building. Guides move visitors through to the enclosed mini theatre space, where they learn about the upcoming journey before moving through to the Bio-Security Checking room. From here, visitors walk along the pier to the boat docking point to journey to the island.

Public access to the beach is maintained by a stair to the beachfront, and unimpeded access along raised walkways. Over time, the floor plan of the exposed deck would slightly change: As the dunes shift, sections of the main deck and the stair would become more visible or be covered over completely, the exposed gridded structure forming a measure and reference point of the sand's movements.

\section{Entrance}

2. Reception + iSite

3. Office/Staff

4. Observation Tower Access

5. Permanent Kapiti Enviro Exhibition Space

6. Toilets

7. Mini Theatre / Briefing

8. Temporary Exhibition Space

9. Flora/Native Fauna Education

10. Bio Security Checking

11. Beach access

12. Public Pier

13. Gate access to Kapiti Boat

14. Native Dune Restoration Planting

15. Park Access / Walkway

Ground Floor Plan

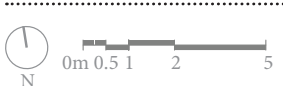

Figure 25: The final plan of The Design 


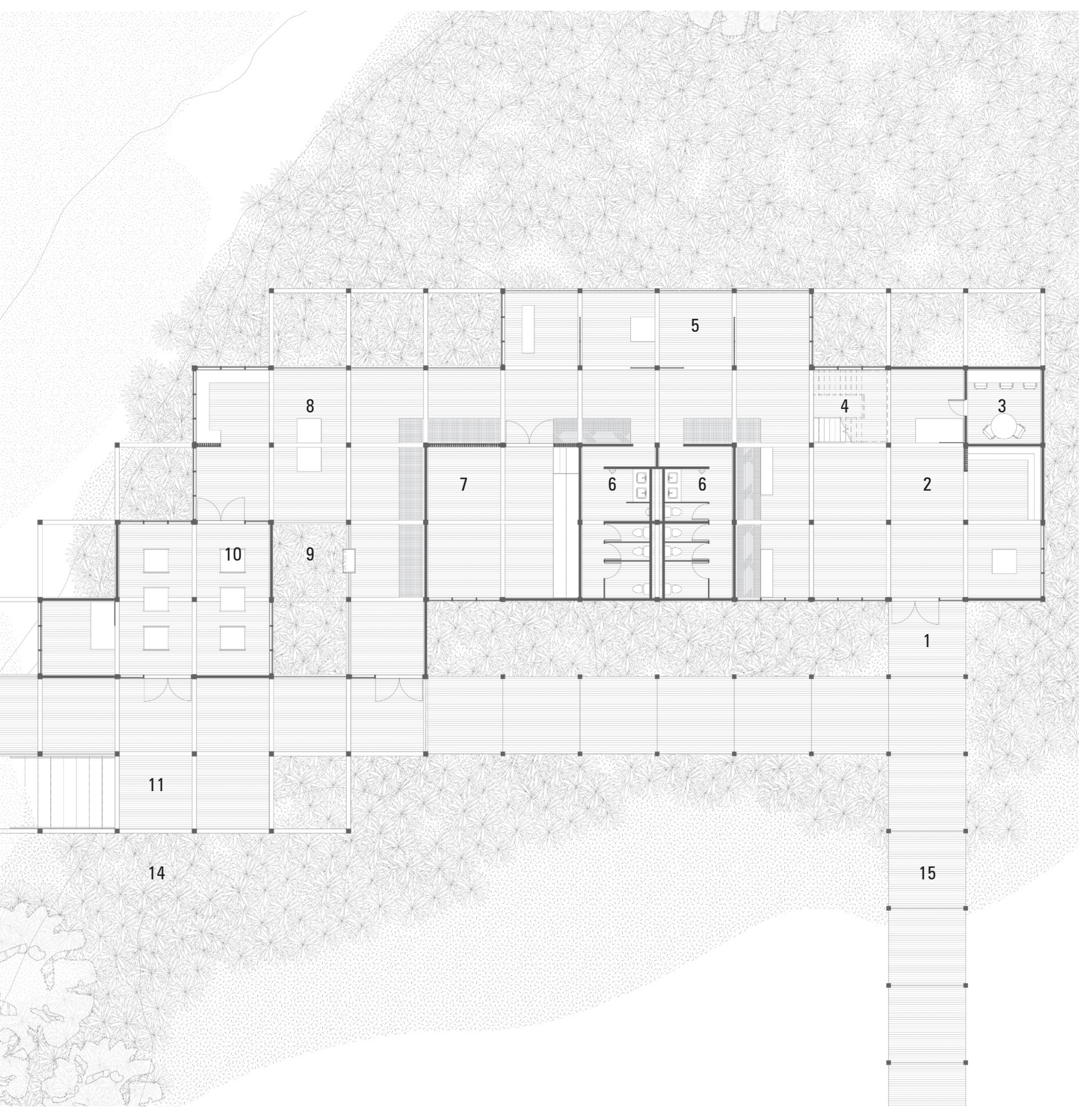




\section{A KIT OF RESPONSIVE PARTS}

A post-tensioned timber framed grid makes up the structural system, with the walls, flooring and ceiling acting as infill panels. The location of the different types of panel is dependent on the programmatic needs of the space and rationalised by the surrounding environmental conditions, similarly to methods employed by Glenn Murcutt on many of his buildings. Steel screen panels located on the northern wall are open to take advantage of predominant winds. Sky lighting panel locations are dictated by wayfinding and also to allow light into spaces such as the mini-theatre at specific times of the day to suit the space's needs.

As a result, the building responds closely to the landscape, as the interior and exterior spaces are tuned, informed and rationalised by observations and measurements of the site and changing conditions.

Figure 26: The final exploded axonometric of The Design, highlighting the modular 'Kit of Parts' approach to the building, dependent on the surrounding conditions 


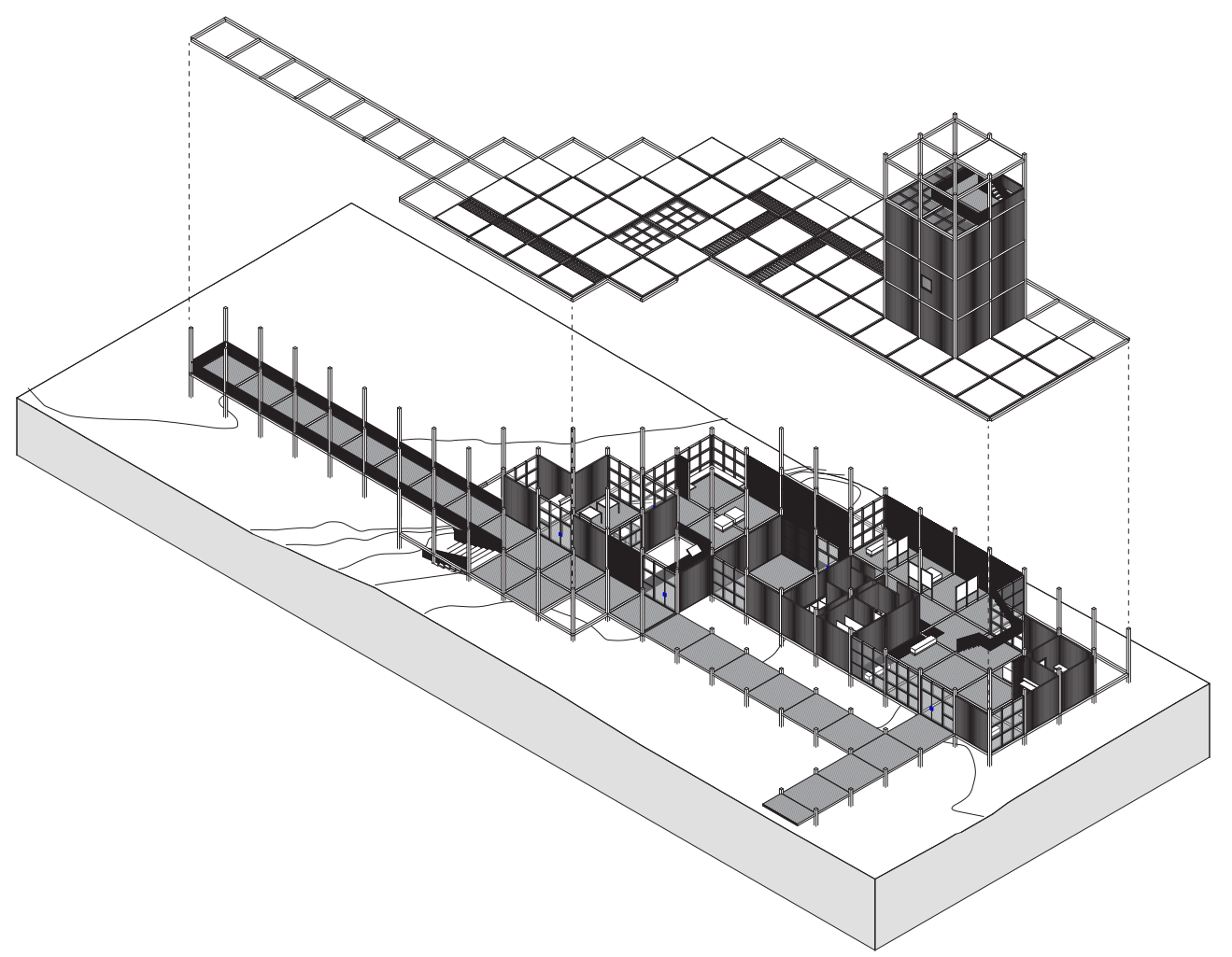




\section{FLOATING ABOVE A DYNAMIC SYSTEM}

At 76 metres long, the structure is intended to impact the processes of the ecological systems below as little as possible. The ground floor is lifted above the ground, allowing for native dune planting to grow underneath, and undulating dunes to be able to shift freely over time. Apertures in the floor of the building encourage growth of plants into the building volume from below letting the structure form a point of reference of its growth and breaking down the boundary between the interior and exterior environmental conditions that visitors can experience.

Vertical circulation encourages visitors to move up the tower to observe the wider landscape, framed by views towards Kapiti Island.
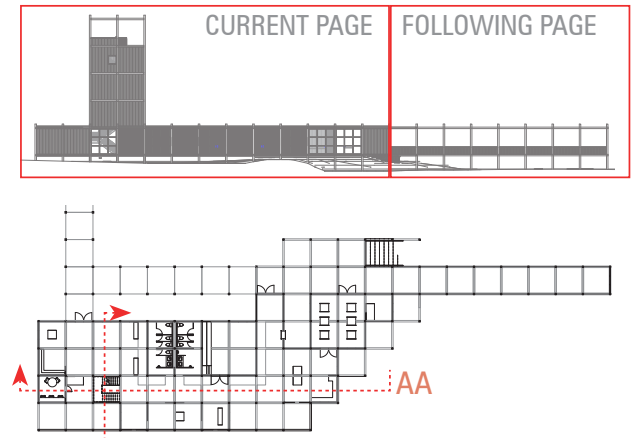

שே

Figure 27: Section AA. The final section of The Design continues on following page

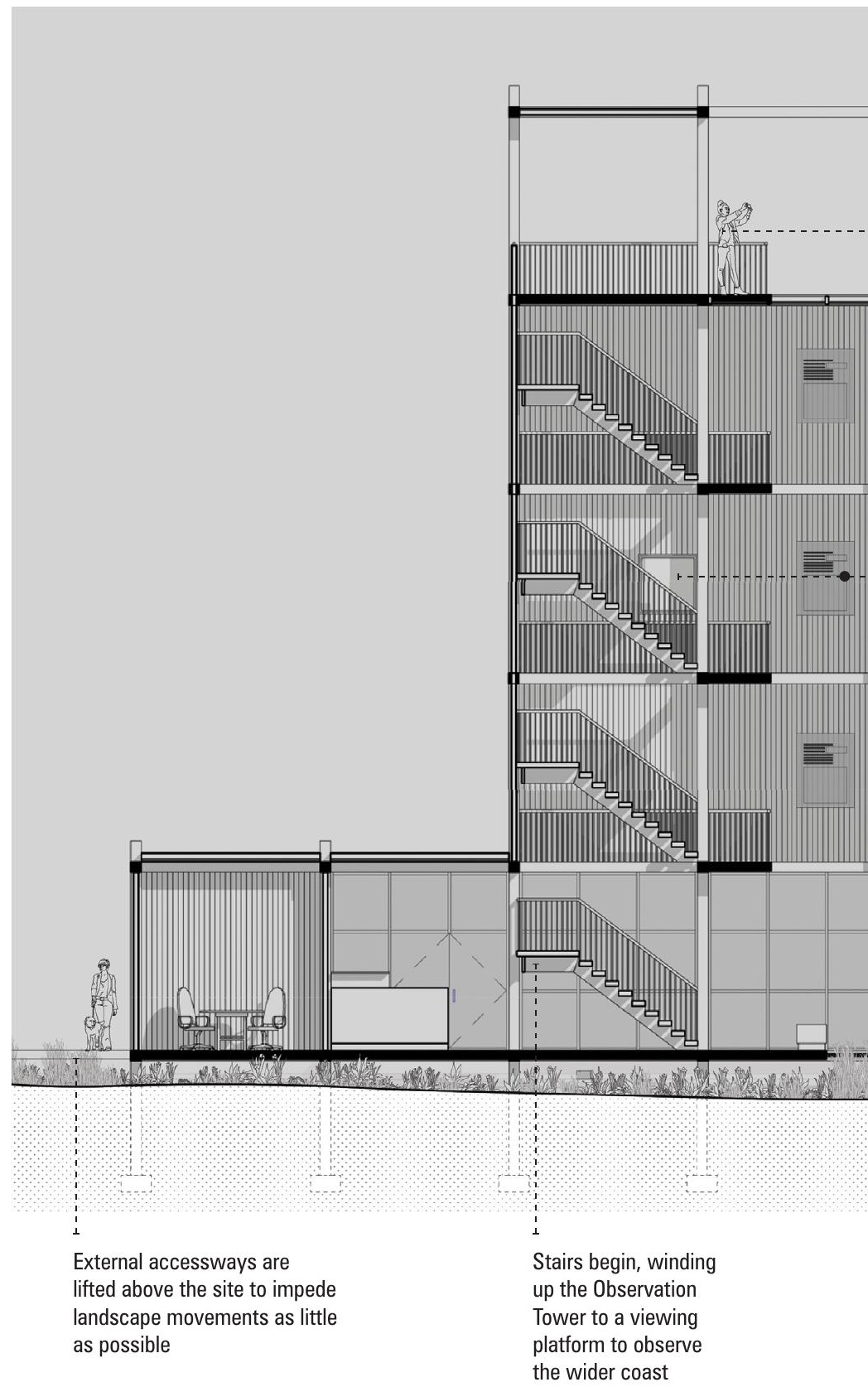


Covered viewing Information boards provide facts about platform provides the surrounding environment and annotate opportunities to openings in the facade that point towards

observe the coast and frame local landmarks
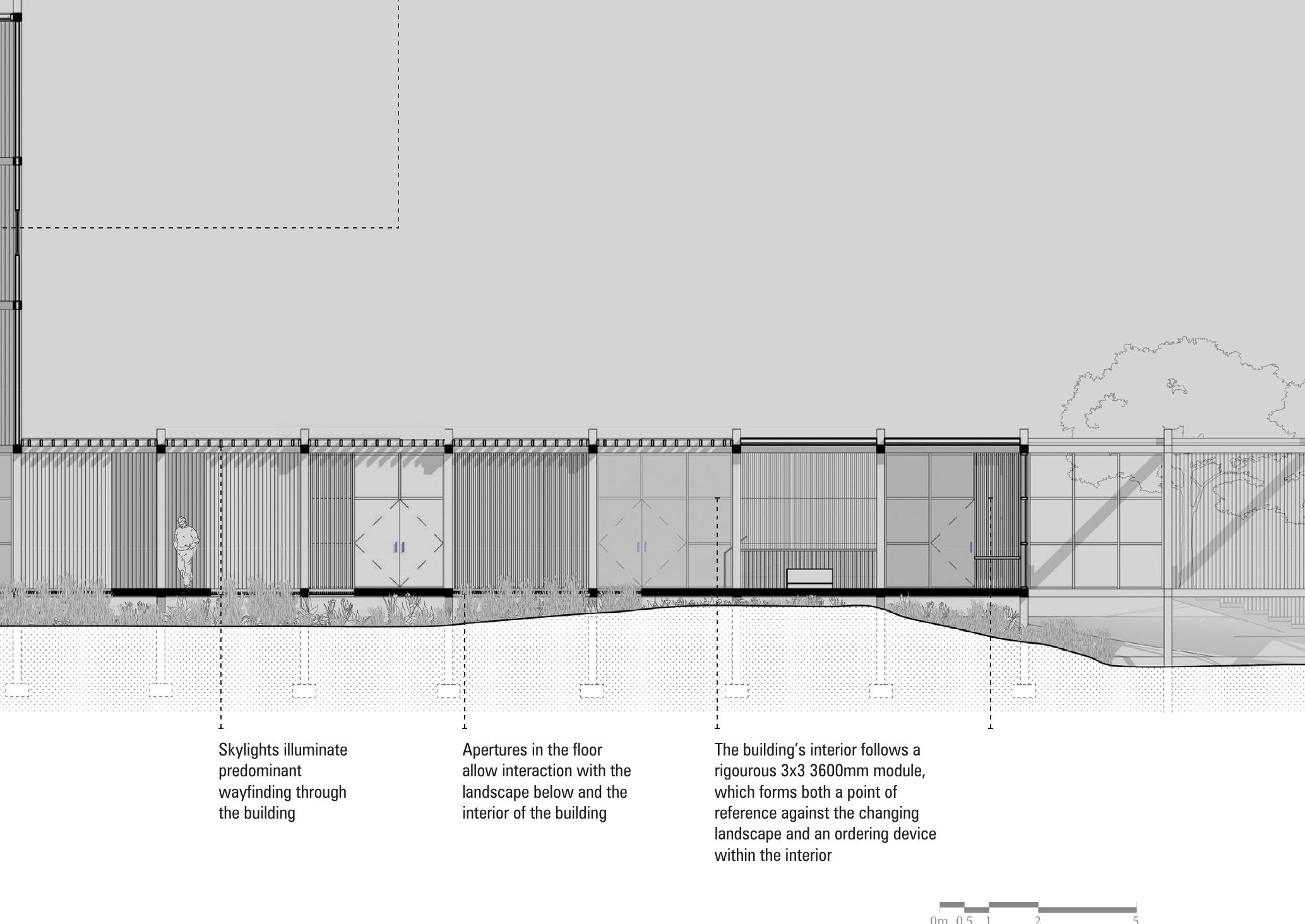


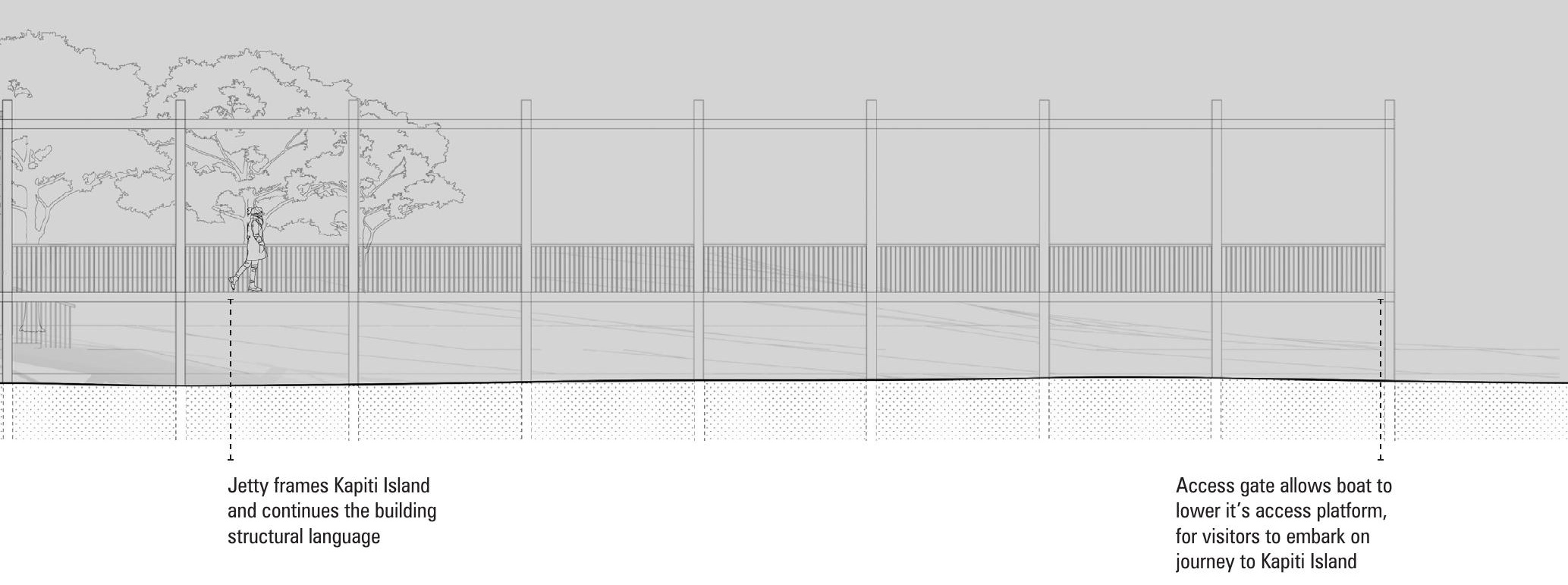




\section{SYMPATHETIC STRUCTURE}

The structure is attached to deep piles just below the surface to ensure that it is planted to the terrain, through the sand to solid rock below. The partial burying of the structure acknowledges that if the building is disassembled in future, the deep piles can remain without trace, allowing the ecosystem process to continue unabated above.
The timber framed structure is post-tensioned in both directions with a steel tendon in the middle of the beam and local joint strengthening. This requires little in the way additional elements to carry horizontal and gravity loads. It has a high degree of prefabrication allowing for both structural accuracy, fast assembly and in future site changes, disassembly.

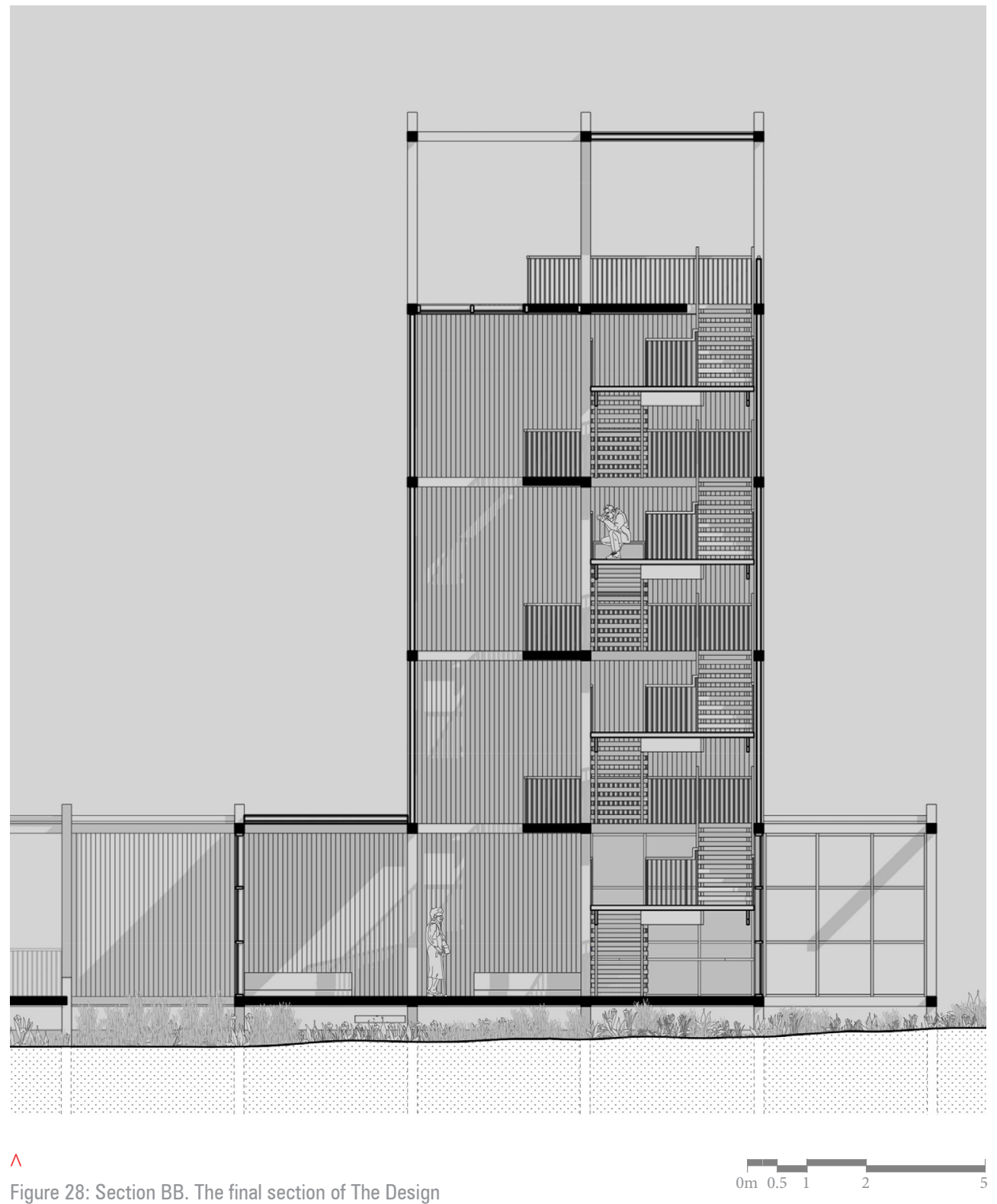




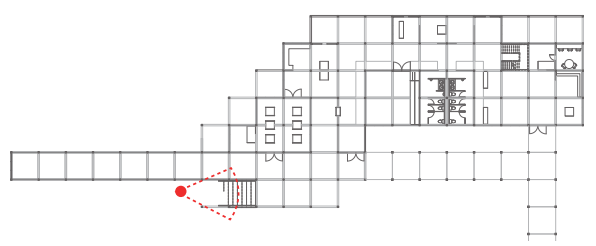

Concrete stair will smooth over time due to exposure to sand, measuring environmental exposure through material

Beachfront access stairs further revealed and concealed depending on the position of the dune, which will build up over time, then recede through storms.

Timber columns reveal tidal markings and movements through patina and wear over time

Figure 29: A perspective of The Design looking towards the main decking from the beachfront 


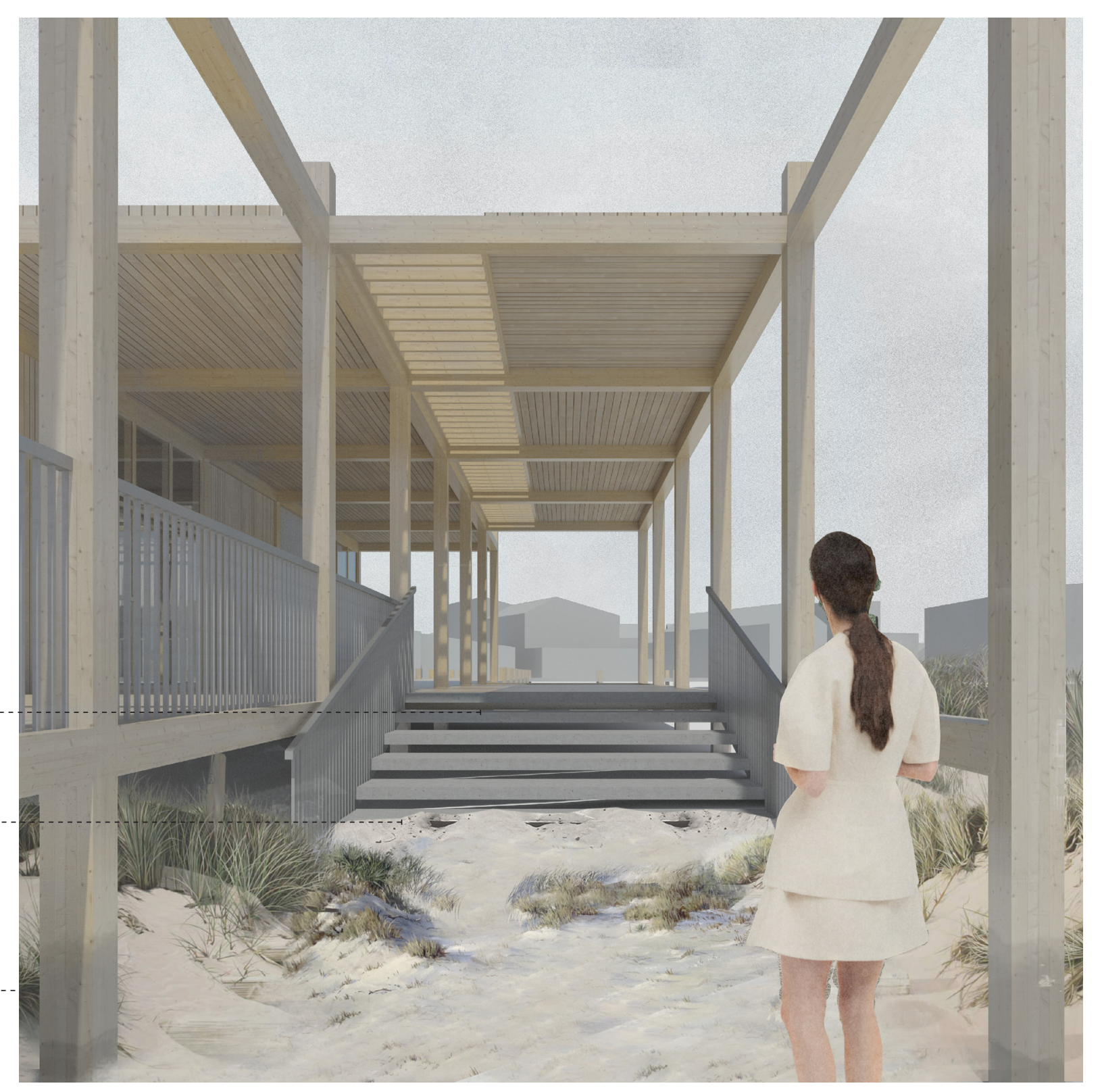




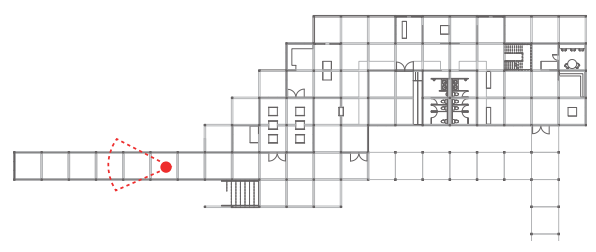

Grid provides clear framing of Kapiti Island beyond

Visual emphasis placed on gridded structure as a static measurement device, with this design language retained across the entire jetty and building structure

Access gate for jetty provided for Kapiti Island boat provides direct access from building. This provides greater surety of bio-security.

Continuity of 3D grid provided through flooring also

Figure 30: A perspective of The Design looking towards Kapiti Island along the jetty 


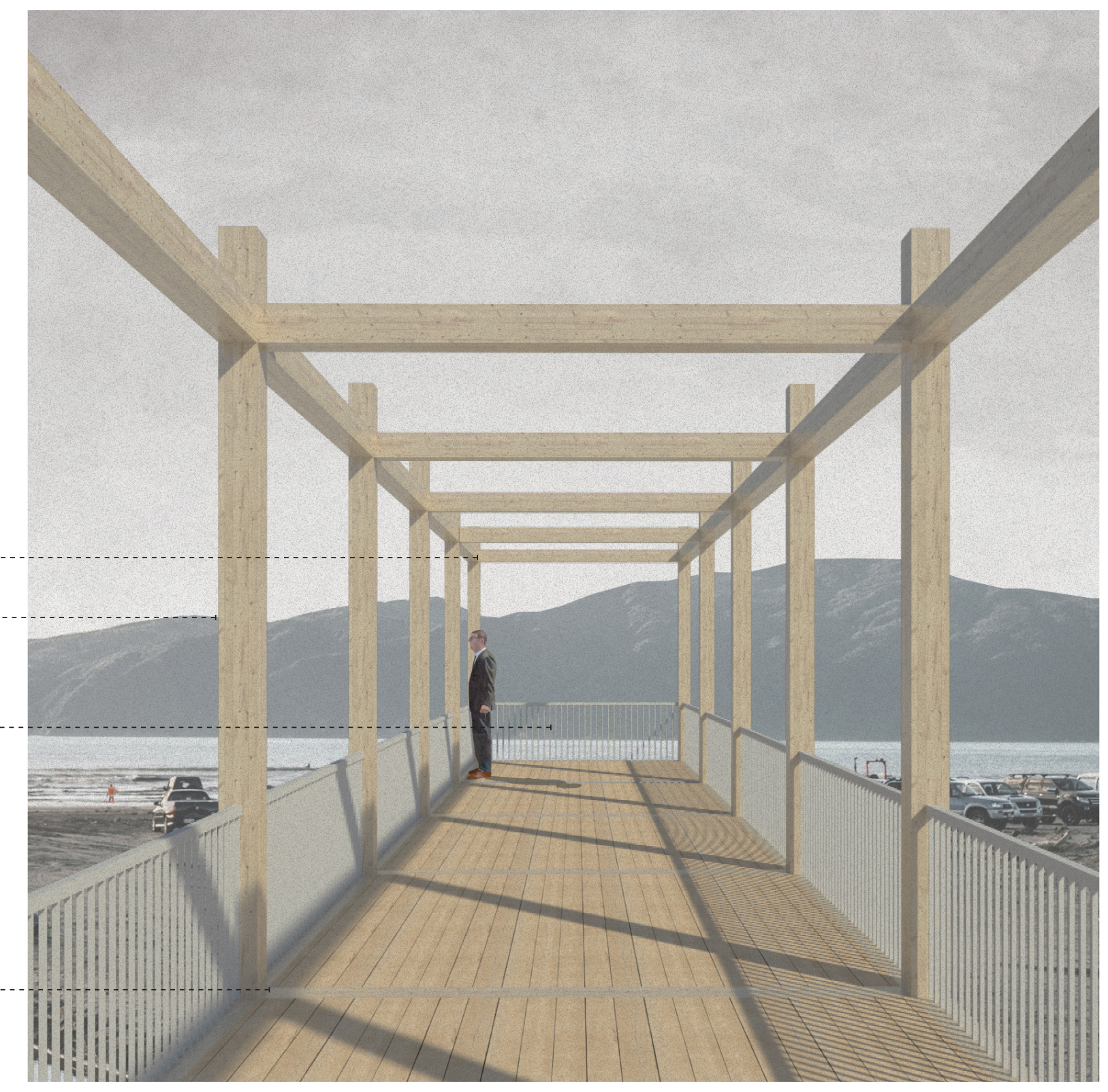




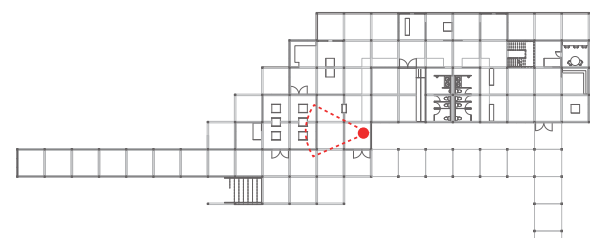

Corten Steel infill wall will patina dependent on exposure to exterior conditions

Bio-Security space beyond frames the island journey ahead and provides direct access to pier and boats.

Aperture in flooring allows for dune plantings to grow
into building, with the regular intervals of the modular gridded structure behind providing a point of reference to measure these movements by

Figure 31: A perspective of The Design looking towards the Biosecurity checking room, with landscape opening in midground 


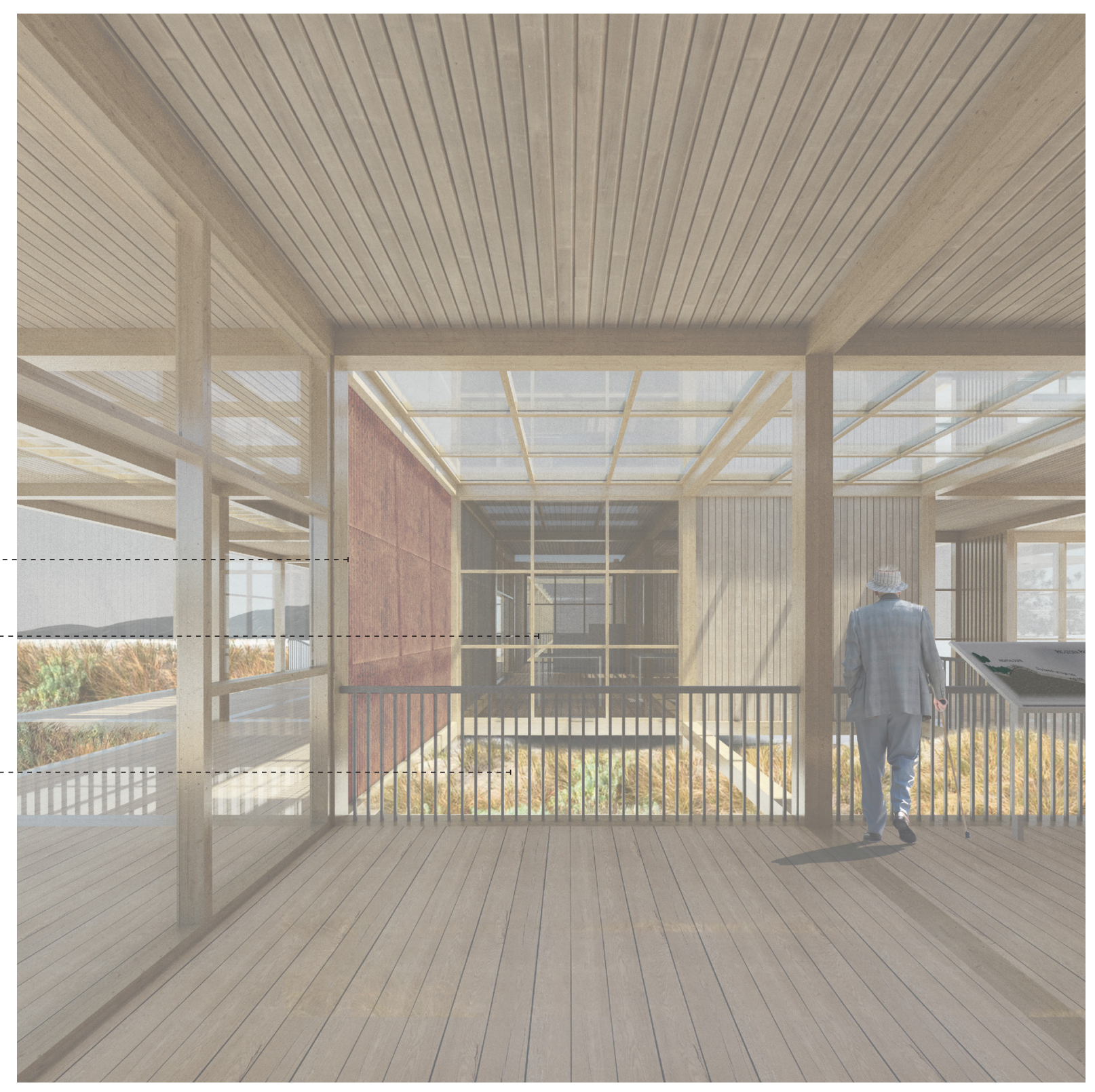




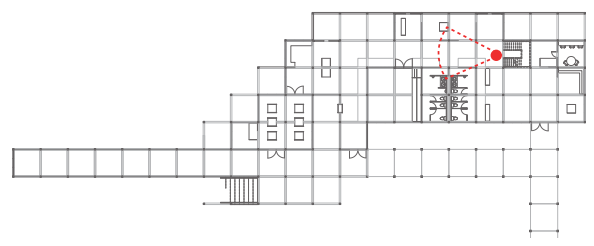

Open steel rain screen, leaving the interior only semi enclosed, orientated to allow visitors to experience summer heat, rain, and winds predominantly coming from the northwest. Roll down shutters prevent damage in extreme weather conditions.

Toilets and mini theatre fully enclosed, seen as areas needing enclosure for longer stationary periods for visitors.

Information boards provide educational opportunities and data about the surrounding environment, including Kapiti Island

Grating in flooring allows for dune plantings to grow into building, further encouraging the revealing of dunes and growth as a natural engagement of the architecture with site and educational opportunity.

Figure 32: A perspective of The Design looking towards the exhibition space, highlighting interactions between the flora and the building 


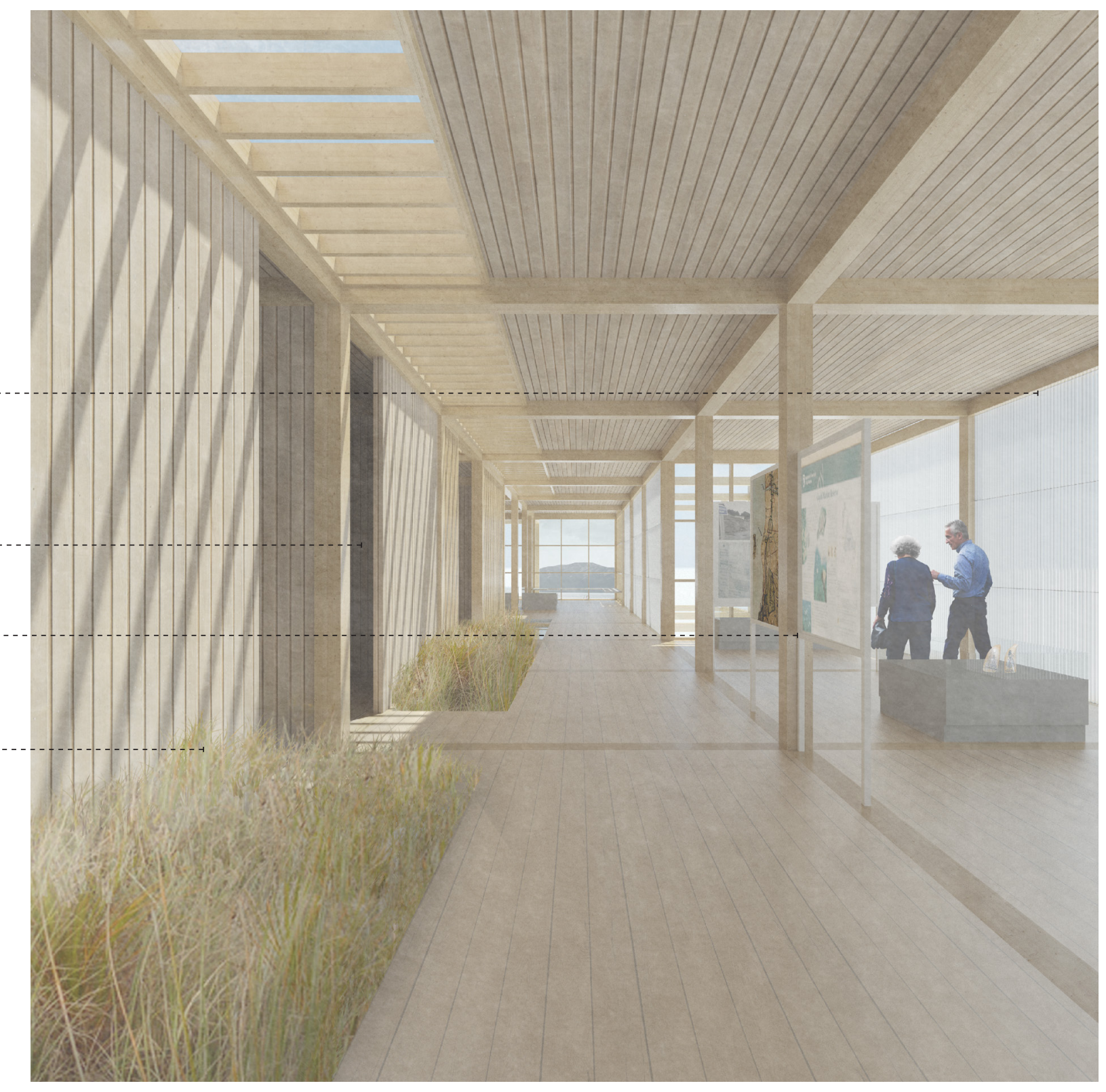




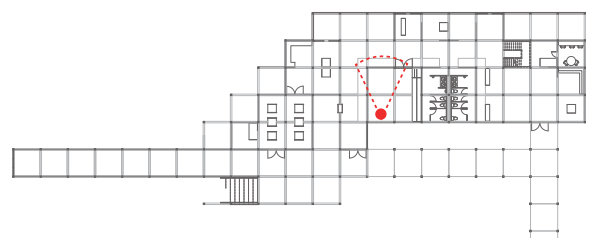

Meetings in the theatre space occur predominantly at 8:30am prior to visiting Kapiti Island, so skylights are designed and located to allow light in at specific times, to find a balance of natural lighting and not to interrupt the programmatic needs of the space.

Presentation of day's events prior to Kapiti Island journey

Theatre is enclosed from the elements completely, as r visitors will likely be stationary inside.

Figure 33: perspective of The Design from the mini-theatre space, showing the implications of lighting from the skylights, tuned to the programme of the space 


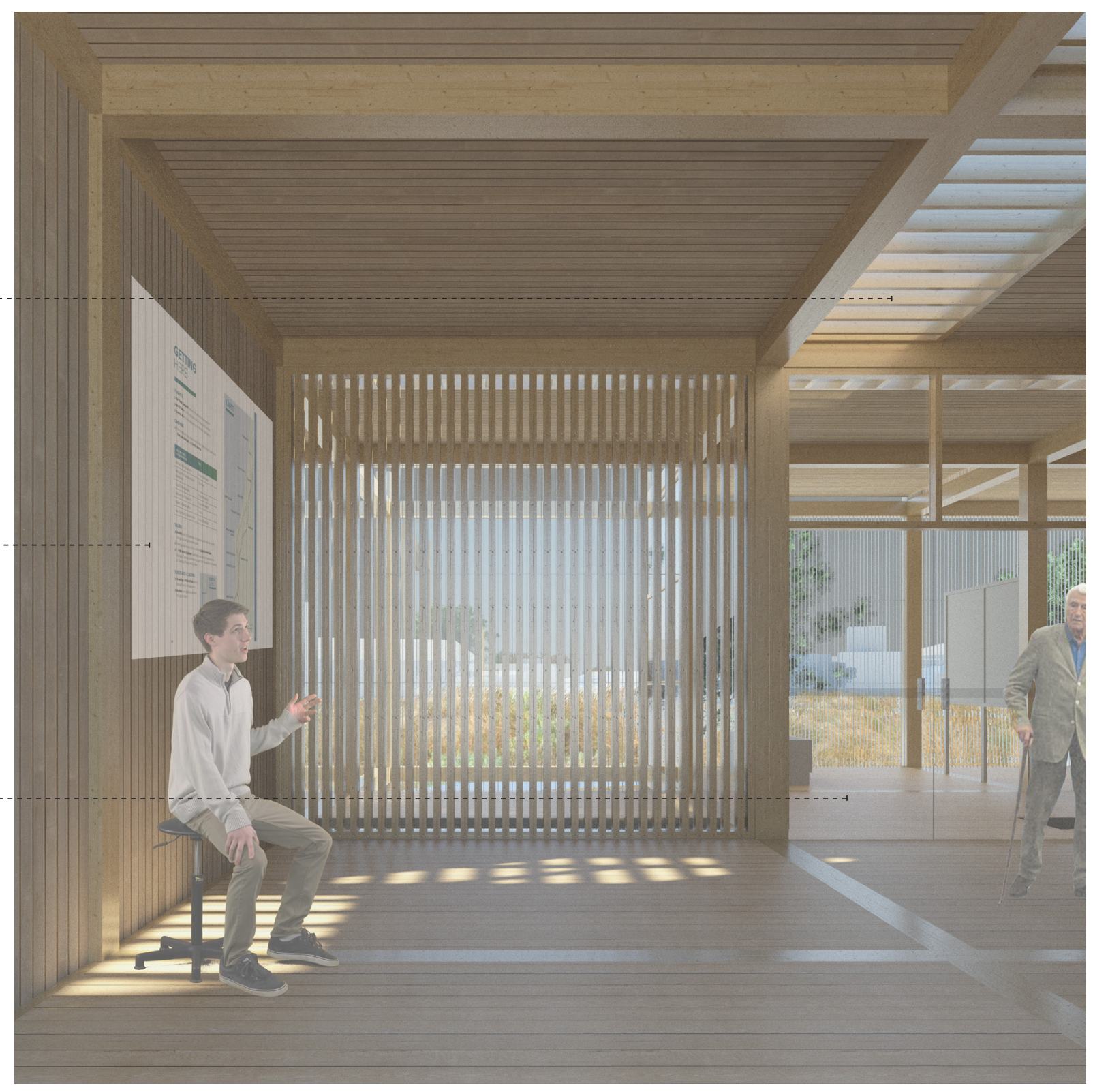




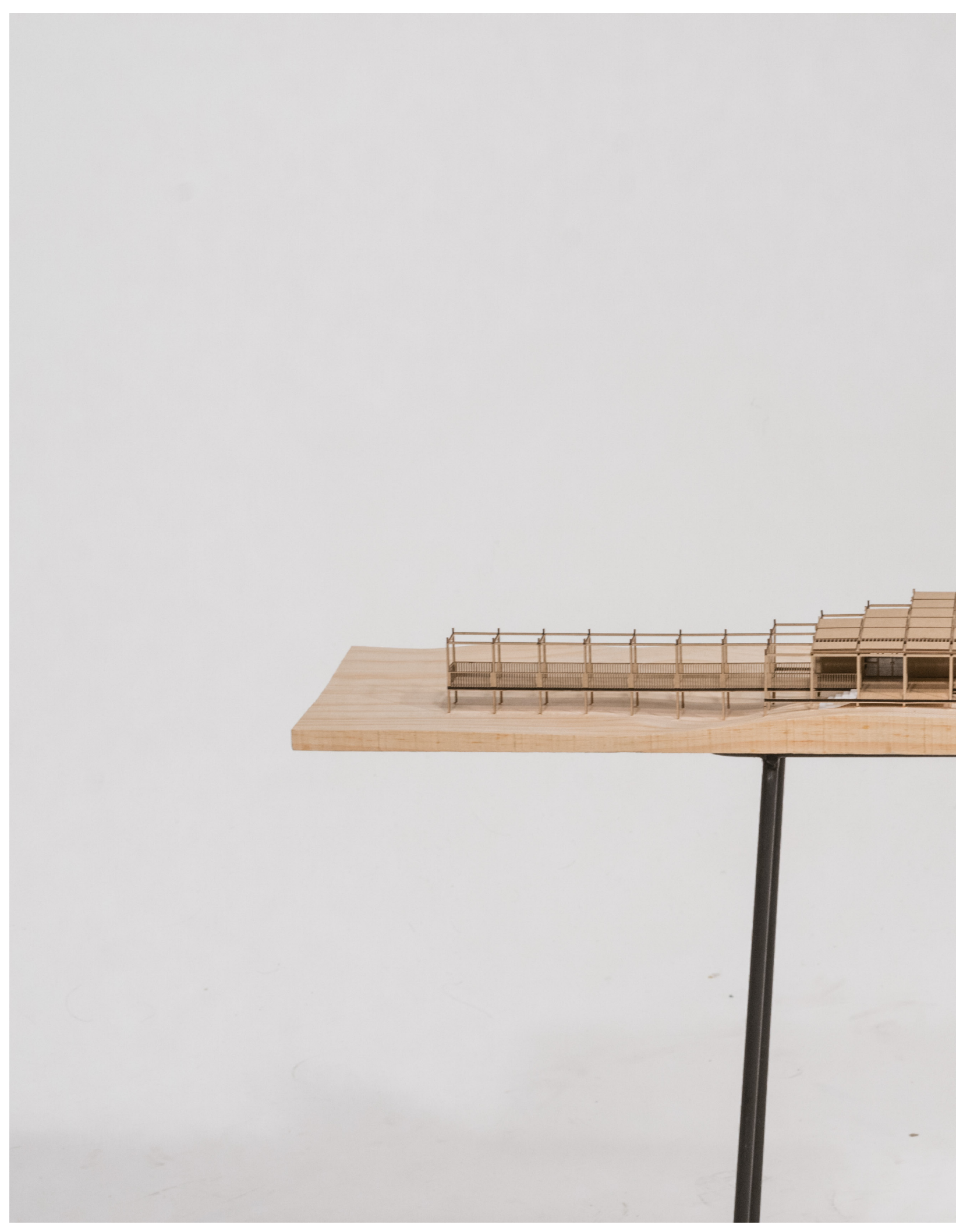

Figure 34: Model of The Design from the southern side.

Routed pine base, MDF and card structure 


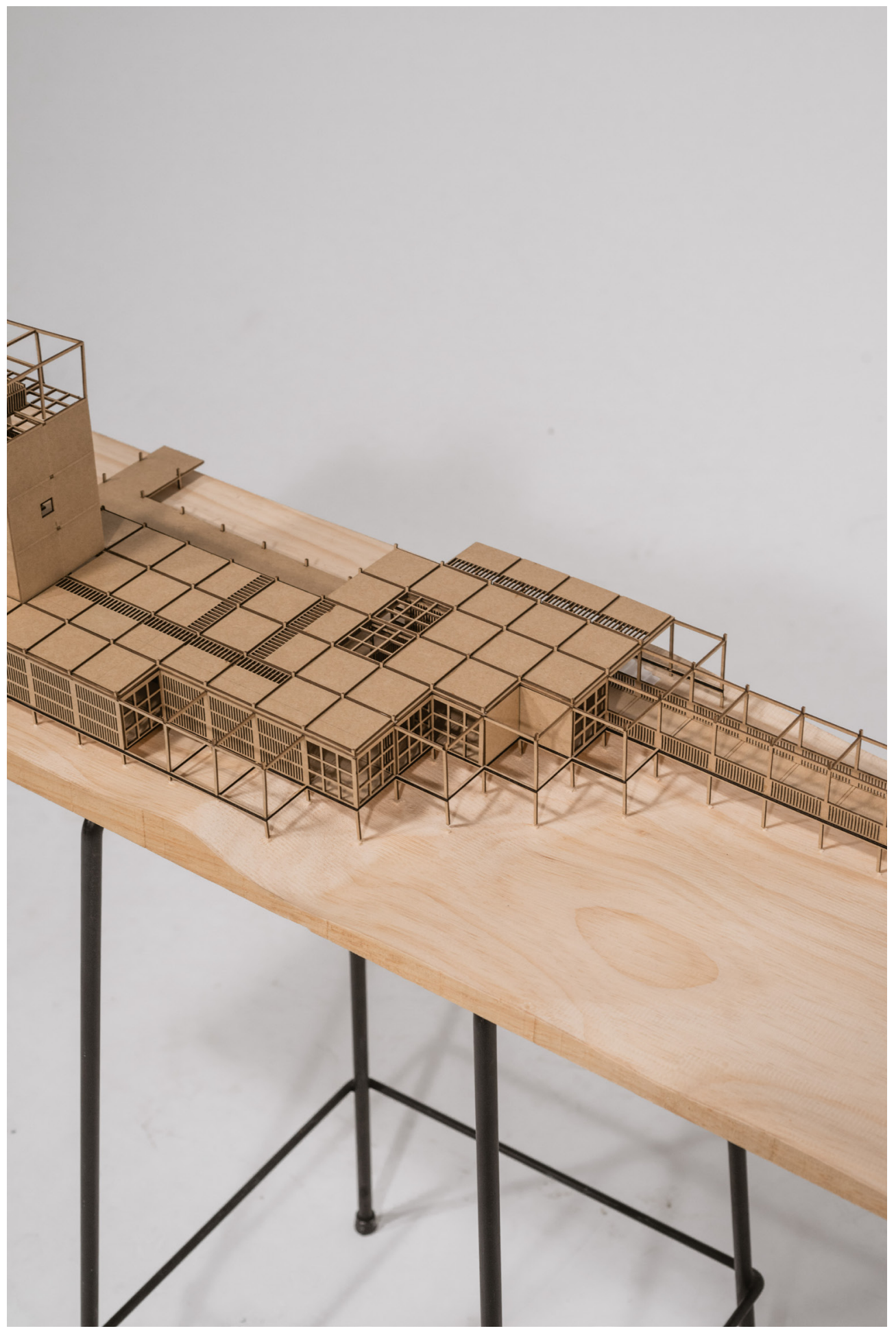

Figure 35: Model of The Design highlighting the gridded framework and semi enclosed nature of the northern façade 


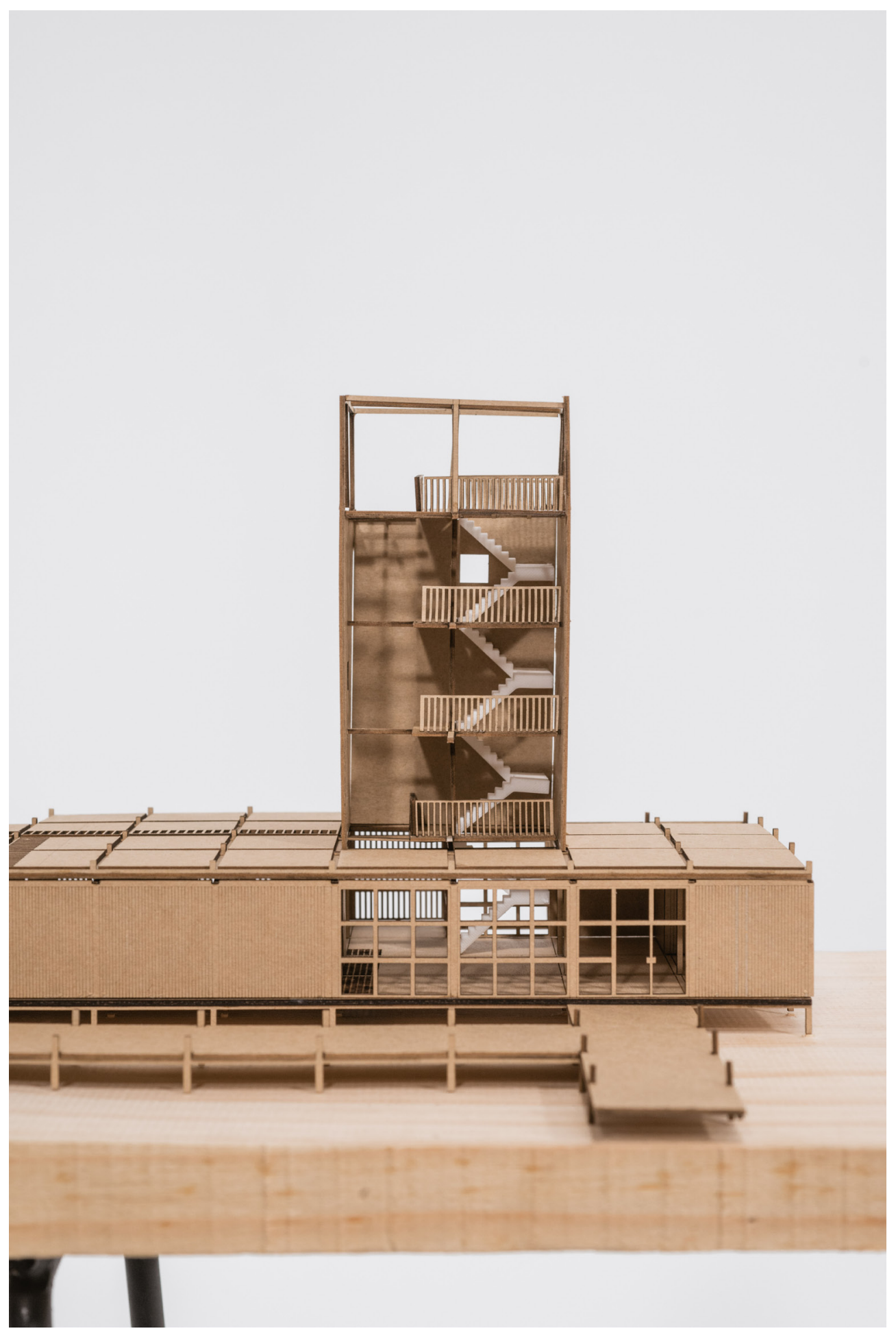




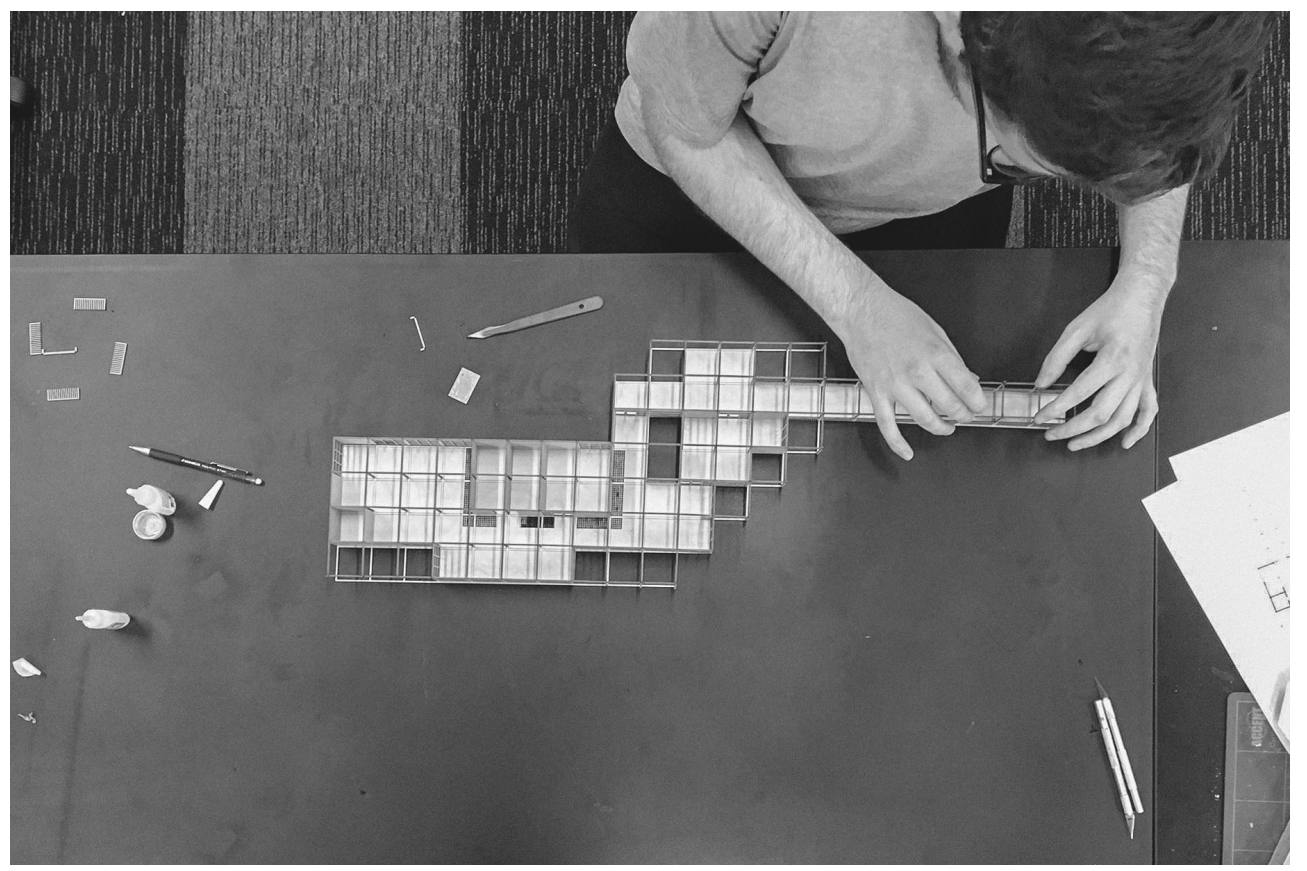




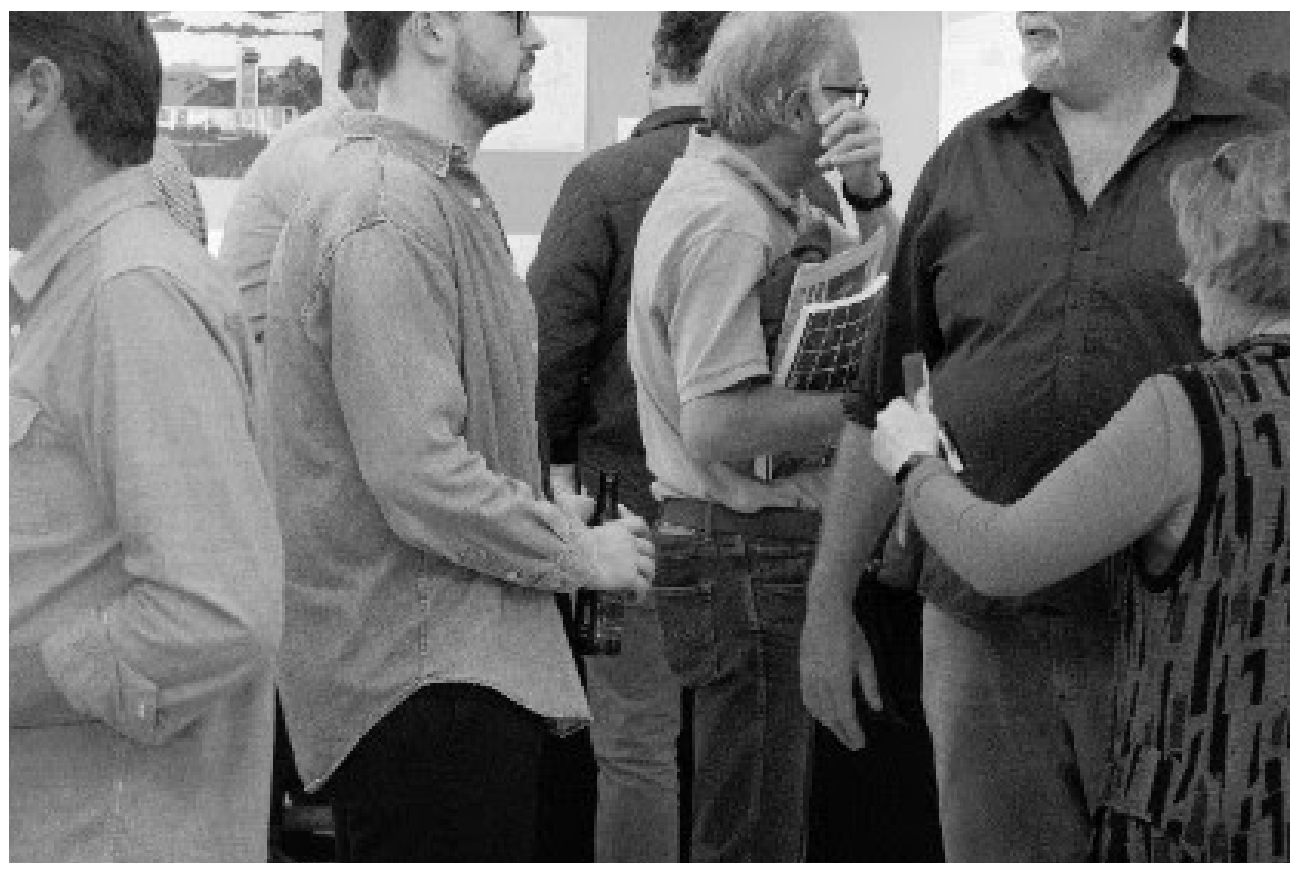

Figure 38: Community consultation in exhibitions gave

further insight into the implications of The Design on site 
THE CONTEXT

\begin{tabular}{|c|} 
THE DESIGN \\
$\vdots$ \\
\hline THE RESEARCH \\
COMPOSITION + GEOMETRY \\
4.01 \\
REGISTERING \\
5.01 \\
OBSERVING \\
\hline
\end{tabular}


III

\section{THE RESEARCH \\ MADE TO MEASURE}

The Design Process,

Case Studies and Final

Discussion 

3.01

COMPOSITION + GEOMETRY 
3.01

COMPOSITION AND GEOMETRY: AN INTRODUCTION

3.02

A PURE GEOMETRY

3.03

SUPERBLOCK

3.04

A GRID TO MEASURE AND COMPOSE BY

3.05

COMPOSITION AND GEOMETRY: A CRITICAL REFLECTION 


\section{COMPOSITION AND GEOMETRY: AN INTRODUCTION}

The design process began with an intuitive hunch. Fairly typical of small coastal towns in New Zealand, the urban planning surrounding the site seemed chaotic as suburban housing, and industrial precincts meet the foreshore, resulting in a complex urban grain.

MacLean Park also exhibited similar complexities at a closer scale. Although the coastal edge acts as a clear point of reference, built structures including ponds and playground structures as well as natural landscape features have been added, removed and altered. So too has the landscape, but by the dynamic movement of natural cycles. Trees grow and die, the dunes erode and grow, the stream mouth moves, and the sea level is slowly rising. With time, it can be difficult to perceive their movements due to the combination of multiple movements of natural features in the landscape at one moment.

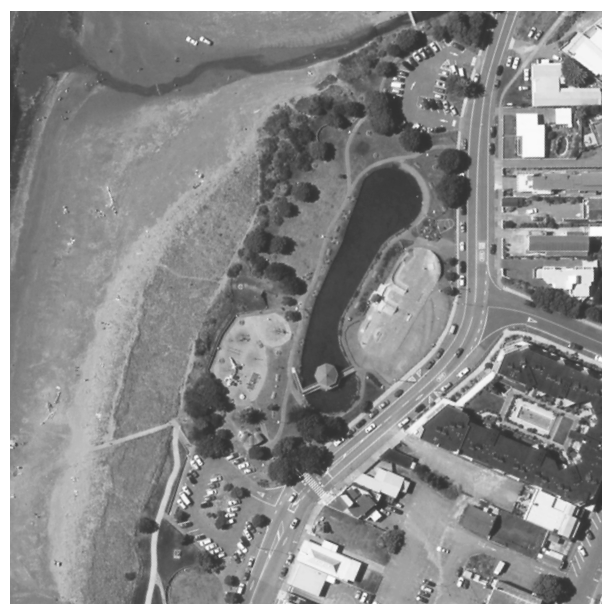

Figure 39: Aerial Site Photo of MacLean Park highlighting general chaotic formlessness of the site
Pierre von Meiss argues that "Cycles, tides and waves give visible order. Rocks, rivers, plants or insects allow their structure to be observed", yet when combined, they become unmeasurable which goes against humankind's tendency to "impose the measurable, the city, upon nature"(Meiss 31). Meiss' observation correlates with the site, as the many overlapping elements of the natural environment on site can be difficult to locate due to their constant flux.

Therefore, the first design experiments attempted to impose the measurable upon the site through a clear division between the urban condition and nature. Using simple, pure geometric forms and reductive building compositions, these first experiments act as an intuitive reaction against issues of urban incoherence and natural environment dynamics, and a starting point for imposing an architectural form and framework upon the site to visually observe and 'organise' the immediate surrounds.

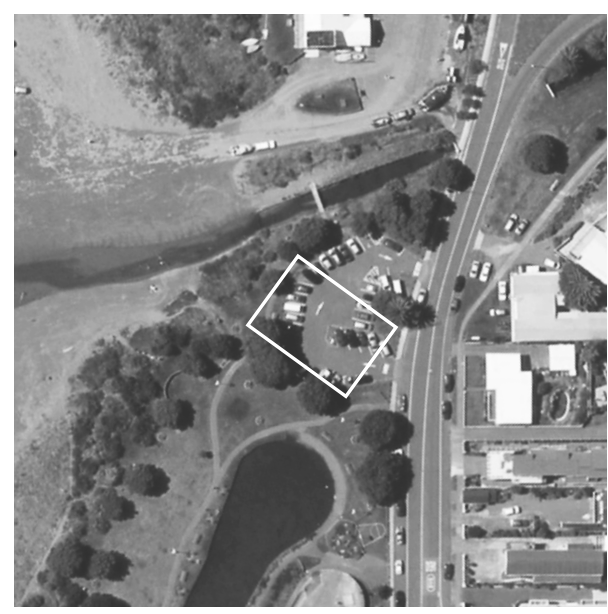

Figure 40: Aerial Site Photo of the location of The Design Experiment within Maclean Park 


\section{A PURE GEOMETRY}

The first approach to form-finding followed an initial hunch to create a simple, clear divide that could enable observation of the site and urban surrounds. At this stage, experimentation was not concerned with scale, but with how a simple form could create this divide clearly on site and potentially fit within a broader sitewide framework. This point would, therefore, be an ideal platform to visually observe the site from, acting as an autonomous archipelago within a dynamic and chaotic natural and urban landscape. 


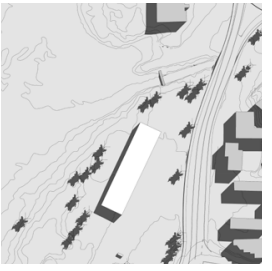

LINE

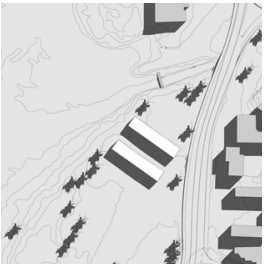

DUPLICATED LINE

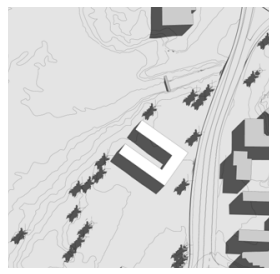

OPEN COURTYARD

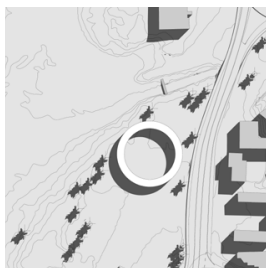

CIRCLE

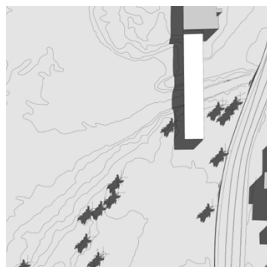

BRIDGE

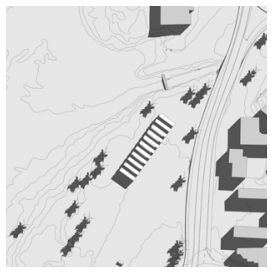

FRAME

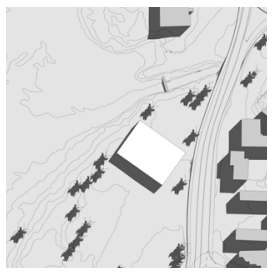

CUBE

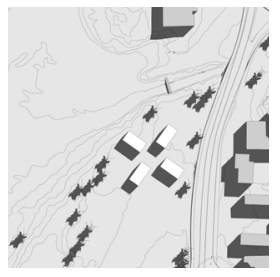

CROSS

Figure 41: Early formal experiment exploring the Visitor's Centre acting as an observation point through pure forms
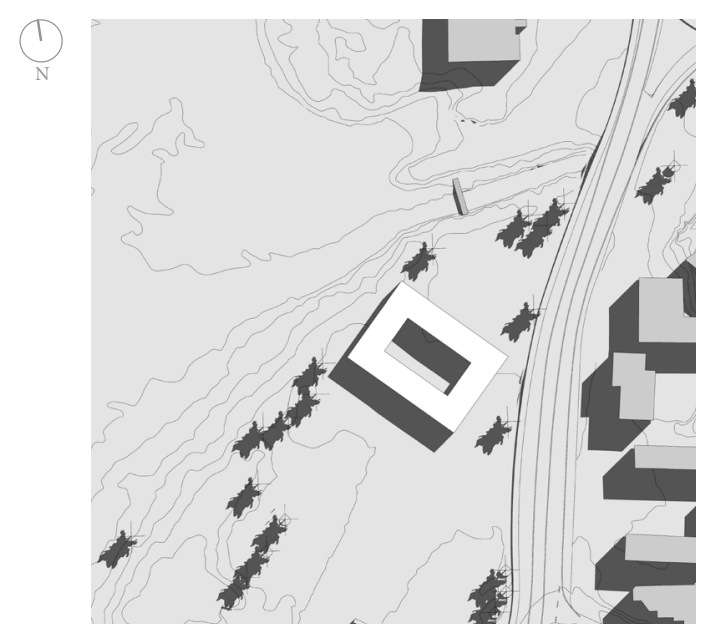

$\wedge$

Figure 42: An Enclosed Courtyard form provided a clear and simple division between the site and its natural surrounds 


\section{TOWARDS A LIMIT IN THE LAND}

The concept of a crucial form within a wider urban context acting as an archipelago is not new. O.M Ungers in "City Within the City, Berlin as a Green Archipelago" described the city as being made up of 'islands', a collection of seperated parts within a sea of amophus urbanity. Conversely, theorist and Architect Pierre Vitorio Aureli describes the archipelago as "envision[ing] the city as the agonistic struggle of parts". However, Aureli's emphasis is not on many 'islands', but on architecture becoming a limit or obstruction to this amorphus urban condition. He states that the "islands of the archipelago describe the role of architectural form within a space more and more dominated by the "sea" of urbanization" as architectural forms act as "frames, and thus as a limit to urbanization"(Aureli xii).

This set of experiments lent themselves towards Aureli's description of the archipelago, with the intent of forming an architectural 'limit' between both amorphous urbanisation, and a dynamic landscape. The resulting forms begin to enact a division between the township and natural environment beyond, acting as potential points for observation.

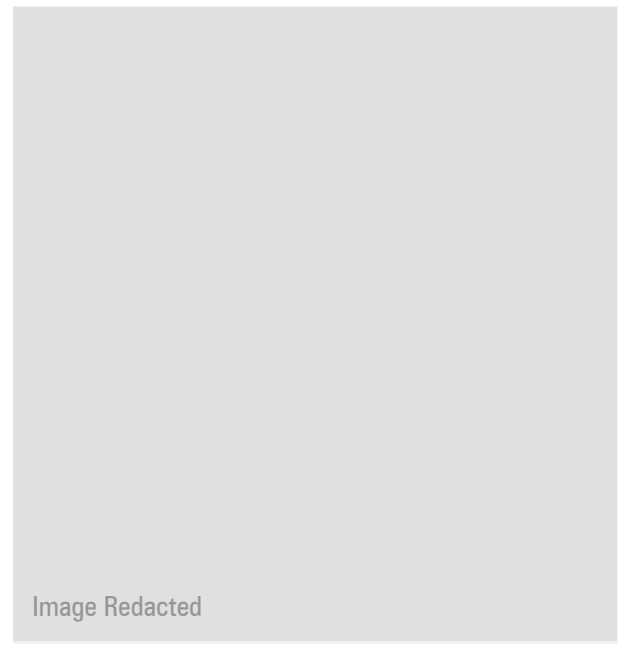

$\wedge$

Figure 43: 0.M Ungers depiction of the archipelago in 'The City within the City': a series of site-specific interventions in a sea of a wider urban fabric.

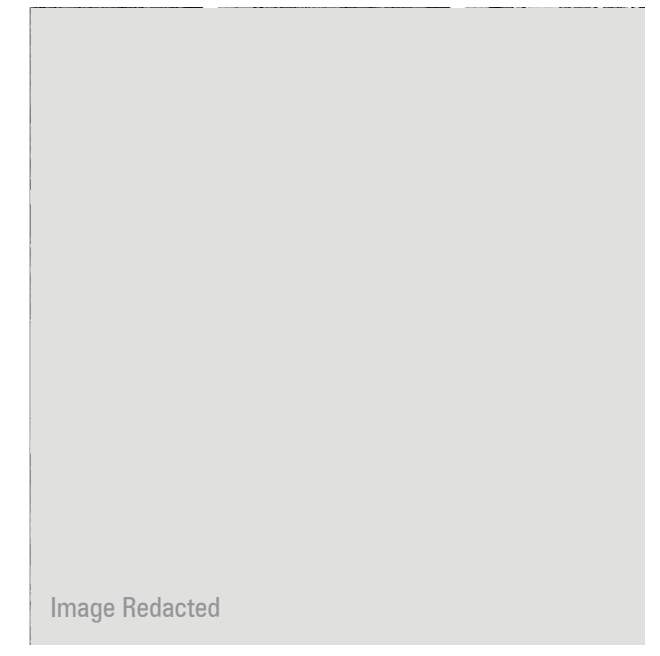

$\wedge$

Figure 44: Aureli's depiction of the archipelago. A series of pure architectural forms that form a hard 'limit' to urban and natural conditions. 


\section{SUPERBLOCK}

In reflection, the resulting blank appearance of the iterations are uncompromising, blocking critical viewshafts towards the island, key to the identity of site. The location of the form too also seems placeless and unconsidered, not identifying at all with the surrounding urban context's architecture of low density housing.

Not wanting to compromise on the seductive linearity of the formal gesture, viewshafts are cut out of the forms in relation to likely viewing angles on street approaches to the building, attempting to address the building's relationship to the island beyond. Whilst the autonomy of a pure form as a point to observe from was desired, an opportunity to establish a more effective visual link between the street, the beachfront and the Kapiti Island beyond would help to retain a greater sense of the site's identity. Therefore, this design enquiry attempts to find a middle-ground between a pure formal gesture and opening to frame and visually observe the landscape.
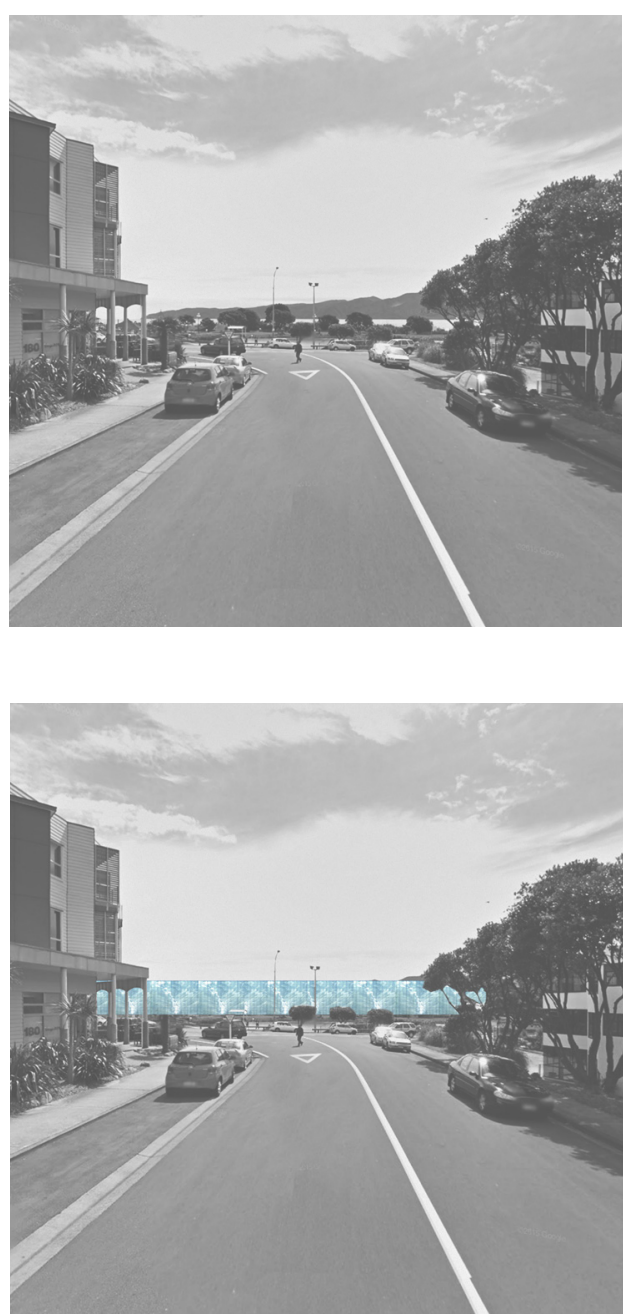

Figure 45: A series of linear Superblock interventions that close off and reveal parts of the landscape. Their forms are blank and uncompromising to the small scale town, similar to Aureli's 'limit'
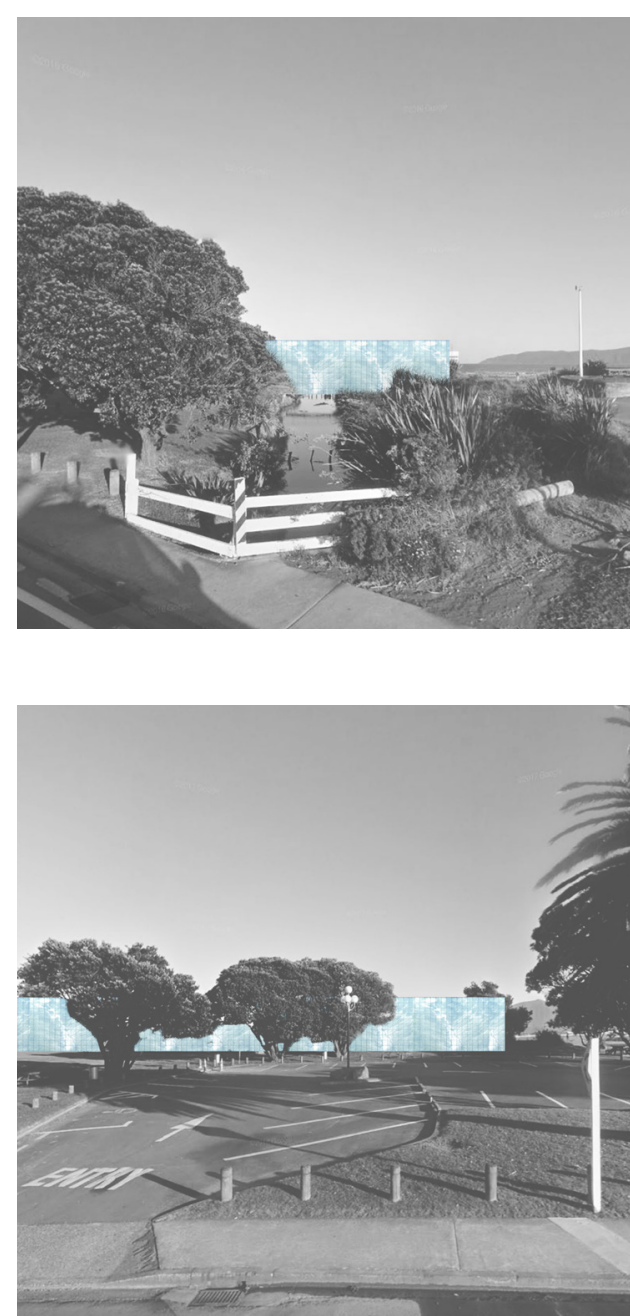


\section{CASE STUDY: STOP CITY}

\section{DOGMA | Unbuilt | 2007-8}

An example of pure, autonomous forms creating a clear division between the urban and landscape condition can be found in a number of architectural projects by Pierre Vitorio Aureli's office, Dogma. A case applicable to the design is Stop City. This conceptual project looks to reconceive 'the city' as a pure geometric form.

Composed of eight five-hundred by five-hundred meter slabs which are twenty-five meters thick with little ornamentation, each slab is a city with a flexible programme (Aureli and Tattara 48). These slabs form a perimeter, a clear border that separates landscape from urbanisation framing a dense forest in the centre.

This project fits Aureli's description of the archipelago, proposing an "absolute limit - thus defining the very form of the city" (48). In doing so, the project somewhat leaves the landscape as a complete afterthought in the search for pure form as the sole driving factor in the design.

Subsequent experiments, while similarly motivated to retain a pure form and geometry acting as a divide and point to observe from, recognise a need to retain a closer relationship with the surrounding landscape, rather than proposing a hard limit like Stop City.
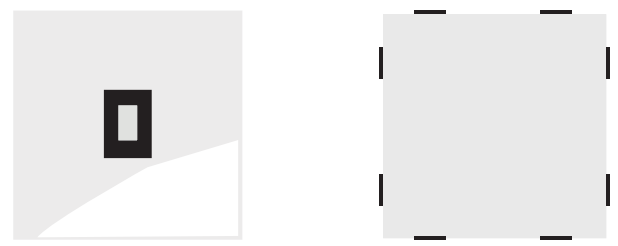

Figure 46: The design forms a hard limit, similarly to Stop City. However, Stop City is of a much larger scale. 
Image Redacted

$\wedge$

Figure 47: Stop City's 'limit', a series of walls

Image Redacted

Figure 48: An Elevation of Stop City

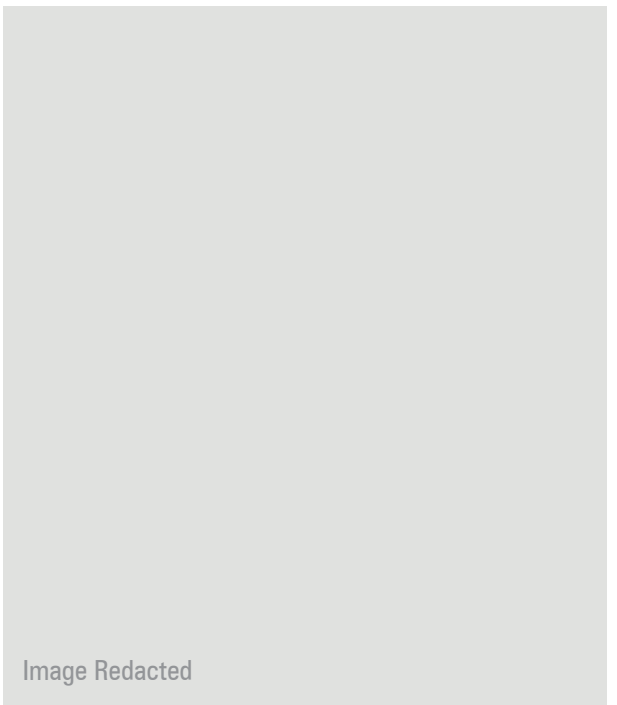

$\wedge$

Figure 49: A Perspective of Stop City 


\section{A GRID TO MEASURE AND COMPOSE BY}

The uncompromising form and grandiose scale of the previous experiments were critiqued for their relentless relationship to the landscape. Given that pure form of its own accord was unable to act as an observational tool, the following experiment's objective was to explore a less visually intrusive framework solution.

The Cartesian Grid provided an obvious framework to compose pure forms with, related to measurement and observation. Simon Unwin describes the use of the grid as creating a "sense of order and consistency" and that "in an irregular and changing world the eternal certainty of mathematical figures intrigues the mind"(159). Historically used as a measuring tool in atlases, mathematics and science, it creates a point of reference which measures the chosen element. Given the changing nature of the site, the certainty of the grid provided an exact point of reference against the shifting landscape, but unlike previous iterations could allow more open architectural expression.

Capitalising on this idea, by utilising a $7200 \mathrm{~mm}$ planning grid as a compositional and diagrammatic tool, the following experiment uses generalised site locations such as the beachfront, adjacent street and park access to inform the composition and plan of the building, forming openings that reveal and frame elements of the landscape and island behind to visually observe.

The use of the grid was a major turning point in the design, as it could simplify the site with a singular geometric gesture that could act as a connecting component, highlighting the architectural expression of measurement within the park and Visitor's Centre. 


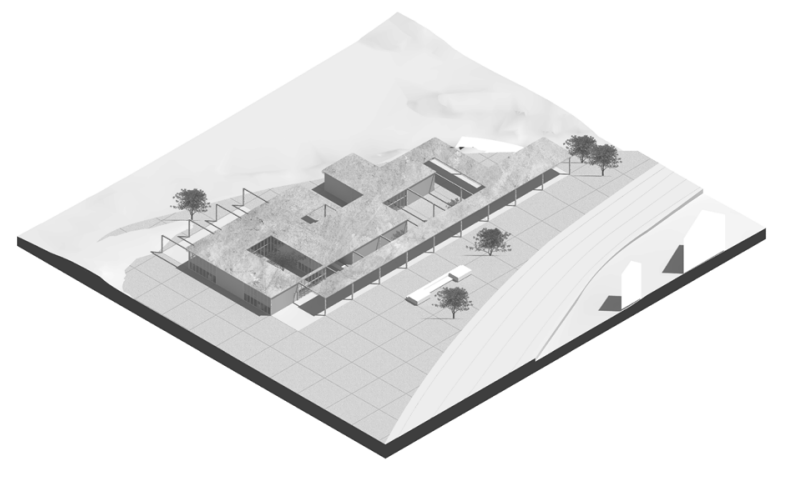

freeform space

grid provides non-hierachy
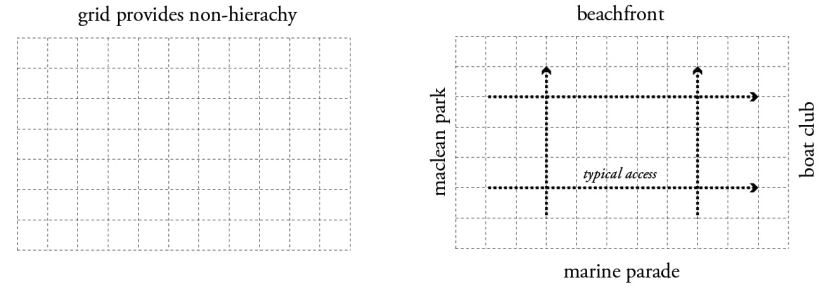

marine parade
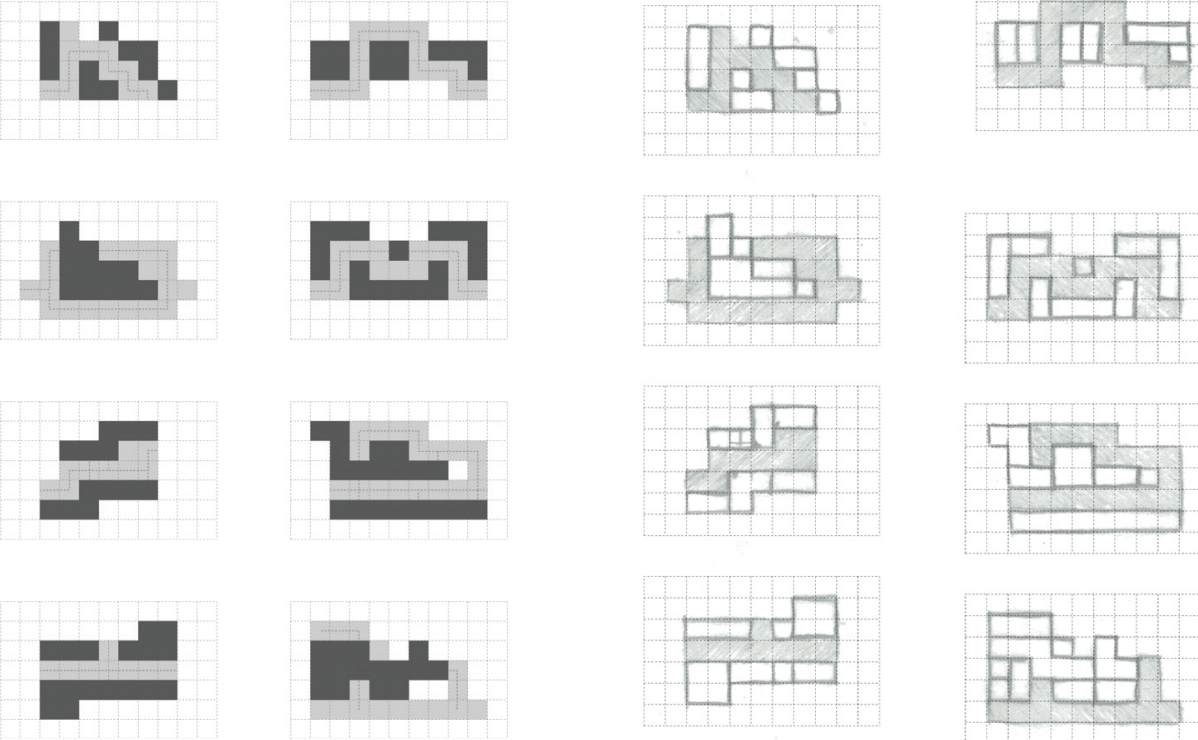

Figure 50: Plan Compositional Study utilising the grid. Forms were dictated by site locations and wayfinding paths through the visitor's centre to reveal and frame the site beyond the building effectively. Their top down approach is still very rigid in comparison to the site's curvilinear nature. 


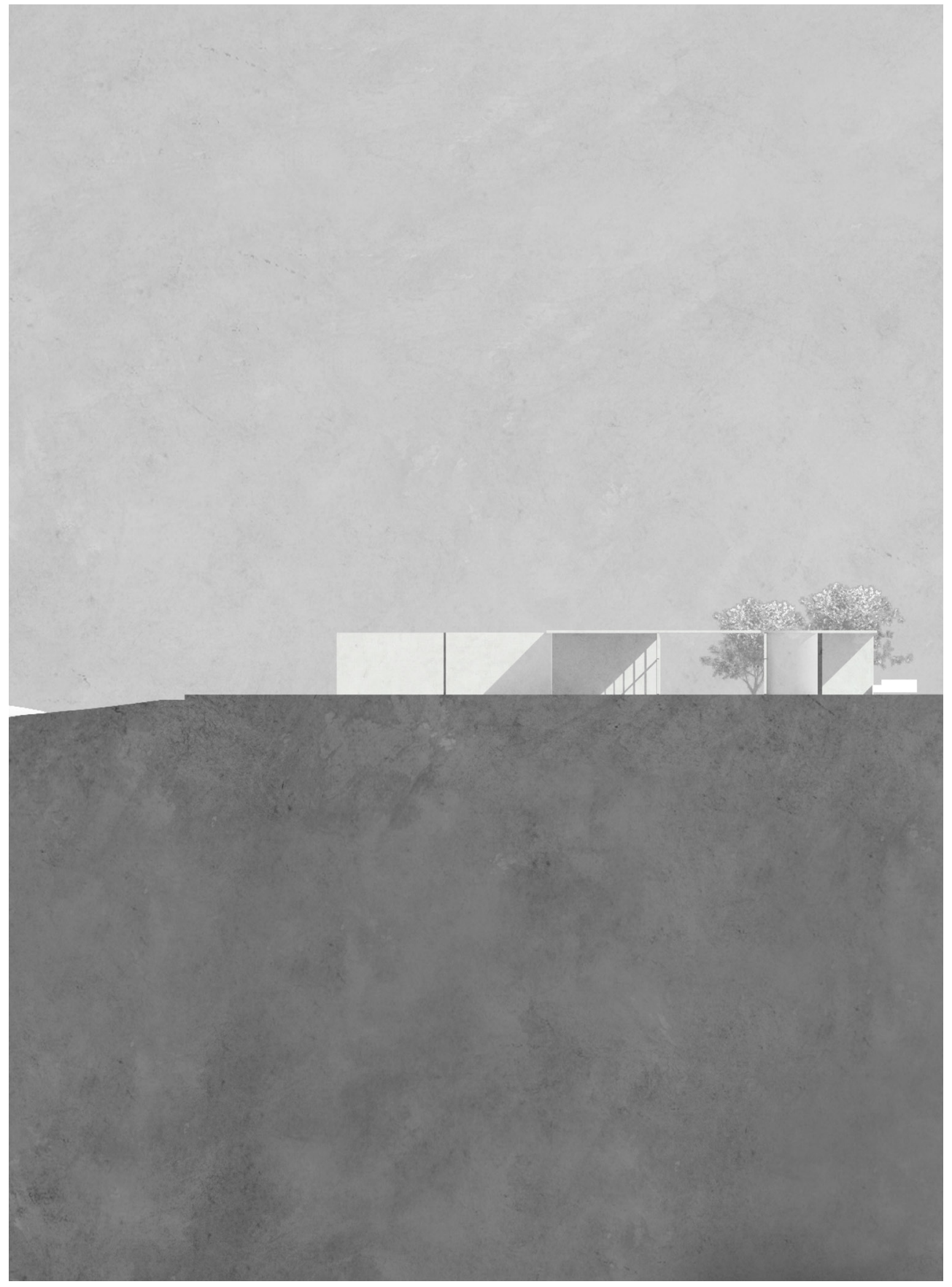

$\wedge$

Figure 51: A section of the following iteration highlights that whilst the form is attempting to be driven by site in plan, the section is flat and non-responsive to the topography of the dune. 


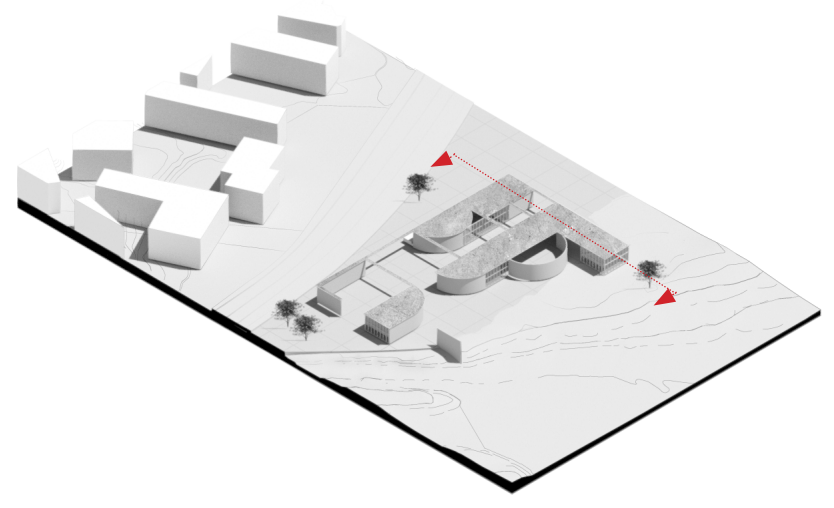

freeform space
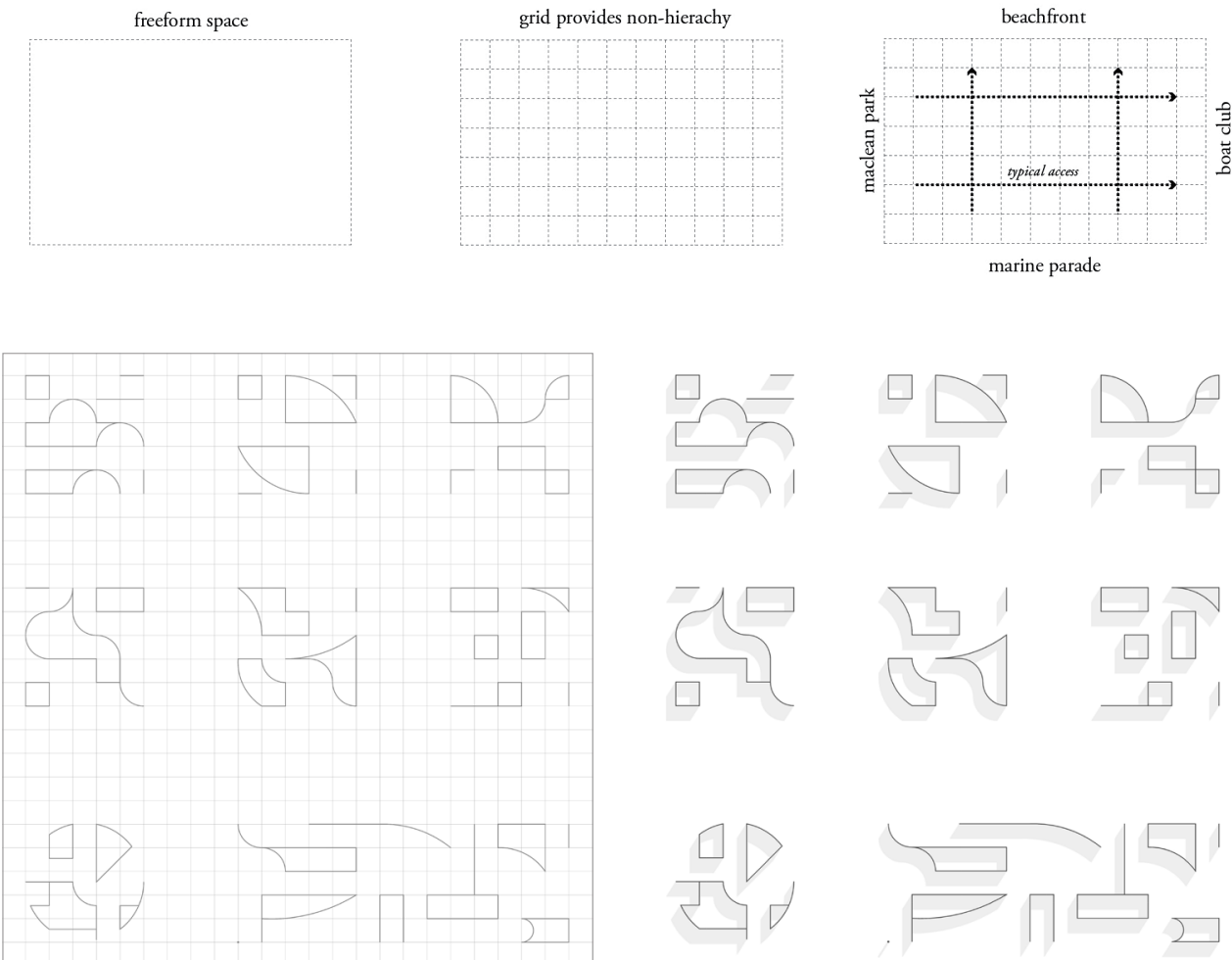

Figure 52: Plan study using the grid, attempting to be sympathetic to site in plan through use of curvature to suit the site's natural curves. These forms were dictated by site locations and wayfinding, and attempted to settle on a composition that felt 'balanced' whilst still framing viewshafts beyond the building 

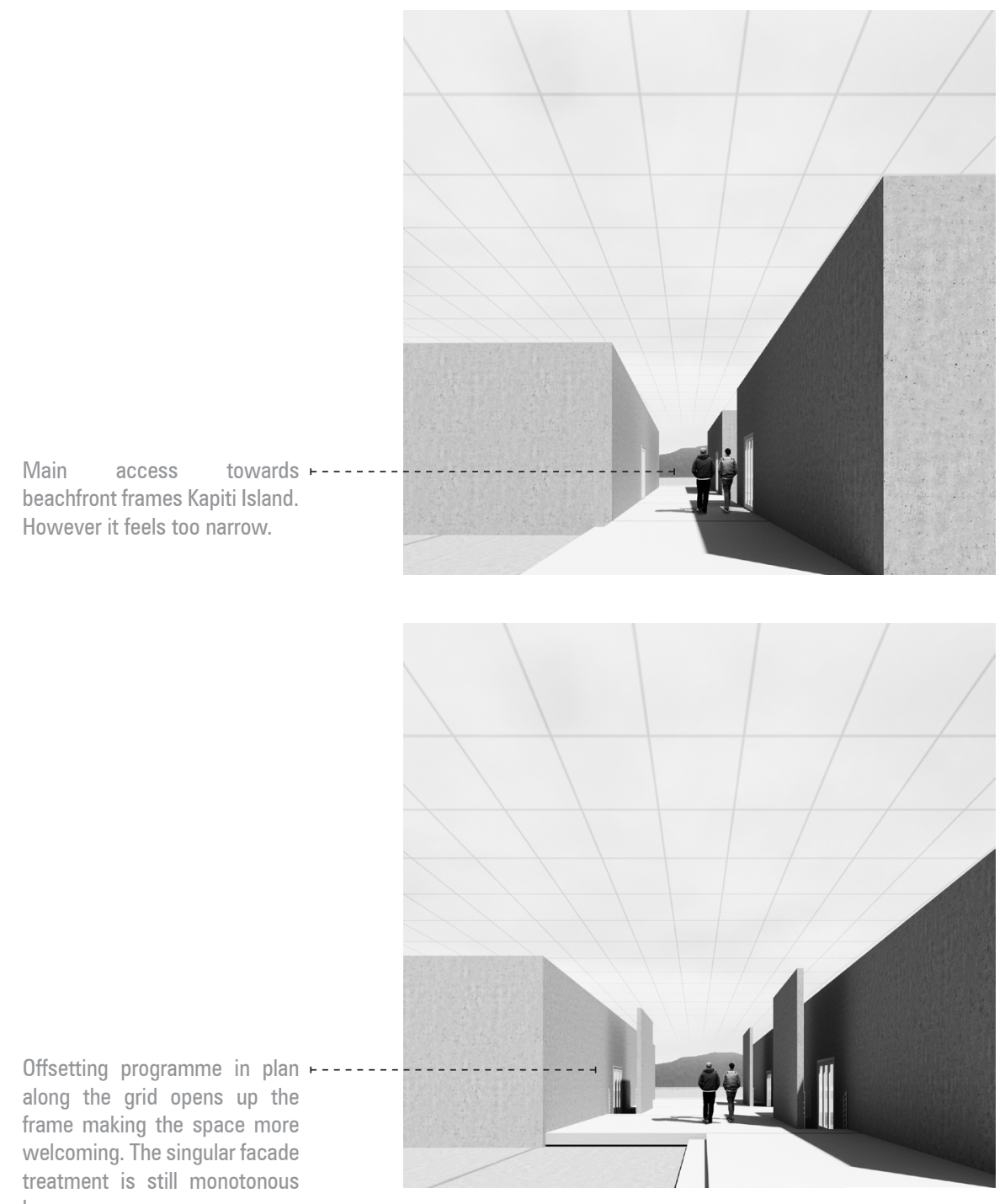

however.

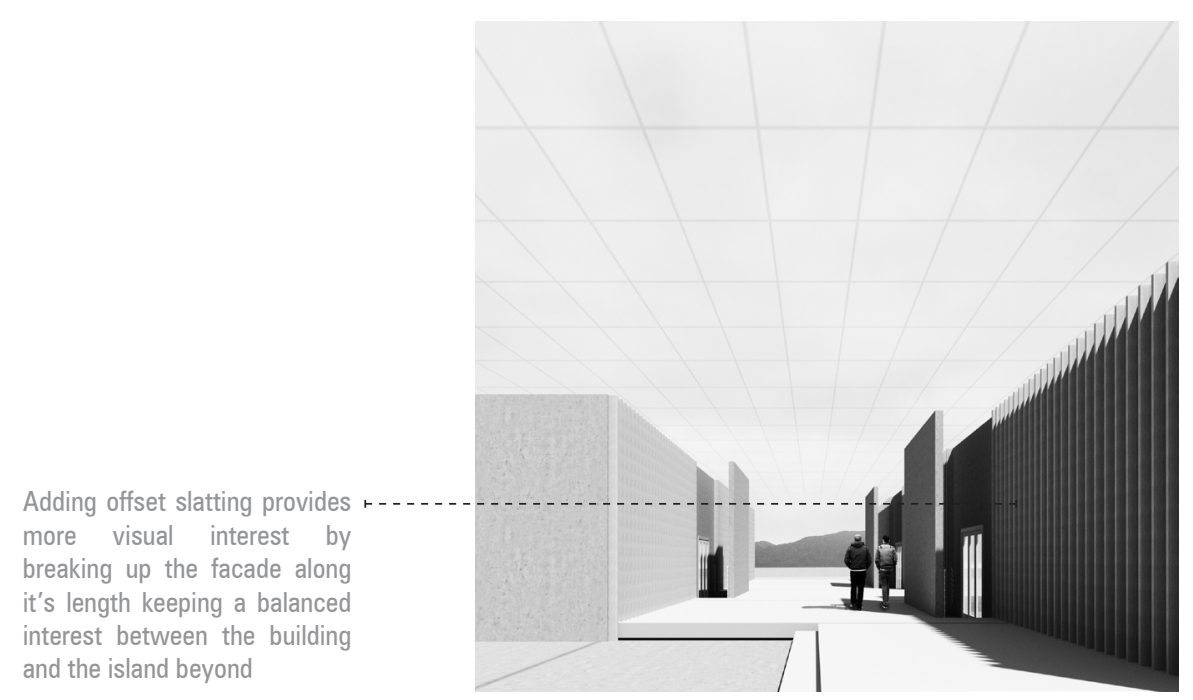

$\wedge$

Figure 53: Perspective study of the plans on the opposite page, attempting to alter composition in perspective to allow less monotonous framing of the landscape behind 

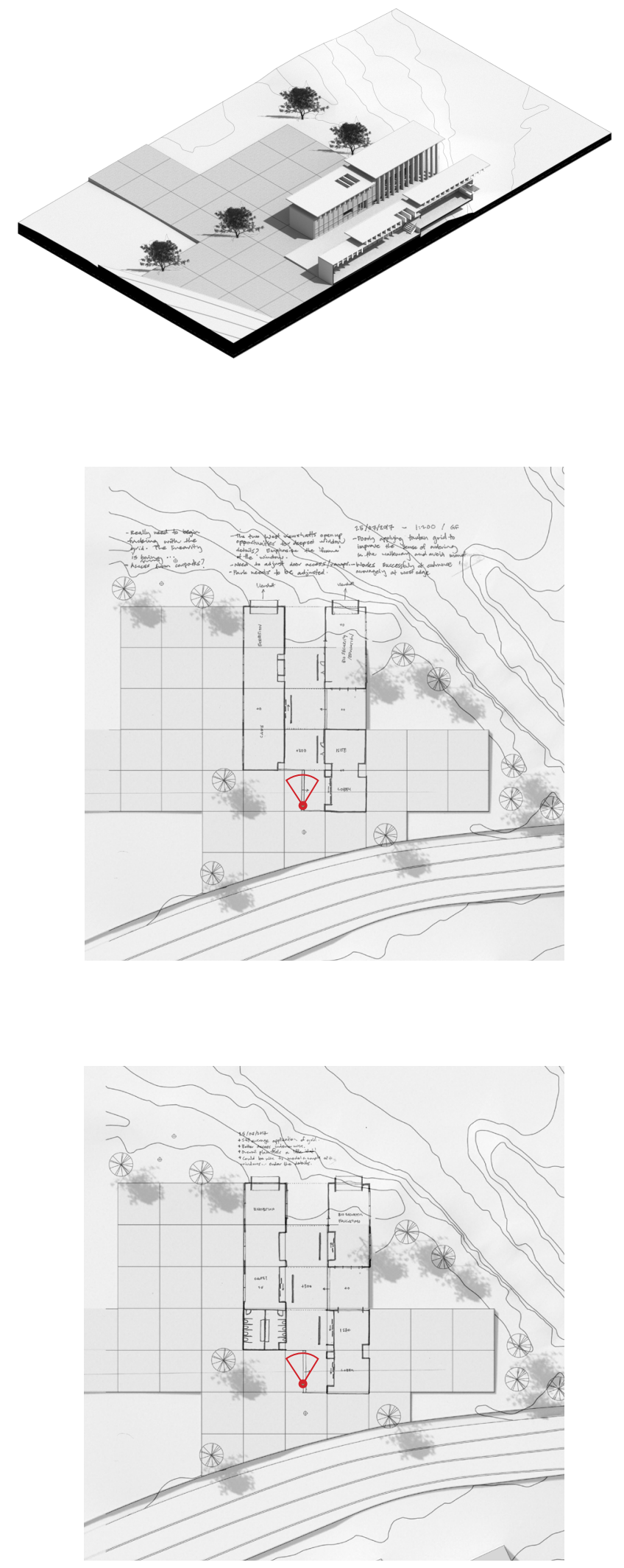

Figure 54: Plan iterations experiment with offsetting the building compositionally on the grid to allow a less monotonous outlook to Kapiti Island beyond 


\section{COMPOSITION AND GEOMETRY: A CRITICAL REFLECTION}

This section demonstrated design explorations of pure geometries and compositions as a method of creating a point to visually take measure of and observe the surrounding urban and natural landscape. The strong delineation between urban and landscape early on perpetuated autonomous forms that failed to engage with the delicate site, showing little compromise to the surrounds, except framing key viewshafts towards the island.

Later experiments in response introduced the grid as a compositional tool and architectural language to break down the authoritarian forms. The grid's historical relationship to measurement is significant, however there is potential within later experiments to further utilise it as a design tool and method for measuring of the site rather than a compositional and representational tool alone.
This chapter highlights that rational form alone is not the answer to addressing the context. Pierre von Meiss makes the argument that "the means for building an architectural place are always physical, but they are not sufficient by themselves". His opinion is that the idea of place must be referred to, not solely "aesthetic principles, utility, or geometric and constructional rules"(137). In the case of both the earlier formal exercises and later grid exercises, the focus was on the visual aesthetic and values of a pure form in an ad-hoc location alone, which in turn, lacked site specificity.

Moving forward, the design experiments begin to consider how the building can further engage with the site, exploring architectural methods to 'read' and represent the landscape, instead of solely visually observing it. 

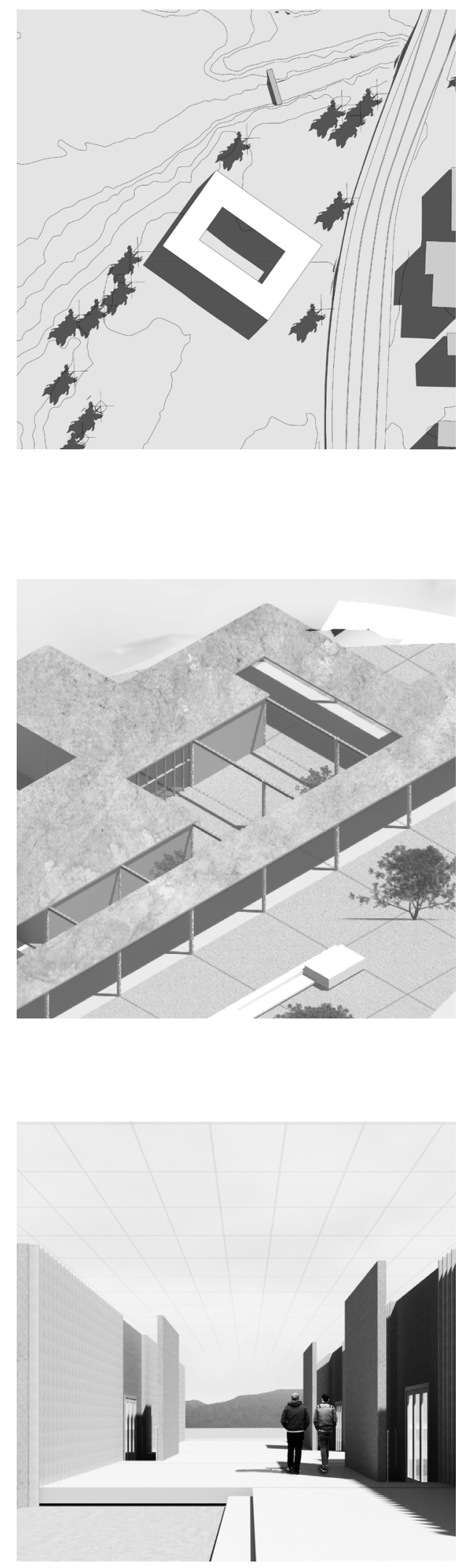

4.01

REGISTERING 
4.01

REGISTERING: AN INTRODUCTION

4.02

REGISTERING THE SITE

4.03

A SPATIAL MARK

4.04

PAVILION

4.05

PAVILION (CONT.D)

4.06

REGISTERING: A CRITICAL REFLECTION 


\section{REGISTERING: AN INTRODUCTION}

This chapter looks to address issues and limitations with observation by composition and geometry alone. The following design enquiries attempt to address the Maclean Park site more specifically by moving beyond observing as a visual means, by measuring and tracing site history and data architecturally, in a process referred to herein as 'registering'.

Noting that the site had a wealth of historical and climate data related to the landscape that could be drawn upon, such as sea levels, dune heights, historical heights of dunes and elevations of pa sites, highlighting and tracing this data becomes a manner of both measuring and cataloguing. By reading and expressing the site's history visually, visitors would gain further insight into these recorded changes and moments in time.

Landscape Architect James Corner determines the notion of tracing as "A subcategory of the instrumental [measurement]". He goes on to describe this process as commonplace throughout history. "In America, one finds a number of marks and traces that are testimony to a particular schedule, sequence or timing"(Corner 97). In response, the experiments in this section therefore wrestle with differing strategies of how to mark or trace this data architecturally on the building and site. 


\section{REGISTERING THE SITE}

The following design experiment investigates the potential for architecturally registering site data within the building. Timber dados are imposed at heights corresponding to selected site datums and historic heights of the surrounding landscape. To differentiate between these datums, the material of the section changes to suit.

This meant that building elements such as door and window heights were rationalised by the measured datums through the dado, resulting in somewhat awkward interior proportions and heights, as well as a decidedly static spatial quality within the main areas. As a result, the following experiments instead propose registering these datums in a visually engaging manner to improve the experiential quality of the space and how visitors engage with the datums.

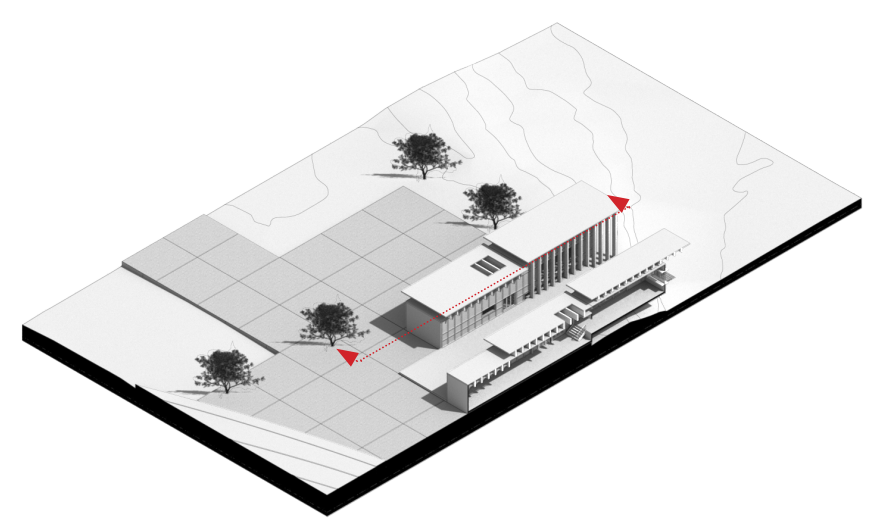

Figure 56: An isometric of The Design and immediate surrounds, indicating the section line of this inquiry. 

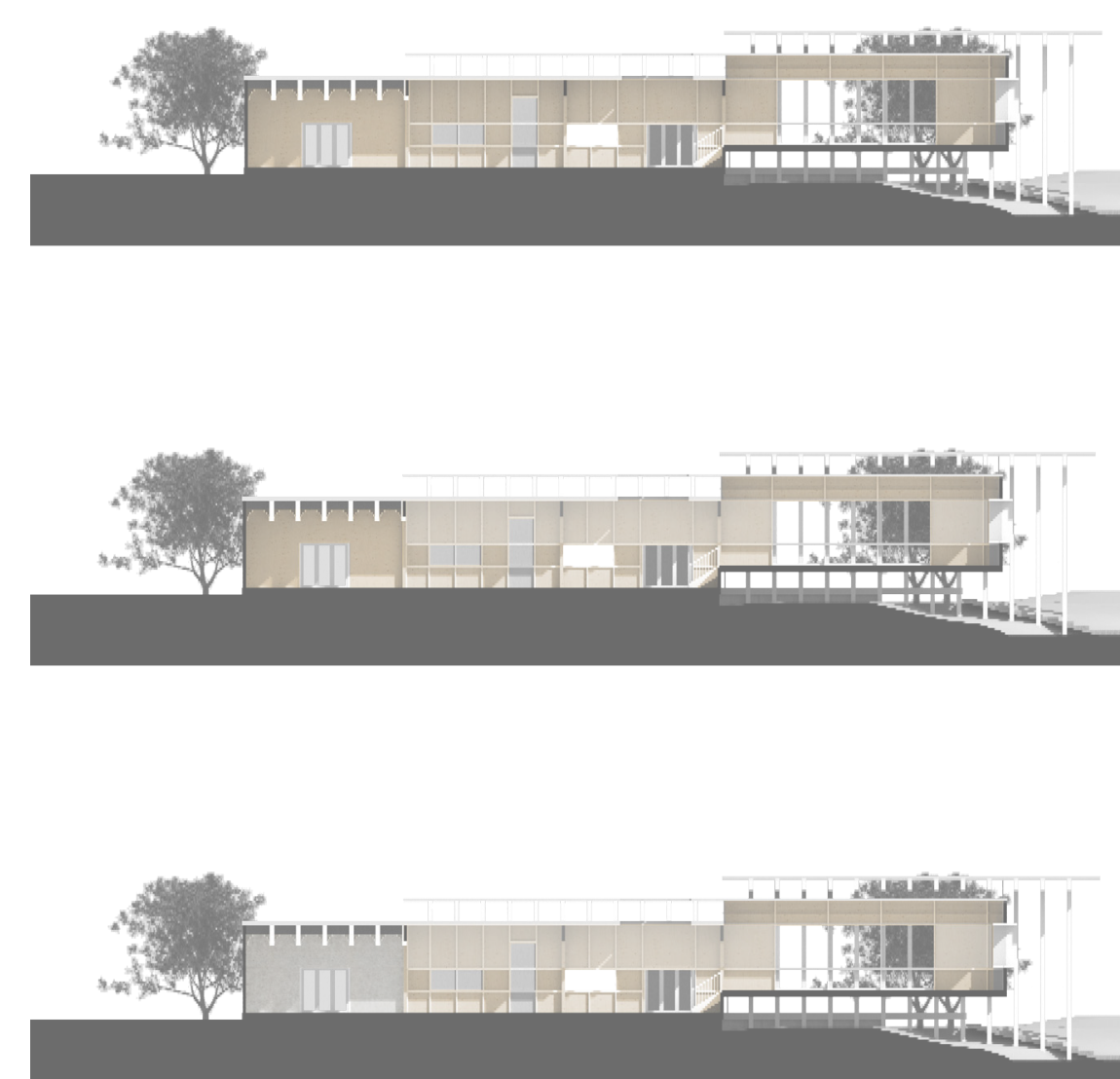

Figure 57: Sectional study investigating registering site datums spatially, represented by timber dados. Proportionally these are awkward, and spatially sparse, with little atmospheric quality

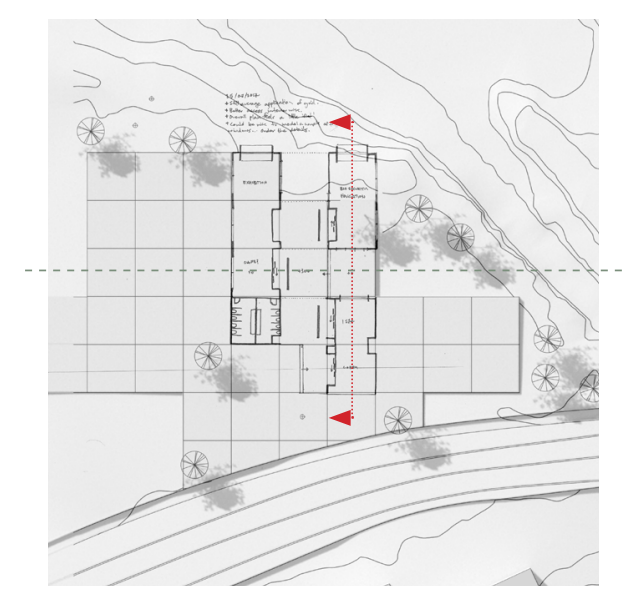

$\wedge$

Figure 58: Location of section taken for 'Registering the Site' and 'A Spatial Mark' 


\section{CASE STUDY: HEDMARKS FYLKESMUSEUM}

\section{Sverre Fehn | Hamar, Norway | 1974}

Architect Sverre Fehn's Hedmark Museum relates to 'Registering' due to the way the architect negotiated the experience of site and traces its history. The architecture creates a horizon like datum. In this regard the building 'measures' the site through a series of ramps and elevated walkways which create a new ground, between and on top of the adjacent ruins. As visitors use the walkways, this highlights the passing of time as visitors pass through and negotiate both the new building and old ruins (Berlanda 114).

Tracing historic markings from a previous time, Fehn introduces an engaging way of observing them, with the walkways and framing experiences establishing a point of reference between their physical place and relation to the ground. Fehn's method of pushing and pulling vertical heights of elements such as the walkway cuts the datum-like horizon, and highlighting historical elements within the ruins with strategic lighting forms a spatially experiential way for visitors to read the site's history.

Whilst the current design engages with historical site data through highlighting it on architectural elements, Fehn instead engages across the wider site by creating an atmospheric quality and sense of motion with the walkway that encourages visitors to explore the wider building and site beyond.
Figure 59: (Right and above) The elevated walkway above the ruins forms a new ground for visitors to trace the past of the site. This extends beyond the building outdoors

$>$

Figure 60: (Right) The elevated walkway allows opportunities for framing different areas of the ruins, allowing new observations to take place - differing materials and heights of elements provide interesting atmospheric quality 


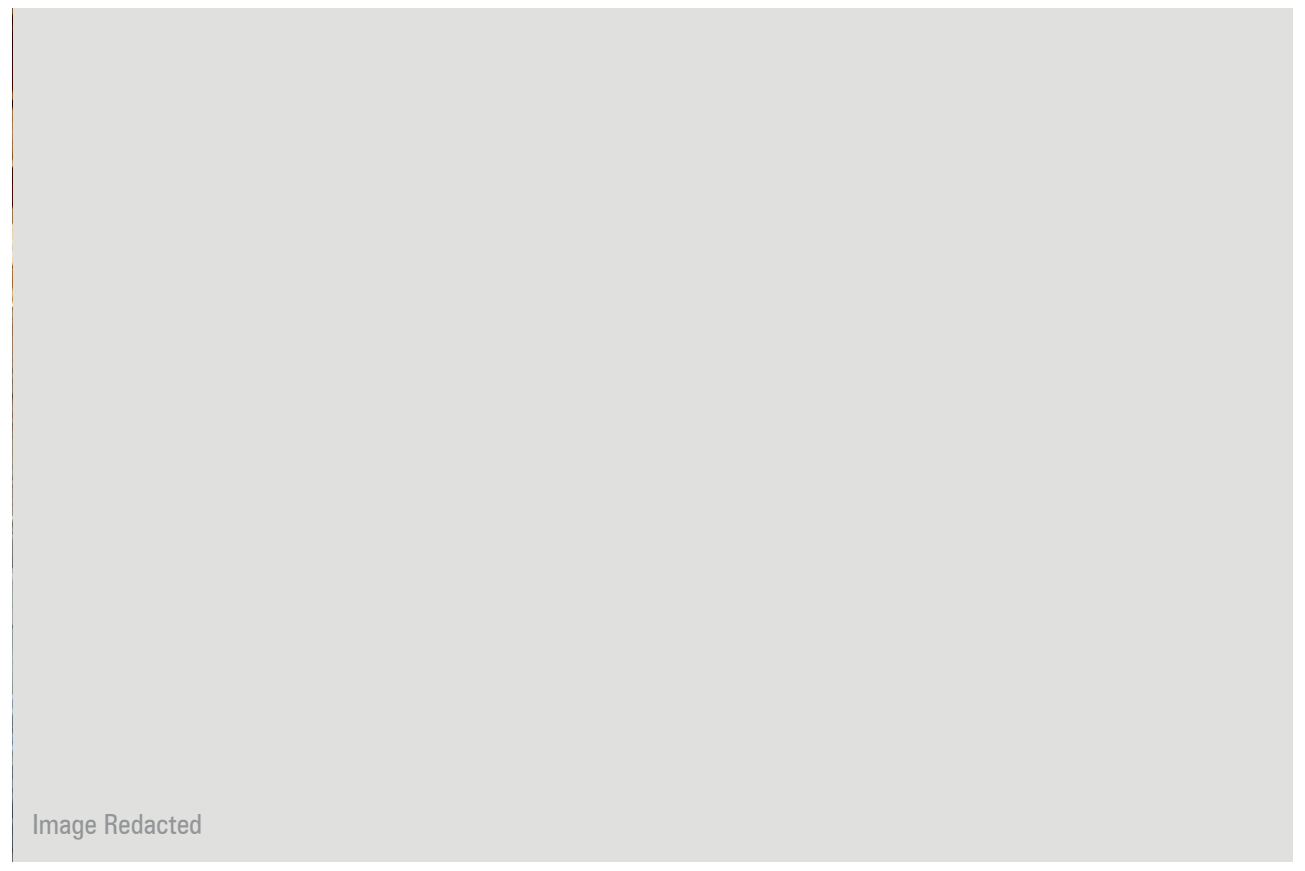


A SPATIAL MARK

To combat the lacklustre experiential quality of the previous design experiment, the following iterations consider how to give the site datums registered a richer spatial quality. These are expressed through interior architectural elements of the building such as ceiling posts, floor posts, clustered columns and exposed wall framing. Differing arrangements of these elements undulate and create a more visually engaging spatial quality through which the visitor can read the site's history and data.

Drawing from the exposed skeletal architectural language of the previous enquiry and to better understand the spatial quality of these iterations, they were physically modelled. Small balsa and wire models highlighted unforeseen implications such as transparencies between elements at different angles, the effects of heights of elements in comparison to the human scale and the overall appearance in situ. To combat the ornamental nature of these iterations, the posts and markers were integrated into key building elements such as the columns, with the form of the building changing to suit.

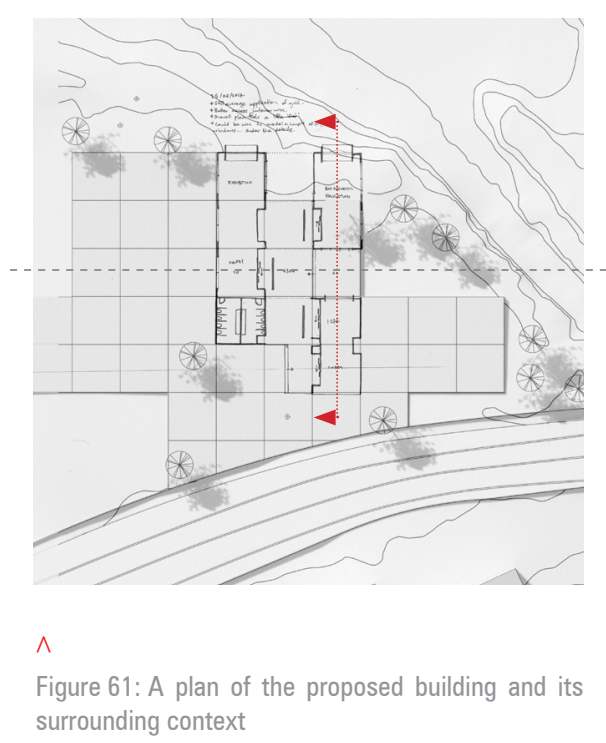




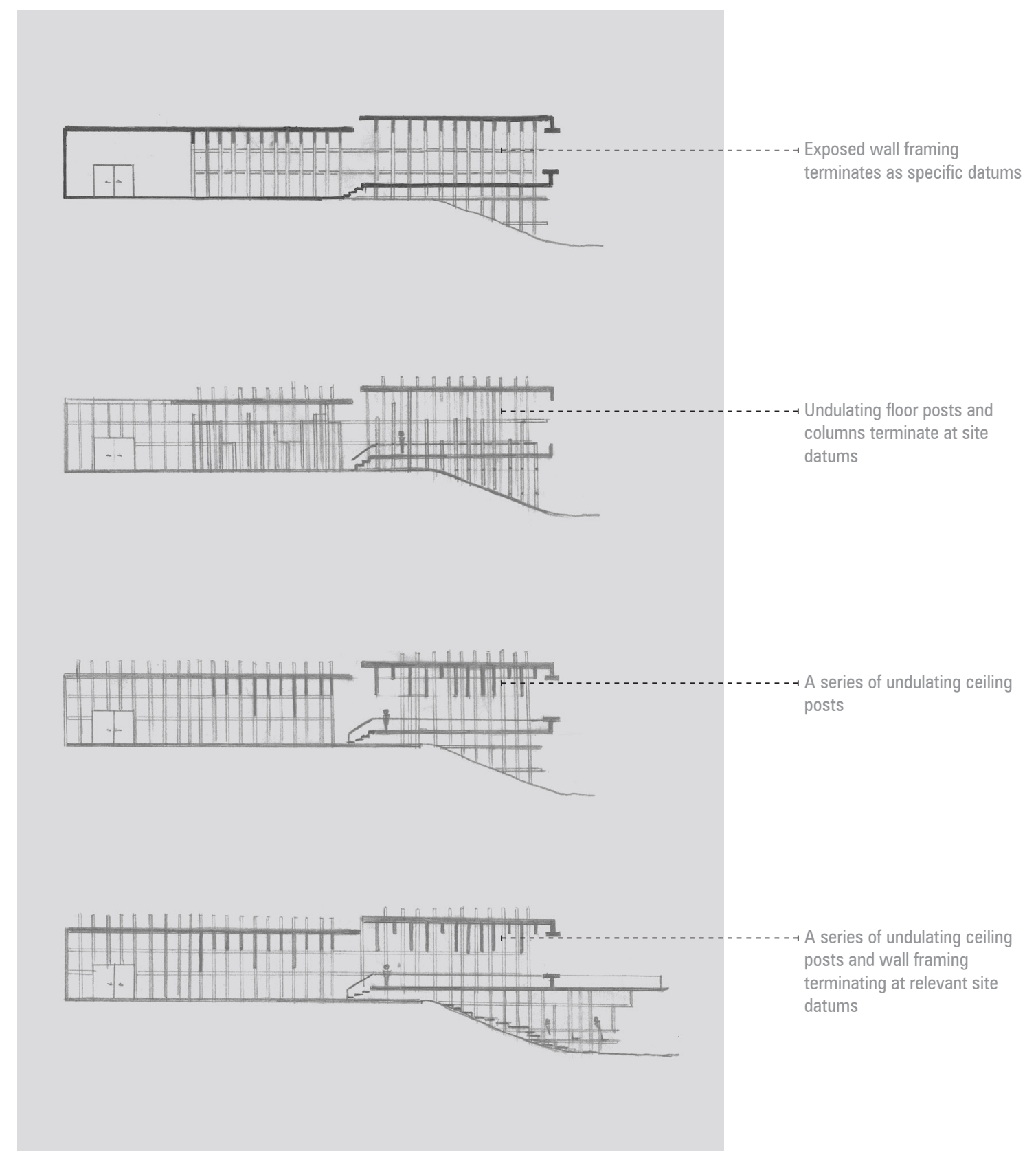

$\wedge$

Figure 62: Section study testing registering through undulating building elements such as ceiling, wall and floor posts to add a deeper spatial and experiential quality. 
Datums could be noted through notches in the framing
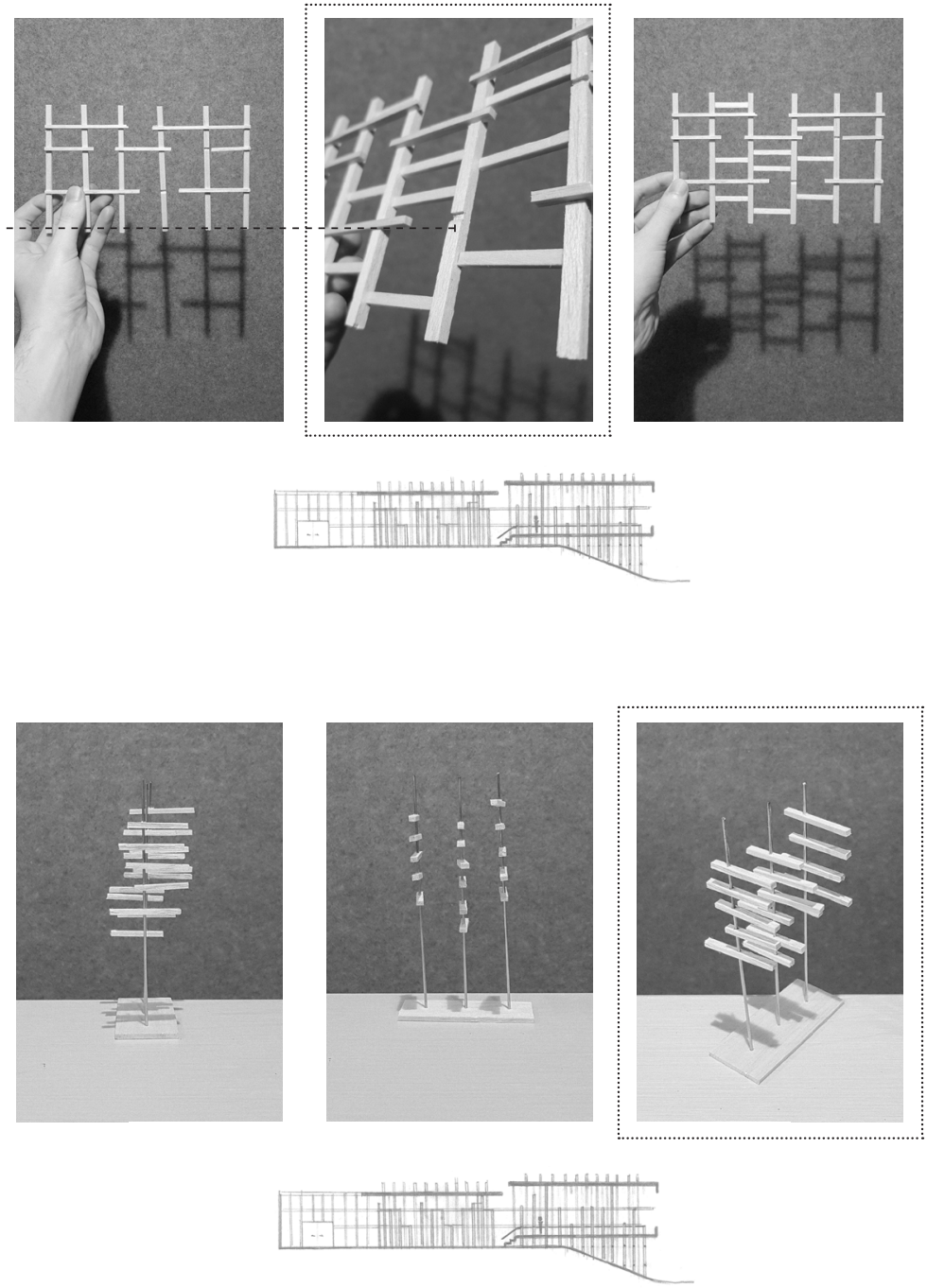

Differing transparencies based on viewing angle provide

interesting visual dynamic and spatial implications
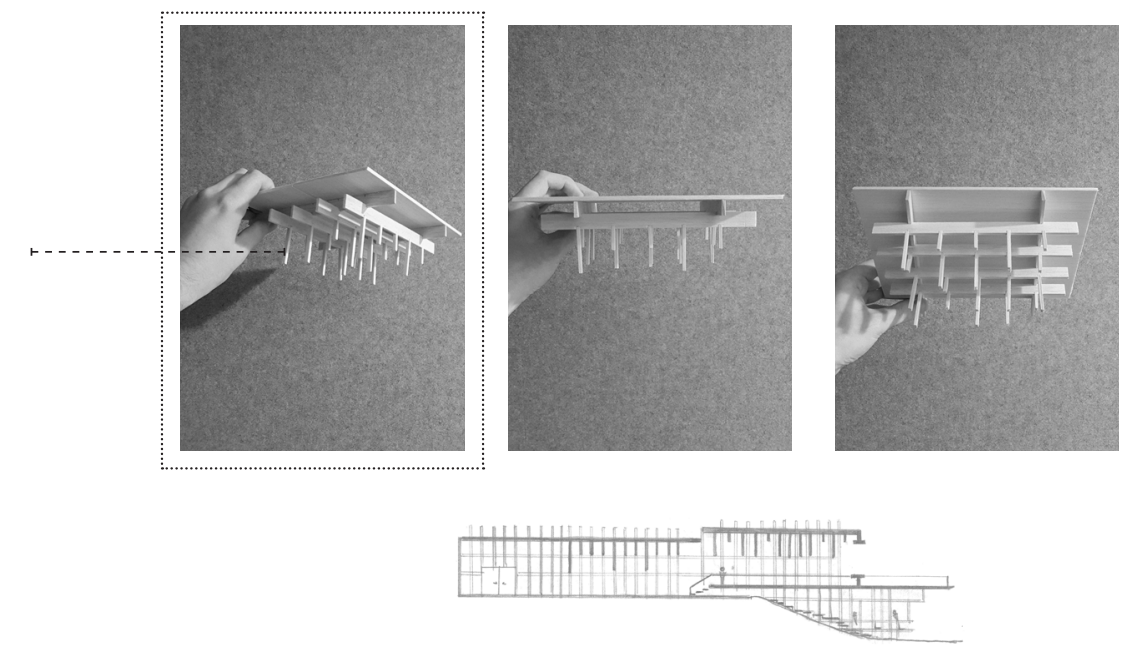

$\wedge$

Figure 63: A series of physically modelled elements from the previous experiment to test the spatial quality of the undulating datum marks 


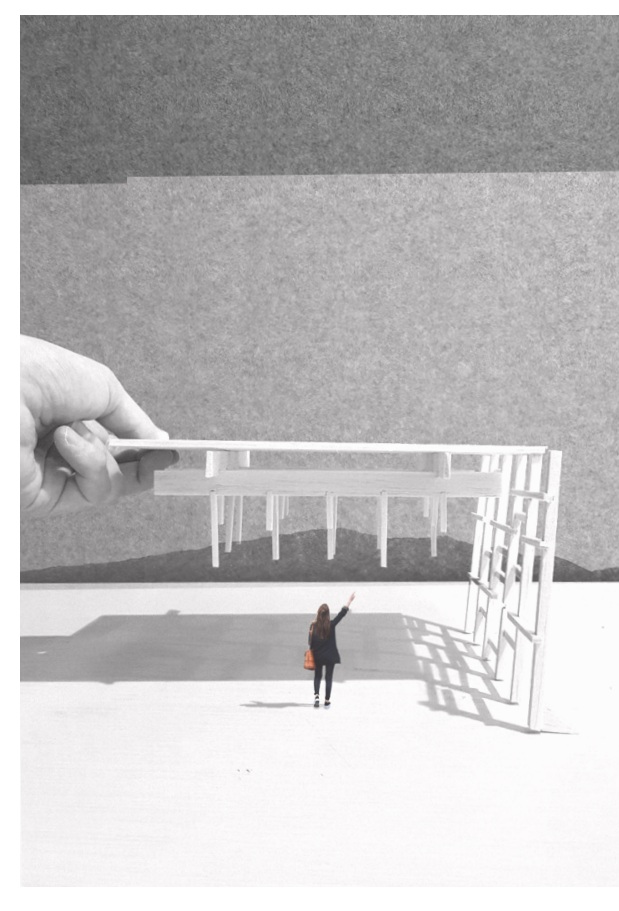

$\wedge$

Figure 64: Combining multiple models together to see the implications spatially once the human scale is considered

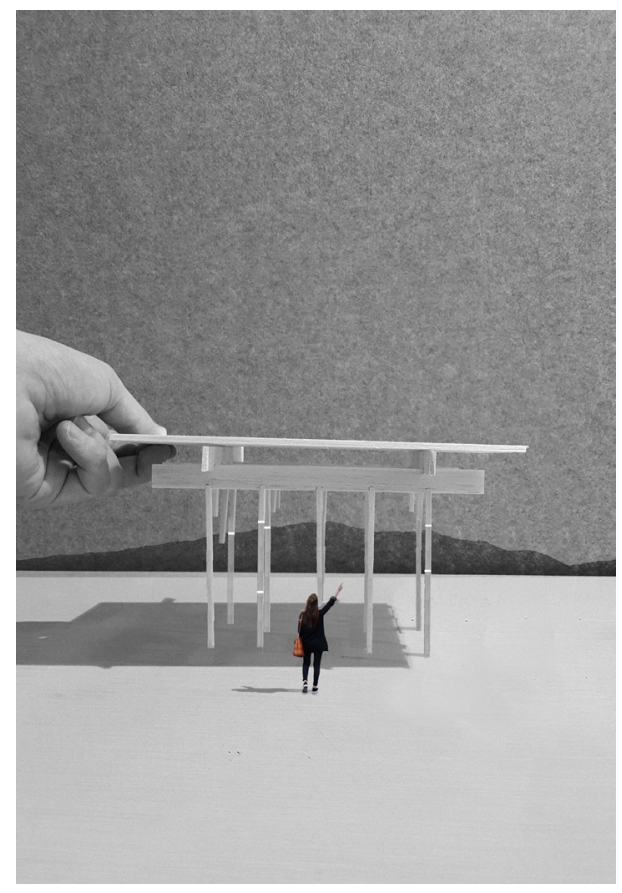

$\wedge$

Figure 65: Testing spatial quality of registering site datums on columns as integral structural elements, rather than on ornamental elements as the previous models showed 

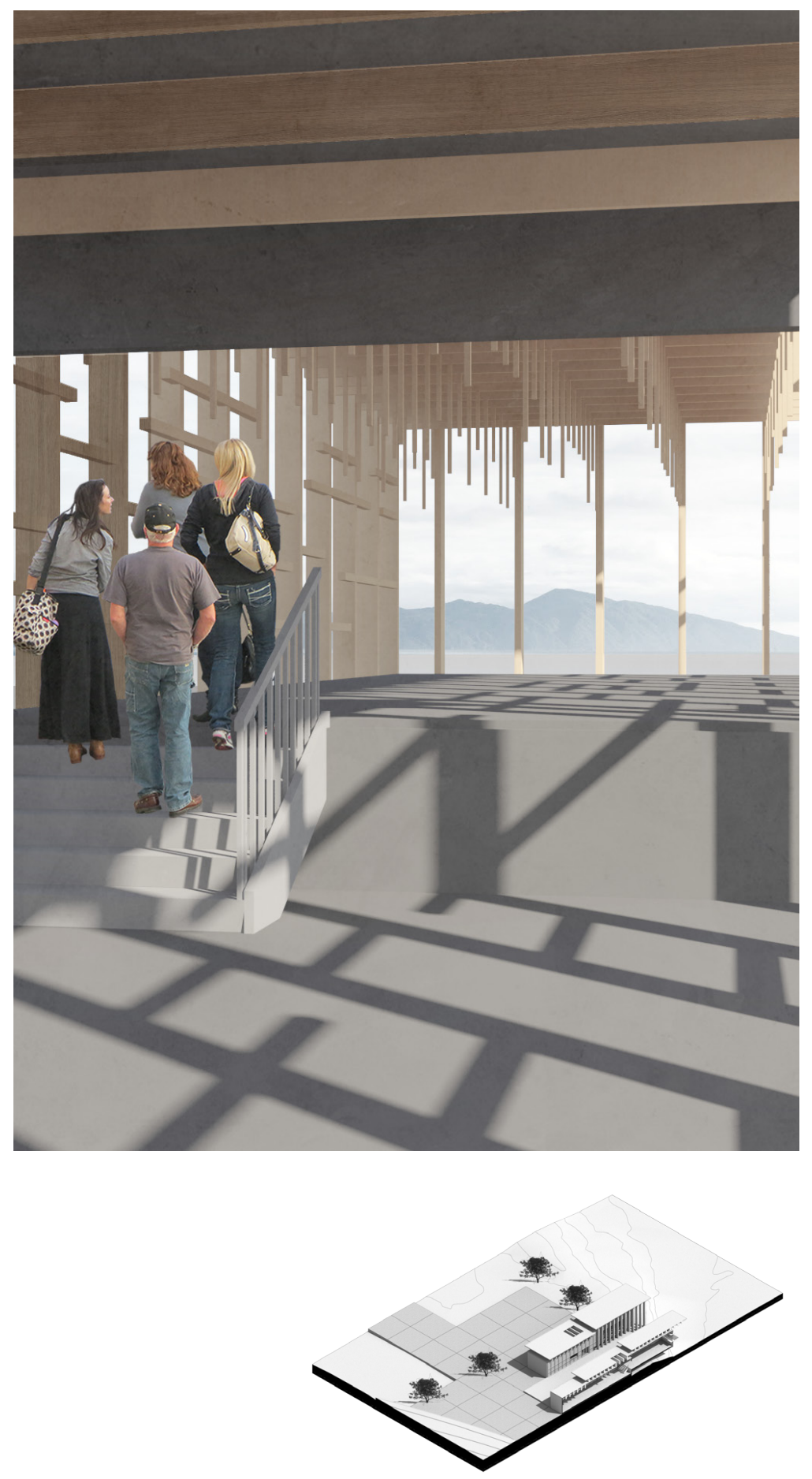

Figure 66: Digitally combining multiple models together to see the implications spatially once the human scale is considered

Figure 67: (Above Right) An Axonometric of the Design and its context 


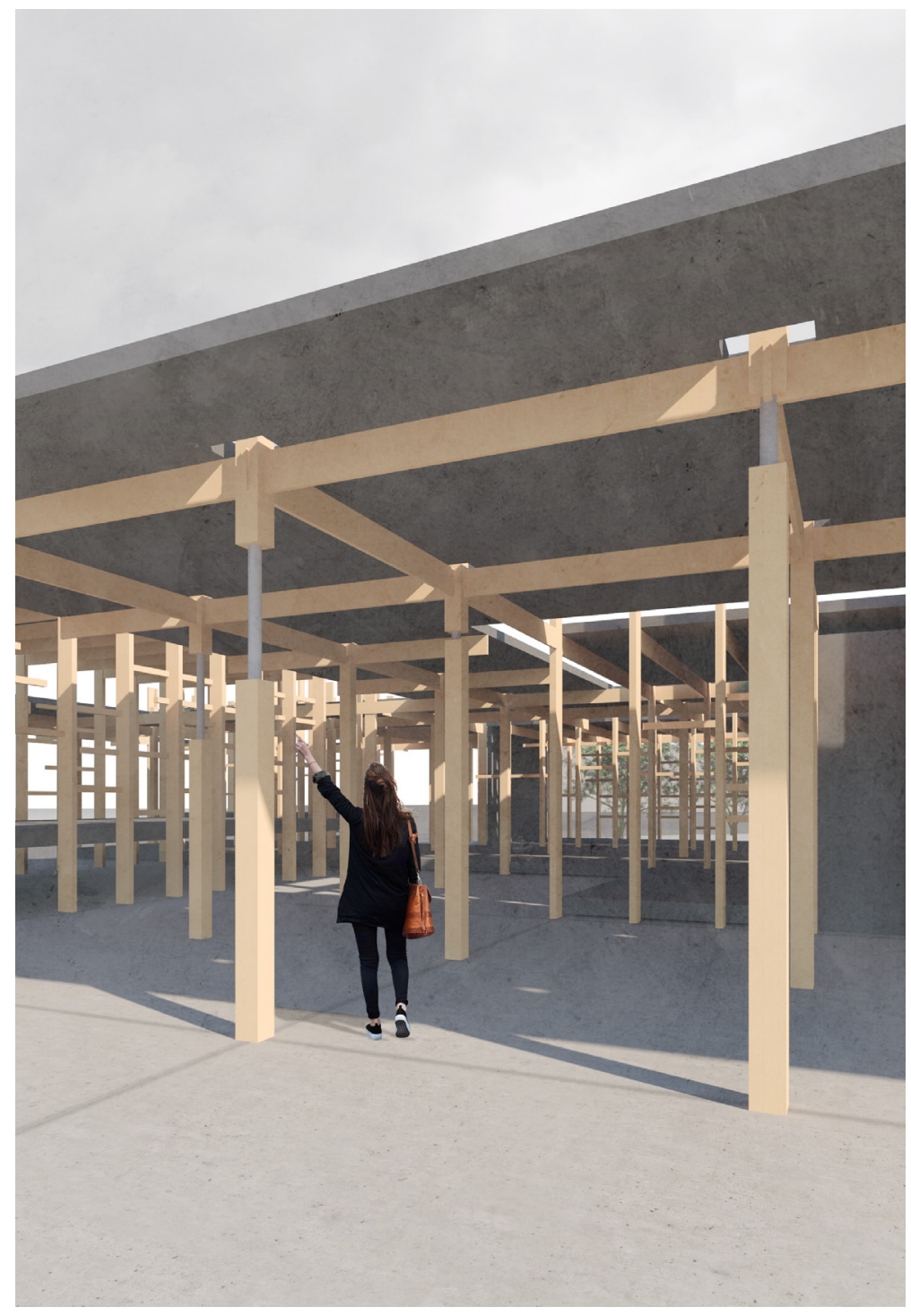

Figure 68: Testing spatial quality of registering site datums on columns as integral structural elements, rather than on ornamental elements as the previous models showed $>$

Figure 69: An Exploded Axonometric of The Design - further developing form by integrating the columns as a unifying language across the building

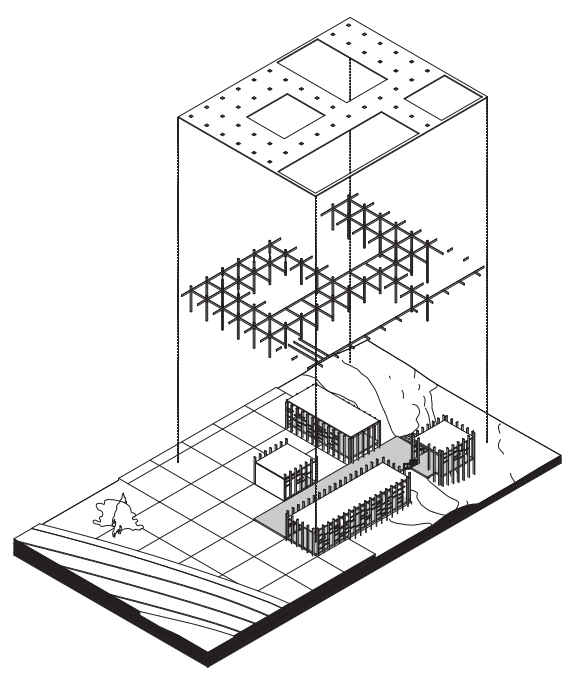


PAVILION

The experiential nature of the previous design enquiry was successful in that it engaged with the localised history of the site and could trace it in a more spatially engaging manner than earlier iterations. However, focussing on a singular building showed a lack of consideration of the wider site. Due to the immense scale of the site, the following experiment investigated ways that similar experiential methods of registering could be expressed across the entire park.

The meandering nature of how visitors currently explore Maclean Park drove the development of a series of pavilions that would engage physically with the surrounding environment. The pavilion interventions, whilst attempting to retain the experiential quality from the previous experiment became somewhat more poetic in execution. Rather than elements of the pavilions acting as site tracing markers or datums, they also fit within the wider context by moving and interacting with the environmental conditions, such as wind or rain, thus forming a more poetic architectural expression and reading of the landscape qualities at that point in time. 


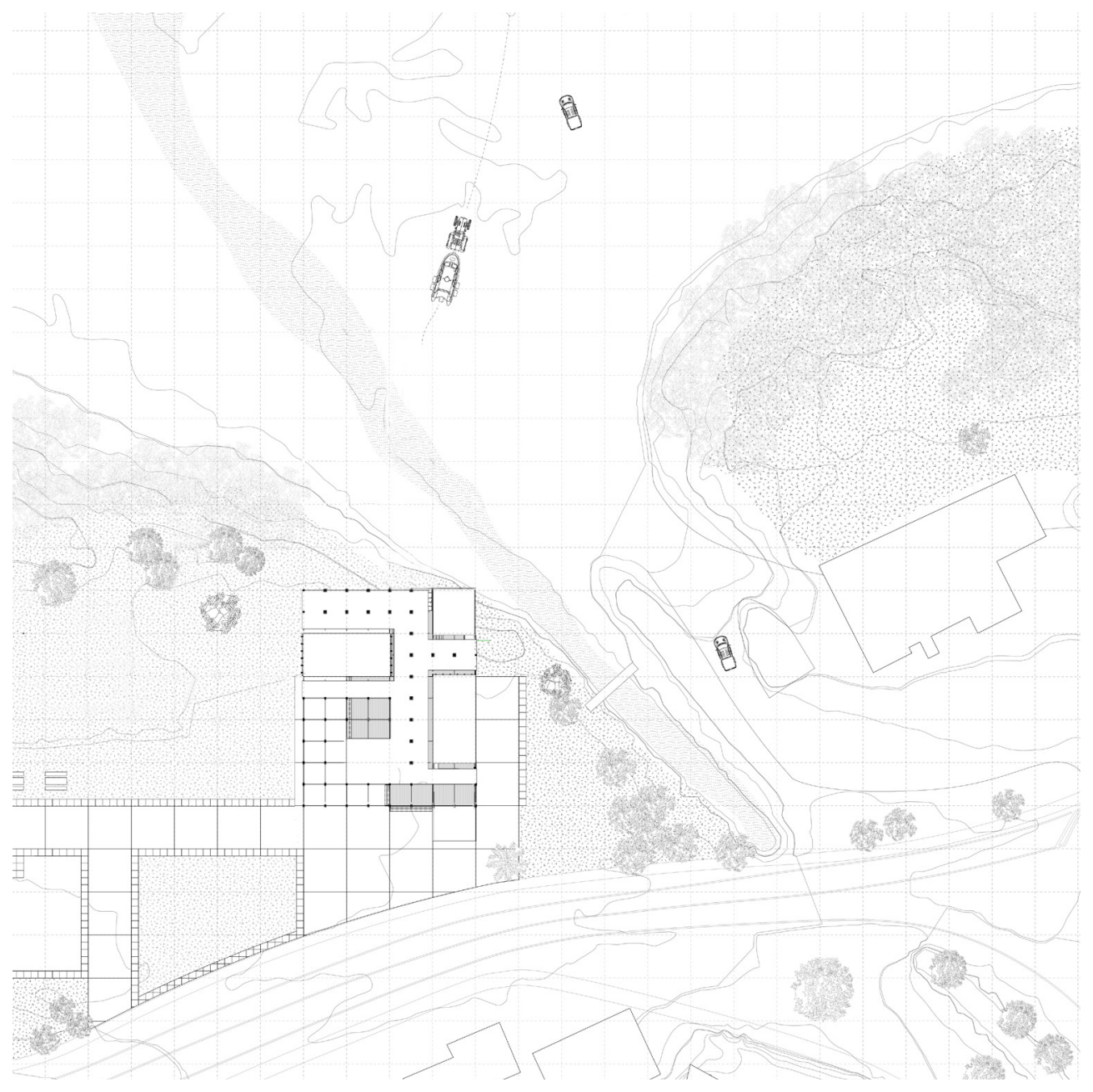

$\wedge$

Figure 70: A Site Plan shows engagement of only a part of the site, missing an opportunity to engage with the wider park 

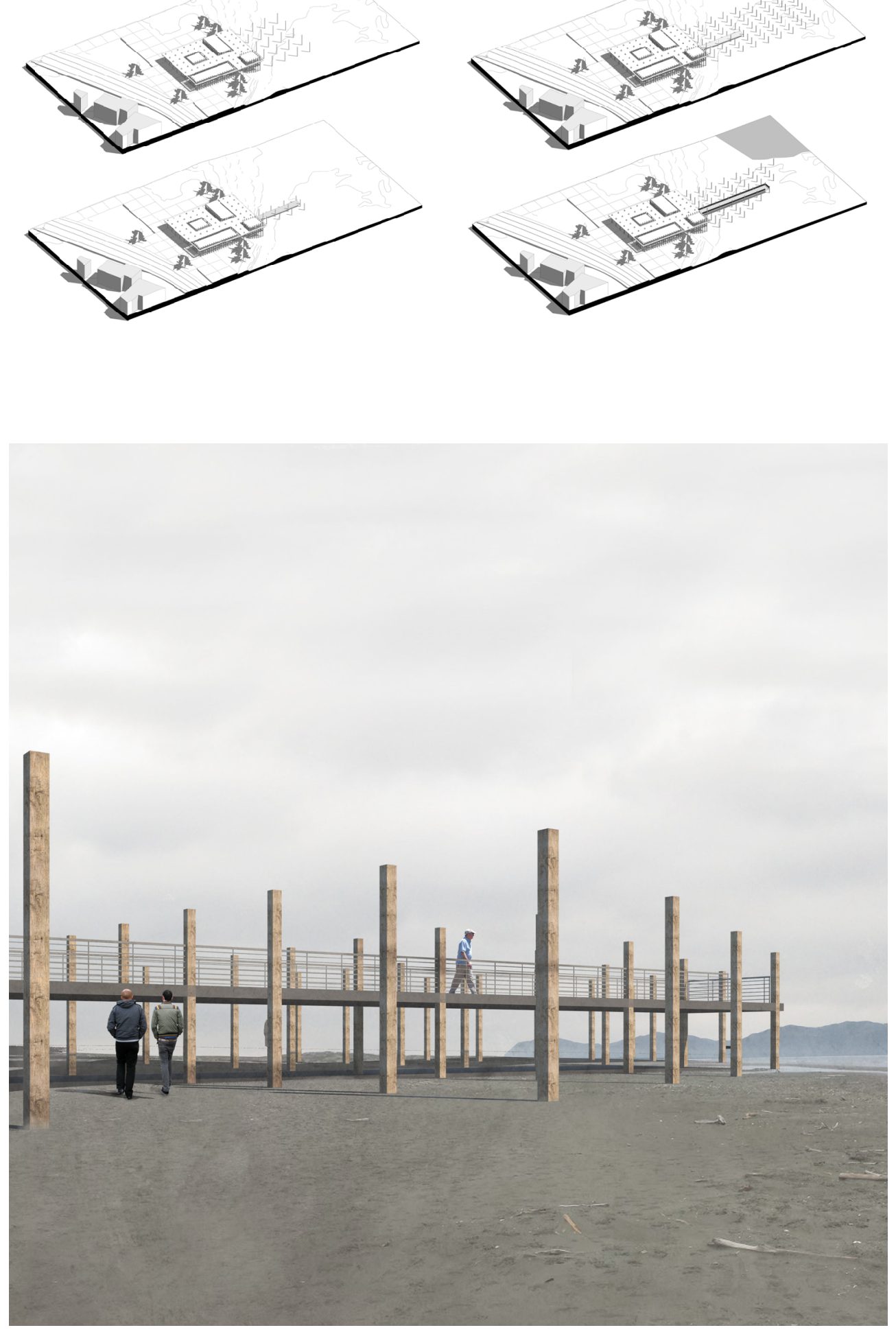

Figure 71: A series of iterations to form a grid of timber stelae across the beachfront. Their formation in plan 'registered' the extents of historic stream mouth movements across the beach over the last decade. The bases of the posts would show as darker and more worn where interacting with the stream's current movements too. 

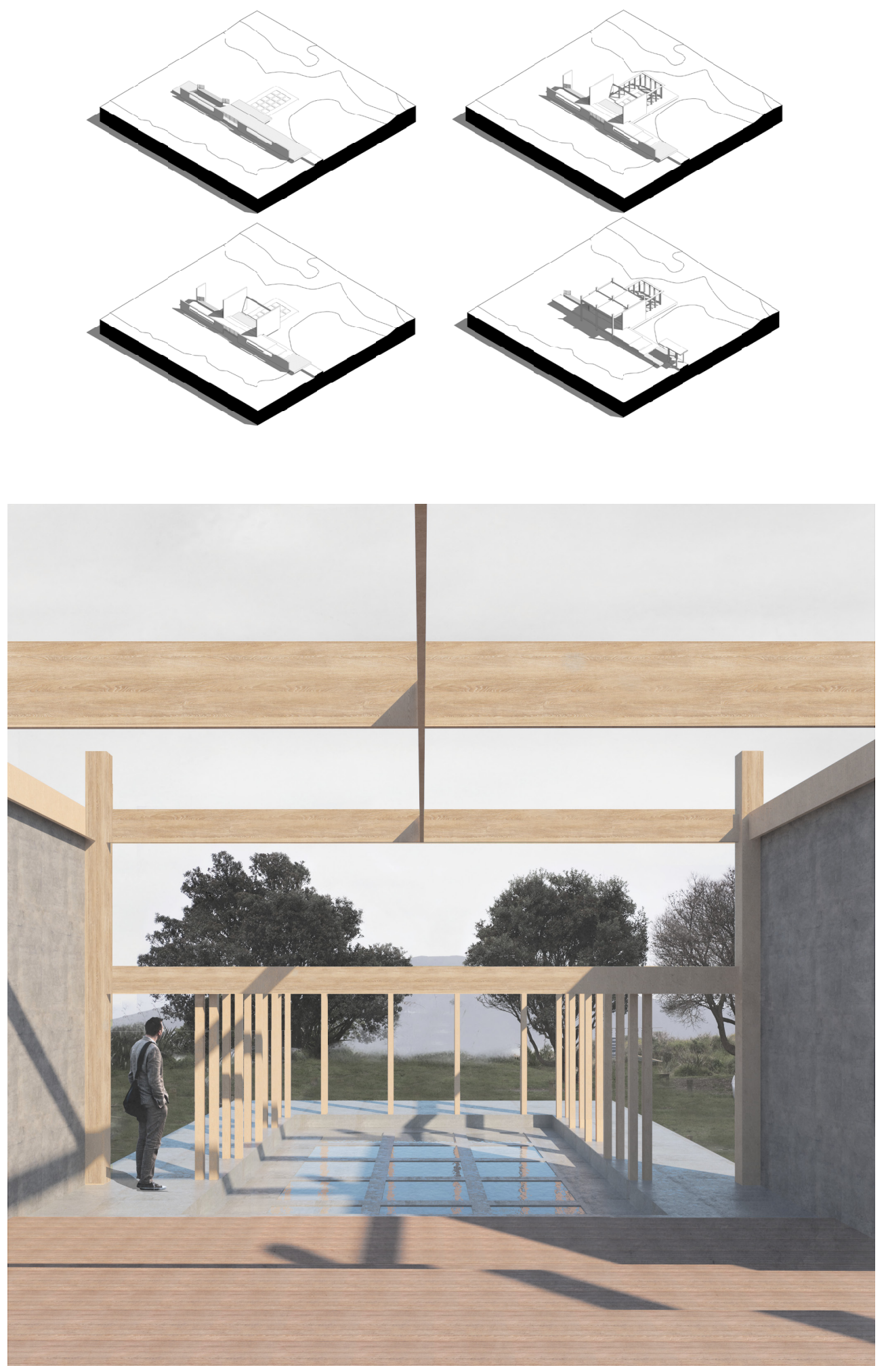

$\wedge$

Figure 72: Iterations testing how to register rainfall through a pavilion that allows water to pool intentionally over time. An experiential quality to the space was sought through a reflecting pool-like nature to the intervention. 

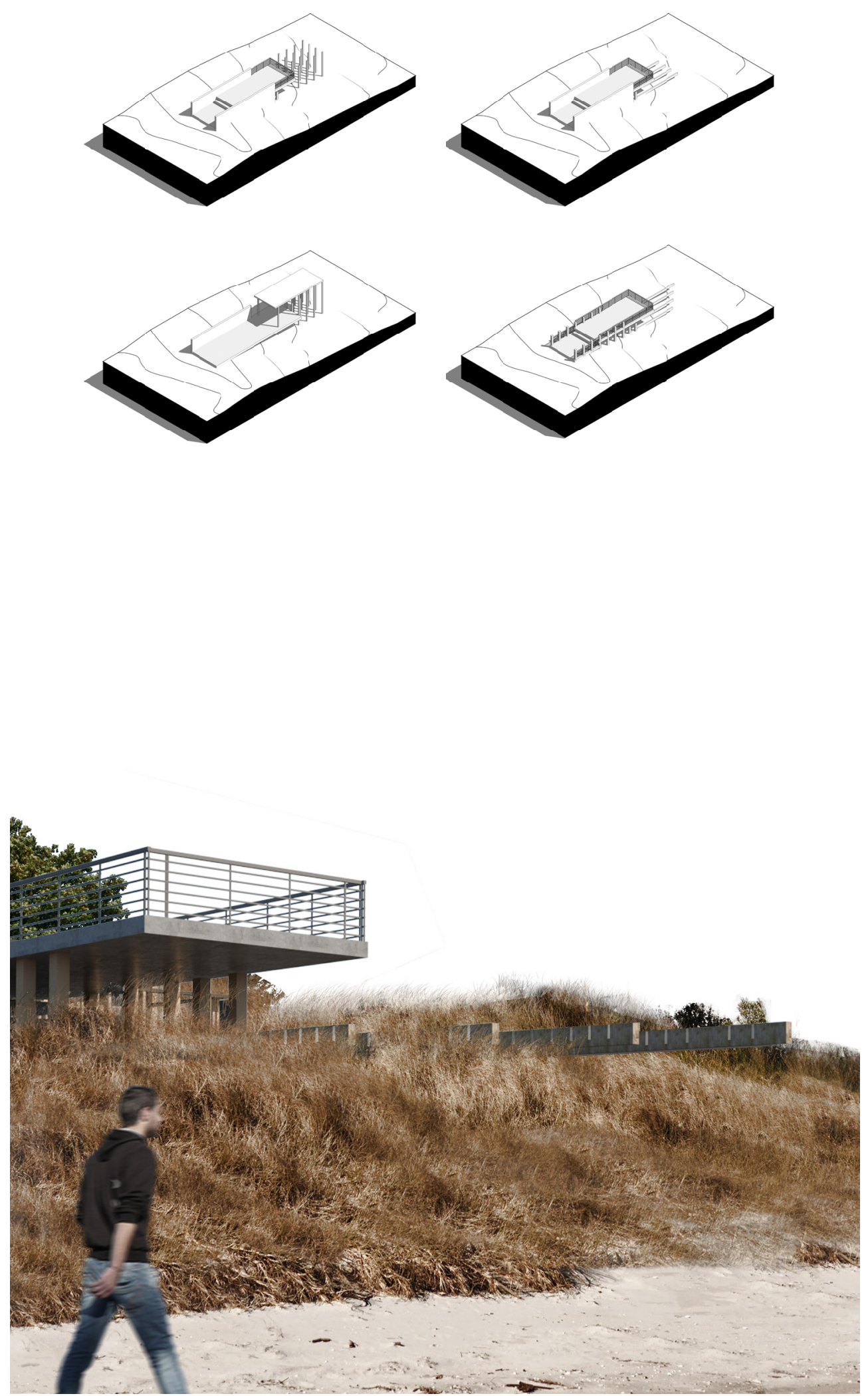

Figure 73: A series of iterations centred on a large marker embedded into

the dune, visually noting its relative position 
PAVILION

I felt that by utilising the more rational and instrumental 'record keeping' notion of tracing historical site data against building elements, as well as the more poetic architectural approach with the pavilions facilitating visual observation of the daily changes in the environment engaged both with the immediate and wider site. However, in practice, the mixing of these two methods of representing taking a measure and reading of the landscape created confusion amongst my reviewers:

"When you were talking about where dunes used to be, what about that space there?.. The pavilions... they're just little artworks, or are they useful?" - Academic Reviewer, August 2017

"You have to be ruthless, if you have a temperature gange that goes 5 degrees, 10 degrees, 20 degrees then its not a temperature gauge, there's no constant!' (in reference to pavilions and building collectively) (Academic Reviewer, August 2017)

At this stage of the project, these pavilions had highlighted what was to become a major tension throughout the design process between a rational and poetic approach to designing, as well as architecturally representing measurement and reading of the landscape. Landscape Architect and theorist James Corner in his book "Taking Measures Across the American Landscape" presents a series of arguments about different ways of reading the land (xi). He suggests that both the instrumental and the poetic aspects of measurement are reciprocal. In past times, they were inseparable, yet in the scientific revolutions of the seventeen century, the links between instrumental and poetic measure seemingly dissolved (xii).

This dissolved relationship between the two aspects of poetic and rational representations meant that I grew concerned that there was a looseness in my definition of 'measurement' and observation. Whilst I was attempting to engage with the rational reading and representation of the site and environment, a risk in these poetic pavilion iterations was that they could be too metaphorical against the quantitative nature of the previous iterations in 'Registering the Site'. The following experiments attempt to reconcile the differences between these approaches and find a collaborative middle ground.

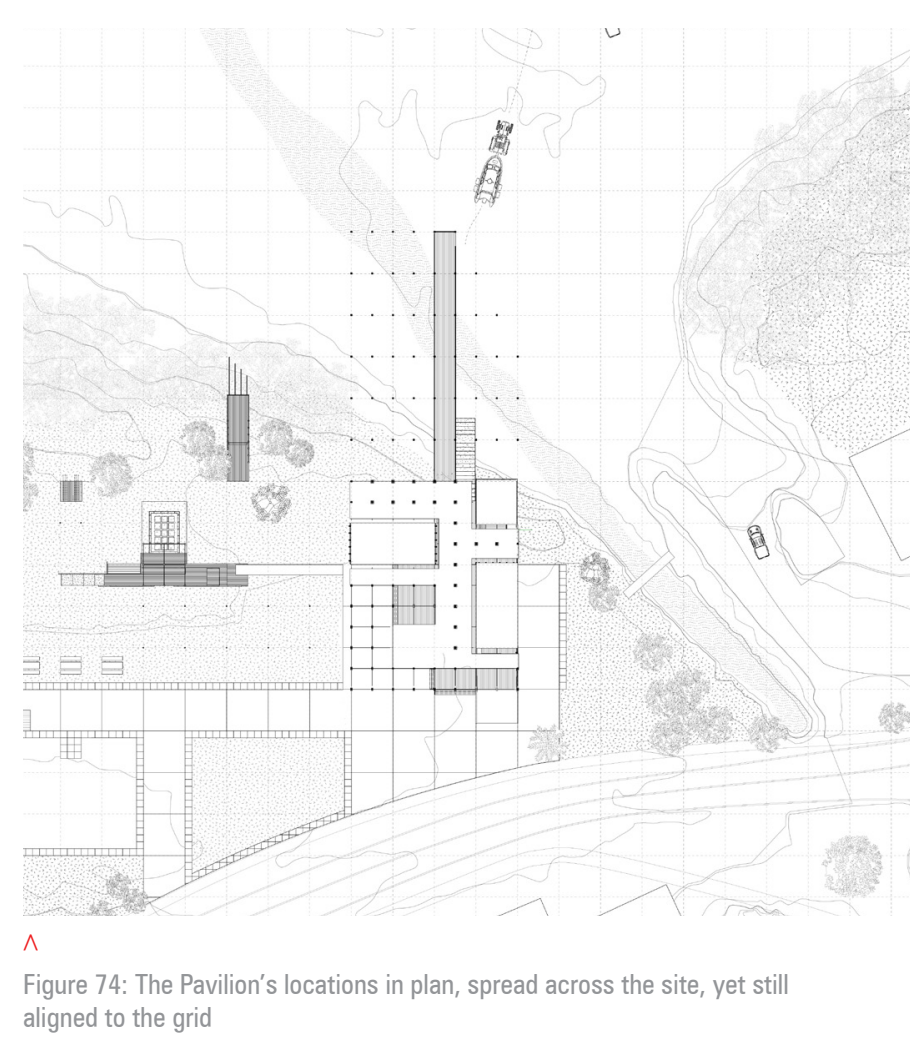




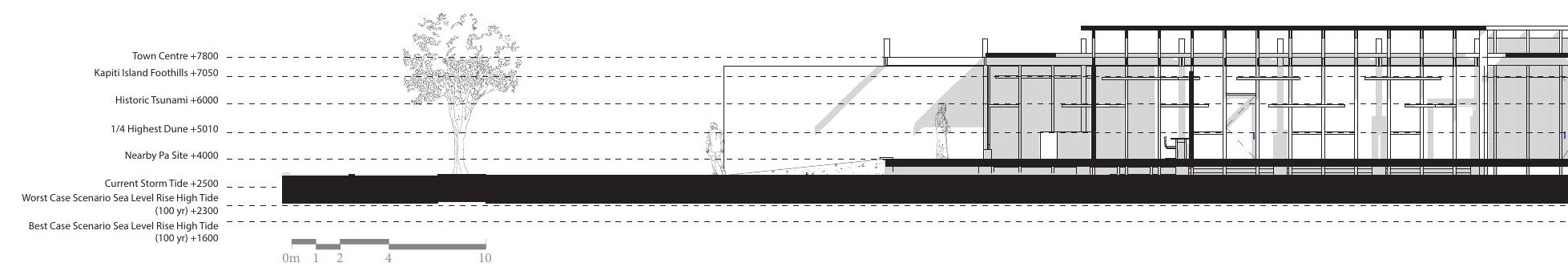

FIGURE: (SECTION AA) A section of The Design at the July review. The jetty provides access to the boat, and heights of building elements are rationalised by site data and datums

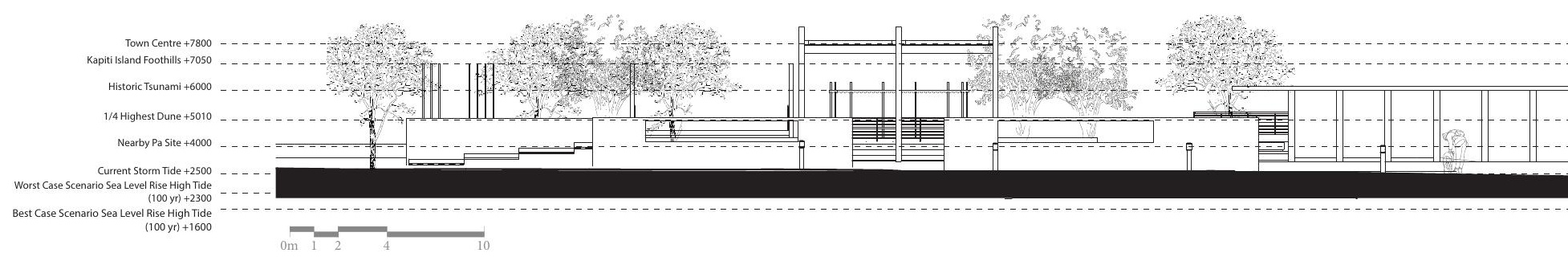

Current Storm Tide +2500 Worst Case Scenario Sea Level Rise High Tide (100 yr) +2300

Best Case Scenario Sea Level Rise High Tide (100 yr) +1600

Figure 75: (SECTION BB) A site section highlights how the datums still continue to rationalise the heights of the pavilions across the wider site 


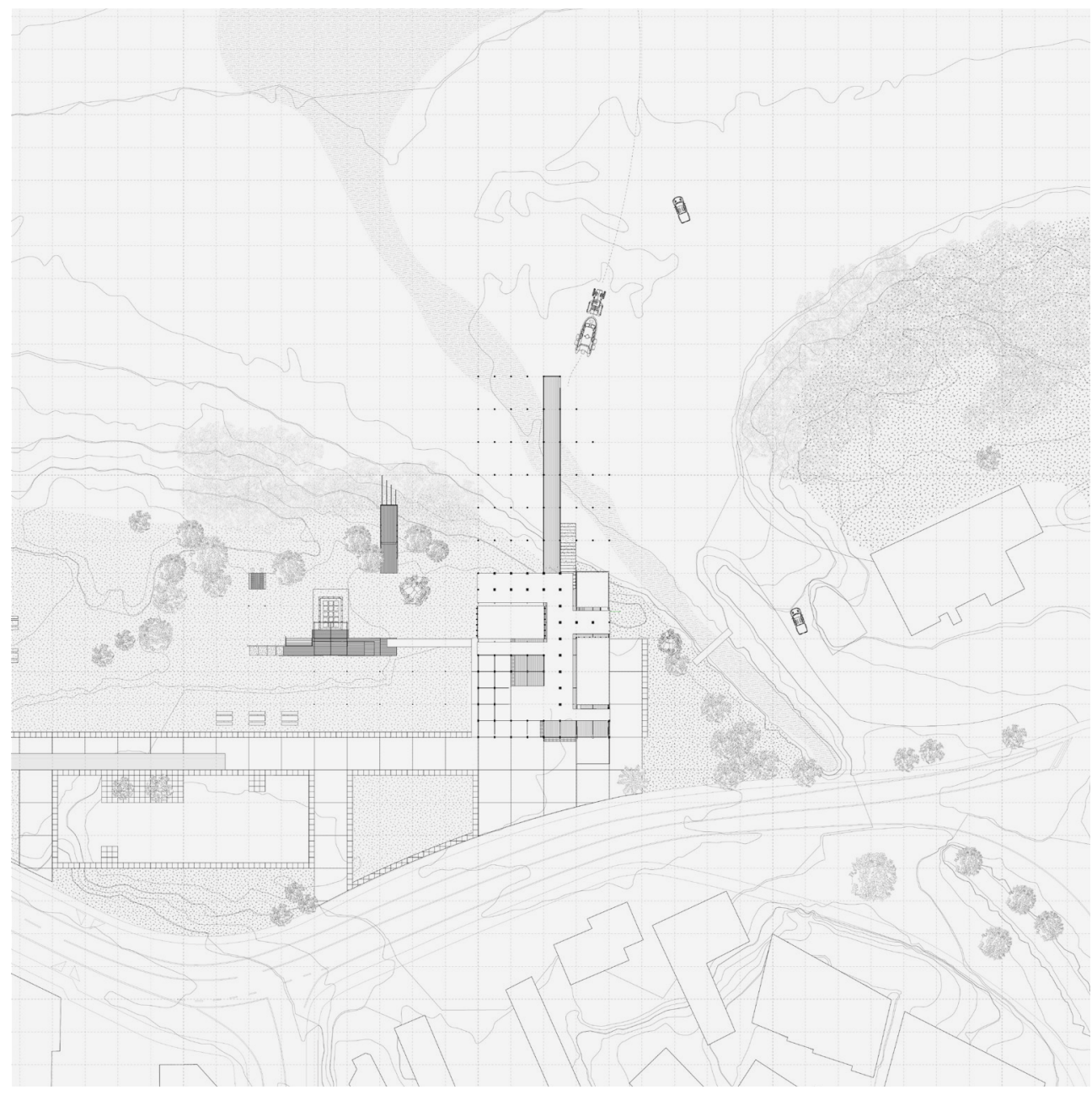

Figure 77: A site plan highlighting The Design and its context, including the pavilions

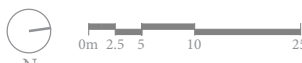
$>$

Figure 78: An Axonometric showing The Design and the surrounding context. This angle highlights the extremely disjointed design language across the interventions 



\section{CASE STUDY: THE LIGHTNING FIELD}

\section{Walter De Maria | Catron County, NM, USA | 1977}

Walter de Maria's Lightning field and Richard Serra's Sea Level are two examples of land art that use both a rational, instrumental measure of their sites in conjunction with expressing more poetic notions of atmosphere and experience to architecturally represent qualities of the landscape.

For de Maria, the notion of measurement occurs frequently throughout his work, with his early $4 / 6 / 8$ sculpture featuring mathematical sequences, and the Equal Area Series which involved a series of steel circles and squares almost perfectly, imperceptibly different distances apart (Nisbet et al. 247).

The Lightning Field took this obsession with measurement to a monumental scale. Consisting of a regular grid of four hundred steel poles and extending a mile long by a kilometre wide, visitors to the lightning field must stay for a full day and night to experience how the work changes over the course of time. Different angles over the course of the day create shadows across the structure indicative of the suns location, illuminating the chamfer at the top of the poles which changes the colour of the work (2). The Lightning Field becomes "an interpretative model not only for the absorption of ecological ideas of environmental movement but also of historical time as itself ecological . . entwining multiple events in time and space"(259). For example, the poles trace history of the site by charring due to being struck by lightning, remaining marked for a period of time before the artist replaces the pole (256).

The lightning field finds a balance between an atmospherically poetic and rational, more instrumental experience. Visitors experience the poetic notion of how the artwork reacts in response to the surrounding environment, light and shadow. Equally, the artwork traces site history in a very literal manner through markings from the lightning itself. There is an ambiguity between these two methods, much like the previous pavilion iterations. However, the architectural language between the two approaches in 'Lightning Field' appears more cohesive.

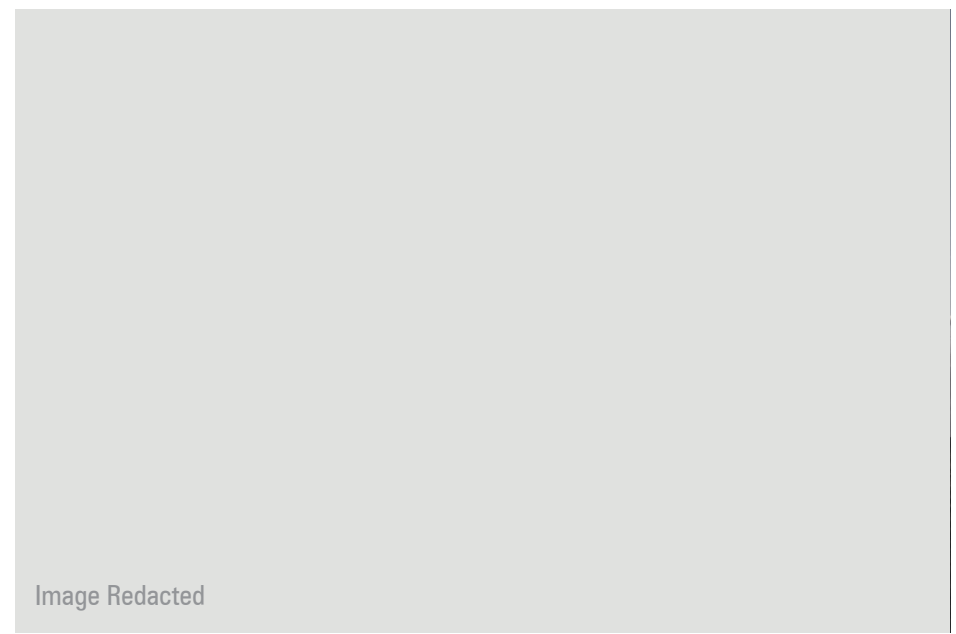

Figure 79: Walter de Maria's Lightning Field. This highlights the sheer monumental scale of the art's ability to measure in a succinct and singular language 


\section{CASE STUDY: SEA LEVEL}

\section{Richard Serra | Zeewolde, Netherlands | 1996}

Sea Level is another example of poetic and rational reading of site on a monumental scale. The structure is comprised to two large concrete walls spanning partially across the valley that indicate the level of the ocean. As the visitors move along the $200 \mathrm{~m}$ long walls, they experience a feeling of submersion as the hill slopes down and the wall stays at continuous height. Serra's intention of the piece was poetic in the sense that it was to visualise the reality that nearby dikes are keeping the town from submersion (Pask).

Rationally expressing the area's water height data as a singular datum line and imposing a vertical measured plimsol of sorts to the relatively flat landscape creates an immersive experience of the place and contemplation beyond reading the site data as only a number.

This shows through Serra's works being described as "not sculptures, rather objects that react to topography", acting as "barometers for reading the landscape"(Berlanda 113). Similarly to the previous pavilion iterations, Serra's focus lies on the "experience of the landscape, gained by physically moving through it, which establishes architectural experience"(113).

Each of these projects highlight ways that tracing site data such as the sea level or events such as lightning could be utilised to form an immersive and experiential way of observing the landscape, as well as being somewhat rational and accurate in their architectural representation of site measurements. In the case of both projects, the sheer monumental scale of the architecture, materiality, experiential quality and the merging of poetic notions with a more rigorous scientific accuracy to how the measure of landscape can be expressed reinforces their strength. Unlike the previous pavilion iterations, the case studies balance these two approaches with a singular elegant architectural language. 


\section{REGISTERING: A CRITICAL REFLECTION}

Registering explored architectural techniques for how the design could index, measure, and indicating historical data from the landscape to build a greater site-specificity. Initial attempts at indicating these datums through materiality was weak in practice, so a more tectonically intricate and experiential manner of tracing and registering was explored through undulating elements and forms within the building to create dynamic spatial qualities. These elements developed further into exterior pavilions across the site.

Whilst the pavilion iterations physically engaged with the wider park, they raised a tension in the design process. There was a shift in emphasis from taking a visual measure and observation of the site through architectural form and composition, to designing to capture a more experiential feeling of the landscape's movements, like land art figures such as Walter de Maria and Richard Serra. This resulted in a tension between instrumental and rational readings of site, against more poetic representations of the landscape.

This tension is not uncommon to the design process. Architects are often attempting to translate quite literal limitations and site constraints yet reinterpret a client's feelings or their own vision into the resulting design. Whilst the designer could be completely rational and analytical in the design process, this could be to the detriment of the design's quality of experience, so a balance is often sought between the two. Within the previous iterations, I had issues with their poetic outlook on landscape observations, which conflicted with the earlier experiments analytical, reductive emphasis.

I am not alone in this dilemma. Architect Glenn Murcutt's architecture is driven by taking literal measurements and readings from the landscape to drive the design. He highlights this tension in the process as an issue for himself, stating that "It is very dangerous to have something romantic. It is also dangerous to have something which is just analytic"(Drew 79).

Moving forward, the following chapter considers a balance between these two approaches, and the implications of 'observing' the site with greater depth, to drive an architectural outcome more responsive to the dynamics of the site.

Figure 81: The main design process stages of the 'Registering' chapter 

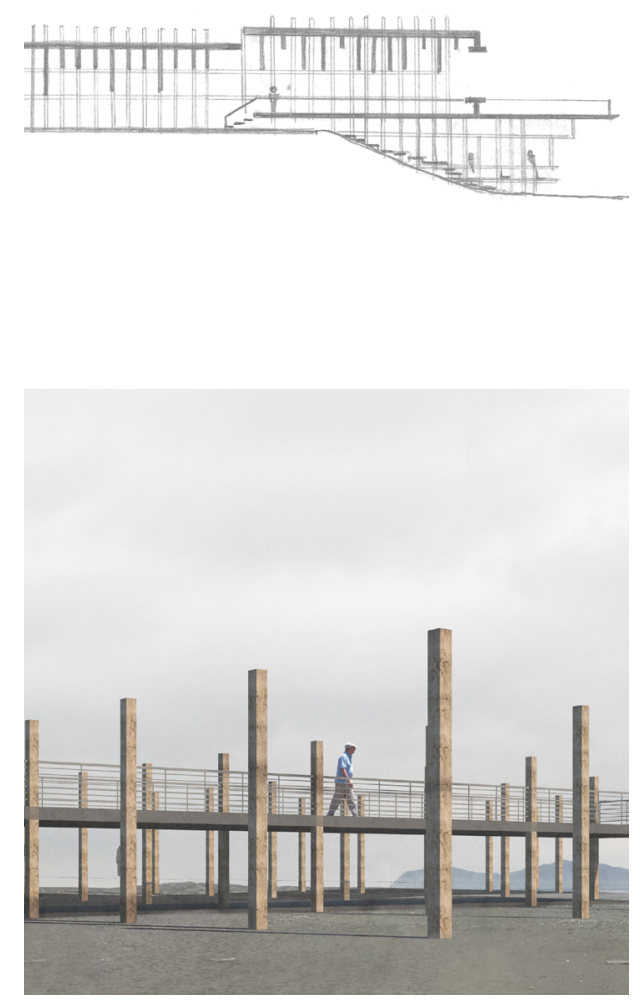

5.01

OBSERIVING 
5.01

OBSERVING: AN INTRODUCTION

5.02

A GRID TO MEASURE BY

5.03

QUANTIFYING THE LANDSCAPE

5.04

A MODULAR MEASURE

5.05

OBSERVING SURROUNDS

5.06

REDUCING IMPACT

5.07

LANDSCAPE: MEASURING PROCESS

5.08

MERGING LANDSCAPE AND BUILDING

5.09

GROWING INTO THE BUILDING

5.10

IN TIME

5.11

OBSERVING: A CRITICAL REFLECTION 


\title{
OBSERVING: AN INTRODUCTION
}

\author{
"That [building is] a mark in this massive system, \\ starting to catch sand behind it, and the architecture \\ just sits ... or works with that [landscape], cause \\ that's the mark that we're making" - Academic \\ Reviewer, August 2017
}

'Composition and Geometry' as an architectural method of visually observing and taking measure of the landscape, as well as 'Registering' by tracing site measurements and data had limitations in their execution, and an awkward balance between poetic and rational approaches to observing and representing the site. In addition, due to prioritising the architectural and spatial qualities of the design iterations, there was a lack of well-considered physical engagement with the landscape.

Whilst the thesis had set out to use architectural methods to enable visitors to better understand and take measure of the shifting landscape, the previous experiments failed to acknowledge the landscape being in flux. Aspects such as the landscape's natural processes, such as dune expansion and recession, flooding and growth of surrounding greenery were also ignored. Whilst talking often of the dynamic quality of the site, the design had conversely been impeding these natural processes in its insensitive placement on the foredune.

As oulined in 'A Shifting Context', this is commonplace in New Zealand, where coastal settlements such as Paraparaumu (Maclean) and elsewhere have historically often flattened dunes, wetlands and built over natural processes (Buxton). Similarly, I had been flattening the delicate landscape even further for architecture's sake, with heavy concrete foundations and forms poorly responding to the landscape's underlying natural systems.

In response, the thesis progresses towards a more collaborative approach between building and landscape, looking not to compose, order or trace, but to 'Observe' its processes as an architectural tool to inform the design. The design takes on a role of physically reflecting and responding to the ongoing effects of these environmental processes as a way of revealing and allowing visitors to observe them. This chapter also looks for a balance between rational and poetic methods of reading and representing the site.

The following experiments rationalise design decisions by rigorous site observations acting as a design tool and in turn, encourage the building to respond more closely to the landscape as a process, rather than focussing on a static representational measurement of a datum or moment captured in time. 


\section{A GRID TO MEASURE BY}

The pavilions developed in the Registering chapter were discarded in favour of a more unified form that responded specifically to the visitor centre site on the foredune. The grid was used as a device to form a singular architectural language across the building, which felt more visually transparent, framed the landscape behind, and still utilised the gridded form as an architectural language of measurement.

Whilst visually lighter on the landscape, integrating the posts and jetty from the pavilion iterations resulted in a large structural footprint.
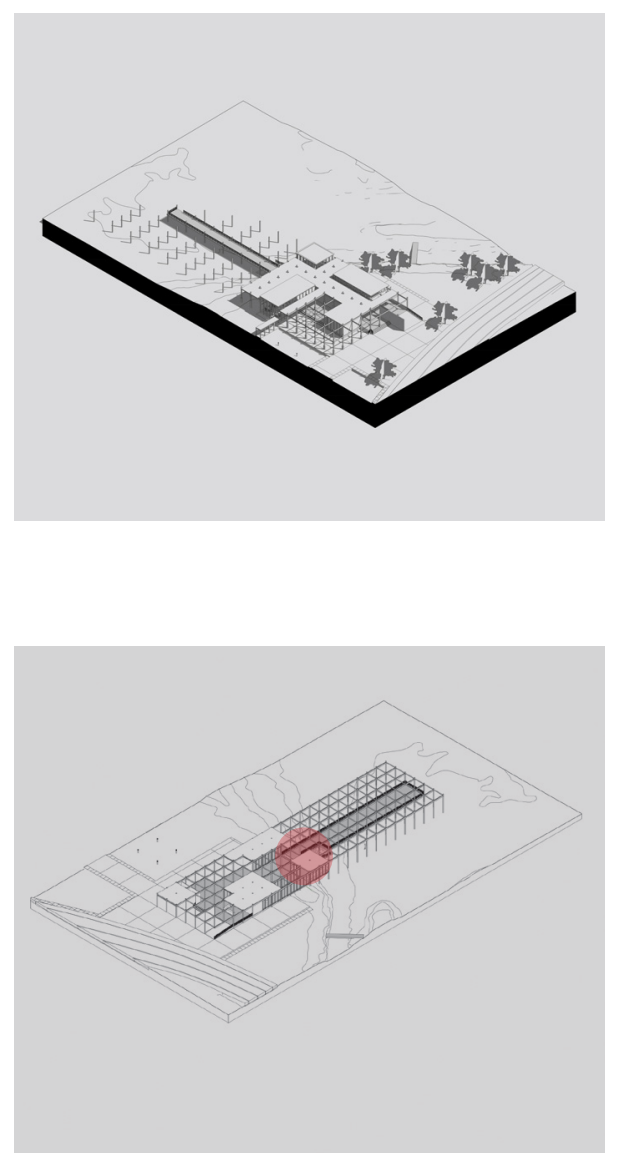

Figure 82: Axonometric of The Design and its immediate context. The gridded framework becomes a unifying architectural language 

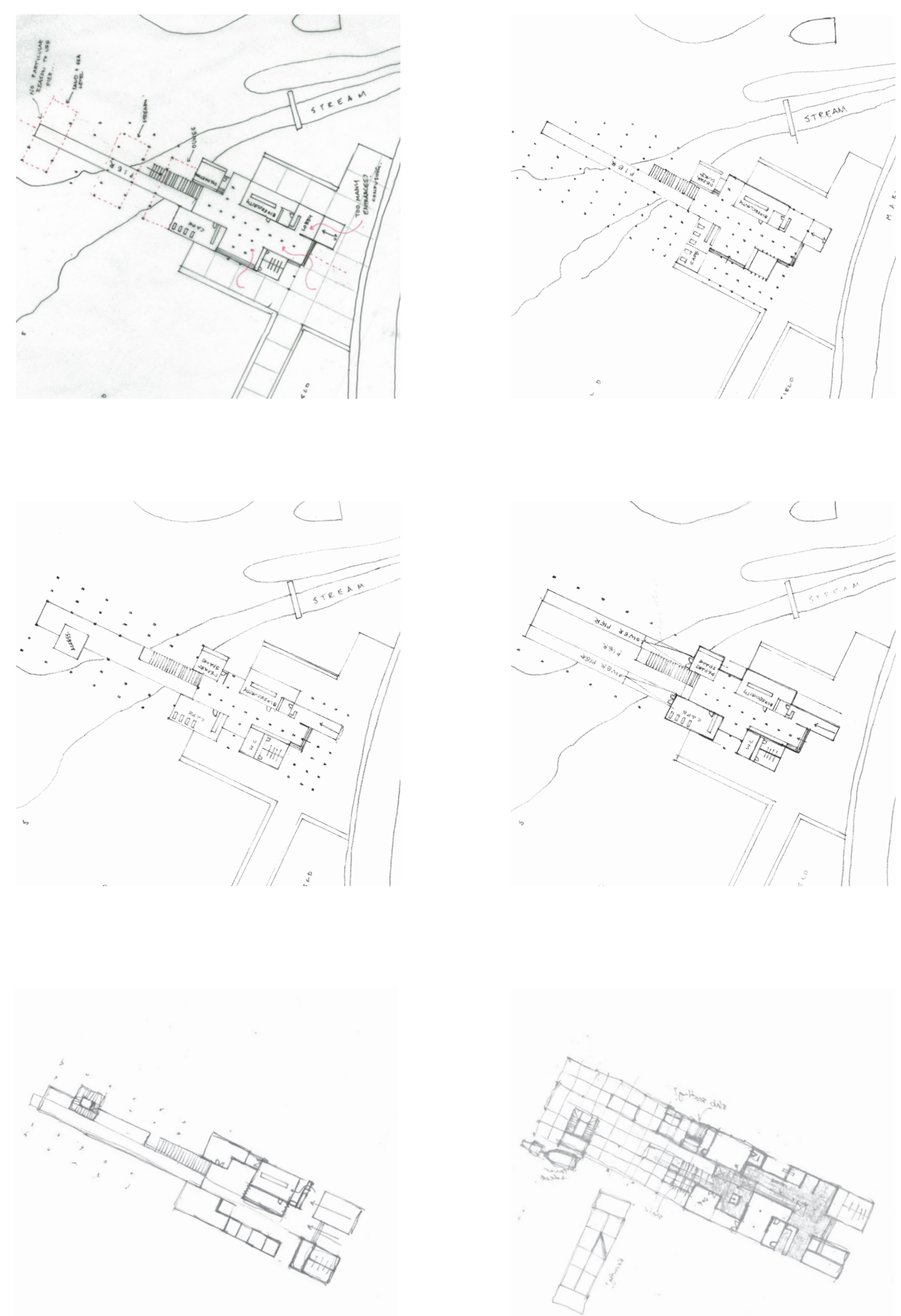

$\wedge$

Figure 83: A series of sketch plans that experiment with extending the gridded framework to form a singular design language 


\title{
QUANITIFYING THE LANDSCAPE
}

\author{
"Somehow you've got to reconcile that.. It \\ is a bit, rather rectilinear for a easy site" - \\ (Academic Reviewer, August 2017)
}

Upon reflection, the building and grid's form still appears insensitive to the curvilinear characteristics of the site topography. Whilst the excess structural elements fit with the notion of the cartesian grid acting as a measurement device in itself, they were critiqued for being unnecessarily overbuilt for the delicate dune system - with little regard for where the building should intersect with the site. The design's overall rectilinear form also was still at odds with the push towards observed landscape processes driving the form of the building.

In the move towards observations of site processes driving the design, theory can be identified that tackles a wider urban based approach, and closer site-specific approach.

Landscape architect Ian McHarg took a quantitative approach to landscape processes. His designs centred on observing, measuring and quantifying ecological systems and processes in order to organise his urban schemes. His working method consisted of overlaying drawings to diagram and determine the suitability of where exactly one should be building, considering the benefits and costs of elements of site such as water, forests, scenic factors and historic environmental factors to create a map of composite layers that determined the most likely area to benefit from development (Wang 306). Ecologist Richard Hart concurs with McHarg's approach arguing that "skilled observation is an effective mode to viewing through and between the strands of the complex weave of Nature's fabric"(Hart).

Looking on a smaller scale than the urban approach of McHarg, Australian architect Glenn Murcutt uses site processes as a fundamental driver for his designs. He draws the conclusion that "It is so much easier just to demolish and destroy it all... whereas, as far as I am concerned, it is our duty to act as custodians for one of the most remarkable landscapes. We are able to develop an architecture which responds more closely - as an instrument might respond to a tune" (Drew 87).

Reflecting on this statement, until this point in the design process, observation of the landscape as a temporal process had been poorly utilised as a design tool. Murcutt conversely utilises this as the driving device for his architecture: "I know the temperature, the wind patterns, the humidity, the trees, the river pattern. I know what happens between the river and the edge of the land... To locate a building I need to locate it in relation to a lot of those things (119)."

The following experiments are positioned with this method in mind, using the $3600 \mathrm{~mm}$ grid to quantify the locations of the dunes, stream paths, high tide and shrubbery across the extent of the site to drive building forms that have a more collaborative relationship with the site's topography. 


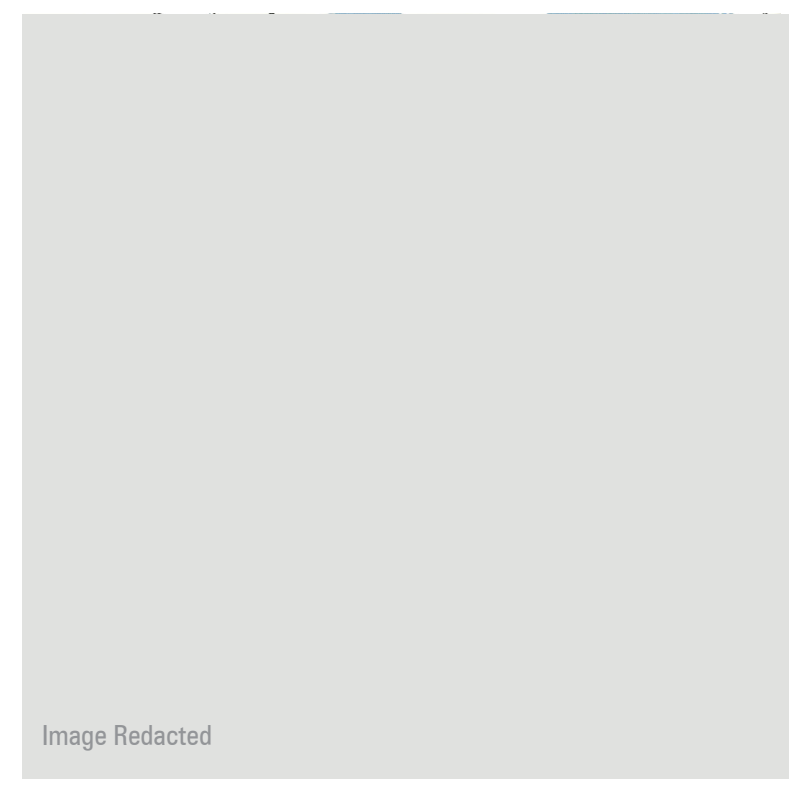

$\wedge$

Figure 84: lan McHarg's 1969 proposal for Staten Island. This composite map overlays a series of environmental information and quantifies it, resulting in an index of areas suitable for various uses.

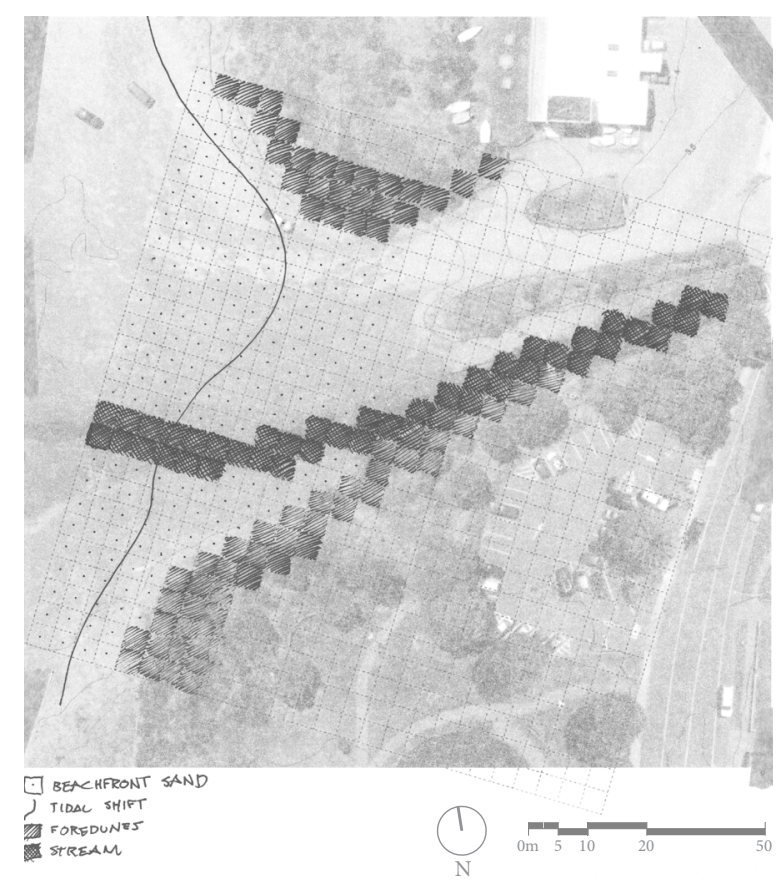

$\wedge$

Figure 85: Similarly, this experiment quantifies and takes measure of natural site elements such as the stream mouth, dune extents and grasses to inform the form of the building in a manner responsive to site topography 
The form is unresponsive to

the site, and programatically oriented only.
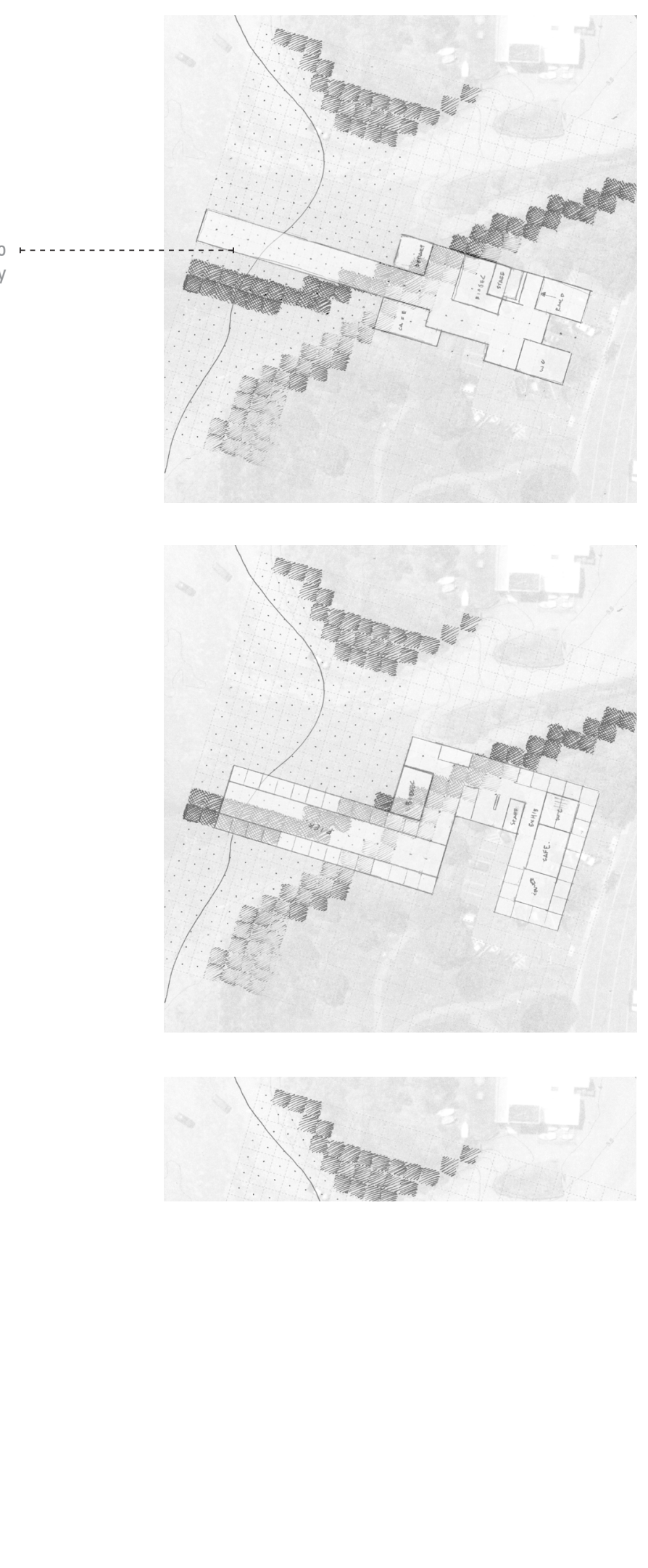

Figure 86: A series of iterations refining the gridded form based on quantified site properties 


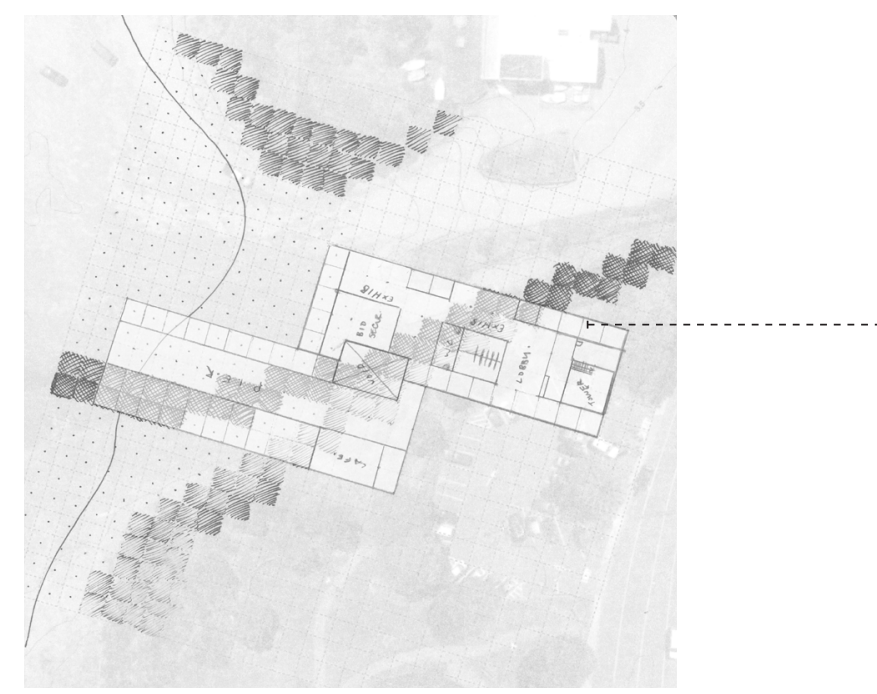

The form begins to move towards responding to the natural curvature of the site, whilst retaining the planning of the jetty

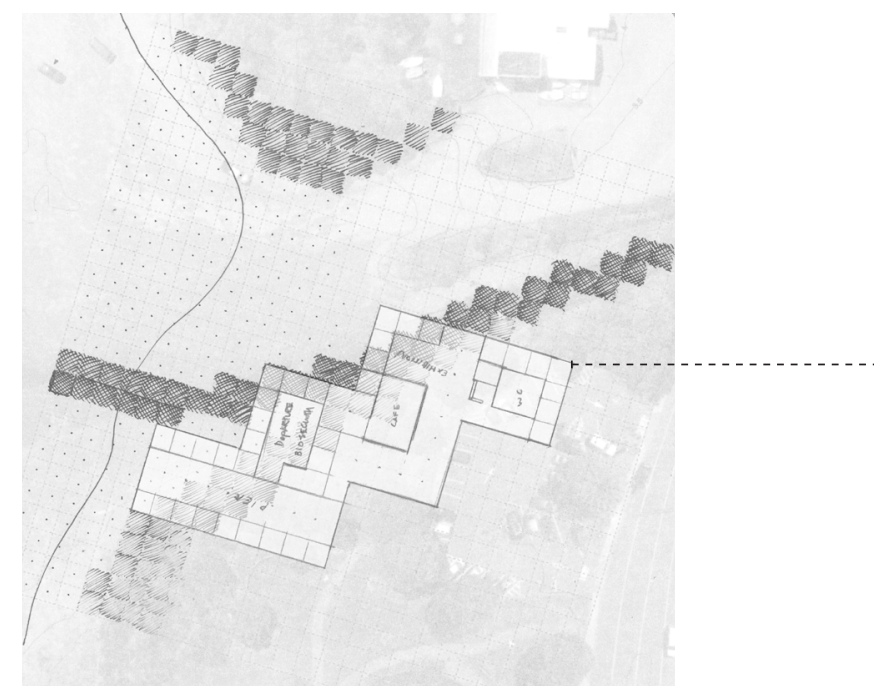

An undulating plan moves the building off the streambed, but feels far too wide for the site, blocking direct beach access.

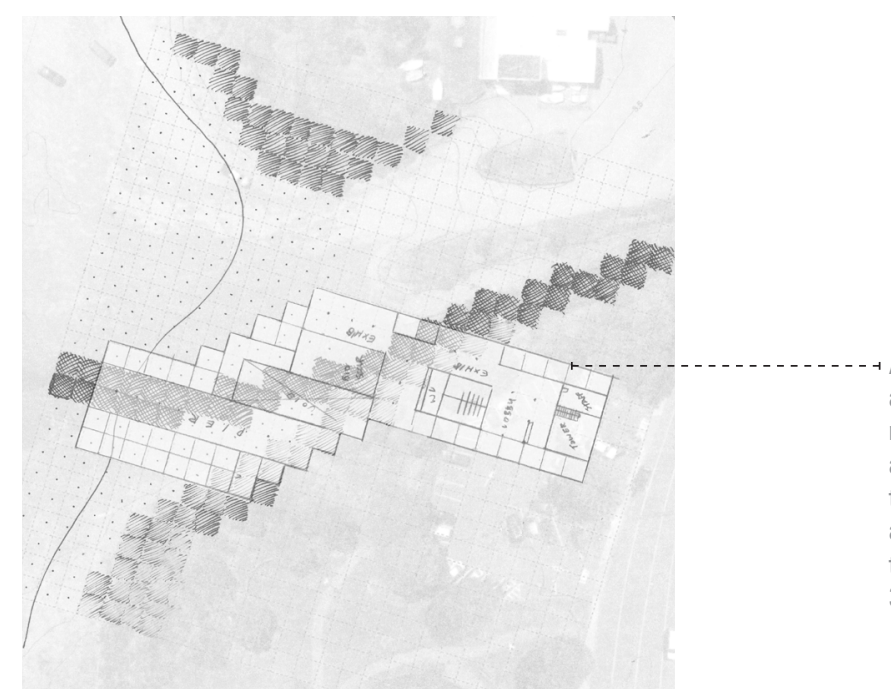

A compromise between the above plans has the building responding to the site curvature, and still retaining a clear access to the beachfront. It still remains an intimidatingly large structure though, at roughly $80 \mathrm{~m}$ long by $32 \mathrm{~m}$ wide 


\section{A MODULAR MEASURE}

To ensure that the structure of the building would be adapted to appropriately respond to the delicate site conditions, a modular approach was explored regarding the structural design. This stemmed from the previous plan iterations, where the building form twisted across the site in gridded planning arrangements in response to the diagrammed site conditions.

An advantage of prefabricated structural modularity is that there is a certainty to the measured dimensions of the structure. Due to the nature of prefabrication, members are constructed to exact dimensions to ensure correct fit. As a result, the structure acts somewhat as a static measuring device as the landscape changes around it, due to its accuracy in form.

Another advantage of modularity is the effect that this can have on the building over time. Prefabricated post-tensioned timber frame construction can be constructed and assembled quickly on site. Most importantly it can be taken apart and reconfigured in the future, given that the landscape will shift dramatically over the next 50 or so years. In the case of local coastal erosion issues, this means that a managed retreat could take place, with the building left adaptable for future landscape changes.

The move towards a modular system can come at the risk of removing the specifics of the site from the design in the name of uniformity. Attention was needed at the module level of the building to ensure that observation of site movements could drive site-specificity in the design. By establishing a kit of parts in the form of infill module panels, these panels could begin to respond to the specific site conditions dependent on their placement and still allow for flexibility in future.

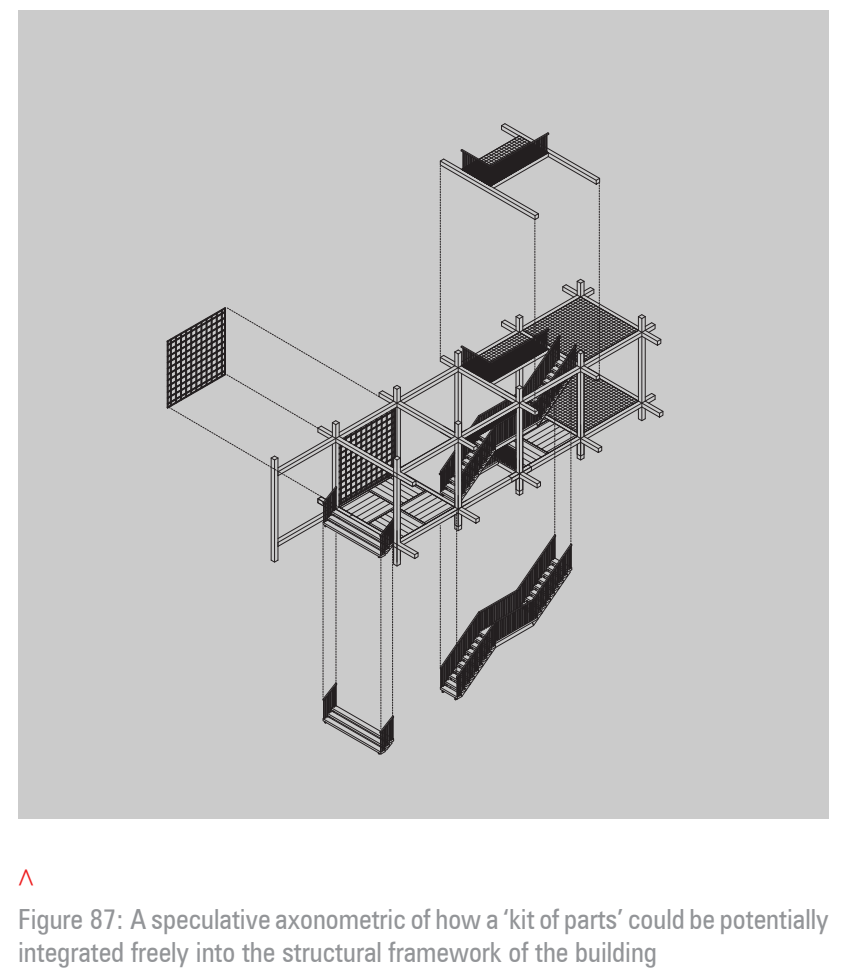



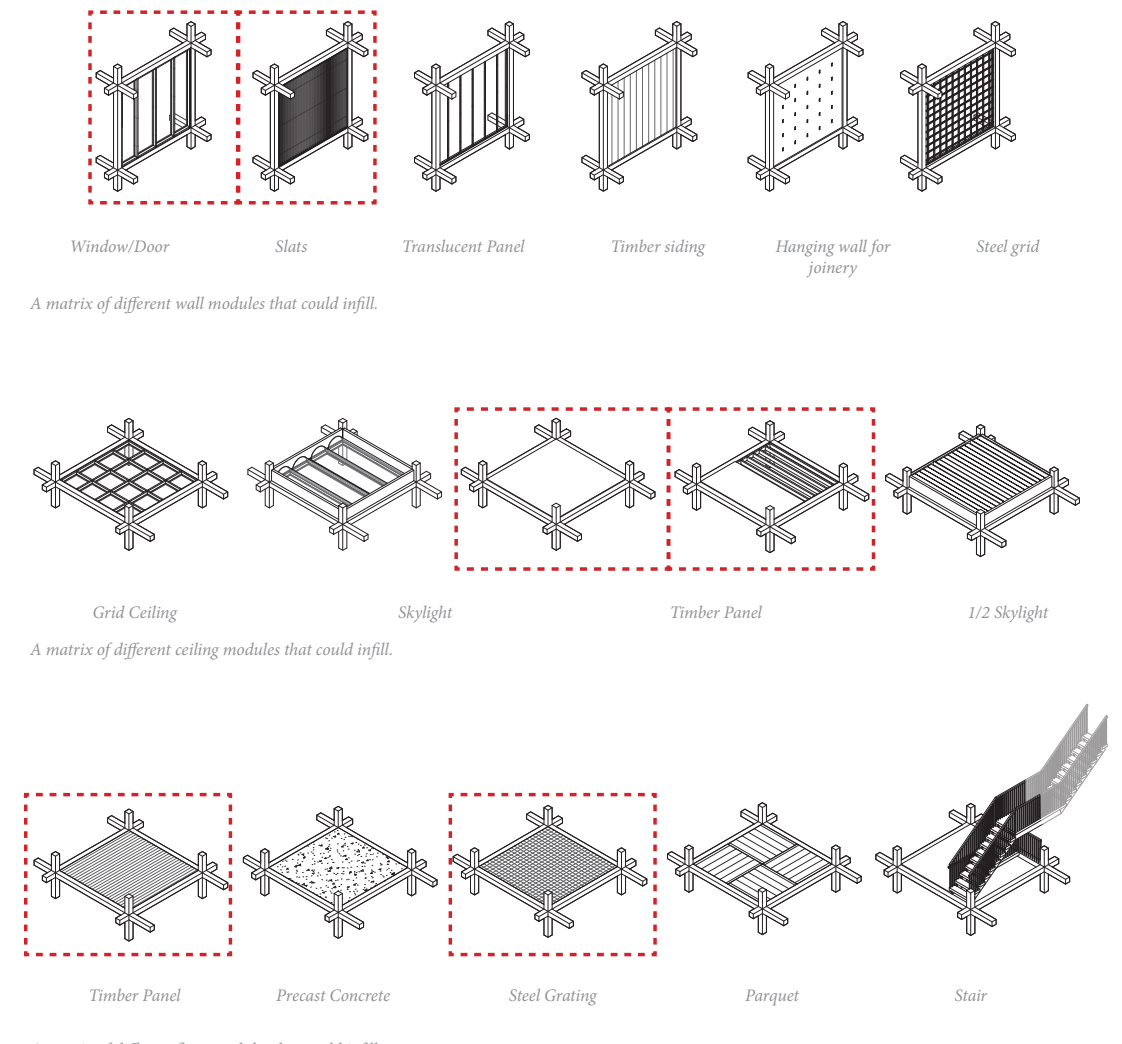

A matrix of different floor modules that could infill.

$\wedge$

A matrix of differing potential options for infill elements. Those highlighted were rationalised into a $3 \times 3$ module configuration and refined for the following physical model 


\section{OBSERVING SURROUNDS}

The following design iterations build on the kit of parts to rationalise the relationship between interior and exterior of the building. The interiority of the building until this stage was limited to planning iterations for the programme, enabling visitors to observe the landscape by looking at it visually, rather than experiencing it. While locating and noting locations of landscape elements helped to inform the building's general structural form, changes in the landscape as a process over time were not considered.

Glenn Murcutt highlights how these continued processes rationalise the interior of his designed spaces. "One designs buildings to perceive the changing light levels, temperatures, wind patterns, and sun positions; to perceive all these things so that the building performs as an instrument of the cycles of the day and year" (Davidson 32). Murcutt explains poetically that how people experience the environment is at the heart of his stance on understanding it. "Today, many of us wake up in our air-conditioned houses, drive to work in our air-conditioned vehicles; we look at the TV news to see what the weather is like rather than experiencing it." Citing an alienation from our environment, he argues that "we have resorted to instruments of all kinds to measure the environment's physical aspects, ignoring its psychological aspects" (31).

Murcutt's method of sketching his observations provides a wealth of insight into the site and how people use architecture to experience physical landscape qualities: Dates, angles, and times are noted. Sun shading diagrams highlight changes over time and ventilation diagrams highlight how predominant winds will move through spaces or are impeded by purposeful shaders in the summertime.

In considering methods for resolving the interiority of the building, similarly to Murcutt, sketch and modelling based iterations considered these deeper time-based measurements of the site to rationalise the modular infill panels used. As a result, allowing visitors to observe through physically experiencing into the landscape's changing conditions.

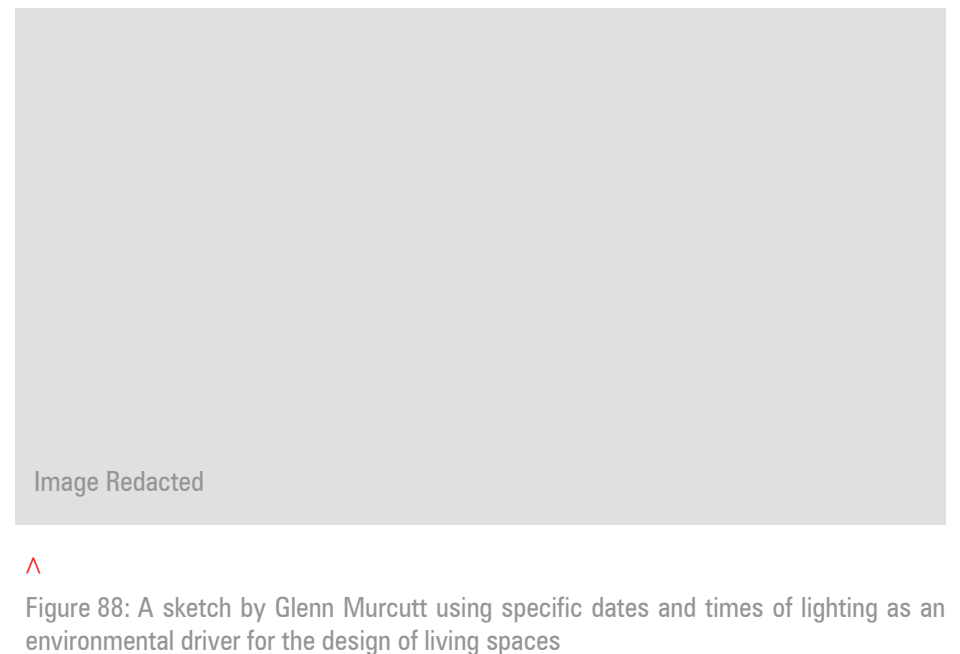

environmental driver for the design of living spaces 


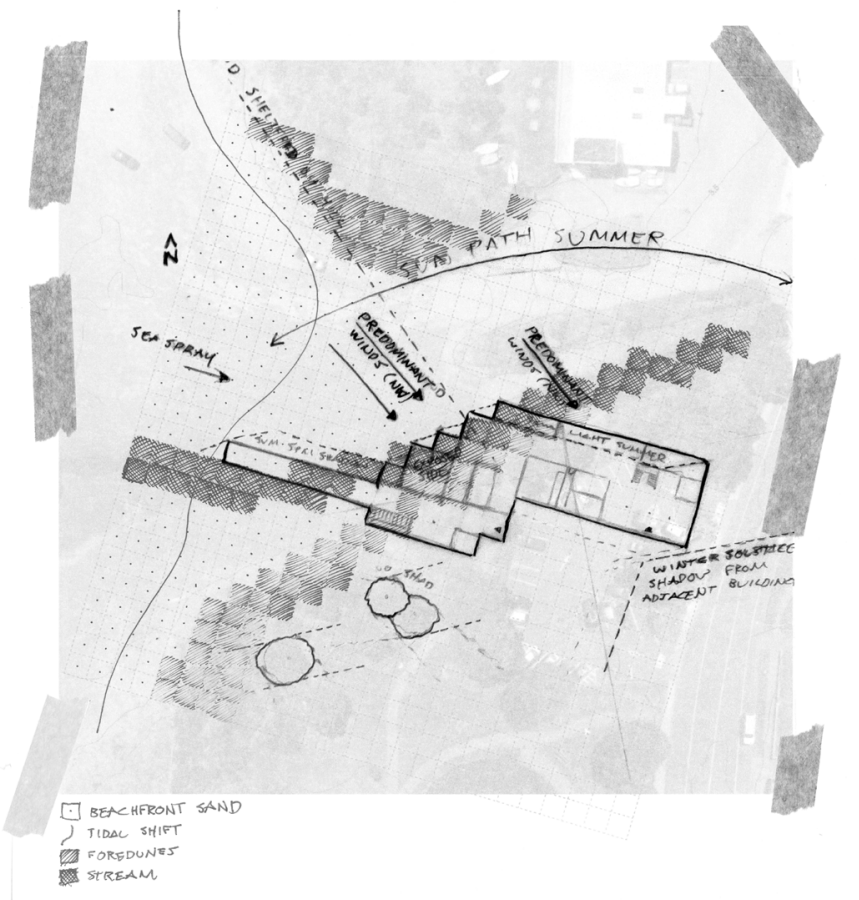

$\wedge$

Figure 89: Noting down differing environmental conditions such as predominant winds, sea spray, movement of the sun and tree shading to inform and rationalise the interior and exterior choices of infill panels for The Design

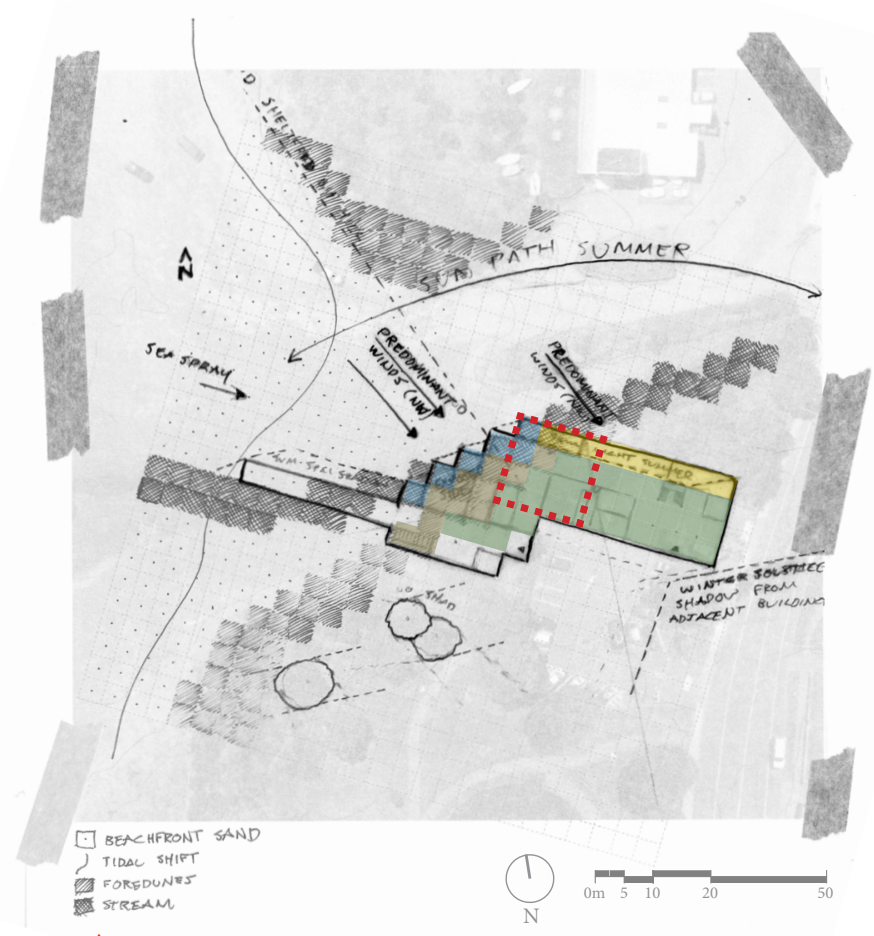

$\wedge$

Figure 90: Highlighting a 'typical' area of the building to model iterations of the interior space. This $4 \times 4$ section of the building experiences many differing environmental conditions, such as wind exposure, stream and dune exposure. Infill panels were chosen to respond most appropriately to the surrounding environmental condition. 


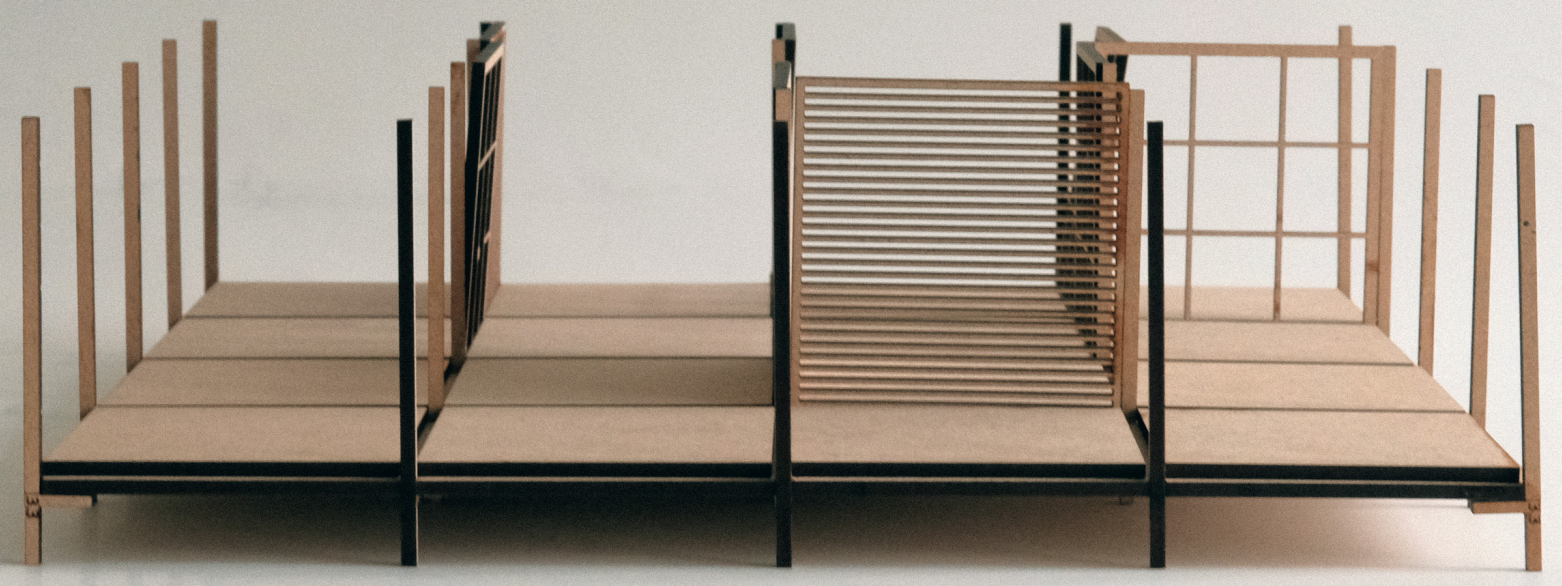



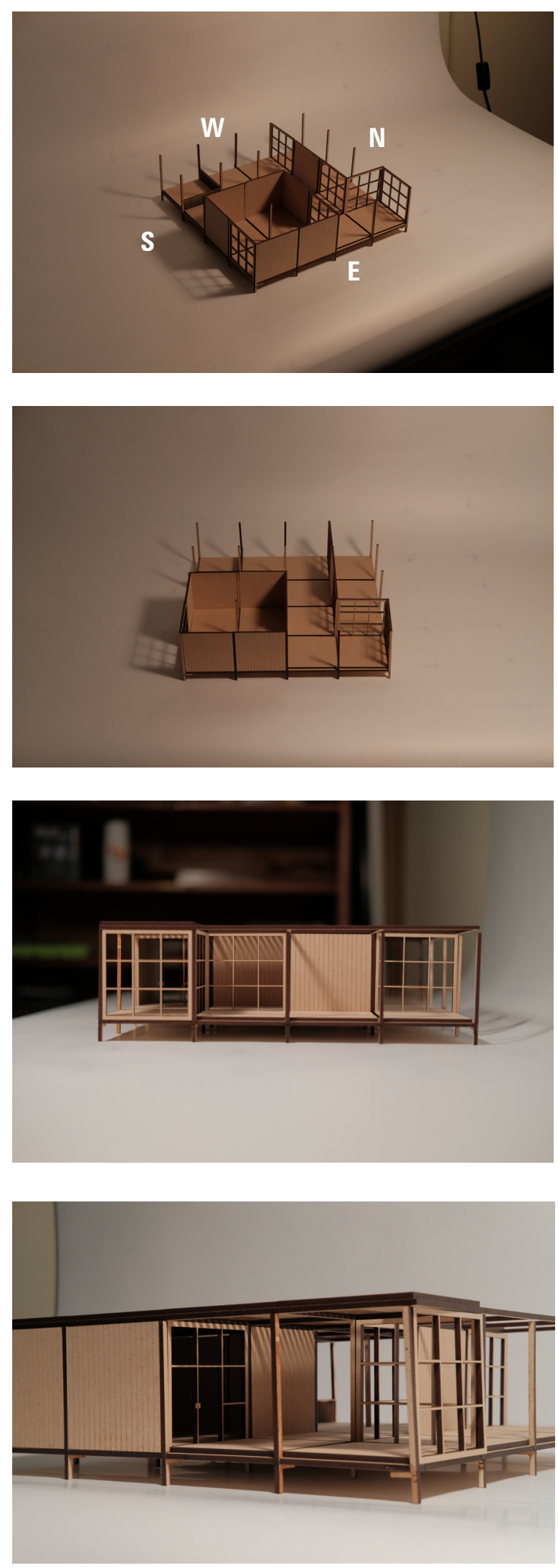

$\wedge$

Figure 92: A speculative model of a $4 \times 43600 \mathrm{~mm}$ gridded area of the building. The interior remains enclosed from exterior. It responds little to the landscape other than a glazed northern façade 

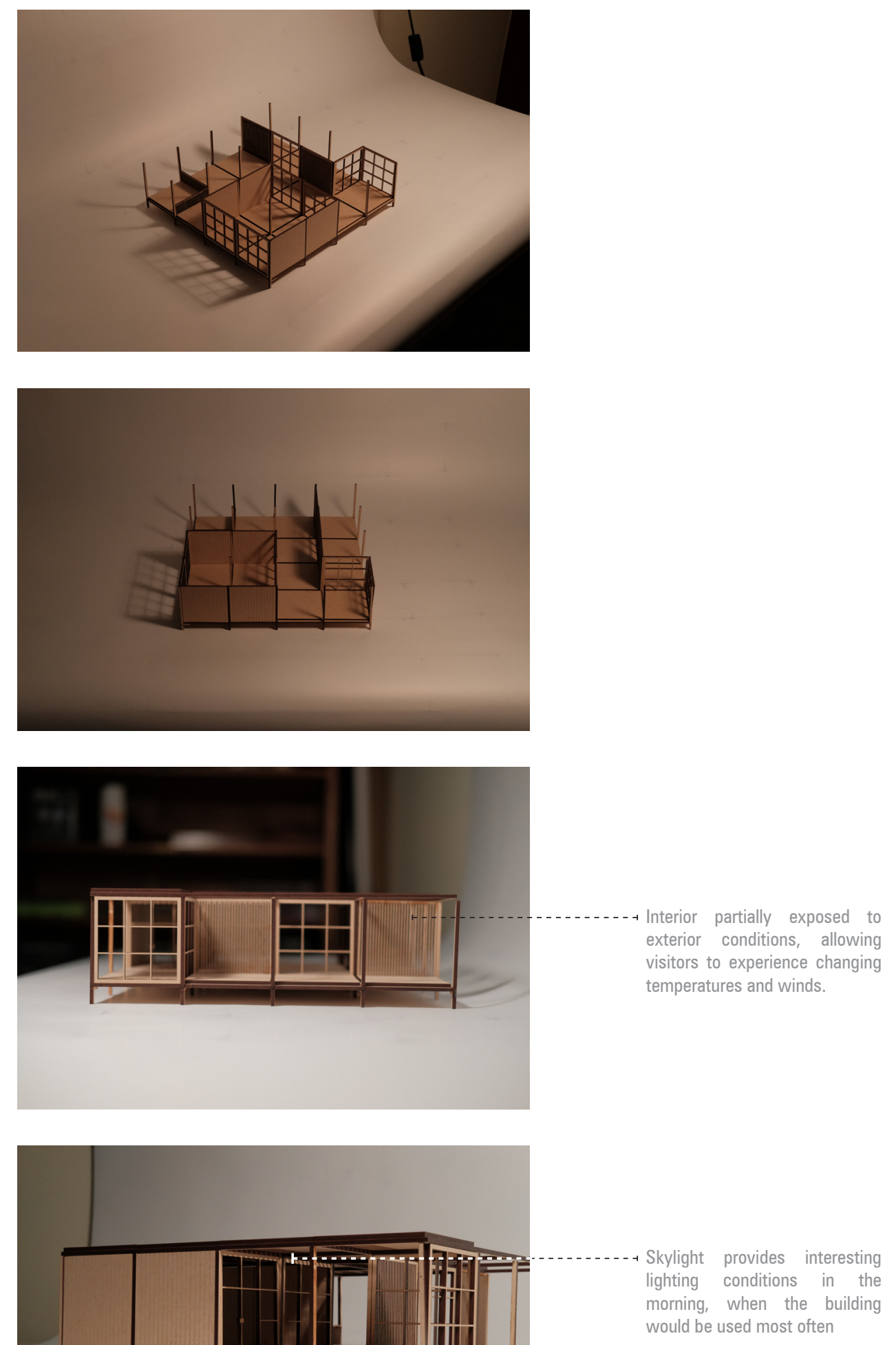

Figure 93: In this iteration, the interior is partially enclosed on the northern façade 
Theatre space fully enclosed

to find a balance between exposing visitors to perceive the surrounding environment, and offering protection from the elements for areas where they will be stationary
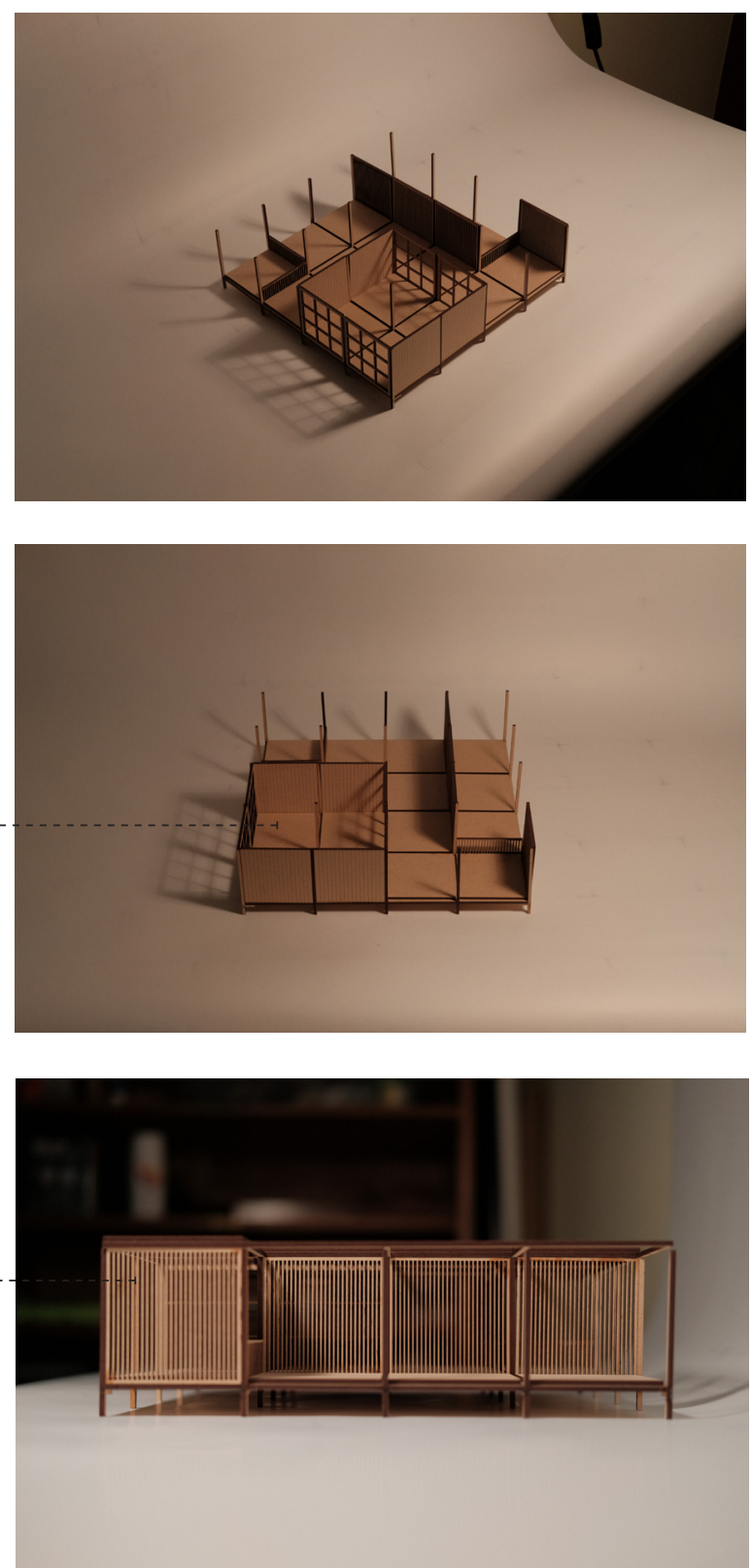

Interior fully exposed to external environment on northern facade,

allowing visitors to experience predominant northern winds

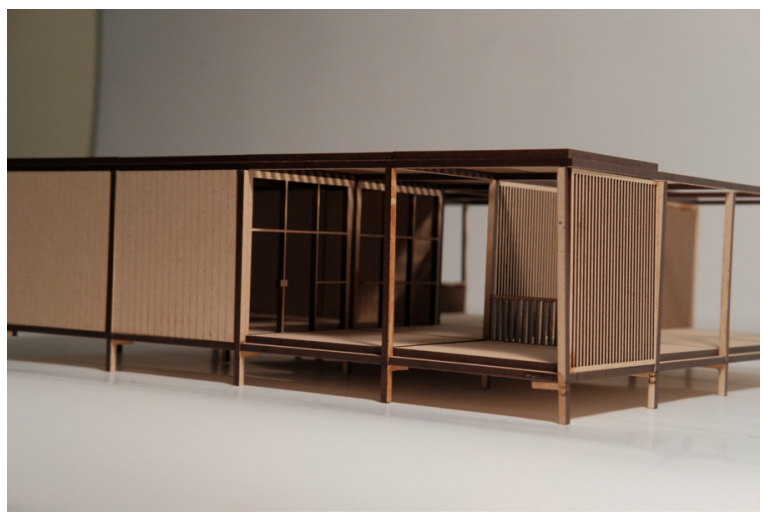

Figure 94: In this iteration, the northern facade is fully exposed, allowing visitors to experience the changing conditions. The central room (minitheatre) becomes fully enclosed, balancing between exposure and enclosure 

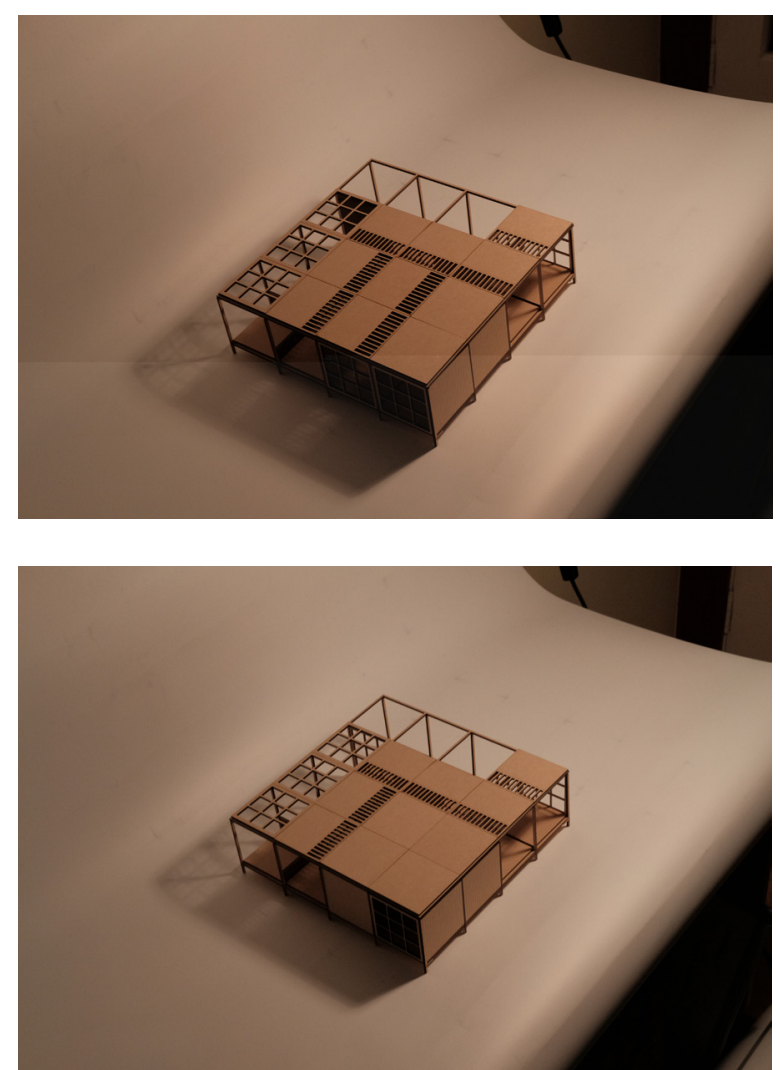

Figure 95: Differing skylight iterations, the second allows light in specifically to the mini theatre space, which would be used at 8:30am in the morning. 


\title{
CASE STUDY: ST ANDREWS BEACH HOUSE
}

\author{
Sean Godsell Architects | St Andrews Beach, VIC, Australia | 2006
}

St Andrew's Beach House is located on a beach exposed to gale winds and ocean views. It has a series of layers of skins of oxidised steel which form Soleil shutters, that act as a filter between exterior and interior, allowing occupants to observe the external environment by breaking down interior and exterior boundaries.

To move between the series of rooms, the clients must go outside onto the partially enclosed promenade, thus being exposed to hot summer conditions and cool winter breezes. It is a rejection of the 22 degree Celsius home and office environment that many are accustomed to and serves to "remind occupants of their own frailty" (Australian Institute of Architects). This layering of building elements engages users with their surrounding environment, allowing them to observe it further as it changes over the course of the day, while simultaneously being selective over which elements are allowing this exposure to protect the home from extreme weather.

Similarly, the experiments test the notion of creating an ambiguity between interior and exterior Modular infill elements such as rain screens to environmentally expose visitors to the breeze, yet sections where visitors will be sitting for longer periods of time are kept sealed off within a core layer of the building. This includes the biosecurity area, bathrooms and theatre. Elsewhere, visitors are exposed to a variety of environmental conditions, experiencing the changes in temperature and weather over their time in the building.

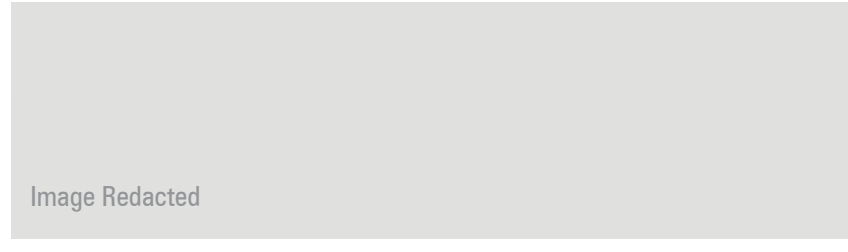

Figure 96: St Andrew's Beach House breaks down exterior and interior conditions, with an internal environmentally sealed layer, highlighted in red. The exterior promenade allows an element of exposure to the environmental conditions for its inhabitants, similarly to the design's northern façade. 


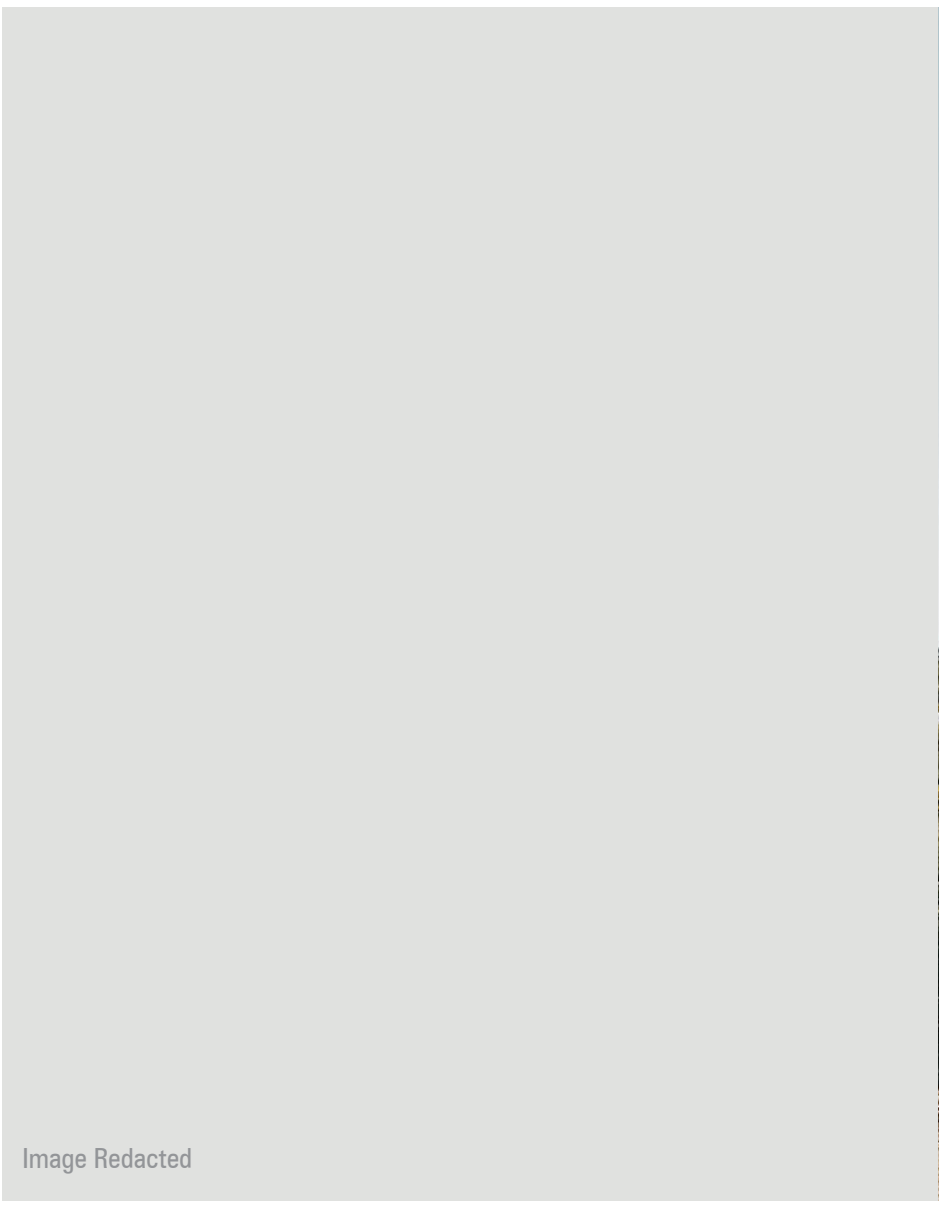

Figure 97: The building is lifted on piloti, with a singular and linear structure

$\wedge$

Figure 98: The exterior promenade - similarly to the design, utilising a steel screen to allow the breeze through 


\title{
CASE STUDY: MARIKA ALDERTON HOUSE
}

\author{
Glenn Murcutt | Yirrkala, NT, Australia | 1994
}

The Marika Alderton house is for an aboriginal client, whose culture has a longstanding relationship with nature in both practical, social and spiritual dimensions. The home is a long rectangular form, and its interiority is directly driven by the observation of the immediate landscape. The building is raised due to tidal surges, giving half a metre of protection. Open at both ends allowing prevailing winds to move through, long facades prevent excessive sun entry in the warm climate.

There is no glass within the building, as only a series of timber flaps allow the house to be opened and closed away from the elements, allowing modulation of the temperature and light. Open flooring allows sand to drop through and cool air to rise through the building, again modulating the boundary condition between interior and exterior.
Observation of landscape dictated the planning too. Unlike Godsell's Beach House, the Marika Alderton House features adult's bedrooms on the west, and children's on the east, correlating with Aboriginal ideas that the way people occupy space is in relation to where the sun rises and sets (Beck and Cooper 133). An incredibly simple gesture, the house evokes a sense of fulfilling the root needs of humans, acting as a mediating shelter from the elements as well as a home.

Each of these projects highlights ways in which the close examination of environmental processes may be used as a design tool to drive the interior and exterior condition of the building, forming a captivating way beyond visuals for visitors to observe through physically experiencing their surrounds.

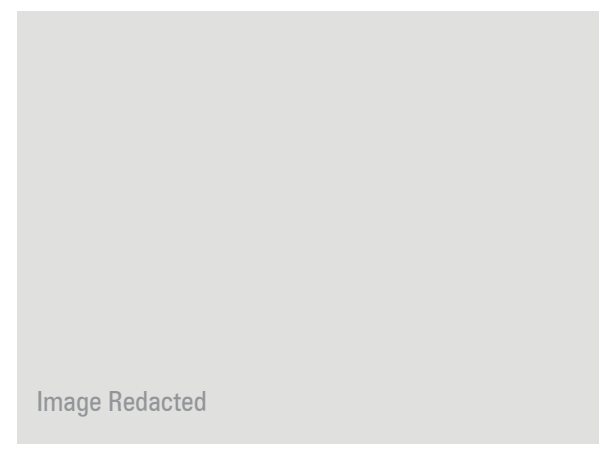

$\wedge$

Figure 99: Red highlights the operable shutters on the building to allow the environment in or shut it out

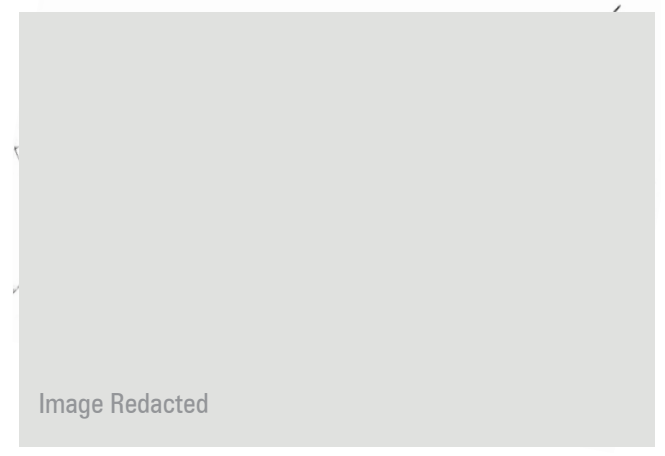

$\wedge$

Figure 100: Murcutt utilises detailed notes of angles of the sun, wind conditions, air flow and ambient temperatures to rationalise the positioning of almost all elements on the building. The Design similarly utilises this method to rationalise what panels to use in the building based on the surrounding conditions 


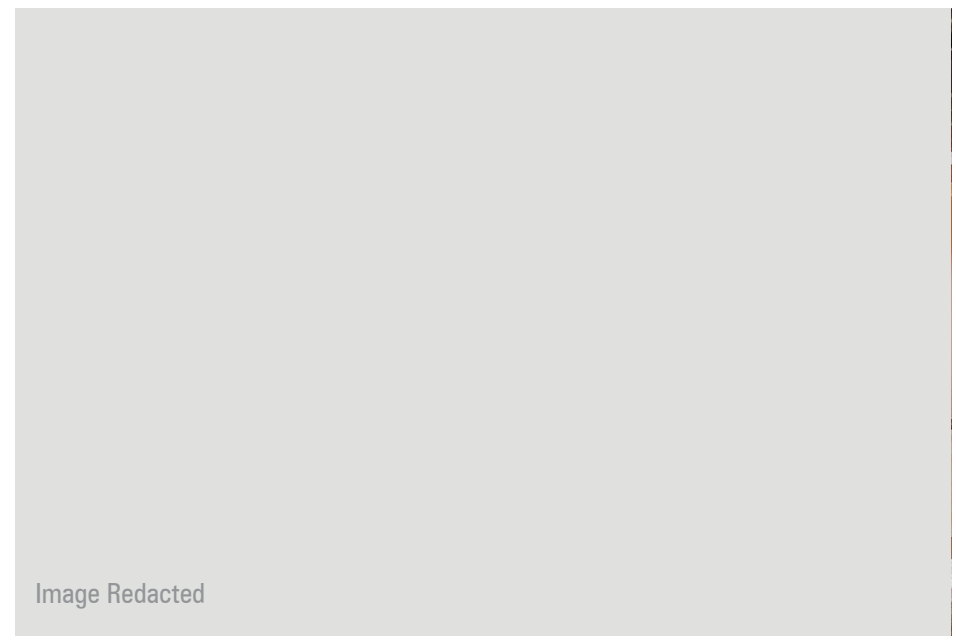

$\wedge$

Figure 101: Glenn Murcutt's responds to the flood plains below as it is lifted above the ground to protect the structure

$\wedge$

Figure 102: The interior responds to the surrounding environment by allowing a high degree of configurability to openings and shutters, so the client can modulate the interior space's lighting and temperature 
REDUCING IMPACT

The previous design enquiries addressed the need for the to engage in a more meaningful manner with the site, using the observation of landscape processes such as lighting, winds, the stream and the dunes as a tool to inform the form and spatial qualities of the interior. Despite an overall reduction in the overall size of the building in 'Building with Sympathy', The Design's placement still impedes dune movements.

In embracing the temporality and changes of the landscape as the driving force in design iterations, the landscape should move as naturally and fluidly as possible. By allowing processes to occur unabated, the static grid structure acts as a framework over which the landscape can freely move, thus forming an indication and point of reference against its movements.

A concern in this sense was how the building physically touched or impeded the dune's movements. Architect and Professor Toma Berlanda describes the process of separating building from landscape as one way for designers to allow the freedom of landscape below:

"Lifting the building on punctual supports suggests the impression of leaving the earth's crust almost intact" (Berlanda 48). In doing this "the attention for the physical qualities of the ground" pushes architects and designers towards investigating interventions that are respectful of the site, and can "accelerate its dynamic and continuous transformation". The strategies that result from this focus on both minimising impact and soil excavation, as well as emphasising the "...ongoing processes, projecting them in new directions"(57).

Therefore, this experiment looks at how the building form can become more autonomous from the shifting landscape, allowing movements to occur freely. It cuts the structure off from the environment below, but situated just above the foredune, remains at a height so as not to completely divorce the building's relationship to the ground.

In conjunction with this experiment, the form was slowly dissolved to reduce the impact of the building's overall size on the site's processes. By slowly cutting the excess structure and wasted space, the building becomes more proportionally pleasing and has less physical site impact. This allows for more landscape and dune movement and more opportunities to observe the site changing against the static structure. 


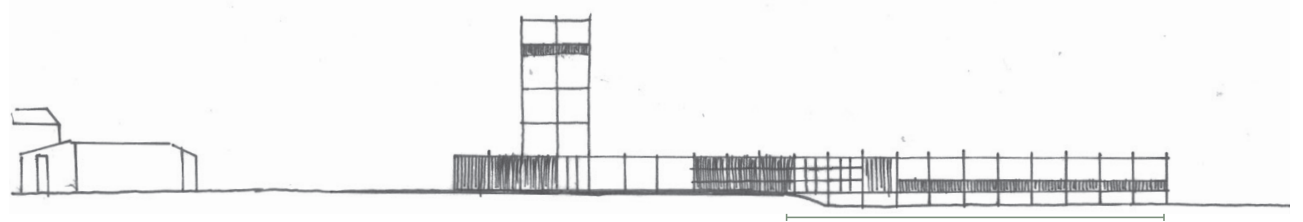

Pier Lifted

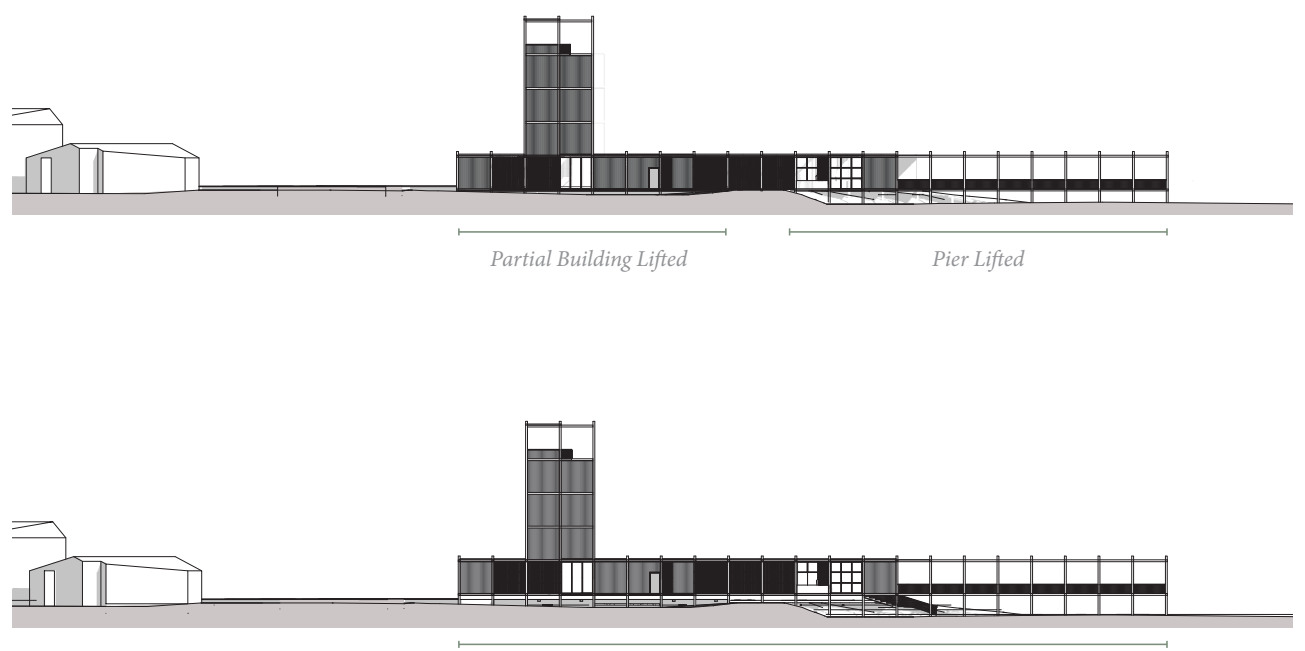

Full Building Lifted above landscape to allow free movement of dune

Figure 103: A series of elevations test how best to interact with the dune, settling on lifting the building off the landscape for its full length to allow

free movement of the dunes and reveal the landscape below. The moves

are subtle, but given the delicate nature of the dune, make a large impact 


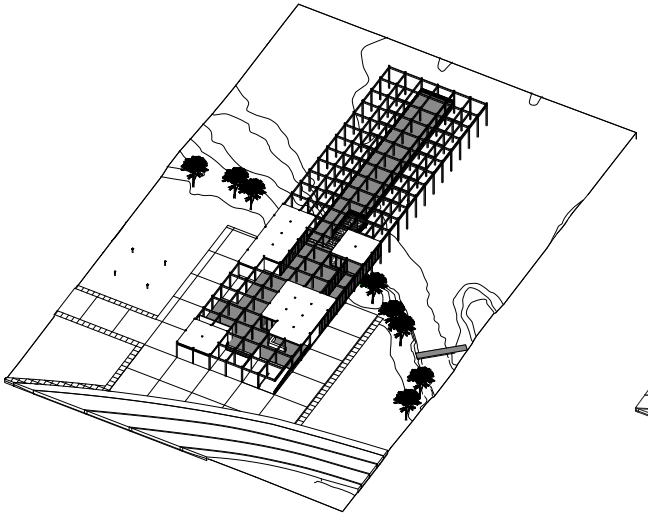

CURRENT

$21.6 \mathrm{~m} \times 86 \mathrm{~m}$ timber grid structure has large site impact

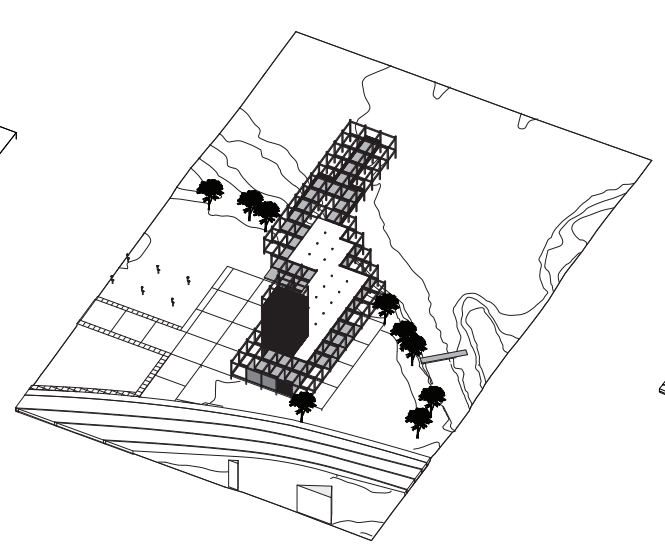

DISSOLVE

Disolving form across park/beach threshold

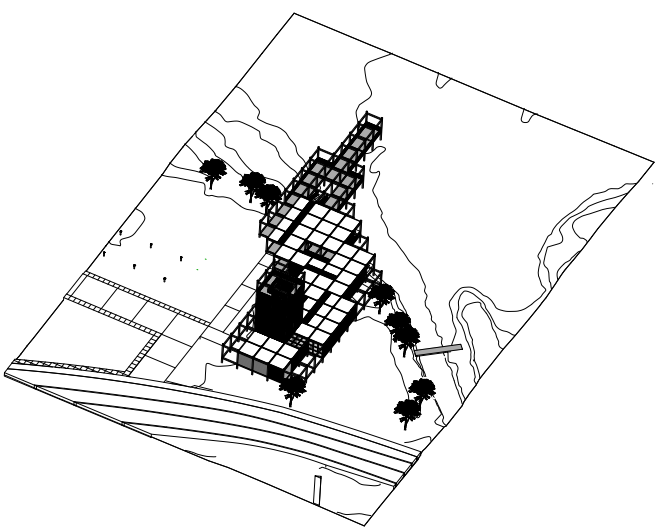

REDUCE

Disolving pier form and ending 


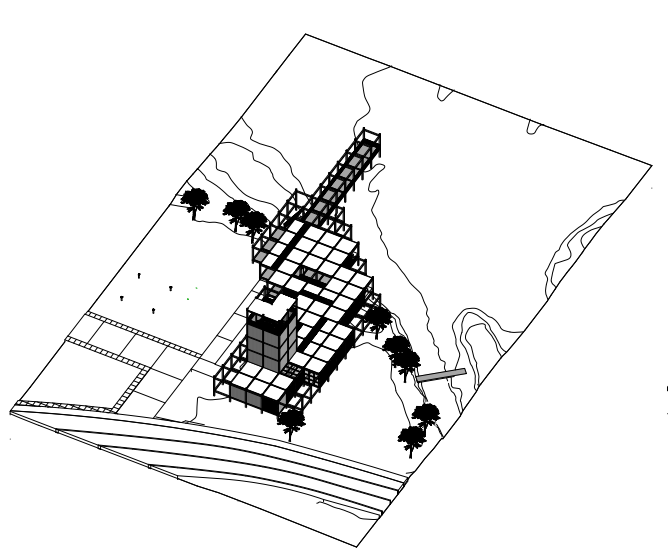

REDUCE

Further reducing excessive pier framing

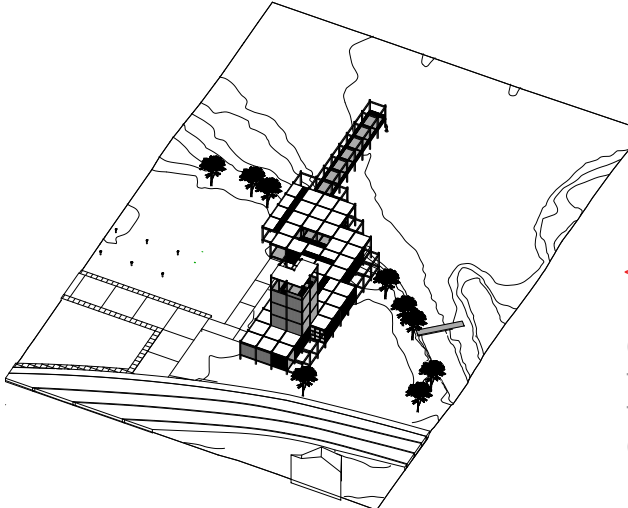

Figure 104: Form iterations test how to reduce the overbuilt grid structure on the landscape. Reducing and narrowing the building proved successful in not physically impacting the site heavily, whilst retaining the architectural language of the open grid structural framework 


\title{
LANDSCAPE: MEASURING PROCESS
}

\author{
“...landscape architecture is a work in process, \\ never really attaining an ideal state at any moment \\ in time, but always exceeding expectations when \\ set in motion over time" (Corner et al. 9)
}

The actual flora on the site itself was a constant factor in the design process. Over time, due to the flattening of dunes to make way for carparks, playgrounds and urban features, natural dune grasses and riparian zones had given way to predominantly concrete and planted grassy fields.

In comparison to hard protection structures currently existing nearby such as seawalls and groins, the following set of design experiments investigates how best to utilise soft planting to further encourage movement and natural protection of the dunes, whether by planting curved forms akin to the current topography or with a rigorous grid more fitting to the building frame.

By extending native planning of the dunes and further into the park, this encourages a further revealing of natural site movements as a process over time.
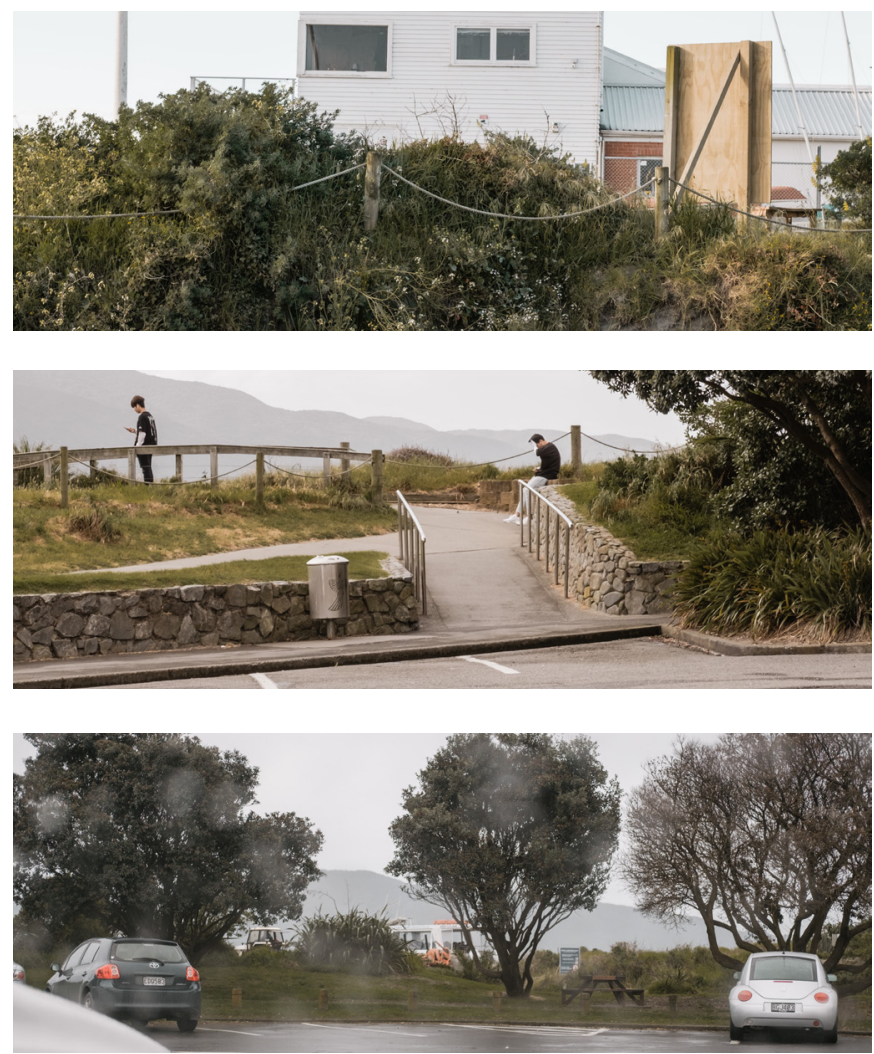

Figure 105: Observing the typical planting of dunes across MacLean Park, varying from poorly planted, to completely flattened, to small sections of regenerative planting. 


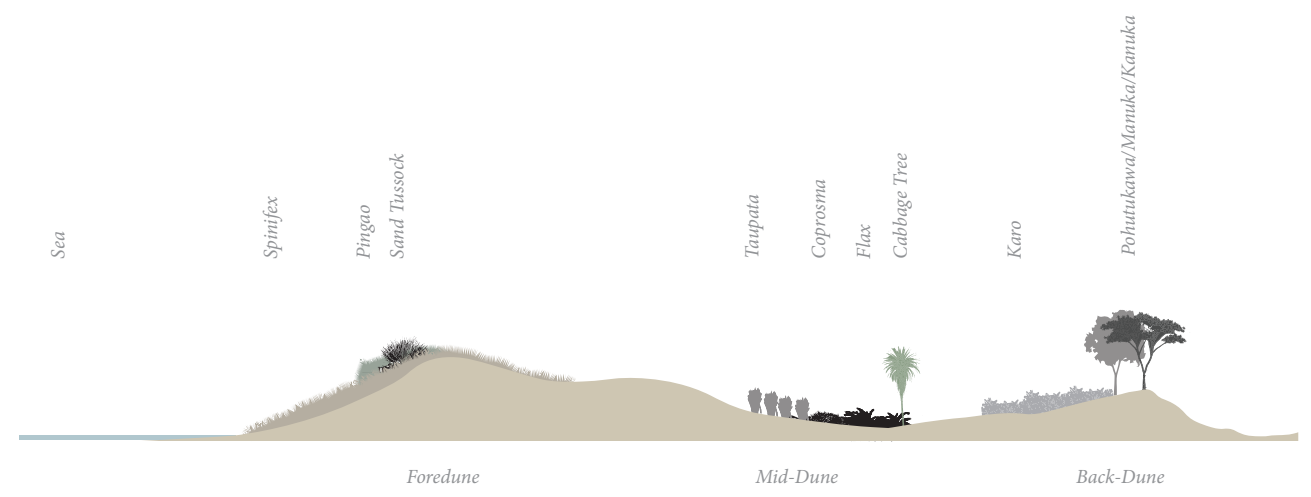

$\wedge$

Figure 106: A typical natural planting of dunes to encourage free movement and natural resilience

THE EXISTING PLANTING

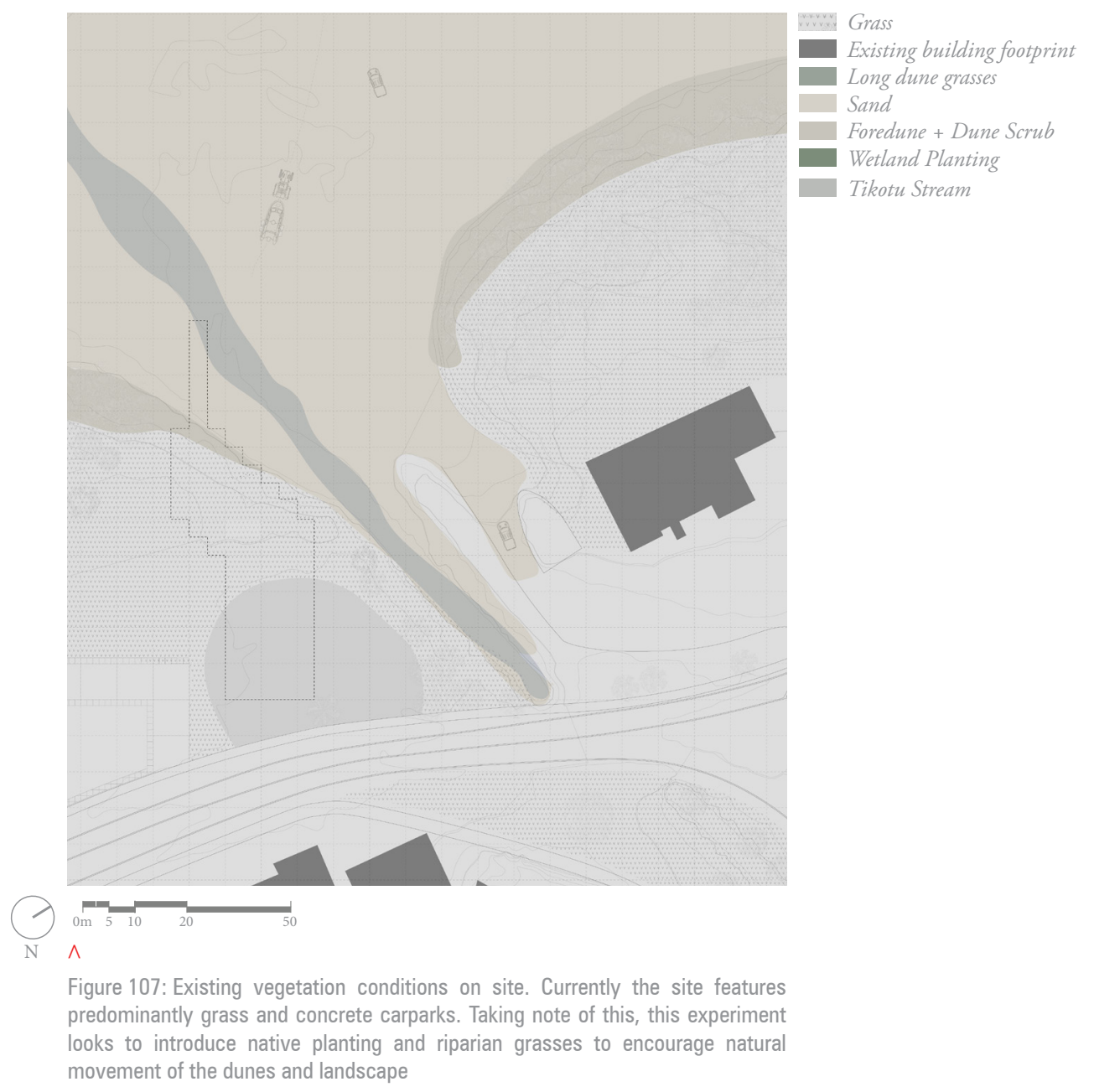




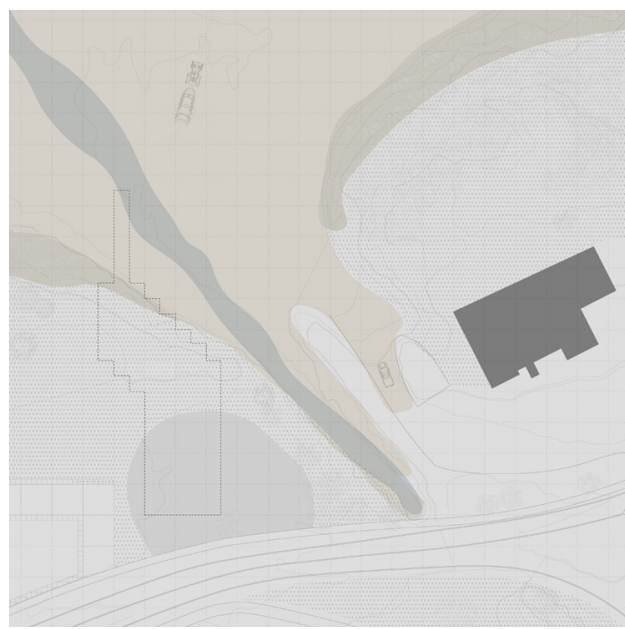

EXISTING

Existing vegetation and planting conditions on site

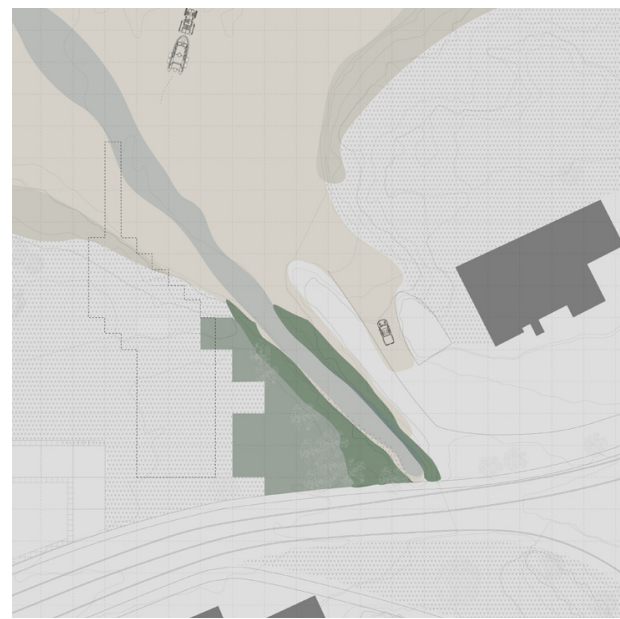

SITE GRID AS LIMIT

Long grass + wetland planting defined by site grid to fit the architectural language of the building

Figure 108: A series of testing how to plant the context. Following the established grid was tested against mimicking the curving topography of the site, noting how this interacts with the building form

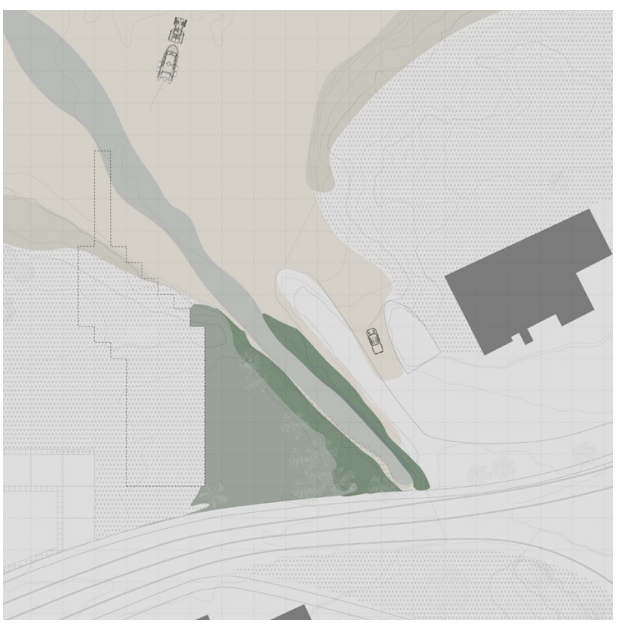

BUILDING AS LIMIT

Native long grass + wetland planting defined by building edges

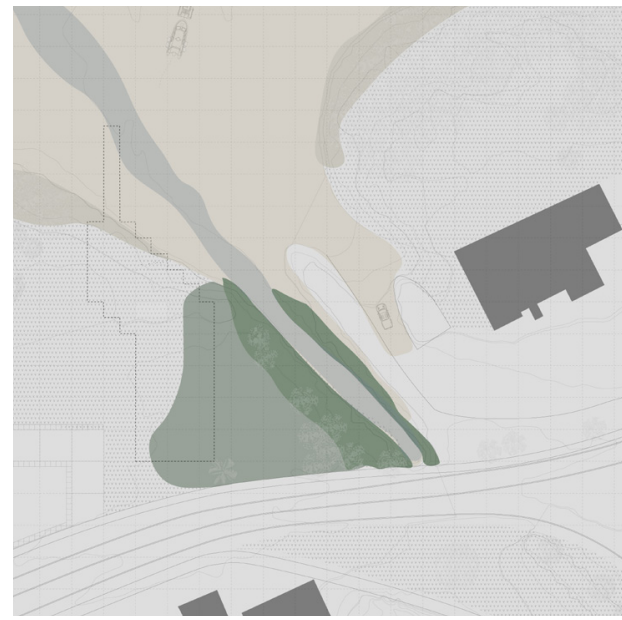

BLENDING LANDSCAPE AND BUILDING

Planting through building partially 


\section{MERGING LANDSCAPE AND BUILDING}

The experiment blurs between the building framework and landscape, using typical natural plantings to protect the dune and allow for the landscape and its process to begin to build a closer relationship with the building. Following the previous planting diagram, the iterations utilise the Tikotu Stream as a potential wetland and allow the natural curvature of the planting to interact with the building, encouraging an equilibrium between the orthogonality of the grid and the landscape beyond. Access walkways lifted on piloti move through the grasses to meet the entranceway to allow the landscape to advance unimpeded beneath the structure.

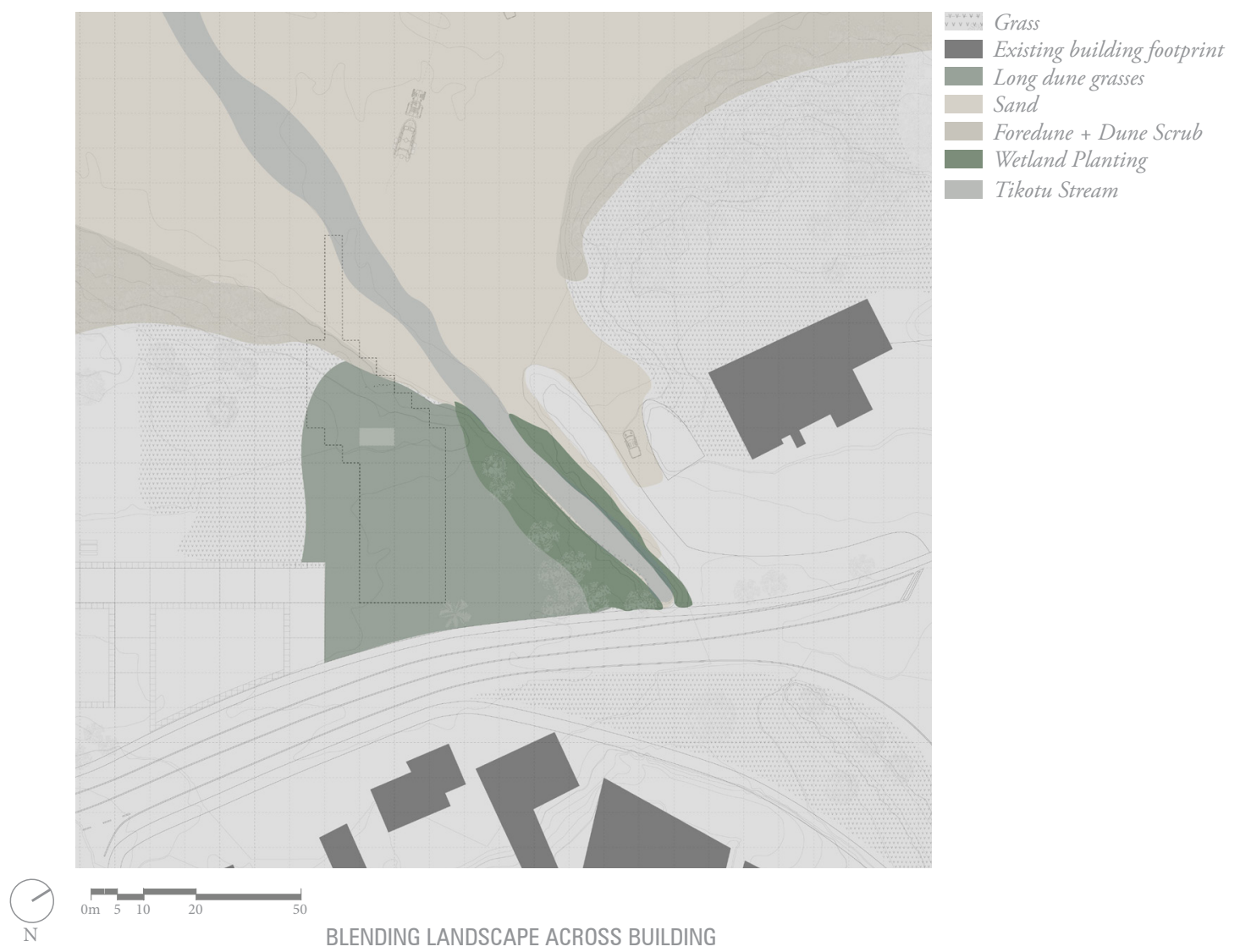

Figure 109: Planting dune grasses under the entirety of the building and into the adjacent park will strengthen the foredune and promote the natural movements of the dune and landscape. This planting could also promote an interaction between the growth of grasses and the building above 


\title{
GROWING INTO THE BUILDING
}

\author{
"The thing about the building... the essence of \\ this building is that you're leaving, it's a corridor \\ and it goes to God knows where. Your planning, \\ wouldn't you want a continuous process? ... It \\ seems like more of a corridor ... Get the drive of \\ the building" (Academic Reviewer, August 2017)
}

The diagrammatic orthogonal planning of the building produced 'dead space' devoid of programme in several places and illegible wayfinding. In response, apertures are created in the floor plate to allow for observation of the flora growing below, in keeping with previous iterations attempting to break down the interior-exterior boundary.

Further plan refinements introduce gratings, through which dune grasses can grow. These openings and gratings provide educational opportunities programme-wise, as well as providing a more regimented, processional wayfinding along the building's length to the biosecurity checking point and pier.

By creating a condition where growth occurs into the building, the effect is twofold. In one sense, the spaces and atmosphere are softened by the introduction of natural features to break up the strongly orthogonal interior, and importantly, the grid and gratings provide a comparative point of reference by which people can see, experience and measure the growth of natural features over time within the building itself.

Figure 110: Floor apertures allow dunes and grasses to grow through the building, registering site movements in a poetic manner against the static structure 

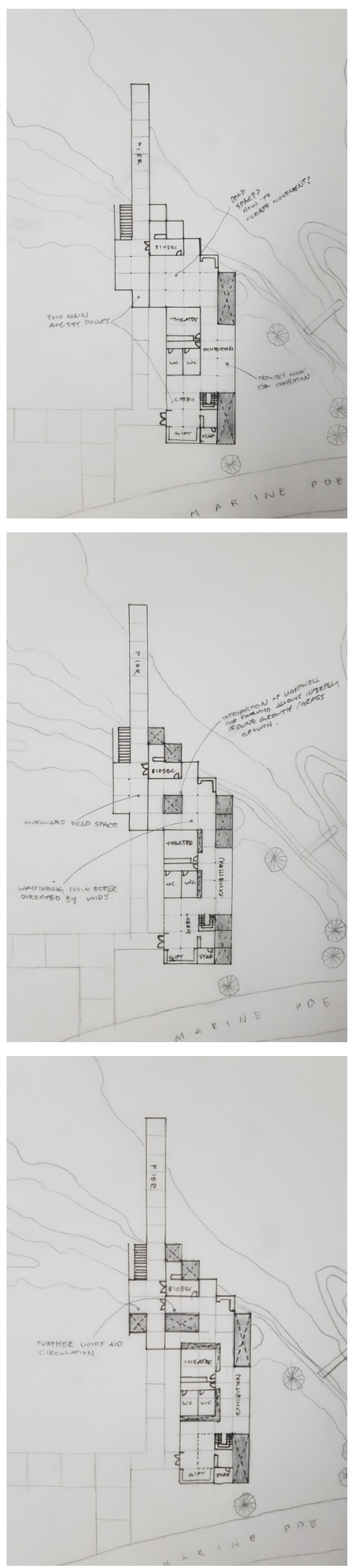


\section{CASE STUDY: DUTCHESS COUNTY RESIDENCE GUEST HOUSE}

\section{Allied Works | New York, USA | 2007}

The use of natural growth through an exposed grid as a comparative measuring device is used in Dutchess County Residence Guest House. the house consists of an eight-inch steel structure which weaves towards the ground plane and upwards to the roof level of the house. This structure "edits and measures the forest", providing a "sense of boundary - held for a moment under the forest canopy, framing the changing light and seasons" (Cloepfil). Due to changes over the seasons in the region, during winter the house is covered in snow which fades away as summer nears, as grasses and plantings growing up and over the frame.

Similarly, The Design uses the interstitial space between the frames to act as a both a rational and somewhat poetic measure of growth, as dune grasses grow over the frame and into the spaces over time, forming an indication of their movements to visitors.

Figure 111: The Guest House is in a lush forest that experiences growth and recession over the seasons. The steel frame delineates the plants clearly 


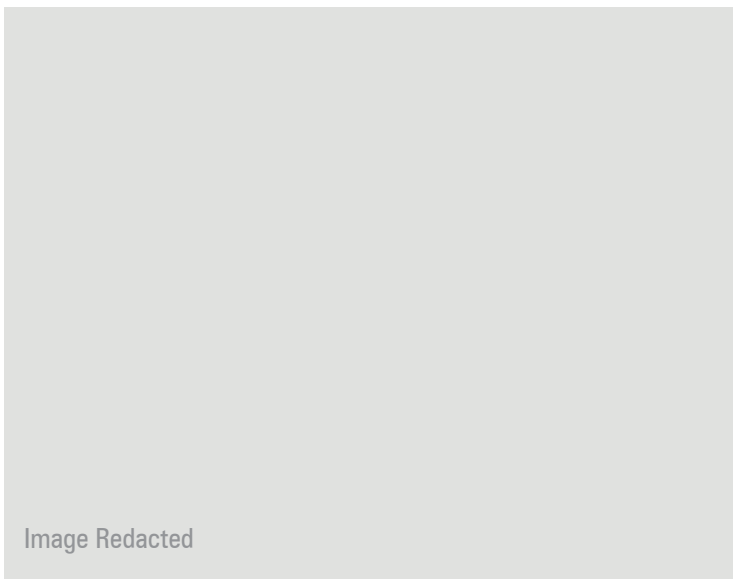

Figure 112: The steel frame provides a point of reference to measure changes in growth of the surrounding grasses against over the different seasons 
The building's exterior too would experience the temporality of site conditions due to site exposure. Against the prevailing sea spray and coastal conditions, wear and accelerated ageing on local buildings is evident, and this effect would be no different on the design.

One of the most poetic notions of the impact over time of an object is that of palimpsest. Palimpsest refers to an ongoing process or rewriting (Handa 11). It reflects how landscapes, buildings, materials and objects are layered, worn and added to through the passing of time. A metaphorical and poetic concept from the outset; it does provide a physical measure of impact. Handa argues that palimpsest also provides "visitors with a direct encounter with the physical aspects of architecture", for example, revealing the actual joints of stone blockwork once concealed on a wall over time (11). Palimpsest is common to landscape architecture too, as Duempelmann argues that landscape architects have often appropriated urban designer Kevin

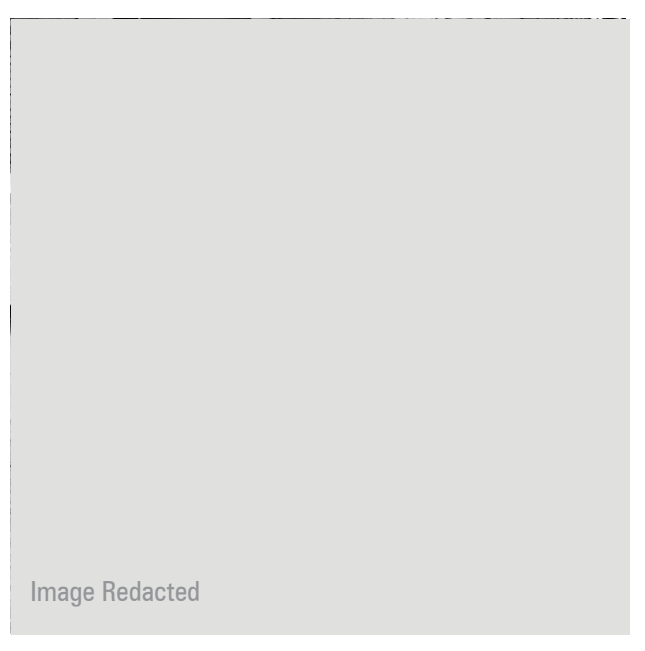

Figure 113: Carlo Scarpa's stairs within Fondazione Querini Stampalia measure the water which raises and lowers with the tides. Lower steps show larger amounts of wear, discolouration and algae growth over time, providing a physical measure
Lynch's ideas about designed environments as a 'temporal collage' for the working and reworking of an landscape (7).

To better understand how the environment would affect the exterior of the building, measurement studies of the building wearing over time simulated environmental changes to the integrity and colour of potential materials over the life-span of the building. The tendency for weathering steel to gain a deep hue, for example, would increase the overall visibility of the structure, while timber would tend to grey and soften the building's appearance over time - blending what is a relatively large structure into the surrounding environment.

These changes in appearance, in turn, become a form of metaphoric and poetic yet physical measure, helping the public to clearly and visibly understand the implications of the exposed coastal environment and landscape, recorded on the appearance of the built structure and layering over time.

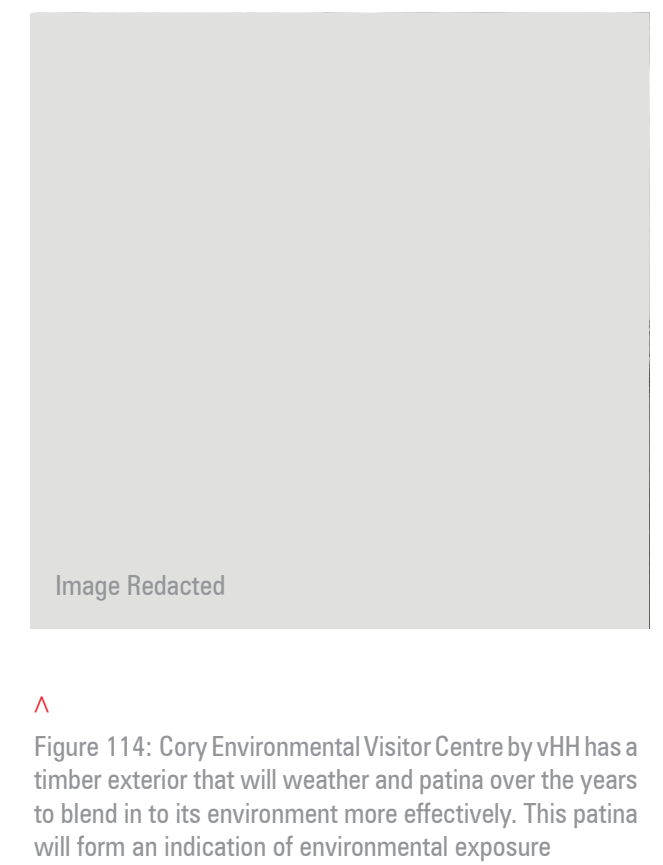




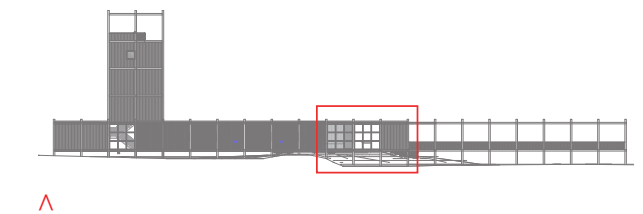

FIGURE: Location on the building of the design iterations

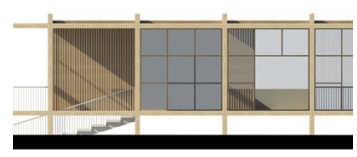

0 Years

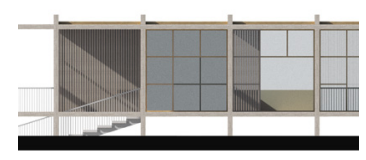

5 Years

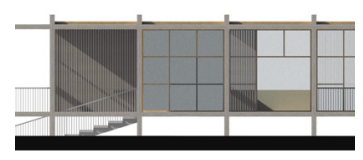

15 Years

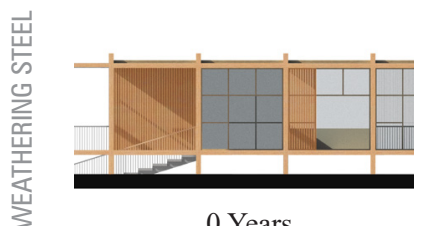

0 Years

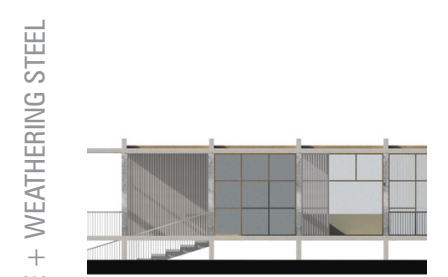

0 Years

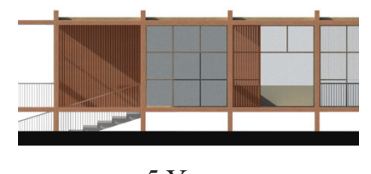

5 Years

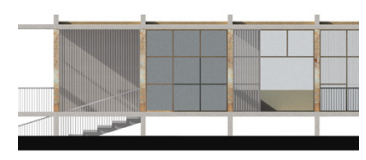

$<1$ Years
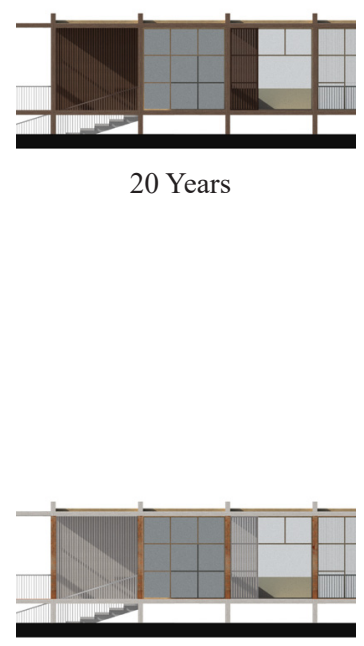

5 Years

Figure 115: Poetic material study into how the building with age and patina over time through material changes that are reflective of the surrounding environment. Time and temporality becomes a material. 


\section{OBSERVING: A CRITICAL REFLECTION}

Observing centred on design explorations that utilised closer observation of landscape processes as a design tool. At first, due to the spread-out and somewhat confusing nature of the previous chapter's design iterations, the design refocused on a singular gesture where the original objectives for the architecture to enable visitors to form an understanding of the site could be simplified.

After attempting to read the landscape, there was a tension between rational and poetic representations of the site and its movements. Literature affirmed that this tension is critical to the design, and a balance between the two approached was acknowledged and sought.

A new-found acceptance of the design's responsibility to be sensitive to the dynamics of site coincided with much of the thinking of contemporary architects and landscape architects, such as Ian McHarg, Sean Godsell and Glenn Murcutt. Their design methods, which observe the landscape as a tool to develop forms, interiors and boundaries, enabled a shift from the architecture enabling a rational measuring of historical data, to landscape being looked at as a fluid and temporal process, which visitors can both observe and immerse themselves in as a means of experiencing a changing environment.

This was achieved in 'Observing' by encouraging visual measuring, through the use of the grid as a point of reference for landscape movements. An experiential observation of the landscape process was of importance too, through the encouragement of natural landscape growth and a breaking down of interior and exterior boundaries to allow visitors to observe. The potential of palimpsest was noted too - a somewhat poetic notion of building change due to exposure to the environment, forming a visual guage of the changing landscape's effects on the building over time.

The shift from measurement and observation of site as a representational tool alone towards a closer observation and measurement acting as a design tool resulted in architectural forms which responded more effectively to site topography and processes, while simultaneously allowing opportunities for both education and observation of the landscape's movements over time.
Figure 116: The stages of the 'Observing' chapter towards a site responsive architectural response utilising measurement and observation over time both visually and as a design tool. 

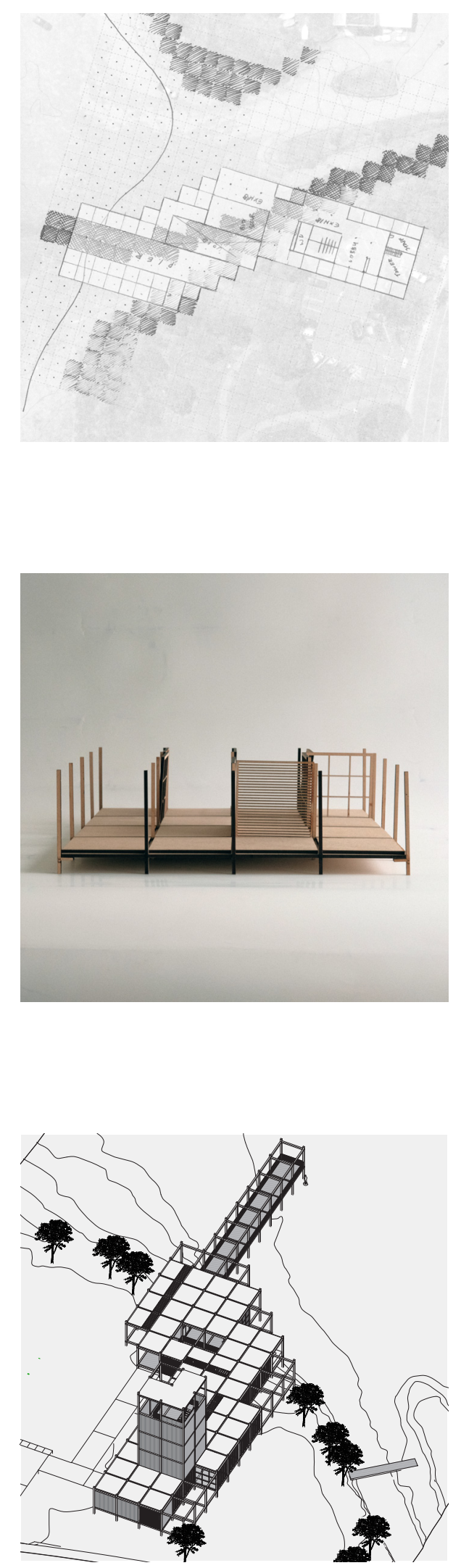
6.01

OVERVIEW

6.02

LOOKING BACK: IN MAKING A MEASURE

6.03

IN CLOSING: A FUTURE TO OBSERVE 


\section{CONCLUSION}



OVERVIEW

This thesis considers architecture's ability to enable the public to take a measure of and observe changes in a dynamic coastal landscape with more clarity. Experiments explored form, landscape relationships, spatial qualities, materials and the effects of these over time as differing strategies to best achieve this, to varying degrees of success. Reflecting throughout the design process of this thesis, these experiments alluded to a broader personal and disciplinary issue that concerned 'rational' and 'poetic' representations of landscape and methods of measurement.

Composition and Geometry tracked a process of rational representations of measurement and observation. Registering examined the site in greater detail, uncovering a method of representing historical measurements of the site and as a result highlighted the tension between rational and poetic representation. Observing looked to inspect the site's processes deeply, embracing observation of site processes as an effective design tool, acknowledging a need for a balance between rational and poetic methods and representation in the design process.

These shifts in method and tensions are uncovered in detail through the experiments. In this chapter, they are summarised to reflect on the limitations and potential of developing an architectural intervention to measure and observe the landscape by. 
LOOKING BACK: IN MAKING A MEASURE

Made to Measure forms a site-specific response to the need for a Gateway Visitor's Centre for Kapiti Island. Rather than a heavy obtrusive building typical of coastal public buildings, it pushes for a light, modular, gridded structure on what is considered a delicate and dynamic site. Positioned on the edge of the foreshore, it looks to reinforce the importance of a collaborative relationship between architecture and the ecological systems that it sits upon, encouraging natural landscape processes to occur, unencumbered. By providing a static gridded framework as a point of reference nestled within a shifting landscape, Made to Measure allows the movements of this landscape over this structure to be observed more clearly by the public, intersecting and impacting it over time, creating a change that can be 'measured' and experienced.

Whilst it does not seek to make scientific insights by accurately measuring environmental change to extreme accuracies, it helps the public to form a deeper understanding of the landscape's general movements. Ultimately, The Design presents itself as an architectural strategy of how we could build in a site responsive manner to allow a closer observation of our dynamic coastal landscapes.

The research set out to examine the design-led process, then reflect upon its opportunities and limitations. Early experiments explored pure autonomous forms as an intuitive response to a dynamic landscape, and incoherent urban condition. Geometric forms and methods of composition created observation points and framing opportunities, to visually take measure of and observe the surrounding urban and natural landscape. While these early experiments did not provide a solution to form, the initial use of the grid as symbolising measurement identified its potential for further use as a design tool. With each enquiry, the rigid geometry and lack of sensitivity to the landscape was considered overbearing and dismissive of the surrounding context and landscape's identity. Case studies such as Dogma's Stop City and theory from Aureli highlighted that an autonomous, puritanical approach to form finding resulted in a 'limit' that was similarly dismissive of site. Measuring and observing the landscape at this stage became a purely visual, representational endeavour, failing to achieve a site specificity.

To combat these criticisms, 'Registering' investigated the observation of site as a landscape to be measured and read, historically. Experiments wrestled with how best to trace and represent site data within the interiority of the building. Earlier spatial interior based experiments took a rational approach, reading and representing site data as literal datums on the building's surface. Later experiments took a more atmospheric approach, with this data interpreted and represented in a manner akin to the Land-Art movement of the 70's which popularised a more poetic reading and representation of the landscape.

On a personal level, differentiating between the rational instrumental methods, and atmospheric experiments was one of the great difficulties encountered during the design process, and as a designer I felt at times that my more poetic interpretations and representations of the landscape did not align with an idea as scientifically oriented as measurement and observation. I discovered that the dialogue between these differing rational, and more poetic representations of reading the landscape are not uncommon to architectural practice, as Tom 


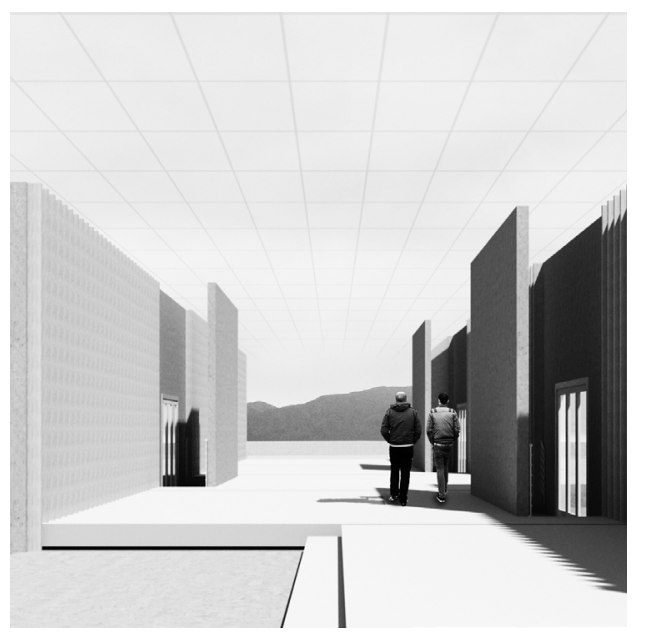

Figure 117: An early perspective, using order and composition techniques to visually observe and frame the landscape behind

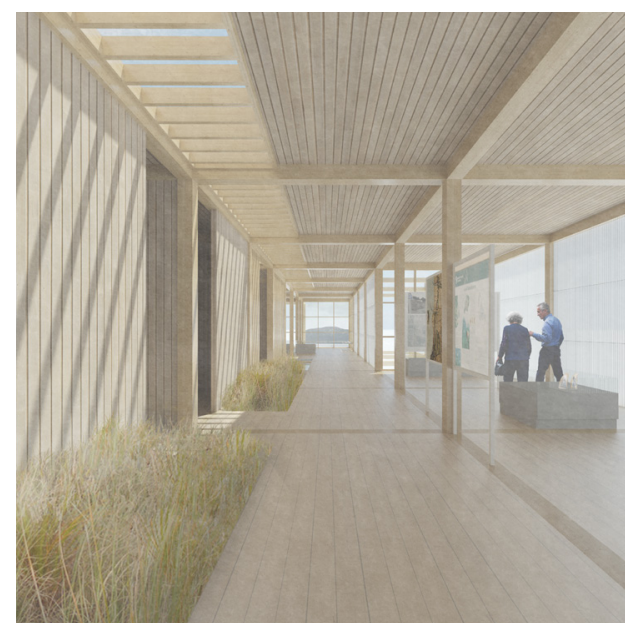

$\wedge$

Figure 118: A perspective looking towards the island through the Exhibition Space. This visually frames the island, as well as the interactivity between the building and landscape below it, which allows observation of growth and softens the linearity of the interior 
Berlanda argues:

"Regardless of how it is achieved, the exploration of a site is not a simple technical operation, nor does it end with the collection of quantitative data and objective elements, but rather requires a process of selection and interpretation, integrated with and inseparable from the design" (68).

This quote shows that the reading and representation of a site is not a solely instrumental and rational endeavour, and that the designer's interpretation of landscape in conjunction with the design process is critical to the design. Similarly, Glenn Murcutt argues that the dialogue between a rational and poetic representation is necessary to a design, stating that "it's very dangerous to have something which is romantic. It is also dangerous to have something which is just analytic" (Drew 79). So how can architecture enable one to measure and observe changes in the landscape in a manner that is balanced between rational representations and poetic metaphors?

With this in mind, and building upon the need for site specificity identified in 'Registering', the later 'Observing' chapter acknowledged that a shift towards an approach that took both the quantitative and the experiential into account was necessary for the ultimate success of the design. Taking a closer observation of the site's ongoing processes, meant the design responded far more effectively to its context. The grid became a rational design tool and a point of reference, through which changing qualities of the landscape could be quantified, with infill panels from a 'kit of parts' approach being rationalised by landscape qualities and enabling opportunities for the public to take measure. This approach was further informed by contemporary architects and landscape theorists such as Ian McHarg, Sean Godsell and Glenn Murcutt. Their design methods of quantifying and literally measuring these processes develops their site responsive architecture, helping to inform a shift towards acknowledging landscape as a temporal process, which architecture responds to in a collaborative manner.

Later developments also embraced the temporality of the dune and flora's movements against the static building as a way of forming a poetic measure too. Experiments achieved this by exploring how the landscape could move more freely by reducing, lifting and lightening the structure. Similarly poetic, the final experiments acknowledge material changes due to exposure over time, and broke down of boundaries between landscape and interior spaces so visitors could experience to understand the coastal conditions and site's movements.

The shift towards using the site's movements over time as the predominant design tool to inform material, form, interiority and tectonics informed a balanced and responsive approach between experiential and literal representations of the site, ultimately allowing not just an instrumental reading of the site for visitors, but a chance for them to physically engage with its movements and effects over time. 


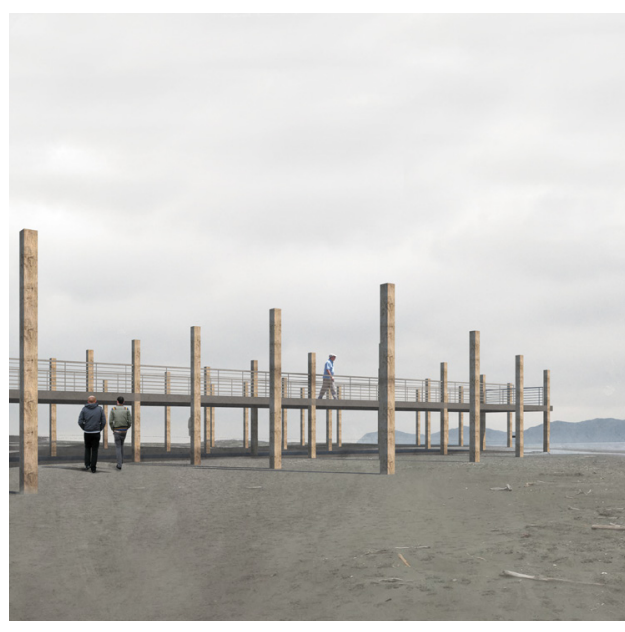

Figure 119: An early perspective of a grid of stelae acting as an architectural device to indicate the movements of the adjacent stream

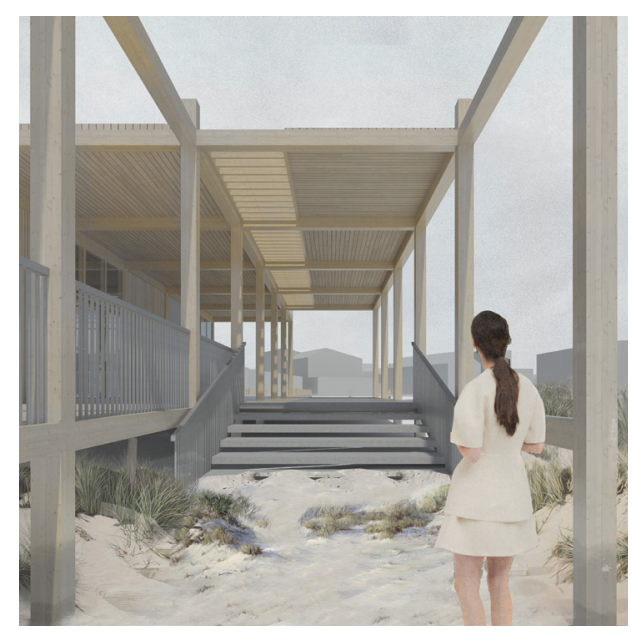

$\wedge$

Figure 120: A perspective of The Design. The changing environment can be read on the structure by the wear, patina and covering of the materials by the landscape over time 


\subsection{3}

\section{LOOKING FORWARD: A FUTURE TO OBSERVE}

Through the design process, a series of tensions in the design process came to the forefront. The tensions underlined the dynamic between rational and poetic readings of the landscape in the search for architectural strategies capable of:

1. An architectural language, material palette and system that can enable the public to observe and measure the changing environment, and enhance the public's ability form a closer understanding of the landscape

2. Imagining how architecture may engage with this dynamic site, enhancing the qualities of the visitor's experience of both the landscape and the public Gateway Centre.

These tensions and challenges resulted in further exploration of new ways that architecture could enable a reading the landscape that were not envisaged from the outset of this study. Throughout, I was challenged by how form, interiority, spatial qualities and metaphoric representations could enable this. The early experiments, despite wishing to allow an 'observation' of the site, ironically did not observe it or 'take measure' closely at all beyond a visual and representational manner. It was not until a closer observation of the site's processes took place that the design began to enable an understanding and 'feeling' for the landscape by forming a collaborative relationship with it, blurring the boundaries between the structure and its surrounds. On a disciplinary level, this reinforces Berlanda's argument that the notion of how designers 'take measure' of the site themselves is critical to the design process:
The discovery of the terrain through its direct survey is a decisive moment in any design process, upon which intuition and invention might have different influences but interact nevertheless. Measuring, describing, and representing the features of a site are necessary operations to know, and hence to transform it. By completing these actions the architect operates as some sort of topographer or surveyor. The very act of walking, to measure and explore a terrain, is a rite practised by many architects and is considered in and of itself a component of the creative process (Berlanda 67).

The earlier experiments attempted to fulfil this argument. They also epitomised the struggle with the describing and representing of site in the quote. The architectural act of solely rationally taking a measure of the site, whether visual in 'Composition and Geometry' or instrumental in early 'Registering' experiments, seemed to be unengaging. I wanted an experiential reading and representation of site, yet the poetic metaphor of the 'Pavilion' experiments opened a conceptual problem in what site representational method formed the ideal solution - one of accuracy, or one of a general experiential feeling and whether they could coexist together.

In this sense, I believe that it was fundamental to find a balance between the two in the case of the design. Attempting to approach the design in a rational way, resulted in a feeling of dissatisfaction and unease when taking a poetic approach. By letting go of this misconception of one method being more 'correct' than the other and accepting that the design could operate in somewhat of a 


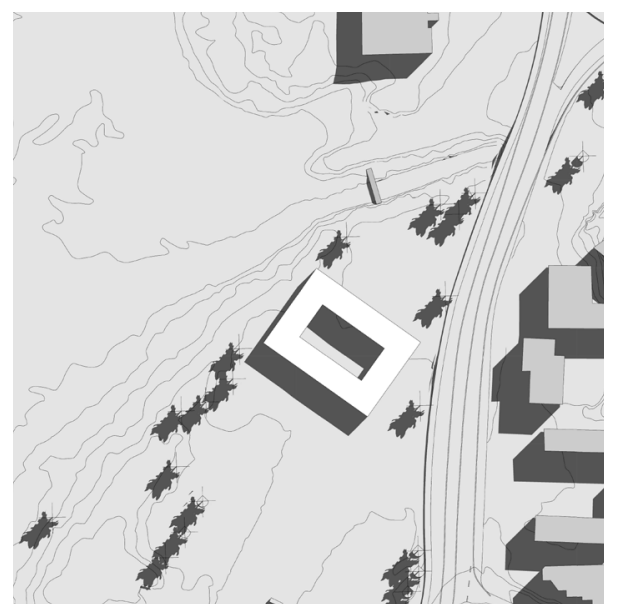

Figure 121: The initial 'Pure Form' design experiment 
limbo in-between the two, I felt a sense of relief and found the 'Observing' chapter as a result to develop far more freely of limitations.

As a discipline, we must take note of the importance of this balance whilst designing in general, and whilst representing landscape qualities architecturally. In general design terms, the balance between rationality and poetic representation is critical to the design. The rational is necessary, but the metaphor combines "all these diverse and disjointed systems and operations into a well working machine" (Fez-Barringten 104). In terms of this balance and its importance to how we design and take measure of the land, Landscape Architect James Corner perhaps summarises this best, stating that:

"More imaginative practices of measure and geometry than those of the calculative and instrumental must first be developed if modern culture is to construct a landscape that is truly fitting of social and ecological life. Such an understanding may be predicated increasingly upon the metaphoricity of measure, its ability to span and join across distance and time" (Corner 37).
As a piece of research, given more time and a larger scope, work could have been done exploring this potential further. Poetic explorations of building wear, palimpsest and their implications on the design could have been explored to a greater depth, providing further weight to the argument, had I arrived to the 'Observing' stage earlier in the process. Opportunities could have been taken to scale up too. At an early point in the project, a townwide 'measurement' framework was considered. It is unclear though whether this larger framework would have resulted in a loss of small-scale resolution that the design outcome ultimately had. The larger site would introduce new opportunities, but also new problems difficult to resolve.

In saying this, whilst the design outcome provides a specific response to the MacLean Park site resulting from an intuitive reaction to the context and its surrounds, there are further opportunities for the potential implications of this framework outside of the scope of MacLean Park. Where the general modular structure of The Design would lead to a certain replicability, utilising a closer observation of different shifting landscapes as a design tool, would offer new and unforeseen spatial solutions and opportunities for taking measure. 


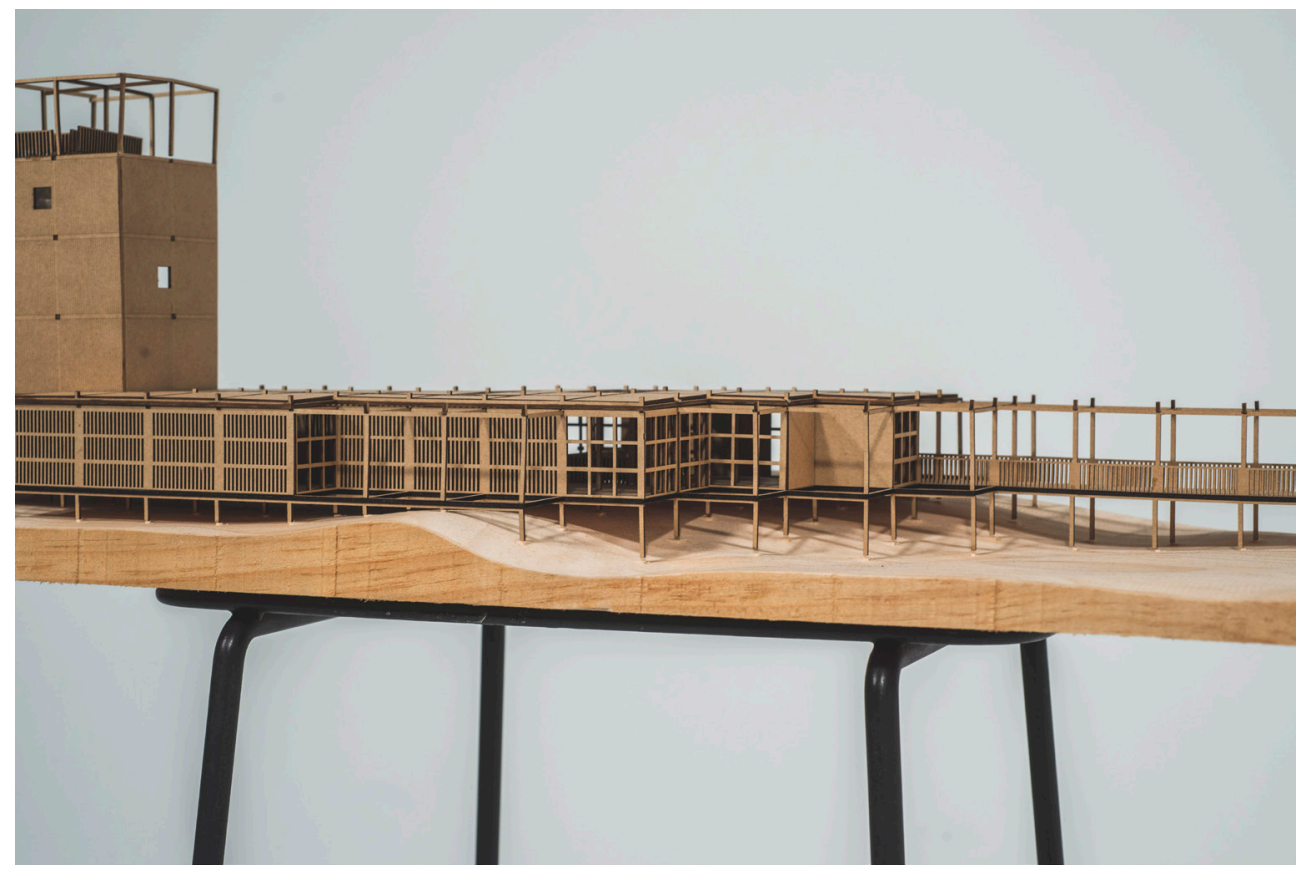

Figure 122: The Design model and its relationship to the undulating dunes 


\section{WORKS CITED}

Aureli, Pier Vittorio. The Possibility of an Absolute Architecture. Cambridge, Mass. : MIT Press, 2011.

Aureli, Pier Vittorio, and Martino Tattara. “STOP CITY.” Perspecta, vol. 43, 2010, pp. 47-181.

Australian Institute of Architects. St Andrews Beach House In the Architect's Words. 2006, https://dynamic. architecture.com.au/gallery/cgi-bin/awardssearch?option=showaward\&entryno=20063138.

Beck, H., and J. Cooper. Glenn Murcutt : A Singular Architectural Practice. Oxford, 2002.

Berlanda, Tom. Architectural Topographies : A Graphic Lexicon of How Buildings Touch the Ground. Taylor and Francis, 2014, doi:10.4324/9781315813196.

Buxton, Rowan. Active Sand Dunes. https://www.landcareresearch.co.nz/publications/factsheets/rareecosystems/coastal/active-sand-dunes.

Cloepfil, Brad. Dutchess County Residence - Guest House / Allied Works Architecture. ArchDaily, 2011, https://www.archdaily.com/115604/dutchess-county-residence-guest-house-allied-worksarchitecture.

Corner, J., et al. Intermediate Natures: The Landscapes of Michel Desvigne. Birkhäuser, 2009.

Corner, James. Taking Measures Across the American Landscape / James Corner, Essays, Drawings, and Commentary. Edited by Alex S MacLean, Yale University Press, 1996.

Davidson, Cynthia. "Raised to Observe: Glenn Murcutt.” Log, no. 8, Anyone Corporation, 2006, pp. $31-39$.

Drew, Philip. Touch This Earth Lightly: Glenn Murcutt in His Own Words. Duffy \& Snellgrove, 1999.

Duempelmann, Sonja, and Susan Herrington. "Plotting Time in Landscape Architecture." Studies in the History of Gardens and Designed Landscapes, vol. 34, no. 1, Routledge, 2014, pp. 1-14, doi:10.108 $0 / 14601176.2013 .850240$

Fez-Barringten, Barie. Architecture: The Making of Metaphors. Cambridge Scholars, 2011.

Fehn, Sverre, and Per Olaf Fjeld. "Has A Doll Life?”. Perspecta, vol 24, 1988. JSTOR, doi: $10.2307 / 1567122$

Handa, Rumiko. Allure of the Incomplete, Imperfect, and Impermanent. Taylor and Francis, 2014, doi:10.4324/9781315735214.

Hart, Richard. Ian McHarg Conversations with Students : Dwelling in Nature. Edited by James Corner et al., 1st ed.., New York : Princeton Architectural Press, 2007. 
"Kapiti Coast Combined Earthquake Risk.” Kapiti Coast District Council.www.kapiticoast.govt.nz/conten tassets/6c88974c60b047d080a463991abe872a/kapiti-coast-combined-earthquake-risk.pdf.

Kapiti Coast District Council. FAQs - Withdrawal of Provisions. https://www.kapiticoast.govt.nz/YourCouncil/Planning/District-Plan-Review/DPR-FAQs/.

---. Proposed Käpiti Coast District Plan: Coastal Environment. 2012, https://www.kapiticoast.govt.nz/ globalassets/your-council/planning/pdp-2012/chapter-04-coastal-environment-withdrawn-may-32017-markup.pdf.

Maclean, Chris. Kapiti Coast. 2007, https://teara.govt.nz/en/wellington-places/page-15.

Meiss, Pierre von. Elements of Architecture : From Form to Place + Tectonics. 2nd ed., Routledge, 2013.

"Natural Hazard Maps.” Natural Hazard Maps - Kapiti Coast District Council. www.kapiticoast.govt.nzl Your-Council/Planning/District-Plan-Review/Natural-Hazards/Natural-Hazard-Maps/.

Nisbet, J. P., et al. Land Is Not the Setting: The Lightning Field and Environments 1960-1980. Stanford University, 2011.

Park, Geoff. The Groves of Life: Nga Uruora : Ecology and History in a New Zealand Landscape. 1st ed., Victoria University Press, 1995.

Pask, Maria. Richard Serra: Sea Level. Land Art Flevoland, 2016, http://www.landartflevoland.nl/en/ permanent-installations/richard-serra-sea-level-1996/.

Phillips, Jock. Perceptions of the Landscape. Te Ara, 2007, https://teara.govt.nz/en/perceptions-of-thelandscape/page-1.

Statistics New Zealand. Are New Zealanders Living Closer to the Coast? http://archive.stats.govt.nz/browse_ for_stats/population/Migration/internal-migration/are-nzs-living-closer-to-coast.aspx. Accessed 25 Apr. 2018.

Unwin, S. Analysing Architecture. Taylor \& Francis, 2013.

Wang, Xinhao. Research Methods in Urban and Regional Planning. Edited by Rainer vom Hofe, Berlin, Heidelberg : Springer Berlin Heidelberg, 2007.

Wright, Jan. The State of New Zealand's Environment. 2016. 


\section{FIGURES LIST}

All figures not attributed are Author's own

Figure 11 Pearse, John. "Hill Road, Possibly Paekakariki Hill Road." National Library of New Zealand Te Puna Mãtauranga o Aotearoa, mp.natlib.govt.nz/detail/?id=39420.

Figure 13 Google. "Various Satellite Images." Google Maps, www.google.co.nz/maps.

Figure 14 Capper, Phillip. "Kapiti and Paraparaumu." Flickr, 6 July 2005, flic.kr/p/382Hp.

Figure 16, 17 Adapted From: Shand, Roger. "Projected Future Shorelines Paraparaumu Beach.” Coastal Systems Ltd, 2014, coastalsystems.co.nz/downloads/Predicted\%20Hazard\%20Erosion\%20 Shorelines\%20-\%20Kapiti\%20Coast.pdf.

Figure 20 Google. "Site Plan at MacLean Park.” Google Maps, maps.google.co.nz.

Figure 43 Ungers, Oswald Mathias. "The City in the City - Berlin: A Green Archipelago.” Architectural Association, cologne.aaschool.ac.uk/omus-idea-of-the-city-2/.

Figure 44 Aureli, Pierre Vittorio. “City Walls.” Dogma, 2005, www.dogma.name/pictures/89.jpg.

Figure 47 Aureli, Pierre Vittorio. “Stop City Plan.” Frac Centre, 2007, www.frac-centre.fr/auteurs/rub/ ruboeuvres-65.html?authID=0\&ensembleID=832\&oeuvreID=9546.

Figure 48 Aureli, Pierre Vittorio. “Stop City Elevation.” Frac Centre, 2007, www.frac-centre.fr/auteurs/ $\mathrm{rub} /$ ruboeuvres-65.html?authID=0\&ensembleID=832\&oeuvreID=7797.

Figure 49 Aureli, Pierre Vittorio. "Stop City Perspective.” Frac Centre, 2007, www.frac-centre.fr/gestion/ public/upload/oeuvre/galerie/DOGMA/DOGM_009_93_01-8-maxi.jpg.

Figure 59 "Hedmark Museum Walkway." The Red List, Hedmark, 2005, theredlist.com/media/ database/architecture/across_the_landscape/fehn_musee_archeologique_/005_fehn_musee_ archeologique_theredlist.png.

Figure 60 Livingstone, Rozy. "Hamar Bispegaard Museum Norway." Flickr, Hamar, 20 Dec. 2003, flic. $\mathrm{kr} / \mathrm{p} / 8 \mathrm{zfHgd}$.

Figure 79 Clett, John. “The Lightning Field.” Dia Art Foundation, 1977, www.diaart.org/visit/visit/ walter-de-maria-the-lightning-field. 
Figure 80 Huisman, Jordi. "Richard Serra’s Sea Level.” Land Art Flevoland, Zeewolde, 2016, www. landartflevoland.nl/en/permanent-installations/richard-serra-sea-level-1996/.

Figure 84 McHarg, Ian. "Composite: Conservation Recreation Urbanisation Areas Staten Island." Missouri SઐT, web.mst.edu/ $\sim$ rogersda/gis/History\%20of\%20GIS.pdf.

Figure 88 Murcutt, Glenn. “Simpson Lee House Sketch.” Archdaily, 17 Jan. 2013, www.archdaily.com. br/br/01-92110/nascido-para-observar-slash-glenn-murcutt.

Figure 96 Godsell, Sean. “St Andrew’s Beach House Plan.” Wikimedia, 17 Apr. 2012, commons. wikimedia.org/wiki/Category:St_Andrews_Beach_House\#/media/File:FLOOR_PLAN.jpg.

Figure 97 Michavila, Ximo. "Exterior St Andrew’s Beach House." Flickr, 2013, flic.kr/p/dQ3ZMV.

Figure 98 Carter, Earl. “St Andrew’s Beach House Promenade.” Detail Germany, 7 Aug. 2007, inspiration.detail.de/weekend-house-at-st-andrews-beach-103291.html?lang=en.

Figure 99 “Marika Alderton House Plan.” WikiArquitectura, wikiarquitectura.com/wp-content/ uploads/2017/01/Casa_Marika_planta-500x271.jpg.

Figure 100 Murcutt, Glenn. “Marika Alderton House Sketch.” Blogspot, 2009, uptaller3.blogspot. com/2011/05/casa-marika-alderton.html.

Figure 101 "Marika Alderton House Exterior." Architect Magazine, 2016, www.architectmagazine.com/ project-gallery/marika-alderton-house_o.

Figure 102 "Marika Alderton House Interior." Subtilitas, 2012, www.subtilitas.site/post/36170863262/ glenn-murcutt-the-marika-alderton-house-for-an.

Figure 111, 112 Bitterman, Jeremy. "Dutchess County Residence Guest House.” Archdaily, 27 Feb. 2011, www.archdaily.com/115604/dutchess-county-residence-guest-house-allied-works-architecture.

Figure 113 Frei, Marcel. "Fondazione Querini Stampalia." Flickr, 28 Sept. 2010, flic.kr/p/92wbTX.

Figure 114 “Core Environmental Visitor Centre.” Van Heyningen \& Haward Architects, 2012, www.vhh. co.uk/our-work/cory-environmental-visitor-centre. 
